\title{
ADENOCARCINOMA DE PANCREAS
}

Relato Oficial | 67ํㅡㄹ Congreso Uruguayo de Cirugía

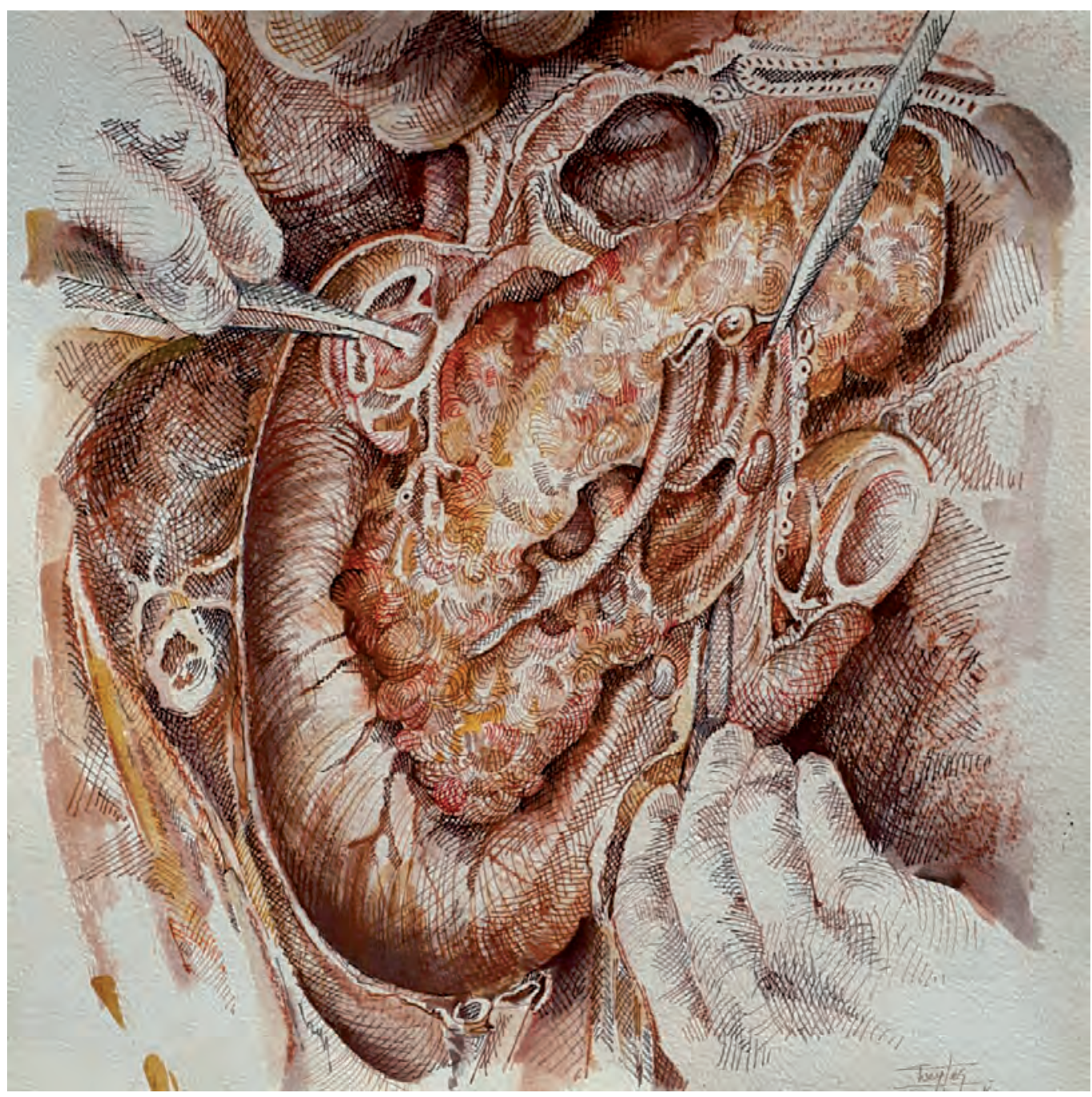

JOAQUIN PEREYRA COSCO JUAN MANUEL DELGADO GALIANA

Punta del Este, 2016 

RELATO OFICIAL

" $67^{\circ}$ Congreso Uruguayo de Cirugía"

ADENOCARCINOMA DE PANCREAS

Dres. Joaquín Pereyra Cosco - Juan Manuel Delgado Galiana 


\title{
"God put the pancreas in the back because he did no want
}

\section{surgeons messing with it"}

Allen O. Whipple (18811963)

\begin{abstract}
Para Mercedes, Gastón y Tomás, por comprender y aceptar ser muchas veces relegados por los avatares de esta profesión. Ellos saben que son lo más importante. ...a mis padres, especialmente mi padre, hasta aquí he llegado siguiendo su ejemplo

A mis padres, y a los mejores hermanos, mis hermanos Gustavo, Diego y Gonzalo.

$\mathrm{JP}(\mathrm{GA})$

ente a Hernán y Mario, quienes nos iniciaron y todavía nos guían en el mundo de la cirugía hepatobiliopancreática... ...verdaderos responsables de este relato.

JD Y JP

Título: Adenocarcinoma de Páncreas

Autores: Dr. Joaquín Pereyra Cosco y Dr. Juan Manuel Delgado Galiana

148 p.-; $21 \times 29,5 \mathrm{~cm}$

Editora: Grupo Elis

Palmar 2240 - Montevideo, Uruguay

Tel.: (+598) 24010534

Impreso en Uruguay - Printed in Uruguay

Este libro se terminó de imprimir en Noviembre de 2016

Impresión y encudaernación: $\mathbf{m}$ msimpresos

www.msimpresos.com

Tiraje: 150 ejemplares

Depósito Legal $\mathrm{N}^{\circ} 370.823$ 


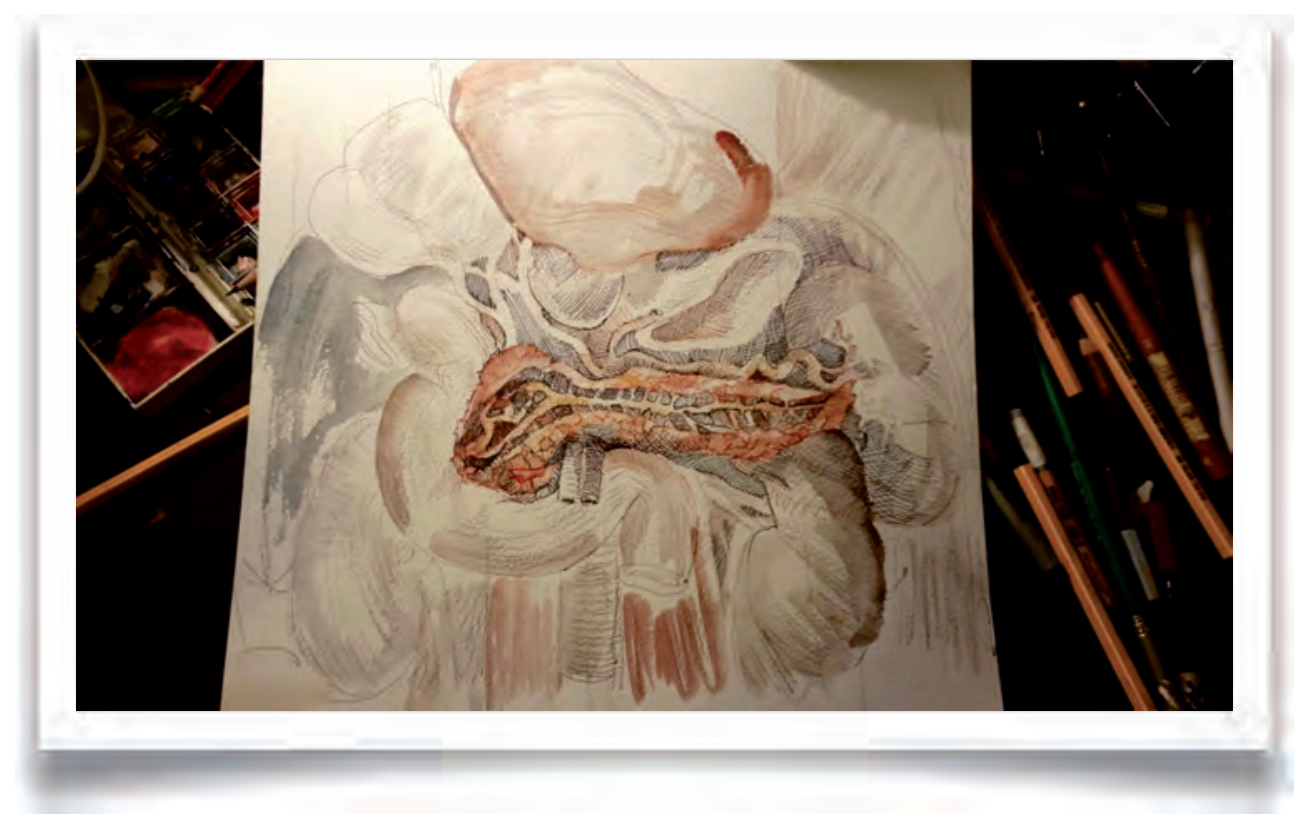

\section{ÍNDICE}

Introducción

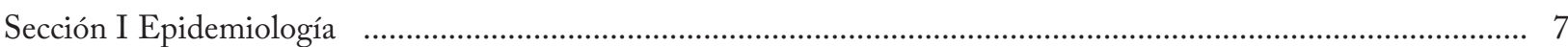

- Aspectos epidemiológicos en el cáncer de páncreas ........................................................................... 8

• Factores de riesgo. Paciente de riesgo ..................................................................................... 14

• El factor genético en la patogenia del cáncer del adenocarcinoma de páncreas .................................. 19

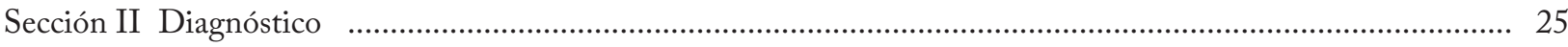

- Rol de los estudios de imagen en la ictericia obstructiva. (Dra. Verónica Gigirey) ............................ 26

- Adenocarcinoma de páncreas. Diagnóstico, evaluación preoperatoria y criterios de resecabilidad.

Rol de la Imágen (Dra. Verónica Gigirey) .................................................................................. 31

- El rol de la biopsia diagnóstica en el adenocarcinoma de páncreas ................................................ 42

• El rol de la laparoscopia estadificadora ...................................................................................... 50

- Marcadores tumorales en adenocarcinoma de páncreas ............................................................. 53

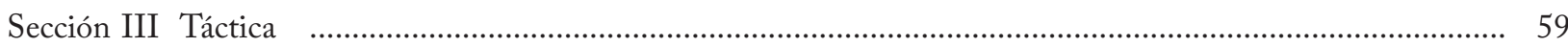

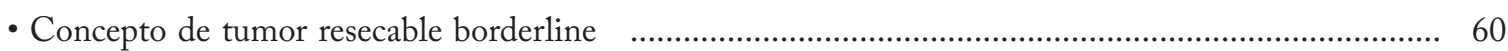

- Drenaje biliar preoperatorio en el cáncer cefalopancreático .......................................................... 64

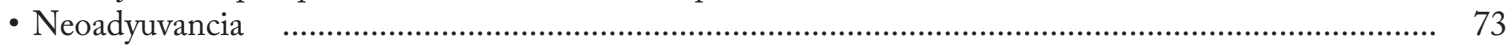

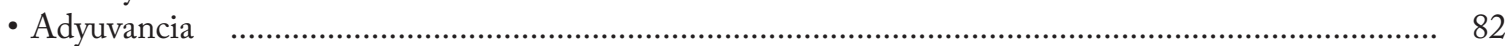

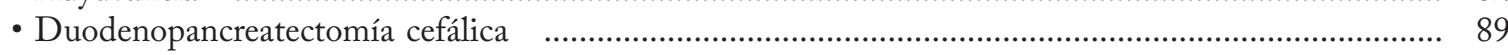

- Pancreatectomía en adenocarcinomas de cuerpo y cola de páncreas .................................................... 109

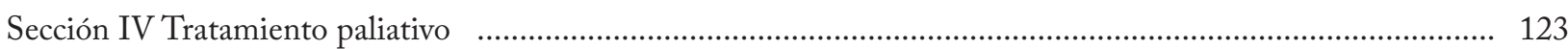

•Tratamiento paliativo del cáncer de páncreas ................................................................................. 124

• Peleación de la ictericia ............................................................................................................ 127

• Tratamiento de la estenosis gastro-duodenal ............................................................................... 134

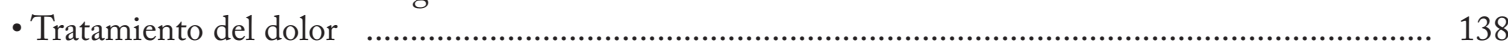

• Quimioterapia y radio-quimioterapia paliativa $\quad$....................................................................... 140 


\title{
PROLOGO. CANCER DE PANCREAS
}

"Deja de pensar en términos de limitaciones y empieza a pensar en términos de posibilidades."

Ferry Josephson

Cada vez que nos enfrentamos a un reto importante donde nuestras posibilidades de vencer no sean muchas, tenemos que salir con las mejores armas que tengamos para tener chance de una victoria o de lo contrario, sufrir una derrota donde al menos podamos sacar experiencias productivas que sirvan para fortalecernos en una próxima oportunidad.

Conociendo al autor, no nos llamó la atención que haya decidido someterse a un desafío de este tipo, cuando le propusimos ser el relator del 67 Congreso Uruguayo de Cirugía.

Ha elegido encarar a un enemigo potente, que pocas veces podemos dominar, contra el cual las chances de éxito hasta el momento son escasas.

Este enemigo es el cáncer de páncreas con su agorera presencia.

Salen a encararlo de todo punto de vista y en todos los terrenos para buscar sus debilidades, hurgando en sus orígenes, en la forma en que se desarrolla y en como nos agrede.

Para esto utiliza un estilo original o al menos poco visto en un relato. Lo hace a través de un auto interrogatorio, que no es ni más ni menos que el que usamos en la práctica diaria cuando nos preguntamos si es mejor estudiarlo con tal o cual examen, o si debemos realizar o no algún procedimiento no quirúrgico, o si debemos operarlo o no, y si optamos por operarlo cual es la táctica y técnica a realizar. Así va recorriendo tanto la historia de la enfermedad en toda su dimensión de principio a fin, como las respuestas obtenidas en los distintos procedimientos de diagnóstico y tratamiento.

Como resultante, tenemos una lectura amena y didáctica expresada a través de sus páginas, con una información que conjuga la profundidad académica que el tema requiere, con elementos prácticos que se manifiestan claramente al final de cada capítulo, cuando expone sus conclusiones, las que resultan sumamente útiles a la hora de tomar decisiones.

Pero el autor va más allá de estos recursos para encarar esta patología ya que también nos muestran en los últimos capítulos cuáles son los caminos posibles a seguir y por donde puede buscarse la vuelta para ir ganando terreno en esta lucha. Son precisamente estos caminos que nos brindan luces de esperanza que, a su vez, logran provocarnos para que nos inmiscuyamos en esta empresa.

Es en el cierre del relato donde menciona el hecho conceptual más importante sin el cual, ningún tratamiento puede llegar a realizarse correctamente y menos en esta enfermedad cuya evolución seguramente habrá de atravesar momentos difíciles. Este concepto lo describe en toda su dimensión cuando señala que: "La base para el tratamiento de una enfermedad incurable y agresiva debe sustentarse en una buena relación médico-paciente”.

Es por todo esto que la frase del físico Ferry Josephson es tal vez la que expresa adecuadamente la esencia de este relato.

\author{
Carlos Tarabochia
}




\section{INTRODUCCIÓN.}

Recibí con gran honor y responsabilidad la invitación para la realización del relato oficial del 67 o Congreso Uruguayo de Cirugía. El exponer este trabajo frente al colectivo quirúrgico ha sido para mi un gran desafío, en mi condición de "cirujano joven".

Por otro lado, colmar las expectativas de quien me seleccionó para la realización de este relato, persona por la cual siento particular afecto, ha sido para mi un gran reto.

La selección del tema se basa en la influencia que ha tenido, luego de compartir años de trabajo, el Profesor Hernán Parodi, verdadero maestro de la cirugía nacional. Con su condición de líder natural, no solo nos ha contagiado la pasión por el conocimiento y abordaje de esta patología, de pronóstico tan sombrío y difícil tratamiento, sino que nos ha enseñado todos los trucos sobre una cirugía, por momentos extenuante, que ha adquirido y desarrollado durante largos años de experiencia en el tratamiento de este cáncer. Sin lugar a dudas, el Profesor Parodi ha continuado con éxito la escuela de la cirugía hepatobiliopancreática nacional de la cual proviene y ha formado a muchos de los cirujanos que en la actualidad se dedican a esta especialidad.

Durante el relato nos referiremos a adenocarcinoma de páncreas y cáncer de pancreas como sinónimos, dada su alta frecuencia dentro de los tumores malignos del páncreas. Se trata de un cáncer poco frecuente pero con una alta mortalidad, según las proyecciones ocupará la segunda causa de muerte por cáncer para el 2030. Uruguay presenta una alta tasa de incidencia en esta patología, teniendo el "privilegio" de ocupar el segundo lugar en América.

Sin entrar tecnicismos puntuales sobre una patología poco frecuente y que operan pocos cirujanos, en el contexto del Congreso Uruguayo de Cirugía, nuestro objetivo fue realizar una puesta a punto del tema, intentar responder los puntos controvertidos sobre el adenocarcinoma de páncreas para el cirujano general, y describir hacia donde se dirige el tratamiento de esta patología, en busca de mejorar los resultados. Un aspecto importante que nos trazamos fue la realización de un trabajo de calidad, para ello solicitamos la participación del Profesor Juan Pablo Arnoletti, uno de los referentes quirúrgicos Uruguayos más prestigiosos y de destacada trayectoria internacional, dedicado a la patología oncológica pancreática, quien gentilmente aceptó y el cual se ha convertido en colaborador de este Relato.

Por último, ha sido un placer realizar este Relato junto a mi compañero de trabajo y amigo Juan Delgado, el mejor compañero para esta difícil tarea que se nos ha encomendado.

Esperamos que sea de su agrado este relato, nuestro relato.

\section{Joaquín Pereyra}




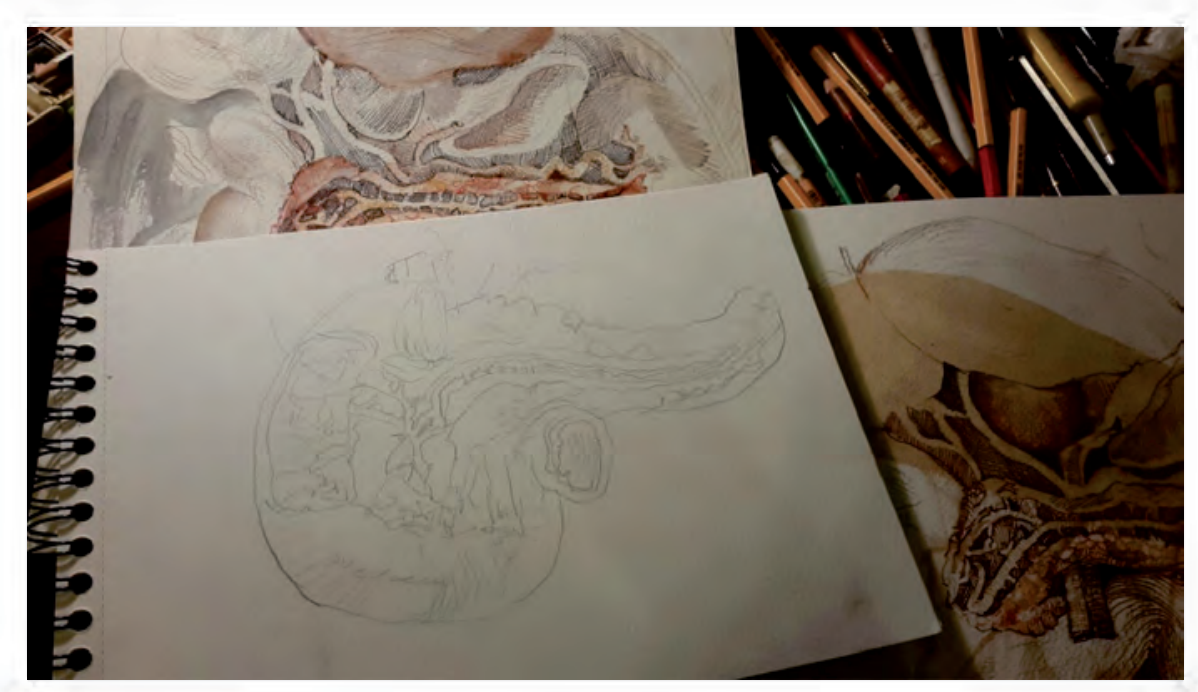

SECCION I EPIDEMIOLOGIA

- ASPECTOS EPIDEMIOLOGICOS EN EL CANCER DE PANCREAS

- FACTORES DE RIESGO. PACIENTE DE RIESGO

- EL FACTOR GENETICO EN LA ETIOPATOGENIA DEL CANCER DE PANCREAS 


\section{ASPECTOS EPIDEMIOLOGICOS EN EL CANCER DE PANCREAS.}

El cáncer de páncreas es un problema mundial de salud, no por su incidencia, sino por su elevada mortalidad.

La incidencia del cáncer de páncreas varía según las diferentes regiones geográficas (Fig. 1), con un predomino por las regiones más desarrolladas. Estas diferencias pueden estar influenciadas por la ausencia de un diagnóstico histológico, sobre todo en los países menos desarrollados, falseando alguno de estos resultados.

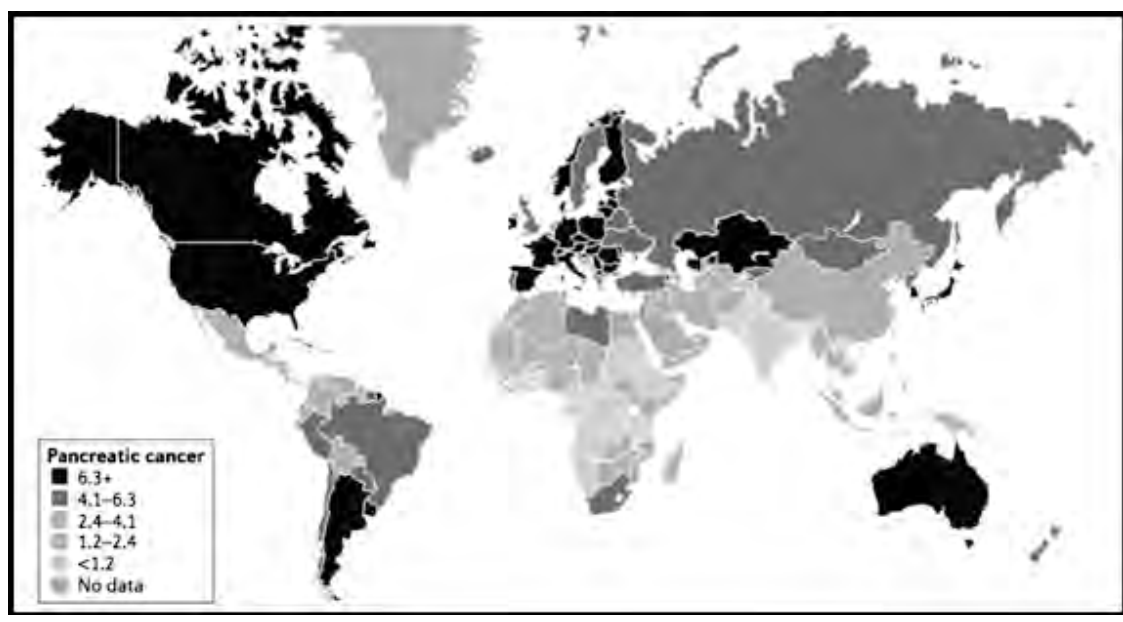

Fig.1. Incidencia mundial del cáncer de páncreas cada 100000 hab. para ambos sexos.

Tomado de GLOBOCAN 2012

v1.0, Cancer Incdence and Mortality

Worldwide: LARC Cancer Base No. 11

[Internet]. Lyon, France: International

Agency for Research on Cancer; 2013.

Availble from: http://globocan.iarc.fr.

Las tasas que se mencionan en la literatura, varían según se analicen como tasas brutas o tasas ajustadas por edad y sexo.

En términos generales, el cáncer de páncreas ocupa el décimo segundo lugar en frecuencia de cáncer a nivel mundial, con tasas globales de 4.1/100000 habitantes (hab.).

En cambio, es la cuarta causa de muerte por cáncer en Estados Unidos, la quinta en Europa y la séptima a nivel mundial, según las diversas series publicadas. ${ }^{1}$

Para la World Cancer Research Fund International, la República Checa, Eslovaquia, Armenia y Hungría ocupan los primeros lugares en incidencia, con tasas de entre 9.7 y 9.3/100000 hab. ajustadas por edad. ${ }^{2}$ Mientras que para la misma publicación, Uruguay ocupa el puesto 17, con tasas de 7.7/100000 hab. Las tasas más bajas se registran en África y algunas zonas de Asia, con cifras que rondan el 1/100000 hab. (Fig. 2) 


\begin{tabular}{|l|l|l|}
\hline \multicolumn{1}{|c|}{ Ranking } & & Tasa ajustada por edad \\
\hline 1 & Czech Republic & 9.7 \\
\hline 2 & Slovakia & 9.4 \\
\hline 3 & Armenia & 9.3 \\
\hline 3 & Hungary & 9.3 \\
\hline 5 & Slovenia & 8.8 \\
\hline 6 & Finland & 8.7 \\
\hline 7 & Japan & 8.5 \\
\hline 7 & Denmark & 8.5 \\
\hline 9 & Austria & 8.2 \\
\hline 10 & Latvia & 8.1 \\
\hline 10 & Malta & 8.1 \\
\hline 10 & French Guyana & 8.1 \\
\hline 10 & Republic of Moldova & 8.1 \\
\hline 14 & Bulgaria & 8.0 \\
\hline 15 & Romania & 7.9 \\
\hline 15 & Germany & 7.9 \\
\hline 17 & FYR Macedonia & 7.7 \\
\hline 17 & Uruguay & 7.7 \\
\hline 20 & Israel & 7.6 \\
\hline
\end{tabular}

Fig. 2. Ranking de incidencia de cáncer de páncreas a nivel mundial. Extraído de Pancreatic cancer statistics.World Cancer Research Fund International. www.wcfr.org. ${ }^{2}$

Según la Comisión honoraria de lucha contra el cáncer del Uruguay, para el quinquenio 2008-2012, el cáncer de páncreas ocupó el noveno lugar en incidencia en hombres y octavo en mujeres. Con tasas de incidencia ajustadas por edad y sexo de 9.7 en hombres y de 7.26 en mujeres cada 100000 hab.

Estas cifras muestran pequeñas diferencias comparadas con Globcan, cabe recordar que Globocan realiza predicciones sobre bases a veces más antiguas y no representativas de la situación actual. La tasa de incidencia según el Registro Nacional de Cáncer (RNC), para hombres es de 9.7 y para mujeres de 7.26 cada 100000 hab, mientras que para Globocan la tasa es de 9.2 para hombres y 6.4 para mujeres cada 100000 hab.

Como vimos, Uruguay presenta una alta tasa de incidencia a nivel mundial y según Globocan, ocupa el segundo lugar en América. (Fig. 3)

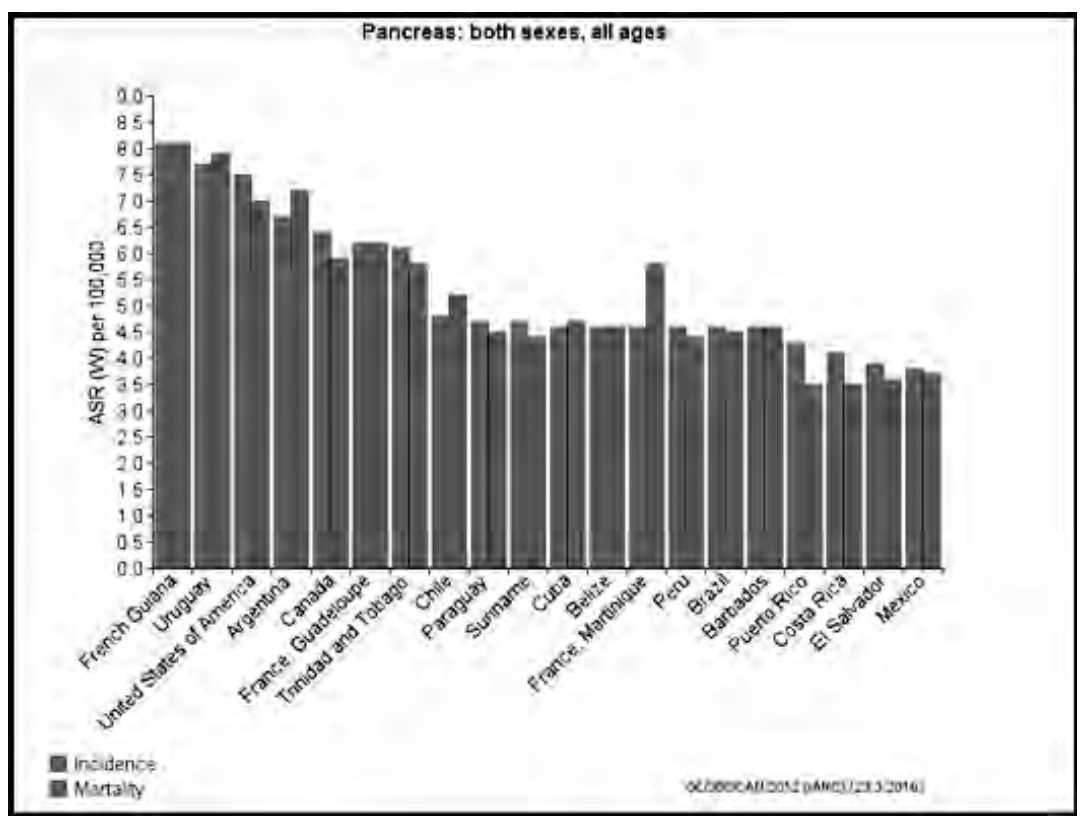

Fig. 3. Incidencia y mortalidad del cáncer de páncreas en América. Tasa ajustada por edad para ambos sexos cada 100000 hab. Extraído de Globocan. http://globocan. iarc.fr.(4) 
En Estados Unidos en el 2015, se presentaron unos 48960 casos nuevos de cáncer de páncreas, ocupando el onceavo lugar en hombres y el noveno en mujeres. Con una tasa cruda de incidencia 13.6/100000 hab. ${ }^{3}$ y una incidencia ajustada por edad 7.5/100000 hab. para ambos sexos. ${ }^{4}$ Se estima que al finalizar el 2016 se habrán diagnosticado unos 53070 casos nuevos en Estados Unidos, evidenciando un aumento en su incidencia. ${ }^{5}$

En el Reino Unido la tasa ajustada por edad es de 6.3/100000 hab.

La incidencia del cáncer de páncreas muestra un aumento año tras año, a un ritmo de crecimiento de $0,6 \%$ anual, en los últimos 10 años. Mientras tanto su mortalidad se ha mantenido estable (Fig. 4). Según las predicciones de Globocan, para el año 2020, en Uruguay habrá un incremento de 97 casos comparado con el 2012. Por lo tanto, si actualmente se diagnostican unos 500 casos nuevos al año en el Uruguay, para el 2020 esta cifra será cercana a los 600 casos.

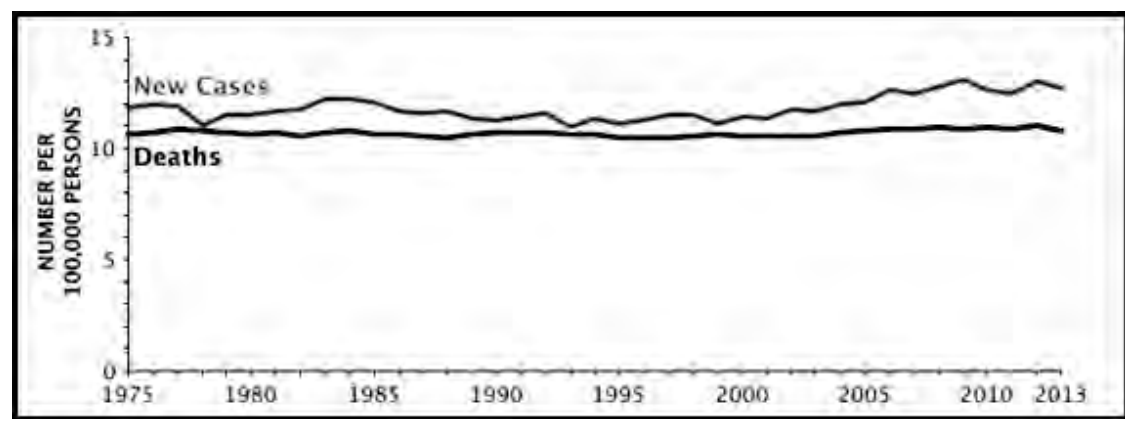

Fig. 4. Evolución de la incidencia y mortalidad del cáncer de páncreas, desde el 1975 al 2013.

Extraído de SEER Stat Fact Sheets: Pancreas cancer. http://seer. cancer.gov/statfacts/html/pancreas.html. Accessed March 3, 2014. (6)

Como muestra el gráfico de la figura 4, la incidencia aumenta y la mortalidad se mantiene, eso evidencia que ha habido una mejora en los tratamientos, y como veremos más adelante, las terapias adyuvantes son las que han tenido mayor impacto.

La edad se considera un factor de riesgo independiente de contraer cáncer de páncreas. Mientras que la edad media de diagnóstico es de 71 años, tres cuartas partes de los pacientes con cáncer de páncreas, se diagnostican entre los 54 y 84 años y menos del $3 \%$ se presentan en pacientes menores a 40 años. ${ }^{6}$

Durante el periodo 2005-2009 la incidencia del cáncer de páncreas era 24 a 30\% más alta en hombres que mujeres. Actualmente esta brecha ha disminuido, vinculado al aumento de la exposición a factores de riesgo que presentan las mujeres, como por ejemplo el tabaquismo. ${ }^{7}$

Los varones presentan cáncer de páncreas a una edad más temprana y en estadíos más avanzados que las mujeres. Por lo tanto, habría desde el punto de vista teórico, un factor protector estrogénico en las mujeres.

La incidencia del cáncer de páncreas es más frecuente en la raza negra, comparada con la raza blanca. Con tasas de incidencia que rondan 17.6/100000 hab. para hombres y 14.3/100000 hab. para mujeres. La raza negra se asocia también, a una edad de presentación más temprana y a un peor pronóstico. Este hecho no deja de ser llamativo, dada la baja incidencia de esta patología en África. Como parte de la explicación a estos hallazgos, se destaca el cambio de los factores de riesgo ambientales a los que se exponen los afrodescendientes, que se trasladan a otros sectores del mundo y el subregistro que presenta el cáncer de páncreas en ciertas regiones, como el continente Africano. El hombre afrodescendiente que viaja a EEUU, se expone a una mayor incidencia de diabetes y tabaquismo, mientras que las mujeres a un mayor consumo de alcohol y aumento de índice de masa corporal, todos ellos identificados como factores de riesgo de cáncer de páncreas. ${ }^{8-10}$

Como ya fue mencionado, no es la incidencia lo que marca el problema sanitario del cáncer de páncreas, sino su mortalidad. Las cifras de incidencia son similares a las de mortalidad, con una relación (ratio) cercana a 1. Además, estas cifras de mortalidad no han experimentado cambios significativos en los últimos años.

Con sus variaciones geográficas ya mencionadas, el cáncer de páncreas ocupa la cuarta causa de muerte en EEUU, la quinta en Europa y globalmente la séptima a nivel mundial por cáncer. Se estima que será la segunda causa de muerte por cáncer en EEUU para el 2030. Dentro de las razones que explican este fenómeno, se encuentra el aumento constante de su incidencia, su mal pronóstico (a pesar de los avances quirúrgicos y de quimioterapia) y el descenso de la mortalidad de otros cánceres. ${ }^{3}$ 
Globocan estimó para el 2015 en Europa, 108.169 casos nuevos, con una mortalidad para ese año de 109.006 pacientes, en tanto en Estados Unidos, 46.349 casos nuevo y 44.910 fallecidos por cáncer de páncreas.

En Uruguay se diagnostican unos 500 casos nuevos al año, según el RNC con una mortalidad de 480 casos anuales.

La sobrevida global a 5 años del cáncer de páncreas oscila entre 3\% y 8\% según las diversas series ${ }^{3,6}$ y la misma se ha mantenido estable en los últimos años.

Si bien el pronóstico de esta patología es generalmente malo, hay ciertos factores determinantes que modifican sus resultados. Se destacan, el estadío de la enfermedad, los márgenes de resección, la presencia de adenopatías positivas, las resecciones en centros de alto volumen, la edad de presentación, la ubicación de la lesión en el órgano y el uso de terapias adyuvantes. Quizá esta última, aumento en la utilización de adyuvancia, sea el factor que ha generado mayor impacto en esta patología, aumentado la sobrevida en los últimos años.

Menos del 10\% de los cánceres de páncreas se encuentran en una etapa localizada de la enfermedad al momento del diagnóstico, observándose una sobrevida global a 5 años de 29.3\%. Sin embargo aquellos con compromiso regional (adenopatías positivas) tienen una sobrevida a 5 años del 11\%, y los que presentan metástasis a distancia (estadio IV) $\operatorname{del} 2 \% .^{6}$

Los pacientes resecados, en cualquiera de los estadíos, I, II y III, muestran una mejor sobrevida que aquellos no resecados (Fig. 5). En términos porcentuales los índices de mejoría se acentúan cuanto mayor es el estadío de la enfermedad. ${ }^{11}$ Crees et al, muestran un aumento 3 veces mayor en la sobrevida media de los pacientes resecados en tumores localizados, frente a los no resecados, aumentado la sobrevida media ${ }^{12}$ de 6 a 21 meses.

Los tratamientos de quimio-radioterapia han aumentado la sobrevida de los pacientes no resecados, pero a niveles menores que aquellos que lograron la resección. En la comparación, el uso de terapias quimo-radiantes aumentó la sobrevida frente a los que recibieron tratamientos de soporte, con sobrevida a un año de 62 vs $32 \%$, $p=0.05$; y sobrevida media de 17 vs 11 meses $(\mathrm{p}<0.03) .^{13}$
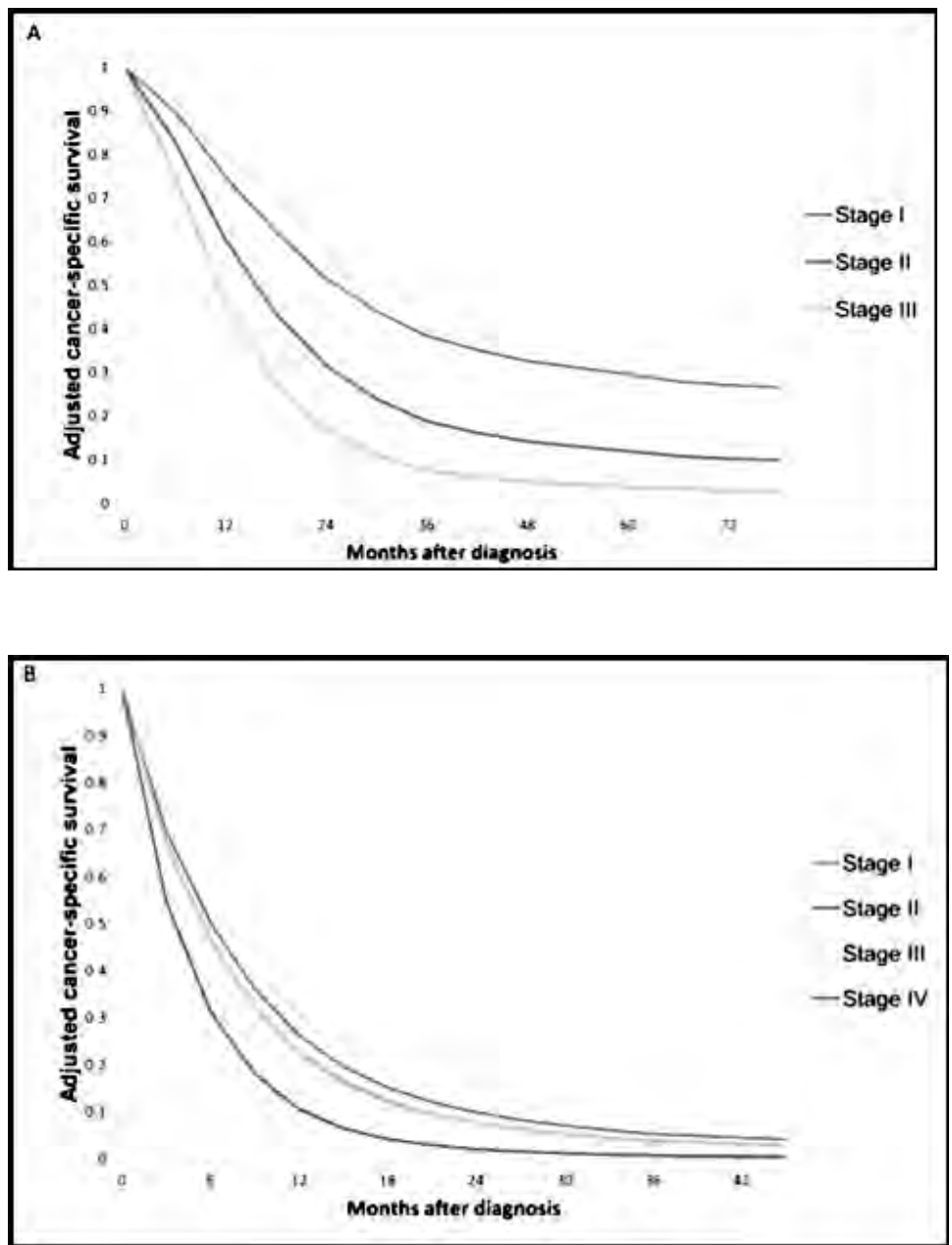

Fig. 5. Comparación en la sobrevida de pacientes resecados (A) y no resecados (B).

Extraído de, Katz et al.Arch Surg. 2012; 147(6): $513-519.11$ 
Asociado a la cirugía, los tratamientos de quimio-radioterapia mejoran aún más la sobrevida de los pacientes. A modo de ejemplo, el estudio GIST mostró una variación de 11 meses a 21 en la sobrevida media, el EORTC de 19 a 24,5 meses, el RTOG 9704 de 16.9 a 20.5 meses $^{14}$. Los pacientes con enfermedad irresecable o metastásica, también muestran mejoría en la sobrevida con el tratamiento quimio-radiante, pasando de una sobrevida media menor a 4 meses en los que realizan tratamiento de soporte, a una sobrevida media de 6 meses. ${ }^{15}$ Con los planes de quimioterapia moderna, se puede llegar a sobrevidas medias de 11 meses, pero asociado a una alta morbilidad. ${ }^{16}$

En términos generales se puede decir que los pacientes en los que se practicó una resección pretendidamente curativa, la sobrevida media es de 20-24 meses, en los localmente avanzados de 9 a 15 meses y en los metastásicos de 6 a 9 meses. Los mejores resultados se obtienen en los pacientes sometidos a una resección pretendidamente curativa y con tratamiento adyuvante.

La literatura demuestra que la topografía cefalopancreática es la más frecuente en los tumores de páncreas, con cifras que rondan el 65\%, en tanto el 15\% se localizan en cola y un $10 \%$ son multifocales. ${ }^{17}$ Los tumores ubicados en la cola del páncreas tienen peor pronóstico que los cefalopancreáticos. ${ }^{18}$ Crees et al, documentan un peor pronóstico de los tumores de cuerpo y cola, tanto en pacientes resecados como en no resecados. ${ }^{13}$

En términos generales, las mujeres menores de 65 años, con tumores de páncreas pequeños $(<3 \mathrm{~cm})$, resecados, con adenopatías negativas, bien diferenciadas y que reciben adyuvancia, muestran los mejores resultados en cuanto a sobrevida y tiempo libre de enfermedad..$^{13}$

Está demostrado que "el efecto centro" mejora los resultados en medicina, sobre todo en la patología oncológica, y el cáncer de páncreas no escapa a esta situación. El mismo logra disminuir las cifras de mortalidad y morbilidad de los procedimientos a realizar, así como también, mejora los resultados en términos de sobrevida y tiempo libre de enfermedad.

Un estudio holandés comparó durante dos períodos de tiempo, los resultados obtenidos en centros asistenciales de bajo volumen y en centros de referencia. Del análisis surge, que en los especializados se logran mayores porcentajes de resección (19 a 30\%), aumento de las resecciones en mayores de 80 años y con mayor número de comorbilidades, ampliando el espectro de pacientes que acceden a la cirugía. Los centros especializados realizan más tratamientos de adyuvancia que los centros de bajo volumen. La morbilidad de los procedimientos también presentó un descenso en los centros de referencia, bajando su incidencia de $72 \%$ a 36\%. La mortalidad cayó de un $24 \%$ a un 3.6\%, en los dos periodos analizados, y la sobrevida a 2 años aumentó de un $38.1 \%$ a un $49.9 \%$. La sobrevida media fue de 11 meses para centros de bajo volumen y de 22.5 meses para los centros especializados.

En conclusión, hay un aumento en la sobrevida de un 25 a 36\%, en favor de los centros de referencia. Además, en estos centros se realiza un diagnóstico precoz de las complicaciones, con mejor manejo de las mismas en base al desarrollo de los procedimientos mínimamente invasivos para su solución. ${ }^{19}$

Un metaanálisis del British Journal of Cancer de 2011, encuentra que en los centros especializados hay una disminución de la mortalidad y un aumento de la sobrevida, alcanzando $13 \%$ a 5 años. Discute el papel del cirujano, como único responsable de esta mejoría en los resultados. Finalmente concluye, que el beneficio radica en el equipo multidisciplinario, en el mejor manejo perioperatorio, en los tratamientos oncológicos, y en los procedimientos de endoscopía y radiología intervencionista. ${ }^{20}$ Por ello parece ser más importante nombrarlos como centros especializados y no centros de alto volumen.

No está claro el número de procedimientos necesarios para determinar que un centro sea de alto o bajo volumen. El mismo está por encima de las 15-20 duodeno-pancreatectomías al año y los de muy alto volumen, por encima de los 35 al año. ${ }^{19,21,22}$

Un reciente estudio con 3400 duodeno-pancreatectomías, no solo evidenció una mejoría en la sobrevida en los centros de alto volumen, mayor a 20 duodeno-pancreatectomías /año, sino también un aumento en el número de resecciones $\mathrm{R} 0$, en el número de ganglios obtenidos y en el uso de adyuvancia. ${ }^{20}$

La existencia de centros de referencia tiene efectos teóricos negativos, por un lado se plantea que los pacientes de bajos recursos tienen dificultad en acceder, frente a los de mayores recursos y por otro lado, puede requerir traslado con distancias variables para acceder al mismo. Un reciente estudio valoró estas dificultades y concluye que a pesar de esta carga, los pacientes deben ser trasladados y tratados en centros especializados, dado que mejoran sus resultados perioperatorios, con un descenso en la mortalidad y una mejora en la sobrevida. ${ }^{23}$ 


\section{BIBLIOGRAFIA}

1. Ferlay J, Soerjomataram I, Dikshit R, et al. Cancer incidence and mortality worldwide: Sources, methods and major patterns in GLOBOCAN 2012. Int. J. Cancer 2015;136: 359-386.

2. Pancreatic cancer statistics. World Cancer Research Fund International. www.wcfr.org.

3. Yeo TP. Demographics, epidemiology, and inheritance of pancreatic ductal adenocarcinoma . Seminars inOncology 2015; 42(1): 8-18.

4. GLOBOCAN 2012 v1.0, Cancer Incidence and Mortality Worldwide: IARC CancerBase No. 11 [Internet]. Lyon, France: International Agency for Research on Cancer; 2013. Available from: http://globocan.iarc.fr.

5. Siegel RL, Miller DK, Jemal A. Cancer Statistics, 2016. Ca Cancer J Clin. 2016;66:7-30.

6. SEER Cancer Statistics Factsheets: Pancreas Cancer. National Cancer Institute. Bethesda, MD, http://seer. cancer.gov/statfacts/html/pancreas.html . Accessed March 3, 2014.

7. American Cancer Society. Cancer facts \& figures. Atlanta: American Cancer Society; 2013.http://www.cancer. org/research/cancerfactsstatistics/2013-cancer-facts-and-figures.pdf.

8. Chang K, Parasher G, Christie C, Largent J, Anton- Culver H. Risk of pancreatic adenocarcinoma cancer: disparity between African Americans and other race/ ethnic groups. Cancer. 2005;103:349-357.

9. Silverman DT, Hoover RN, Brown LM, et al. Why do black Americans have a higher risk of pancreatic cancer than white Americans? Epidemiol. 2002;14: 46-54.

10. Eloubeidi MA, Desmond RA, Wilcox CM, et al. Prognostic factors for survival in pancreatic cancer: a population-based study. Am J Surg. 2006;192: 322-329.

11. Katz MHG, Hu CY, Fleming JB, et al.A Clinical Calculator of Conditional Survival Estimates for Resected and Unresected Pancreatic Cancer Survivors.Arch Surg. 2012; 147(6): 513-519.

12. Cress RD, Yin D,Clarke L, et al. Survival among patients with adenocarcinoma of the pancreas: a population-based study (United States). Cancer Causes Control. 2006;17:403-409.

13. Imamura M, Doi R, Imaizumi T, et al. A randomized multicenter trial comparing resection and radiochemotherapy for resectable locally invasive pancreatic cancer. Surgery. 2004;136(5):1003-1011.

14. Li D, O’Reilly EM. Adjuvant and Neoadjuvant Therapy for Pancreatic Cancer. Surg Oncol Clin N Am 2016;25: 311-326.

15. Gong J,Tuli R, Shinde A, el al.Meta-analyses of treatment standards for pancreatic cancer (Review).Molecular and Clinical Oncology 2016;4:315-325.

16. Conroy T, Desseigne F, Ychou M, et al. on behalf of the Groupe Tumeurs Digestives of Unicancer and the prodige Intergroup. folfirinox versus gemcitabine for metastatic pancreatic cancer. N Engl J Med 2011;364:18171825.

17. Ghaneh P, Costello E, Neoptolemos JP. Biology and management of pancreatic cancer. Gut 2007;56:11341152.

18. Raju RS, Coburn N, Liu N, et al. A population-based study of the epidemiology of pancreatic cancer: a brief report. Curr Oncol. 2015;22(6):478-484.

19. Lemmens VEPP, Bosscha K, van der Schelling G, et al.Improving outcome for patients with pancreatic cancer through centralization. British Journal of Surgery 2011; 98: 1455 - 1462.

20. Gooiker GA, van Gijn W, Wouters MWJM, et al. Systematic review and meta-analysis of the volume-outcome relationship in pancreatic surgery. British Journal of Surgery 2011; 98: 485-494.

21. van der Geest LGM, van Rijssen LB, Quintus Molenaar I, et al. Volume-outcome relationships in pancreatoduodenectomy for cancer. HPB 2016.18; 317-324.

22. Mosquera C, Vohra NA, Fitzgerald TL, et al. Discharge with Pancreatic Fistula after Pancreaticoduodenectomy Independently Predicts Hospital Readmission.Am Surg. 2016 Aug;82(8):698-703.

23. Lidsky ME, Sun Z, Nussbaum DP, et al.Going the Extra Mile: Improved Survival for Pancreatic Cancer Patients Traveling to High-volume Centers. Ann Surg. 2016; 20 (10):1-6.DOI: 10.1097/SLA.0000000000001924. 


\section{FACTORES DE RIESGO. PACIENTE DE RIESGO.}

Debido al pobre pronóstico que presenta el cáncer de páncreas, el cual ha permanecido estable en términos de sobrevida desde la década de los 80 , surge el interés por el conocimiento de su etiología y los factores de riesgo implicados. Cada año se publican cerca de 500 artículos en este sentido, enfocados en describir los factores de riesgo en el cáncer de páncreas. ${ }^{1}$

Si bien la etiología exacta permanece desconocida, la identificación de factores de riesgo, podría determinar pacientes de riesgo y generar medidas de prevención o acciones para un diagnóstico temprano.

Tabaquismo: es el factor de riesgo modificable más importante. Incrementa el riesgo de padecer cáncer de páncreas de 1,5 a 5,5, según las diversas series publicadas. ${ }^{2}$

Un metaanálisis de 83 estudios elaborado por Iodice et $\mathrm{al}^{3}$, demuestra un aumento del riesgo relativo (RR) de $1.74^{3}$, esto quiere decir un aumento del 75\% en el riesgo de padecer cáncer de páncreas. Ese riesgo disminuye a 1.48 cuando hay un abandono de 10 años del hábito y se iguala a los no fumadores luego de 20 años de abandono del tabaquismo ${ }^{4}$. Se ha demostrado que se pueden evitar una gran cantidad de muertes por esta patología con la cesación del tabaquismo.

El riego producido por el tabaco en el cáncer de páncreas es dosis dependiente. Según lo demuestra el metaanálisis de Zou et al., esta relación no es lineal y luego de 20 cigarros día, el aumento es menos pronunciado. ${ }^{5}$

El tabaquismo también se asocia a una edad más temprana de presentación, de 3 años por 1 paquete de cigarros día y de 6 años para más de un paquete día. ${ }^{6}$

La exposición ambiental o fumador pasivo, también presenta aumento del riesgo, con una edad más temprana de presentación y depende del tiempo de exposición. ${ }^{7}$

Datos experimentales en animales, indican que la asociación de la exposición al humo de tabaco y cáncer de páncreas es multifactorial. Esta genera lesiones de tipo inflamatorio a nivel pancreático, con destrucción de células acinares y aumento de la matriz extracelular a expensas del colágeno tipo 1. Estos cambios son mediados por el factor de crecimiento transformante beta.

Otro de los elementos descritos en la patogénesis, es el desequilibrio entre preoteasas y antiproteasas a favor de las primeras, con un aumento de la destrucción titular.

Además, el humo de tabaco presenta sustancias carcinógenas dentro de las que se encuentran la nitrosamina y la nicotina, que determinan cambios genéticos y epigenénticos. La nicotina desencadena una serie de mecanismos de señalización paracrinca, que podrían tener relación con un peor pronóstico, presencia de metástasis hepáticas y quimiorresistencia. ${ }^{8}$ Faltan estudios que aclaren como actúa cada sustancia por separado. ${ }^{9}$

Obesidad: Un metaanálisis del 2003, demuestra un aumento del riesgo de un 20\% (RR 1.19) en pacientes con un índice de masa corporal (IMC) mayor a 30, comparado con los de índice normal. ${ }^{10}$ El perímetro abdominal y la distribución de la grasa corporal son considerados factores riesgo adicionales. ${ }^{11}$

El mecanismo por el cual la obesidad es considerado un factor de riesgo, se basa en la alteración del metabolismo glucídico que produce el tejido adiposo, asociado a hiperinsulinemia y cambios inflamatorios. El riesgo es mayor cuando la obesidad se produce antes de los 40 años. ${ }^{12}$

Una reciente revision que documentó un aumento del riesgo de entre 19\% a 40\% en los pacientes obesos, identifica a la hiperinsulinemia como la clave patogénica. ${ }^{13}$

A su vez, la obesidad se asocia a un peor pronóstico en los pacientes con cáncer de páncreas. ${ }^{8}$

Además de la obesidad, se ha encontrado vinculación entre la dieta y el cáncer de páncreas. El consumo de carnes y otros productos de origen animal, así como los azucares refinados, se asocian a un riesgo aumentado. Mientras que las dietas ricas en vegetales y frutas tiene un efecto protector. ${ }^{14}$

Diabetes: Es considerado el tercer factor de riesgo modificable en importancia. La diabetes es tanto causa, así como forma de presentación en el cáncer de páncreas.

E1 50-80\% de los pacientes con esta patología tiene diabetes o hiperglicemia. ${ }^{7}$

La diabetes incrementa entre 2 a 3 veces el riesgo, cuando se compara con los no diabéticos. ${ }^{15}$

Diversos estudios de cohorte y casos control han demostrado aumento del riesgo cercano a 2, muchos de ellos han carecido de validez dada la asociación con otros factores de riesgo, como la obesidad, o porque no diferencian entre diabetes de reciente comienzo o diabetes de larga duración.

Los datos más concluyentes hablan de un aumento del riesgo del $80 \%$. 
Independientemente de la cifra, está bien establecida la asociación entre diabetes y cáncer de páncreas, pero aún no se sabe cual es la relación entre ellos, pudiendo considerarse como causa y/o consecuencia.

Si la consideramos causa de cáncer de páncreas, los elementos más importantes son la hiperinsulinemia e hiperglicemia. Ambas activan mecanismos de señalización molecular, que están en la génesis y el crecimiento del tumor pancreático. Aquellas terapias que tienden a descender los niveles de insulina, disminuirían el riesgo de padecer esta patología. ${ }^{16}$

En ese sentido, el uso de metformina tiene un efecto protector, debido al descenso de la glucosa y a través de un efecto antineoplásico sobre mediadores celulares de la replicación y la síntesis proteica. ${ }^{13,17}$

Se ha reportado un incremento en el riesgo de cáncer de páncreas, en aquellas pacientes que presentaron diabetes gestacional. ${ }^{18}$

En dos investigaciones demuestran que el 26 a 31\% de los a pacientes con cáncer de páncreas, presentaron diabetes de reciente comienzo ${ }^{19}$

Los argumentos que apoyan el concepto de diabetes como forma de presentación de un cáncer de páncreas son:

- La existencia de una relación temporal entre el debut de la diabetes o "new onset" y la aparición del cáncer de páncreas. La diabetes puede presentarse entre 6 meses y tres años antes del diagnóstico.

- Estudios de laboratorio sugieren la mejoría en del control metabólico una vez resecado el tumor.

- La presencia de una forma de diabetes distintas a la tipo 1 y $2 .{ }^{12}$ Este tipo de diabetes tipo 3, conocida también como diabetes pancreática, se caracteriza por la ausencia de varias hormonas pancreáticas como la insulina, glucagon y pepito pancreático (PP), a lo que se le suma un resistencia hepática a la insulina. ${ }^{20}$ Esta deficiencia de PP, podría ser un marcador serológico de cáncer, en aquellos pacientes con diabetes de reciente comienzo.

Alcohol: En cuanto al consumo del alcohol, los datos son en general inconsistentes en lo que respecta a la relación causal. Pero hay bastante concordancia en que el consumo excesivo de alcohol, se asocia a un aumento del riesgo de cáncer de páncreas.

Los datos más contundentes son para los alcoholistas severos (+ 60 gr./día), con un riesgo relativo de $1.53 .{ }^{21}$

Los mecanismos carcinogénicos implicados son: 1) la formación de radicales libres, 2) procesos inflamatorios y de inmunosuoresión local. 3) bajos niveles de folatos. 4) activación de la citocromo P450 y la biotransformación enzimática.

Pancreatitis: Los pacientes con episodios de pancreatitis de más de 2 años de evolución, tienen 3 veces más riesgo de padecer cáncer de páncreas.

Este aumento del riesgo fue consistente hasta por intervalos de 25 años de evolución de la pancreatitis. Esto apoya el concepto, de que la inflamación crónica del páncreas juega un papel importante en la carcinogénesis. ${ }^{22}$

Sin embargo, hay un porcentaje importante de pacientes, que ronda el 30\%, con una corta evolución de pancreatitis (menos de 2 años) y cáncer de páncreas. En estos casos, se sospecha que más que una causa, la pancreatitis es una consecuencia del cáncer de páncreas.

El período en el que aparece un cáncer de páncreas en el contexto de una pancreatitis crónica es de 10 a 20 años. La asociación mas fuerte es con las formas raras de pancreatitis como las hereditarias o tropicales. La pancreatitis crónica explica solo el $3 \%$ de los casos de cáncer de páncreas. ${ }^{23}$

Enfermedad hereditaria: El cáncer de páncreas se origina a partir de una sumatoria de alteraciones genéticas. Las mismas pueden ser en la línea germinal o somática. Las alteraciones mas frecuentes, $80 \%$, se dan en la línea somática, con lo cual se genera el cáncer de páncreas esporádico, Un componente hereditario o familiar esta demostrado en hasta un $10 \%$ de los pacientes.

El cáncer de páncreas familiar se define por la presencia de 2 familiares de primer grado con dicha patología, en ausencia de los síndromes hereditarios asociados. La presencia de un familiar con cáncer de páncreas eleva el riesgo nueve veces, la presencia de 3-4 lo eleva 32 veces. Además, el riesgo aumenta si la edad de presentación es temprana, entre los 45 y 64 años. ${ }^{24}$

En forma global hay un aumento del riesgo relativo 1.80, independiente del grado de parentesco. ${ }^{25}$

Por otra parte hay síndromes hereditarios asociados a alelos de alta penetrancia, dentro de los que se encuentran, la poliposis adenomatosa familiar, el síndrome de Peutz-Jeghers, el síndrome familiar de melanoma multiple, la pancreatitis hereditaria, la fibrosis quística,

el síndrome hereditario del cáncer de mama y ovario y el síndrome ataxia-telangiectasia. Estas condiciones genéticas aumentan el riesgo de 2 a 132 veces. $^{26}$ 
Se ha reportado un aumento del riesgo del 30\% de cáncer de páncreas, asociado al grupo sanguíneo ABO, para aquellos grupos no-O 27,28

Infecciones: $\mathrm{E} 1$ helicobacter Pylori tiene potencial carcinógeno mediante la formación de nitrosaminas, las cuales producen alteraciones en el ADN. A su vez, genera un estado de hiperclorhidria, con disminución de la somastostatina e incrementos del bicarbonato pancreático y de la secretina. Estos cambios en modelos animales, producen displasia a nivel de las células ducales pancreáticas. Existiría un aumento del riesgo de cáncer de páncreas en lo pacientes colonizados por Helicobacter Pylori. ${ }^{29}$

La infección crónica con el virus de la hepatitis $\mathrm{B}$, también aumenta el riesgo de cáncer de páncreas, sobre todo en aquellos que presentan niveles positivos de $\mathrm{HBsAg}$ y anti-HBc. ${ }^{30}$

También se ha registrado un aumento de cáncer de páncreas en pacientes HIV, bajo tratamiento antirretroviral. Se presenta a edades más tempranas y en estadíos más avanzados. ${ }^{31}$

Litiasis vesicular: Se ha estudiado la relación tanto de la colecistectomía, como la litiasis vesicular, con el cáncer de páncreas. Los resultados como factores de riesgo independientes han sido contradictorios.

Un reciente meta-análisis determinó que son factores de riesgo independientes y que asociados, aumentan el riesgo para el desarrollo de un cáncer de páncreas. ${ }^{32}$

Otros: La exposición laboral a determinadas sustancias también ha mostrado un aumento del riesgo, pero con un nivel de evidencia más discutido. Entre ellos se destaca la exposición a hidrocarburos clorados, cloruro de metileno, hidrocarburos aromáticos e insecticidas. También aquellos trabajadores metalúrgicos expuestos fundamentalmente al níquel. Las evidencias sobre el papel de la vitamina $\mathrm{D}$ es pobre.

La actividad física ha mostrado un papel protector, vinculado a la disminución de los niveles de insulina, descenso ponderal y hábitos de vida más saludables. ${ }^{1,733}$ 


\section{BIBILIOGRAFIA}

1. Maisonneuve P, Albert BL. Risk factors for pancreatic cancer: a summary review of meta-analytical studies. International Journal of Epidemiology, 2015; 44(1):186-198.

2. Fuchs CS, Colditz GA, Stampfer MJ, et al. A prospective study of cigarette smoking and the risk of pancreatic cancer. Arch Intern Med. 1996;156:2255-2260.

3. Iodice S, Gandini S, Maisonneuve P, Lowenfels AB. Tobacco and the risk of pancreatic cancer: a review and met-analysis. Langenbecks Arch Surg. 2008;393: 535-545.

4. Bosetti C, Lucenteforte E, Silverman DT, et al. Cigarette smoking and pancreatic cancer: an analysis from the International Pancreatic Cancer Case-Control Consortium (Panc4). Ann Oncol. 2012;23:1880-1888.

5. Zou L, Zhong R, Shen N et al. Non-linear dose-response relationship between cigarette smoking and pancreatic cancer risk: Evidence from a meta-analysis of 42 observational studies. Eur J Cancer 2014;50:193-203.

6. Anderson MA, Zolotarevsky E, Cooper KL, et al. Alcohol and tobacco lower the age of presentation in sporadic pancreatic cancer in a dose-dependent manner: a multicenter study. Am J Gastroenterol. 2012;107:1730-1739.

7. Yeo TP.Demographics, Epidemiology, and Inheritance of Pancreatic Ductal Adenocarcinoma. Seminars in Oncology.2015; 42(1): 8-18.

8. Delitto D, Zhang D, Han S et al.Reduces Survival via Augmentation of Paracrine HGF-MET Signaling in the Pancreatic Cancer Microenvironment. Clin Cancer Res; 2016;10:1-12.

9. Wittel UA, Hopt UT, Batr SK. Cigarette smoke-induced pancreatic damage-experimental data. Langenbecks Arch Surg (2008) 393:581-588.

10. Berrington de Gonzalez A, Sweetland S, Spencer E. A meta-analysis of obesity and the risk of pancreatic cancer. Br J Cancer. 2003; 89:519-523.

11. Arslan AA, Helzlsouer KJ, Kooperberg C, et al. Anthropometric measures, body mass index, and pancreatic cancer: a pooled analysis from the Pancreatic Cancer Cohort Consortium (PanScan). Arch Intern Med. 2010;170:791-802.

12. Li D, Morris JS, Liu J, et al. Body mass index and risk, age of onset, and survival in patients with pancreatic cancer. JAMA 2009;301:2553- 2562.

13. Preziosi G, Oben JA, Fusai G. Obesity and pancreatic cancer. Surgical Oncology. 2014; 23: 61-71.

14. Bosetti C, Bravi F, Turati F, et al. Nutrient-based dietary patterns and pancreatic cancer risk. Annals of Epidemiology 2013;23:124-128.

15. Li D, Tang H, Hassan M, et al. Diabetes and risk of pancreatic cancer: a pooled analysis of three large case-control studies. Cancer Causes Control. 2011;22:189-197.

16. Trent Magruder J, Elahi D, Andersen DK, Diabetes and Pancreatic Cancer. Chicken or Egg?. Pancreas 2011; 40: 339-351.

17. Bodmer M, Becker C, Meier C, et al. Use of antidiabetic agents and the risk of pancreatic cancer: a case-control analysis. Am J Gastro. 2012; 107:620-626.

18. Sella T, Chodick G, Barchana M, et al. Gestational diabetes and risk of incident primary cancer: a large historical cohort study in Israel. Cancer Causes Control. 2011;22:1513-1520.

19. Yeo TP, Burrell SA, Sauter PK, et al. A progressive post- resection walking program significantly improves fatigue and health-related quality of life in pancreas and periampullary cancer patients. J Am Coll Surg. 2012;214:463--475.

20. Slezak LA, Andersen DK. Pancreatic resection: effects on glucose metabolism. World J Surg. 2001;25(4):452460.

21. Genkinger JM, Spiegeloman D, Anderson KE, et al. Alcohol intake and pancreatic cancer risk: a pooled analysis of fourteen cohort studies. Cancer Epidemiol Biomarkers Prev. 2009;18:765-776.

22. Duell EJ, Lucenteforte E, Olson SH, et al. Pancreatitis and pancreatic cancer risk: a pooled analysis in the International Pancreatic Cancer Case-Control Consortium (PanC4).Annals of Oncology 2012; 23: 2964-2970.

23. Raimondi S, Lowenfels AB, Morselli-Labate AM et al. Pancreatic cancer in chronicpancreatitis; aetiology, incidence, and early detection. Best Pract Res Clin Gastroenterol 2010; 24(3): 349-358.

24. Klein AP, Brune KA, Petersen GM et al. Prospective risk of pancreatic cancer in familial pancreatic cancer kindreds. Cancer Res. 2004; 64(7):2634-2638.

25. Permuth-Wey J, Egan KM. Family history is a significant risk factor for pancreatic cancer: results from a systematic review and meta-analysis. Fam Cancer 2009;8:109-117.

26. Connor AA, Gallinger S.Hereditary Pancreatic Cancer Syndromes. Surg Oncol Clin N Am .2015;24: 733764.

27. Iodice S, Maisonneuve P, Botteri E et al. ABO blood group and cancer. Eur J Cancer 2010;46:3345-3350.

28. Risch HA, Lu L, Wang J et al. ABO blood group and risk of pancreatic cancer: a study in Shanghai and meta-analysis. Am J Epidemiol 2013;177:1326-1337. 
29. Risch HA. Pancreatic cancer: Helicobacter pylori colonization, N-nitrosamine exposures, and ABO blood group. Mol Carcinog. 2012;51:109-118.

30. Wang DS, Chen DL, Ren C, et al. ABO blood group, hepatitis B viral infection and risk of pancreatic cancer. Int J Cancer. 2012;131:461-468.

31. Zanet E, Berretta M, Di BF, et al. Pancreatic cancer in HIV-positive patients: a clinical case-control study. Pancreas. 2012;41:1331-1335.

32. Fan Y, Hu J, Feng B, et al. Related to Gallstones and Cholecystectomy. A Systematic Review and Meta-Analysis.Pancreas 2015;00: 1-7.

33. Eskander MF, Bliss LA, Tseng, JF. Pancreatic adenocarcinoma. Current Problems in Surgery 2016; 53:107154. 


\section{EL FACTOR GENÉTICO EN LA PATOGENIA DEL ADENOCARCINOMA DE PÁNCREAS}

Las neoplasias malignas del páncreas se clasifican según el sector pancreático en el que se originan. Combinado con el aspecto macroscópico que presentan, sólido o quístico.

E1 85\% de los adenocarcinoma de páncreas derivan de las células ductales (adenocarcinoma ductal). Estas células ocupan alrededor del 10\% de la celularidad del páncreas y menos del 4\% del volumen total del mismo. Se ha descrito una ruta alternativa de transformación a partir de células acinares, estimulado por las vías de señalización derivada de la mutación de K-Ras. ${ }^{1}$

Se describen 3 lesiones precursoras del adenocarcinoma de páncreas, las displasias conocidas como PanINs, la neoplásia mucinosa quística y la neoplásia papilar intraductal mucinosa (IPNM). Las dos variantes quísticas, se encuentran en estadío más precoz al momento del diagnóstico y tienen mejor pronóstico. Sus sobrevidas pueden llegar al $50 \%$ a los 5 años, incluso en sus formas infiltrantes.

En cuanto a los PanINs, son el origen de la mayoría de los adenocarcinomas, pasando por todas sus etapas de displasia hasta la producción del cáncer invasor.

Si bien estos tres precursores, comparten algunas de las mutaciones genéticas, presentan otras que los diferencian.

Los malos resultados en la sobrevida, ha impulsado el interés en la investigación genética de esta patología con fines terapéuticos.

Los avances en biología molecular han permitido tener una mejor comprensión del mapa genético en el cáncer de páncreas. La evolución desde una célula normal a un cáncer de páncreas infiltrante, conlleva la acumulación escalonada de mutaciones genéticas y epigenéticas. Este proceso puede tener una duración de hasta 20 años. ${ }^{2}$

Si las mutaciones se presentan en la linea germinal (10-15\% de los casos), se producirá la forma hereditaria de la enfermedad. En cambio, si se producen en las células somáticas (85-90\% de los casos), estaremos frente a la forma esporádica de la misma. Si bien comparten algunas mutaciones como las del K-Ras, CDKN2A, SMAD 4 y TP53, las formas hereditarias se asocian a otras mutaciones como BRCA2, BRCA1, PALB2, ATM, STK11, PRSS1, entre otras. ${ }^{3}$

En los PanINs las células pasan por diferentes etapas o grados histológicos de displasia. Se dividen en 3 categorías PanIN-1 (a y b), que son lesiones de bajo grado de displasia, los PanIN -2 displasia de grado moderado y los PanIN-3 que son lesiones con displasia de alto grado. Actualmente se está intentando simplificar esta clasificación, a PanINs de bajo grado(1 y 2) y aquellos de alto grado de displasia los PanIN-3. ${ }^{4}$

Una de las primeras alteraciones que se producen en la carcinogénesis del adenocarcinoma de páncreas, es la mutación del oncogén K-Ras. La misma está presente en el 90\% de estos pacientes. Posteriormente, se produce una serie escalonada de mutaciones, que involucra la inactivación de genes supresores de tumores CDKN2A, TP53 y SMAD4, los cuales codifican las siguientes proteínas p16, p53 y Smad4 respectivamente. Estas 4 mutaciones son conocidas como los “ big 4" en el adenocarcinoma de páncreas. (Fig 1.)

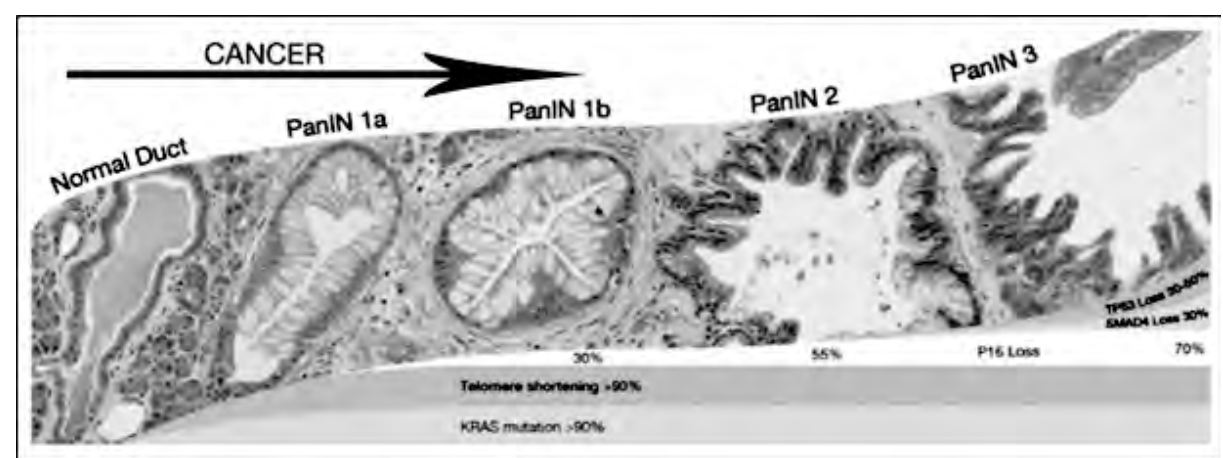

Fig. 1. Modelo de progresión del PanIN, desde la célula normal, hasta la producción de un cáncer invasor, asociado a las mutaciones genéticas. Extraído de Hackeng et al.Diagnostic Pathology. 2016; 11:47-64

- K-Ras: En condiciones fisiológicas la proteína Ras induce el crecimiento celular, mediante la activación de un receptor de crecimiento. Esta activación la realiza unido a GTP. Luego de su acción, Ras mediante una GTPasa intrínseca, pasa de GTP a GDP y se inactiva el sistema. Cuando se producen mutaciones K-Ras, se pierde esta capacidad de pasar de GTP a GDP, con lo cual el sistema permanece activo. 
- Acortamiento de telómeros: los telómeros son repeticiones de nucleoproteínas, que se encuentran en los extremos de los brazos de los cromosomas. Estos juegan un rol en la estabilidad genómica y cumplen funciones en el mantenimiento de la estructura del cromosoma. Evitan la fusión con otros cromosomas, así como también en el control del crecimiento y división celular. Estas alteraciones se han visto en las etapas iniciales de los paciente con IPMNs y en casi todos los PanINs.

- CDKN2A: es la mutación más frecuente dentro de los genes supresores de tumores, se encuentra en el 95\% de los pacientes con cáncer de páncreas (95\%). Este gen codifica una proteína p16 que actúa bloqueando la transición G1-S del ciclo celular, permitiendo la reparación de los defectos. Cuando el gen muta, hay una perdida de esta proteína, se produce una desregulación del ciclo y la imposibilidad de reparación del ADN.

- TP53: La mutación del gen TP53, productor de la proteína p53, se presenta tarde en la progresión hacia el cáncer de páncreas. Está presente en el 70\% de los pacientes y se asocia a las lesiones PanIN-3. Está implicado en la detención del ciclo celular, en la reparación del ADN, el bloqueo de la angiogénesis y en la apoptosis. Su perdida permite el crecimiento descontrolado con inestabilidad genética y proliferación aberrante. ${ }^{6}$

- SMAD4: es un gen que codifica la proteína Smad4 que está inactiva en aproximadamente el 50\% de los cánceres de páncreas. Al igual que TP53, la mutación se produce tarde en la progresión de la enfermedad, y se encuentra en el pasaje de PanIN-3 - cáncer. Esta proteína esta vinculada al factor de crecimiento transformante beta (TGF-B), el cual es un inhibidor del crecimiento. Su mutación produce la promoción y crecimiento de tumores. ${ }^{7}$

Los IPNMs (neoplasia papilar intraductal mucionosa) evolucionan de adenomas a carcinomas y en promedio presentan 26 mutaciones somáticas. Las mutaciones de los "big 4" se presentan con menor frecuencia que en los PanINs. Se encontraron otros factores también implicados en la carcinogénesis del IPNMs, como son el gen GNAS y factor de transcripción llamado DPC4. ${ }^{8}$

En tanto, la neoplasia quística mucinosa presenta en promedio 16 mutaciones somáticas. La más frecuente el K-Ras, está mutado entre el 26\% y $89 \%$ de los casos. Al igual que en los PanINs la mutación del p53 aparece asociado al pasaje displasia-cáncer. Otro gen implicado y recientemente documentado es el RNF43.

Las 4 mutaciones centrales (4 big) están presentes en casi todos los adenocarcinomas de páncreas, o en su defecto encontramos combinaciones de 2 o 3 de ellas.

La presencia de 3 o 4 de las mutaciones antes mencionadas, se asocia a un peor pronóstico y las de TP53 y SMAD4 se asociaron a enfermedad metastásica. ${ }^{9}$

En el estudio de la biología molecular del cáncer de páncreas, se encontraron otros genes involucrados. Jones y col. documentaron 63 mutaciones demostrando la heterogenicidad de la patología y por consiguiente su difícil tratamiento. Estas otras mutaciones se encuentra en un muy bajo porcentaje y se denominan, mutaciones "passenger".

Sin embargo, todos estos genes convergen en 12 vías de señalización hacia el núcleo, cambiando la perspectiva de tratamiento. En otras palabras, un número mayor de genes comparten las mismas vías de señalización y acción carcinogénica y deben ser los blancos de tratamiento. ${ }^{10}$

Con esta nueva visión del genoma como un conjunto limitado de vías de señalización, simplificamos la heterogeneidad genética intrínseca del adenocarcinoma de páncreas y podemos desarrollar estrategias terapéuticas, que apunten a los efectos fisiológicos de las mutaciones, más que a las mutaciones en sí.

Las nuevas lineas de investigación proponen que si actuamos sobre las vías de señalización: habilidad de reparar el ADN o detener el ciclo celular, factores de crecimiento, etc, podríamos evitar o disminuir la resistencia terapéutica.

Siguiendo esta línea de investigación, Biakin y col. demostraron los mismos hallazgos documentados por Jones y aportaron datos sobre nuevos genes y vías de señalización. Se destacan los genes de orientación axónica (STIL/ROBO), que juegan un rol en la migración celular y angiogénesis. ${ }^{11}$ Waddell y col. en el 2015 demostraron alteraciones en la estructura cromosómica y en los genes que regulan la cromatina, como mecanismos involucrados en la patogénia del adenocarcinoma de páncreas. Dentro de estos últimos se destacan aquellos que modifican las histonas (MLL2, MLL3, $\mathrm{KDM} 6 \mathrm{~A})$ y genes que regulan la forma del $\mathrm{ADN}(\mathrm{SWI} / \mathrm{SNF}){ }^{12}$

Concluyeron, que las variaciones de la estructura genómica son uno de los mecanismos mayores de acción. En base a esto se fundamenta el uso de planes en base a platino para el tratamiento del adenocarcinoma de páncreas. 


\section{Cancer hereditario:}

Comprende del 10 al 15\% de todos los adenocarcinoma de páncreas y se deben a mutaciones en la linea germinal. Hay una predisposición hereditaria al cáncer de páncreas en 3 situaciones: 1) Los síndromes de predisposición hereditaria; 2) La pancreatitis hereditaria; 3) El cáncer de páncreas familiar.

Mas del 20\% de los cánceres hereditarios están asociados a síndromes con diferentes tipos de mutaciones genéticas. Dentro de ellos se encuentran el síndrome de Peutz-Jeghers (mutaciones STK1), la pancreatitis hereditaria familiar (mutación de PRSS1) , síndrome de melanoma múltiple atípicos (p16) , la asociación con el cáncer de mama y ovario (mutación de gen BRCA1 y BRCA2) y el síndrome de Lynch.

Al igual que sucede en las mutaciones somáticas, el conocimiento de las alteraciones genéticas y sus vías de señalización, han determinado líneas de investigación en vistas al tratamiento.

\section{BIOLOGIA MOLECULAR Y ESTROMA.}

Además de las mutaciones genéticas y las alteraciones epigenéticas (la metilación y los microARN), el estroma juega un rol preponderante en la génesis, progresión o supresión tumoral en el cáncer de páncreas.

Hay una estrecha relación entre las células cancerígenas y el ambiente que lo rodea (estroma), mediante diversas vías de señalización bidireccionales. Debe entenderse este modelo células tumorales-estroma, como una unidad funcional que se retroalimenta.

Dentro de las vías de señalización que se producen, por las alteraciones genéticas en las células tumorales, se destaca el aumento de factores de crecimiento y sus receptores. Estos amplificarían el desarrollo del cáncer pancreático, y podrían ser blancos de tratamientos. Dentro de estos factores de crecimiento se destacan, el factor de crecimiento epidérmico (EGF) y su receptor (EGFR); el factor de crecimiento de fibroblástico (FGF) y su receptor (FGFR); el factor de crecimiento derivado de la insulina (IGF) y su receptor (IGFR); El factor de crecimiento derivado de las plaquetas (PDGF) y el factor de crecimiento vascular (VEGF).

Estos factores están presentes en muchos de los pacientes con cáncer de páncreas, y es las bases argumentales del uso de las terapias blanco moleculares. Sin embargo estas no han tenido el impacto esperado, por lo que se cree que deben haber otros mecanismos asociados en la génesis de esta patología. ${ }^{13}$

Estos factores de crecimiento actúan en forma apocrina (dentro de la lesión) y paracrinca interactuando con el estroma que lo rodea, produciendo el conocido componente desmoplásico característico de estos tumores.

Este estroma esta compuesto por ácido hialurónico, colágeno, células estrelladas y células inmunitarias, entre otras.

Estos factores activan células quiescentes del estroma, como las células estrelladas, que estimulan la fibrosis del mismo.

Este crecimiento de la matriz extracelular y la presencia de fibrosis, determina un tejido de alta resistencia que comprime los vasos sanguíneos, generando lesiones hipovasculares, que imposibilitan, por ejemplo, la llegada de los fármacos quimioterápicos, siendo un mecanismo de quimiorresistencia. ${ }^{14}$

Dentro de las células inmunitarias presentes en el estroma, se destacan los linfocitos T, en su mayoría CD4+ regulatorias. Este componente inmune se encuentra activado e influenciado por vías de señalización que se producen por las células tumorales.

Este infiltrado inflamatorio genera un estado inmunosupresión local, protegiendo a las células tumorales, y propiciando su desarrollo y crecimiento. Este hecho ha sido motivo de estudio, en búsqueda de tratamientos que aumenten la inmunidad local como mecanismo antineoplásico.

Las células $\mathrm{T}$ regulatoria juegan un rol importante, impidiendo el efecto antitumoral de las células $\mathrm{T}$ activadas. La relación células $\mathrm{T}$ regulatorias/células $\mathrm{T}$ activadas $\mathrm{CD} 4+$, tiene un valor pronóstico. ${ }^{3,14}$

Recientemente se han identificado también un grupo de células madres en el estroma, con propiedades promotoras del tumor primario y de metástasis.

Estas células tienen capacidad de mantenerse en cierto número dentro del tumor, con capacidad de perpetuarse en G0 (sin replicacion), impidiendo la acción de la quimioterapia. Esto determina otro elemento de quimiorresitencia y recaída. ${ }^{13}$

El estroma mediante algunas de sus vías de señalización (TGF- $\beta, \mathrm{HGF}$, TNF $\alpha$, entre otros), permite la transición de células tumorales de estirpe epitelial a mesenquimáticas. Estas nuevas células mesenquimáticas tumorales, tienen gran capacidad de migración y pueden difundir por el estroma y diseminarse, pudiendo explicar en parte, el gran poder de metastásico de estos tumores. ${ }^{13}$ 


\section{Implicancias clínicas.}

La heterogeneidad genética del cáncer de páncreas explica gran parte de los malos resultados y resistencias a la quimioterapia. Luego del trabajo de Jones donde identificaron 63 genes mutados que convergen en 12 vías de señalización, se comenzaron a dirigir la terapias hacia estas vías.

La identificación del rol del estroma en la progresión de la patología y quimiorresitencia, lo han convertido en un posible blanco de acción.

Esto ha ampliado la gama de fármacos que se han estudiado como parte del tratamiento quimioterápico. Entre ellos se destacan los platinos, el irinotecan, las terapias biológicas e inmunes, de manera de personalizar el tratamiento. ${ }^{15}$

Aún queda terreno por recorrer y muchas de estas terapias son parte de ensayos clínicos. Pero en la exploración de las vías de señalización parece estar la clave para combatir la heterogeneidad genética del cáncer de páncreas.

\section{EN SUMA}

- $\quad$ El adenocarcinoma de páncreas tiene en su origen una acumulación escalonada de mutaciones genéticas.

- Sus mutaciones pueden producirse en la línea somática determinado su variante esporádica o en la línea germinal con su variante hereditaria

- $\quad$ Se origina de tres lesiones precursoras las IPNM, la neoplasia mucinosa quística y las PanINs.

- Se destaca su heterogeneidad genética, con mas de 63 genes involucrados, lo que dificulta su compresión y tratamiento farmacológico.

- Esa heterogeneidad de genes desemboca en 12 vías de señalización que se han convertido en el blanco de tratamiento.

- La interacción del tumor con el estroma, produce la reacción desmoplásica conocida. Esta tiene un rol importante en la progresión y quimiorresistencia.

- Es por ello, que a la conocida gemcitabina se le han sumado los platinos, el irinotecan y las terapias biológicas e inmunes, dentro del arsenal quimioterápico disponible, en el marco de ensayos clínicos.

- El estroma esta compuesto por células del sistema inmunitario que generan una inmunosupresión local, que confiere protección y facilita el crecimiento tumoral. 


\section{BIBLIOGRAFIA}

1. Eskander MF, Bliss, LA, Tseng JF. Pancreatic adenocarcinoma. Current Problems in Surgery 2016;53:107-154.

2. Bernard V , Fleming J, Maitra A.Molecular and Genetic Basis of Pancreatic Carcinogenesis. Which Concepts May be Clinically Relevant?. Surg Oncol Clin N Am (2016);25: 227-238.

3. Hackeng WM, Hruban RH, Offerhaus GJA, Brosens LAA. Surgical and molecular pathology of pancreatic neoplasms. Diagnostic Pathology. 2016; 11:47-64.

4. Hruban RH, Adsay NV, Albores-Saavedra J, et al. Pancreatic intraepithelial neoplasia: a new nomenclature and classification system for pancreatic duct le- sions. Am J Surg Pathol 2001;25(5):579-586.

5. Campbell PJ, Yachida S, Mudie LJ, et al. The patterns and dynamics of genomic instability in metastatic pancreatic cancer. Nature 2010;467(7319):1109-1113.

6. Scarpa A, Capelli P, Mukai K, et al. Pancreatic adenocarcinomas frequently show p53 gene mutations. Am J Pathol 1993;142(5):1534-1543.

7. Maitra A, Adsay NV, Argani P, et al. Multicomponent analysis of the pancreatic adenocarcinoma progression model using a pancreatic intraepithelial neoplasia tissue microarray. Mod Pathol 2003;16(9):902-912.

8. Adsay NV. The "new kid on the block": Intraductal papillary mucinous neoplasms of the pancreas: current concepts and controversies. Surgery. 2003;133:459-463.

9. Yachida S, White CM, Naito Y, et al. Clinical significance of the genetic landscape of pancreatic cancer and implications for identification of potential long-term sur-vivors. Clin Cancer Res 2012;18(22):6339-6347.

10. Jones $\mathrm{S}$, Zhang $\mathrm{X}$, Parsons DW, et al. Core signaling pathways in human pancre- atic cancers revealed by global genomic analyses. Science 2008;321(5897): 1801-6.

11. Biankin AV, Waddell N, Kassahn KS, et al. Pancreatic cancer genomes reveal aberrations in axon guidance pathway genes. Nature 2012;491(7424):399-405.

12. Waddell N, Pajic M, Patch AM, et al. Whole genomes redefine the mutational landscape of pancreatic cancer Nature 2015;518(7540):495-501.

13. Polireddy K, Chen Q. Cancer of the Pancreas: Molecular Pathways and Current Advancement in Treatment. Journal of Cancer 2016; 7(11): 1497-1514.

14. Kleeff J, Korc M, Apte M, et al. Pancreatic Cancer.Nat Rev Dis Primers. 2016; 21;2:1-22. doi: 10.1038/ nrdp.2016.22.

15. Sjoquist KM, Chin VT, Chantrill LA, et al. Personalising pancreas cancer treatment: When tissue is the issue. World J Gastroenterol 2014; 20(24): 7849-7863. 


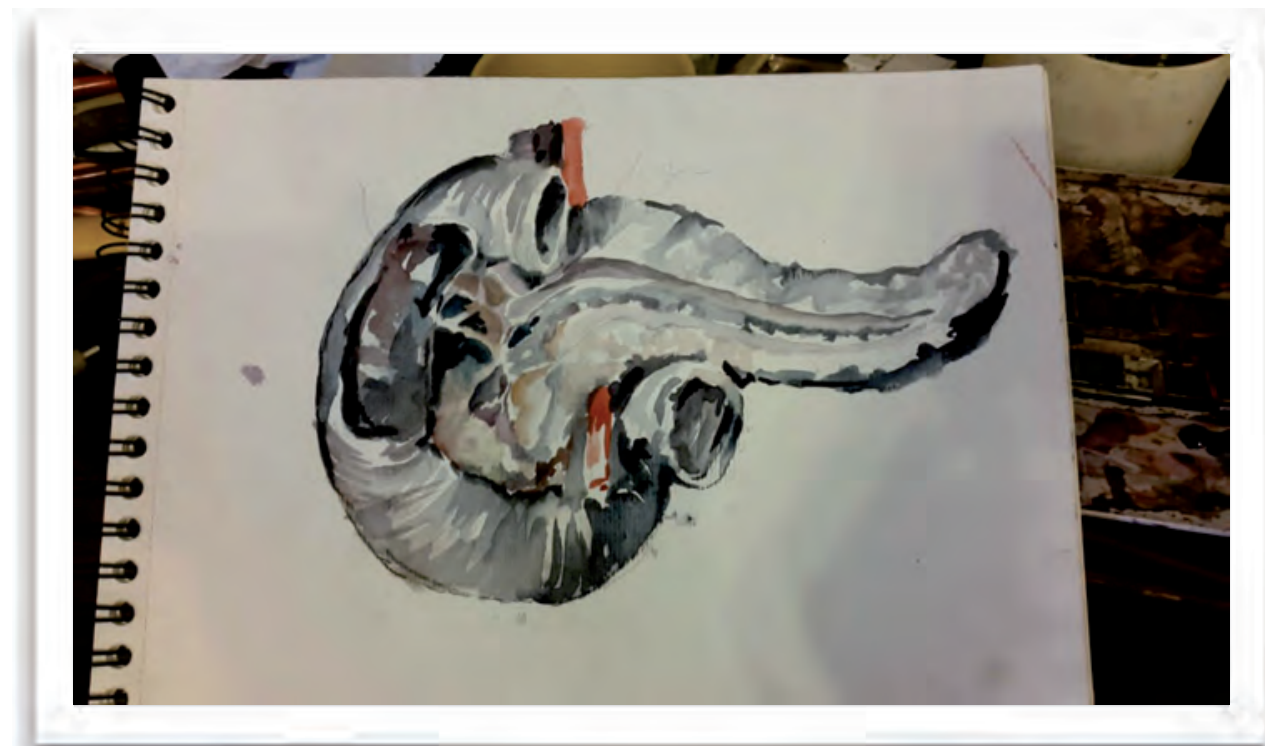

SECCION II DIAGNOSTICO

- ROL DE LOS ESTUDIOS DE IMAGEN EN LA ICTERICIA OBSTRUCTIVA (Dra. Verónica Gigirey).

- ADENOCARCINOMA DE PÁNCREAS: DIAGNÓSTICO, EVALUACIÓN PREOPERATORIA Y CRITERIOS DE RESECABILIDAD. (Dra Verónica Gigirey)

- ROL DE LA BIOPSIA DIAGOSTICA EN EL ADEOCARCINOMA DE PANCREAS

- ROL DE LA LAPAROSCOPIA ESTADIFICADORA

- MARCADORES BIOLOGICOS 


\section{ROL DE LOS ESTUDIOS DE IMAGEN EN LA ICTERICIA OBSTRUCTIVA}

Los estudios de imagen juegan un rol importante en el manejo de la ictericia ya que:

- determinan si existe dilatación de la vía biliar

- definen el nivel y la severidad de la obstrucción

- identifican la causa de la obstrucción

Para ello disponemos de un amplio abanico de técnicas de imagen, por lo que debemos de conocer las ventajas y limitaciones de las mismas, a fin de realizar una correcta selección de estudios.

\section{Ecografía abdominal}

Es el procedimiento de elección para iniciar el estudio del paciente ictérico, dado que permite estudiar el parénquima hepático, así como la vía biliar principal y accesoria, aportando información clave para el diagnóstico.

Entre sus ventajas destaca ser un estudio no invasivo, no usar radiación ni agentes de contraste, poder realizarse en la cama del paciente, repetirse las veces que sea necesario, un bajo costo y la posibilidad de realizar punciones aspirativas o biopsias dirigidas.

Como desventajas tenemos que la calidad del estudio es operador dependiente y que la obesidad y el gas intrabdominal impiden una visualización óptima.

Además de distinguir la ictericia obstructiva de la no obstructiva, otro papel importante de la ecografía es determinar el nivel y la causa de la obstrucción (fig.1) . La ecografía puede determinar el nivel de la obstrucción en más del 90\% de los pacientes y puede identificar la causa en aproximadamente el $80 \%{ }^{2,3}$ Aunque la precisión para definir entre maligno y benigno es del $47-90 \%{ }^{4}$

La sensibilidad para diagnosticar dilatación de la via biliar varía entre 55 a $91 \%{ }^{4}$ y los niveles de sensibilidad más alto se logran cuanto mayor es el valor de bilirrubina sérica y mayor el tiempo de evolución de la obstrucción. ${ }^{5}$

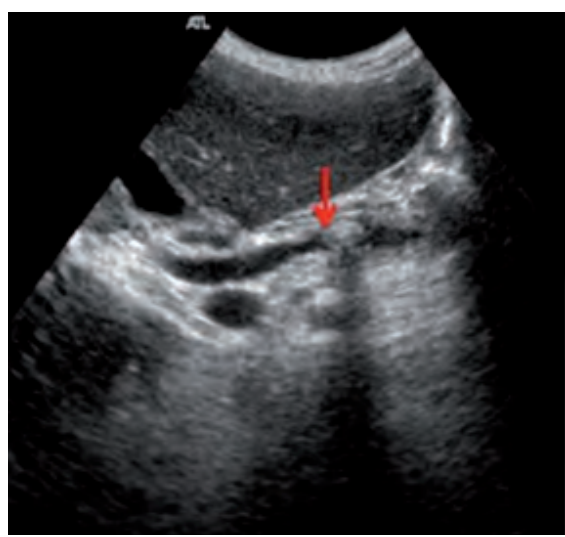

Fig. 1. Ecografía abdominal, corte transversal. Colédoco dilatado, con imagen hiperecogénica con cono de sombra posterior, compatible con litiasis (flecha)

\section{Tomografía computarizada (TC):}

Está indicada en caso de que exista sospecha clínica de neoplasia o que la ecografía demuestre un tumor como causa de obstrucción biliar. En este sentido, consideramos que debe ser el segundo estudio de imagen a solicitar, luego de la ecografía.

Tiene una precisión en diagnosticar dilatación de la via biliar de entre un 81 y $94 \%$ y del nivel de obstrucción de 88 $92 \% .^{14}$

Ayuda a confirmar y valorar la extensión local y a distancia en el cáncer de páncreas, así como sus relaciones vasculares. Se puede utilizar ante la sospecha de coledocolitiasis, con ecografía negativa, si no se dispone de colangiorresonancia (sensibilidad $80 \%$ y especificidad 100\%). La TC tiene escaso valor en el diagnóstico inicial de la coledocolitiasis porque una gran cantidad de las litiasis son isodensas, respecto a la bilis. Cuando se identifican, se observan como imágenes hiperdensas de diverso tamaño (fig. 2).

Su capacidad multiplanar nos permite abarcar grandes volúmenes en un menor tiempo de exploración y con una mejor resolución espacial que la Resonancia Magnética (RM), incluso en pacientes no colaboradores.

Las desventajas son la utilización de radiación y de contraste endovenoso con el consiguiente riesgo de nefrotoxicidad y reacciones alérgicas. 
A diferencia de la ecografía, la tomografía es más exacta en determinar el lugar y la causa de la obstrucción. Es útil en el diagnóstico y estadificación de la neoplasia de páncreas, de los tumores hepáticos y de las estenosis malignas de la vía biliar, permitiendo predecir la resecabilidad de las mismas.

Tiene una precision del 93\% para diferenciar entre obstrucción maligna y benigna. ${ }^{6}$

La tomografía, al igual que la ecografía, sirve de guía en la realización de biopsias hepáticas y en el tratamiento local de los tumores malignos en forma (inyección de alcohol absoluto, ablación por radiofrecuencia, etc). ${ }^{7}$
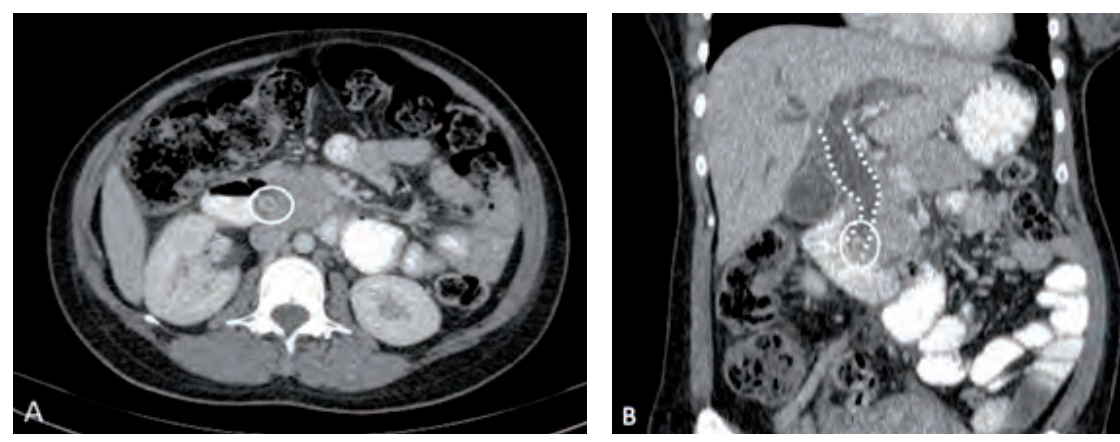

Fig. 2. A) Corte axial y B) reconstrucción coronal, donde se identifica la dilatación del colédoco (líneas punteadas), debido a la presencia de una litiasis (círculo) ubicada en la porción distal del mismo.

\section{Colangiorresonancia (CRM):}

La colangiografía por resonancia magnética permite una excelente evaluación de la patología de la vía biliar. Consiste en una serie de secuencias muy potenciadas en T2 que visualizan los conductos pancreatobiliares.

La bilis y las secreciones del conducto pancreático son estáticas o se mueven muy lentamente, y aparecen con una señal muy alta en T2. La señal de los tejidos circundantes está totalmente suprimida en este tipo de secuencias. ${ }^{1}$

La colangiorresonancia permite evaluar de forma muy precisa el estado del árbol biliar intra y extrahepático, así como del conducto pancreático, y además se visualiza con precisión las posibles variantes anatómicas.

Es inadecuada su realización en pacientes claustrofóbicos, o portadores de implantes metálicos, prótesis osteroaticulares o marcapasos cardíacos. ${ }^{4}$

La CRM ha demostrado su utilidad en la evaluación de la coledocolitiasis, donde presenta una alta sensibilidad y especificidad (90-98\% y 89-100\% respectivamente). ${ }^{8,9}$

Si la ecografía muestra litiasis vesicular, pero no coledocolitiasis, la CRM es la exploración de elección previa a la Colangiopancreatografía endoscópica retrógrada

(CPER). Cuando hay una dilatación de la vía biliar principal la sensibilidad para diagnosticar una litiasis superior a $4 \mathrm{~mm}$ es del 90 al 95\%10,11 (fig.3).

La colangiorresonancia también es útil para diagnosticar las causas no litiásicas de ictericia (estenosis inflamatorias, postquirúrgicas y tumorales). Es necesaria para valorar la extensión de la afectación del árbol biliar en las estenosis tumorales hiliares y como mapa prequirúrgico para identificar variantes anatómicas. Una de sus ventajas, comparado con la CPER, es que valora tanto la lesión intraductal como la extensión extraductal, al visualizar los conductos biliares pre y post-estenóticos y evaluar las características de la tumoración ${ }^{12}$. El uso de contraste está limitado a la valoración de lesiones focales biliares, pancreáticas o hepáticas.

En la colangitis esclerosante, su utilidad en el diagnóstico inicial es controvertida por la menor resolución espacial que presenta frente a la CPER. Sin embargo, es muy útil en el seguimiento de casos avanzados y en la detección precoz de complicaciones como el colangiocarcinoma, que desarrollan el 10\% de los pacientes.

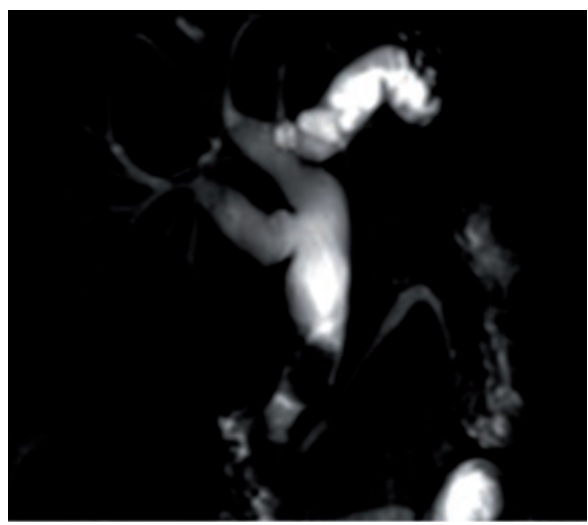

Fig. 3. Colangiorresonancia. A nivel del colédoco distal se observa litiasis obstructiva de aprox. $18 \mathrm{~mm}$ la cual determina moderada dilatación de la vía biliar intra y extra hepática. 


\section{Colangiografía transparietohepática (CTPH):}

Es un procedimiento invasivo. La sensibilidad para diagnosticar obstrucción es de $98-100 \%$ y la especificidad de 89-100\%, similar a la obtenida con la $\mathrm{CPER}^{1,7}$. Se pueden realizar procedimientos terapéuticos como dilatación de estenosis, colocación de stents internos y/o externos y colocación de material radiactivo en pacientes con colangiocarcinoma. La presencia de ascitis masiva o coagulopatía, imposibilita este procedimiento. Hay complicaciones en el orden de 3-6\% que incluyen sangrado, sepsis, fuga biliar, neumotórax, reacción vasovagal, fístula arteriovenosa y reacción al contraste.

Sus principales indicaciones son: la sospecha de obstrucción biliar completa, especialmente a nivel del hilio hepático, cuando interesa conocer el estado de la vía biliar proximal a la obstrucción con vistas a una derivación quirúrgica, y en pacientes en los cuales cirugías previas dificultan la realización de la CPER o frente al fracaso de esta.

\section{Colangiopancreatografía retrógrada endoscópica (CPRE):}

Esta técnica está indicada tras la comprobación de dilatación de la vía biliar en casos de coledocolitiasis, colangitis, estenosis postquirúrgicas de la vía biliar, y ante la sospecha de pancreatitis crónica, o en obstrucciones malignas (fig. 4). Además del diagnóstico radiológico, es útil en la toma de biopsias o cepillado para citología y permite la realización de manometría del esfínter de Oddi, para el diagnóstico de la estenosis papilar. Por otra parte, permite la práctica de técnicas terapéuticas como la esfinterotomía, la extracción de cálculos del colédoco, la dilatación de estenosis y la colocación de endoprótesis en las obstrucciones neoplásicas.

Este procedimiento tiene una sensibilidad en el diagnóstico de obstrucción biliar de 89-98\% y una especificidad de 89-100\%. ${ }^{8}$ Las complicaciones son del orden de 2-7\% e incluyen sangrado, perforación, colangitis y pancreatitis. Por ello ha disminuido su utilización como método diagnóstico frente a métodos no invasivos como la colangiorresonancia.

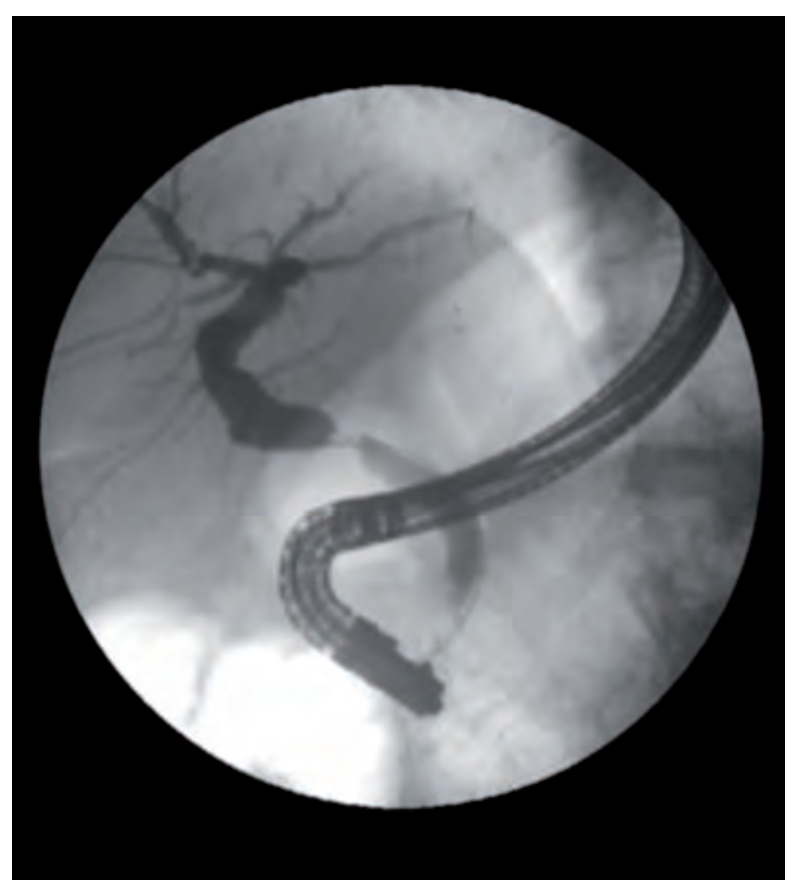

Fig. 4. CPER. Dilatación de la vía biliar intra y extrahepática, con estenosis del colédoco

\section{Ecoendoscopía:}

La ecoendoscopía tiene la ventaja de colocar el transductor en íntimo contacto con la zona a explorar, y en consecuencia, elimina las interferencias ocasionadas por la grasa abdominal o el gas intraluminal. Tiene la misma sensibilidad que la colangiorresonancia y la CPER para diagnosticar dilatación de la vía y su causa, cuando está situada en la vía biliar baja. La ecoendoscopía es excelente para el diagnóstico de pequeños cálculos en las vías biliares que pueden no ser detectados con otros métodos de imagen como la ecografía, TAC y RM. ${ }^{1}$

Scheiman et al, compararon la ecoendoscopía con la CRM y CPER en el diagnóstico de enfermedad biliar extrahepatica, confirmando que la ecoendoscopía es más sensible para diagnosticar coledocolitiasis pequeñas (80 vs $40 \%$ ) frente a la CRM y ademas evita la realización de CPER en presencia de un árbol biliar normal.,13 
Es útil para valorar tumores ampulares y de la cabeza de páncreas y puede facilitar la realización de biopsias.

Se considera que es el método más sensible para diagnosticar tumores cefalopancreáticos, sobre todo aquellos menores a $3 \mathrm{~cm}(93-100 \%){ }^{4}$

Es una prueba semi-invasiva y poco disponible, por lo que, en la actualidad, su uso queda restringido al diagnóstico de extensión local de procesos neoplásicos periampulares y a la toma de biopsias.

Como es de notar, existe una amplia gamma de estudios para valorar a un paciente que se presenta con una ictericia. $\mathrm{El}$ algoritmo diagnóstico debe ser lo mas efectivo y preciso posible para que sea rentable y con el menor riesgo para el pacientes. Debe basarse en la historia clínica y los estudios humorales. En este sentido, la ecografía parece ser una buena herramienta de cribado, aunque en general requiere de una imagen adicional. Si bien la TC y la Resonancia Magnética siguen teniendo preponderancia en el estudio del árbol biliar, aparece la CRM y la ecoendoscopía con resultados diagnósticos excelentes y evitan en muchos casos la realización de métodos más invasivos como la CPER o la CTPH.

\section{RECOMENDACIONES}

1) Ante un cuadro de ictericia con manifestación clínica y laboratorio compatible con obstrucción, el primer método por imagen deberá ser una ecografía de abdomen. Esta se deberá realizar de rutina en los pacientes con cuadro de ictericia obstructiva, pudiendo diferenciar si la causa es de origen alta o baja, siendo el límite por arriba del colédoco supra duodenal. Este estudio es fundamental para el algoritmo diagnóstico. Es un estudio económico con buenos índices de sensibilidad y especificidad para ser el primer estudio diagnóstico.

2) En pacientes con cuadro clínico, laboratorio y ecografía sugestiva de patología neoplásica se deberá realizar TC dinámica trifásica y/o resonancia de abdomen.

3) En pacientes con parámetros clínicos y bioquímicos de colestasis, sin causa obstructiva biliar evidente pero sospechada, con o sin vesícula biliar, se debería realizar colangiopancreatorresonancia, con el fin de evaluar la anatomía de la vía biliar. 


\section{BIBLIOGRAFÍA}

1. Calzado A, Rodríguez R. Imagen por tomografía computarizada. Principios técnicos. Radiología esencial. Seram. Vol 1. Madrid: Panamericana; 2010. p. 16-26.

2. Knebb K, Wden SK. Vesícula y Vías Biliares. En Rumack,C, Wilson SR, Charboneau W, Levine D.Rumack Wilson. Diagnóstico por ecografía. Vol 1.Marban; 2014. p. 176 - 179.

3. Middleton WD, Kurtz AB, Hertzberg BS. Via Biliar. En Ecografia. Madrid: Marbiar; 2007. p. 87 - 102.

4. Addley J, Mitchell RM. Advances in the Investigation of Obstructive Jaundice. Curr Gastroenterol Rep.2012;14(6):511-519.

5. Gold RP, Casarella WJ, Stern G, et al Transhepatic cholangiography: the radiological method of choice in suspected obstructive jaundice. Radiology. 1979;133(1):39

6. Ferrari FS, Fantozzi F, Tasciotti L, al. US, MRCP, CCT and ERCP: a comparative study in 131 patients with suspected biliary obstruction. Med Sci Monit. 2005;11(3): 8-18.

7. Zajaczek JE, Keberle M. Value of radiological methods in the diagnosis of biliary diseases. Radiologe. 2005;45(11):976-978, 980-986.

8. Yarmuch J, Navarrete MF, Lembach H. Rendimiento de la colangiopancreatografía por resonancia magnética respecto a la colangiopancreatografía endoscópica retrógrada en el diagnóstico de colédocolitiasis. Revi Chil Cir. 2008;60(2): 122-126.

9. Kim JH, Kim MJ, Park SI, et al. MR cholangiography in symptomatic gallstones: diagnostic accuracy according to clinical risk group. Radiology 2004;224 (2): 410-416.

10. Busel D, Pérez L, Arroyo A, et al. Colangioresonancia (CPRM) VS Ultrasonido (US) focalizado en pacientes con ictericia o sospecha de obstrucción de la vía biliar. Resultados Preliminares. Rev Chil Radiología. 2003; 9(4): 173-181.

11. Varghese JC, Liddell RP, Farrell MA, et al. Diagnostic accuracy of magnetic resonance cholangiopancreatography and ultrasound compared with direct cholangiography in the detection of choledocholithiasis. Clin Radiol. 2000; 55(1): 25-35.

12. Shanmugam V, Beattie GC, Yule SR, et al. Is magnetic resonance cholangiopancreatography the new gold standard in biliary imaging?. Br J Radiol. 2005;78(934): 888-893.

13. Scheiman JM, Carlos RC, Barnett JL, et al. Can endoscopic ultrasound or magnet- ic resonance cholangiopancreatography replace ERCP in patients with suspected biliary disease? A prospective trial and cost analy-sis. Am J Gastroenterol. 2001;96(10):2900-2904. 


\section{ADENOCARCINOMA DE PÁNCREAS: DIAGNÓSTICO, EVALUACIÓN PREOPERATORIA Y CRITERIOS DE RESECABILIDAD. ROL DE LA IMAGEN.}

Cualquiera que sea la modalidad de imagen que se utilice, el objetivo de la evaluación frente a un posible cáncer de páncreas será detectar el tumor, determinar la estadificación local y a distancia y valorar su resecabilidad, para llevar a cabo un tratamiento óptimo.

Dentro del arsenal de estudios de imagen con que se cuenta para este propósito, la Tomografía Computada (TC) es la técnica de elección y la más empleada.

\section{ULTRASONOGRAFÍA ABDOMINAL (US)}

El estudio inicial en pacientes con sospecha clínica de afectación hepato-bilio- pancreática es a menudo la ecografía abdominal, debido a su inocuidad y amplia disponibilidad. ${ }^{1,2}$

Permite detectar la neoplasia pancreática (imagen hipoecoica y mal definida), valorar la vía biliar/ conducto pancreático (fig.1 y 2), evaluar las estructuras vasculares peri pancreáticas (técnica Doppler color), metástasis hepáticas y en ocasiones implantes peritoneales.

Existen limitaciones para el estudio del páncreas debido a la interposición de gas intestinal, por tratarse de una exploración «operador-dependiente» y por su baja sensibilidad y especificidad para determinar la resecabilidad (63\% y $83 \%$ respectivamente).

Ecográficamente la gran mayoría de los cánceres pancreáticos son masas hipoecogénicas, en relación al parénquima pancreático adyacente. Pueden distorsionar o no el contorno del páncreas, dependiendo de su tamaño y localización. La dilatación y obstrucción del colédoco son frecuentes en las lesiones cefálicas, él mismo puede ser seguido distalmente y mostrar un cambio brusco de calibre a la altura de la masa pancreática. La obstrucción del conducto pancreático y su dilatación, distal a la lesión, son otros hallazgo frecuente en pacientes con carcinoma pancreático. . $^{3,4}$

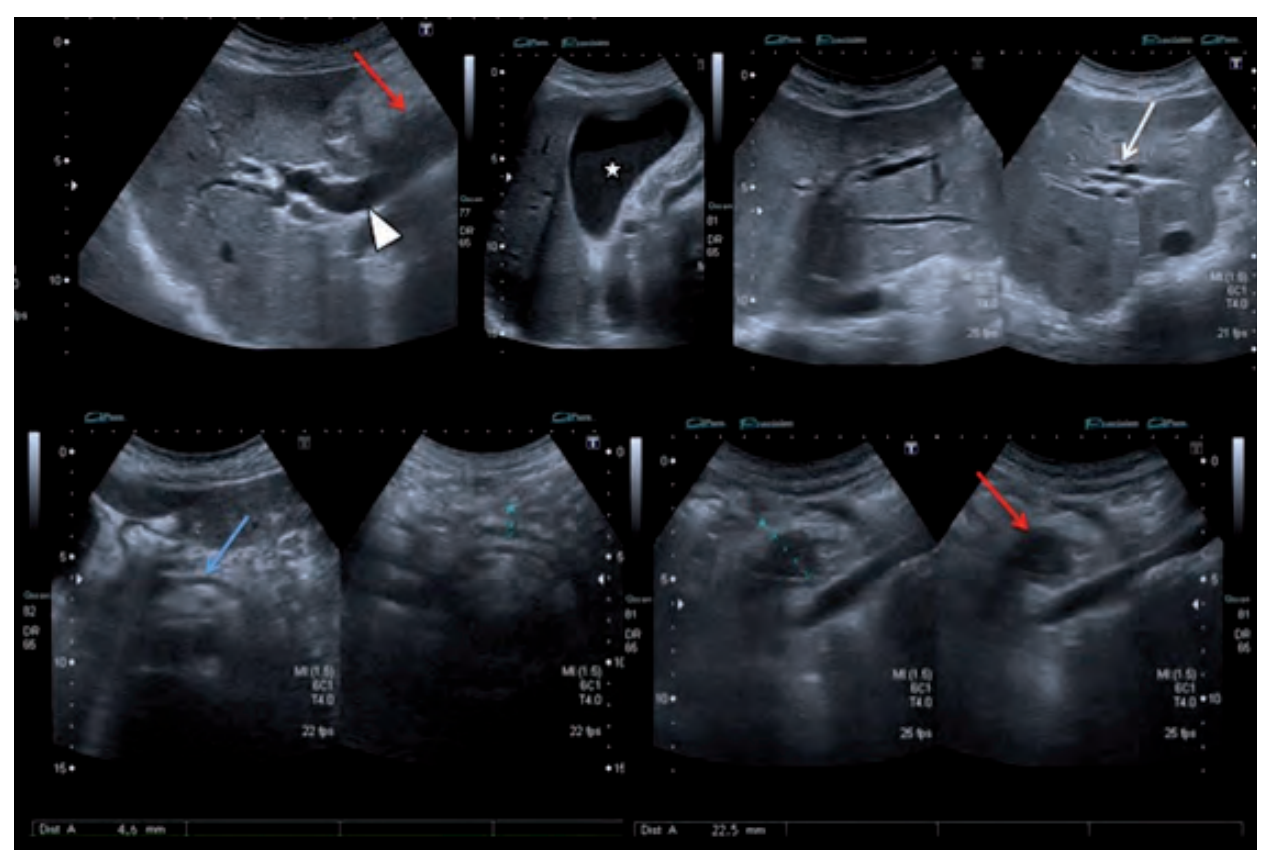

Fig. 1. Ecografía abdominal: formación hipoecoica a nivel de la cabeza pancreática (priemera flecha ) que produce dilatación de la vía biliar intrahepática (segunda flecha arriba), distensión de la vesícula biliar (asterisco blanco) y dilatación de la vía biliar principal (cabeza de flecha ), así como dilatación del conducto pancreático. 

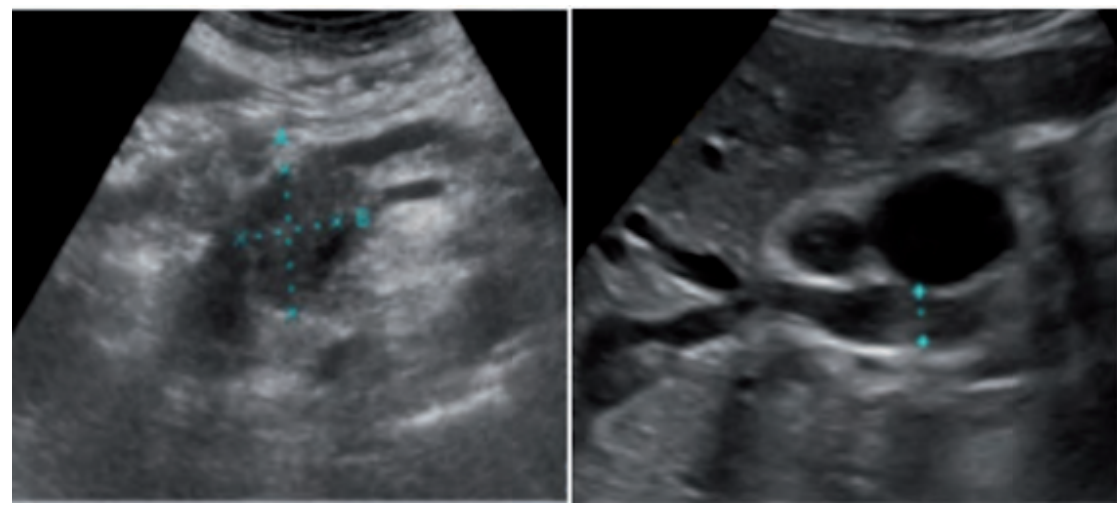

Fig. 2. Ecografía abdominal. Masa hipoecogénica de contornos irregulares situada en cabeza pancreática, correspondiente adenocarcinoma pancreático. Dilatación de ducto pancreático principal y colédoco

\section{TOMOGRAFÍA COMPUTARIZADA (TC)}

La disponibilidad actual de equipos de TC multidetector (TCMD) de alta calidad (16 hileras de detectores o superior), han mejorado la estadificación preoperatoria y el manejo terapéutico en una proporción significativa de pacientes. La TC es el método de imagen más utilizado para la detección, caracterización y evaluación preoperatoria del adenocarcinoma pancreático, ya que aporta una buena resolución espacial y temporal, y permite realizar reconstrucciones multiplanares de alta calidad.., 6

Para ello resulta crucial conocer los parámetros técnicos adecuados, que permitan maximizar la diferencia de atenuación entre el tumor y el parénquima pancreático normal, valorar los vasos cercanos y las estructuras distantes. También es una herramienta fundamental para la planificación quirúrgica y seguimiento de los pacientes tratados de cáncer de páncreas. ${ }^{1}$

Para algunos autores, la TCMD ha demostrado tener un valor predictivo negativo para la invasión vascular, próximo al $100 \%$, y un valor predictivo negativo (87\%) para la determinación de la resecabilidad del adenocarcinoma de páncreas. ${ }^{7}$

\section{Técnica de adquisición}

Se requiere un estudio dinámico bifásico, una fase parenquimatosa pancreática (o pancreatográfica), que se obtiene con un retraso con respecto al inicio de la inyección de contraste de 40 segundos, seguido de una fase venosa portal, obtenida con una demora de unos 70 segundos. $3,4,7$

La opacificación máxima de la glándula tiene lugar durante la fase pancreatográfica, que maximiza las diferencias de atenuación entre el páncreas normal (que muestra un realce vigoroso) y el tumor (hipodenso, debido a proliferación fibroblástica y la hipoperfusión). Esta fase también permite el adecuado realce de las estructuras vasculares críticas, para la detección de invasión vascular.

La fase venosa portal es ideal para la detección de metástasis hepáticas, ganglios linfáticos e implantes peritoneales, así como la creación de reconstrucciones de imágenes de las estructuras venosas, que podrían ser esenciales para la planificación quirúrgica. También proporciona una segunda mirada al páncreas, lo que puede ser útil en ocasiones.

La adquisición de imágenes en fase arterial (retraso de 20 segundos) no aporta información adicional en la detección y estadificación del adenocarcinoma de páncreas, puesto que la visibilidad de las lesiones es subóptima y la representación de la anatomía venosa es inferior a la fase portal.

Es necesaria la evaluación de los estudios en consolas de trabajo, complementando las imágenes axiales con reconstrucciones multiplanares y $3 \mathrm{D}$, que permitan una mayor precisión para determinar la extensión local y a distancia.

\section{Detección tumoral}

Aproximadamente el $90 \%$ de los adenocarcinomas de páncreas se presentan como una masa focal,y el resto se manifiesta de forma difusa.

En la TC con contraste intravenoso, la lesión suele ser hipodensa con respecto al tejido pancreático.

Aunque hay que tener en cuenta que alrededor del $10 \%$ de los adenocarcinomas de páncreas son isodensos en relación al parénquima pancreático no tumoral, y es una forma de presentación, más característica, de las lesiones de pequeño tamaño (menos de $3 \mathrm{~cm}$ ). En estos casos, el diagnóstico de neoplasia pancreática se puede apoyar en signos indirectos como:

1. Interrupción y obstrucción ductal abrupta (Fig. 2,3 y 4).

2. Efecto de masa y/o convexidad del contorno pancreático.

3. Atrofia distal del parénquima pancreático (fig. 4).

4. Dilatación e interrupción de los conductos biliar y pancreático: signo del doble conducto, evidenciado en tumores que asientan en la cabeza pancreática (Fig. 5). 


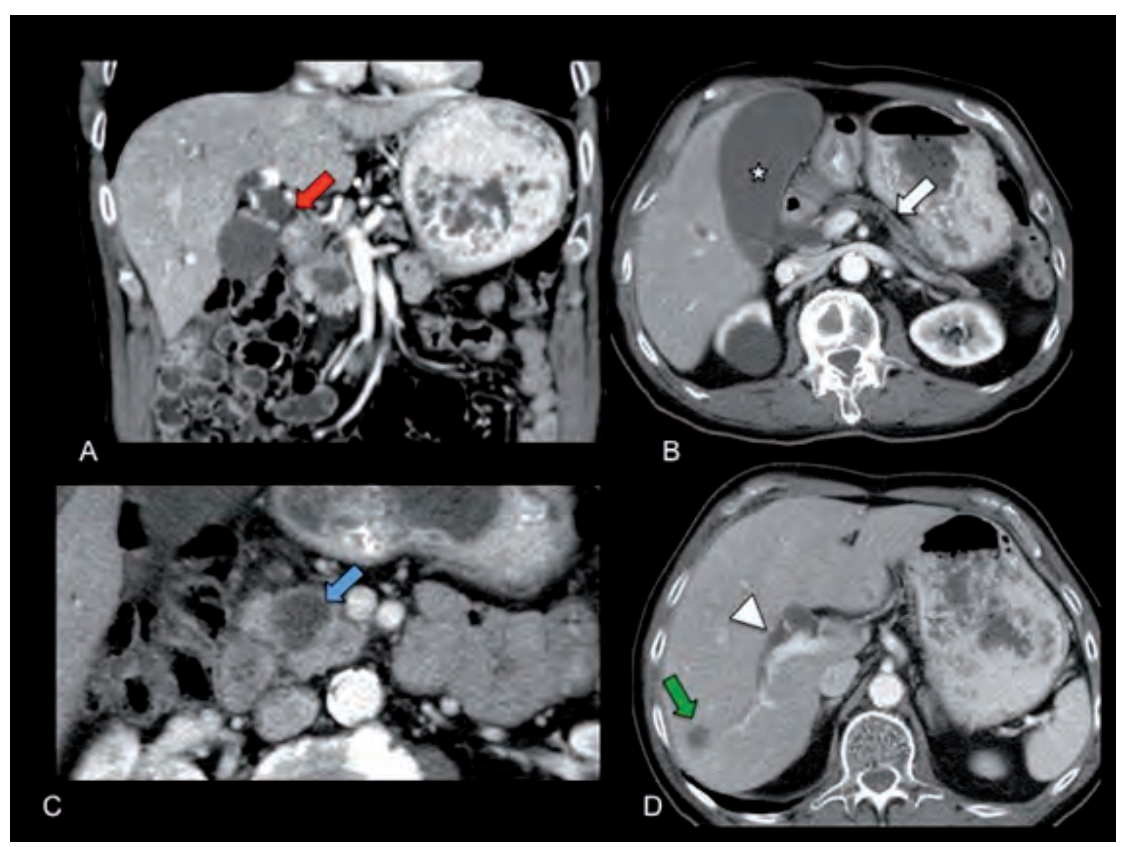

Fig. 3: Mismo paciente que figura 1. TC abdominopélvico con contraste intravenoso en los planos coronal (A) y axial (B, C y D): lesión hipodensa a nivel de la cabeza pancreática (flecha imagen C) que produce dilatación del conducto pancreático (flecha B) y vía biliar principal (con interrupción abrupta, flecha A) e intrahepática (cabeza de flecha blanca) con distensión de la vesícula biliar (asterisco blanco).

Lesiones focales hepáticas en relación con metástasis (flecha D).

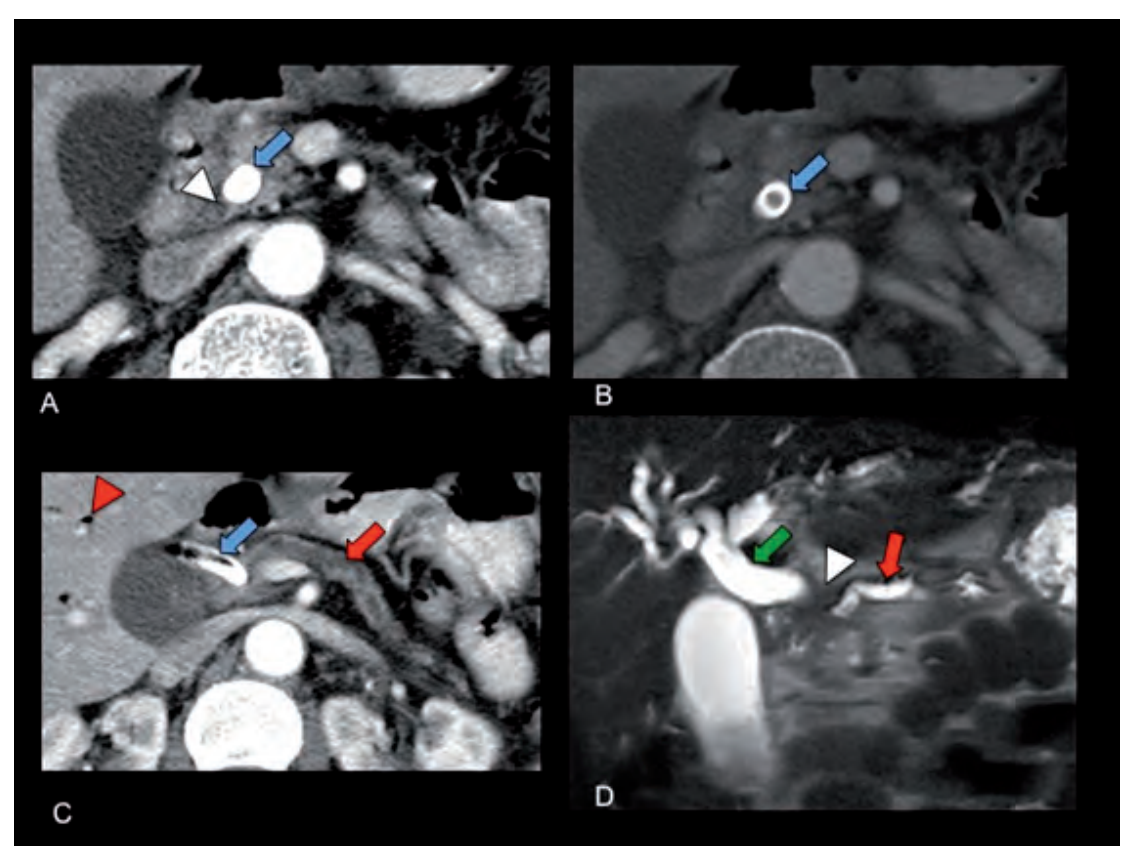

Fig. 4. TC abdominopélvico con contraste intravenoso en el plano axial (A, B y C) y colangio RM en plano coronal (D): aerobilia (cabeza de flecha imagen C). Endoprótesis biliar en colédoco (Imagen A,B,C) que puede dificultar la valoración del estudio. Área hipodensa en la cabeza pancreática rodeando la endoprótesis (cabeza de flecha blanca) que ocasiona dilatación de la vía biliar intrahepática, vesícula biliar, dilatación arrosariada del conducto pancreático (con atrofia glandular distal, imagen $\mathrm{C}, \mathrm{D}$ ) y dilatación de la vía biliar extrahepática (imagen D): signo del "doble conducto" 


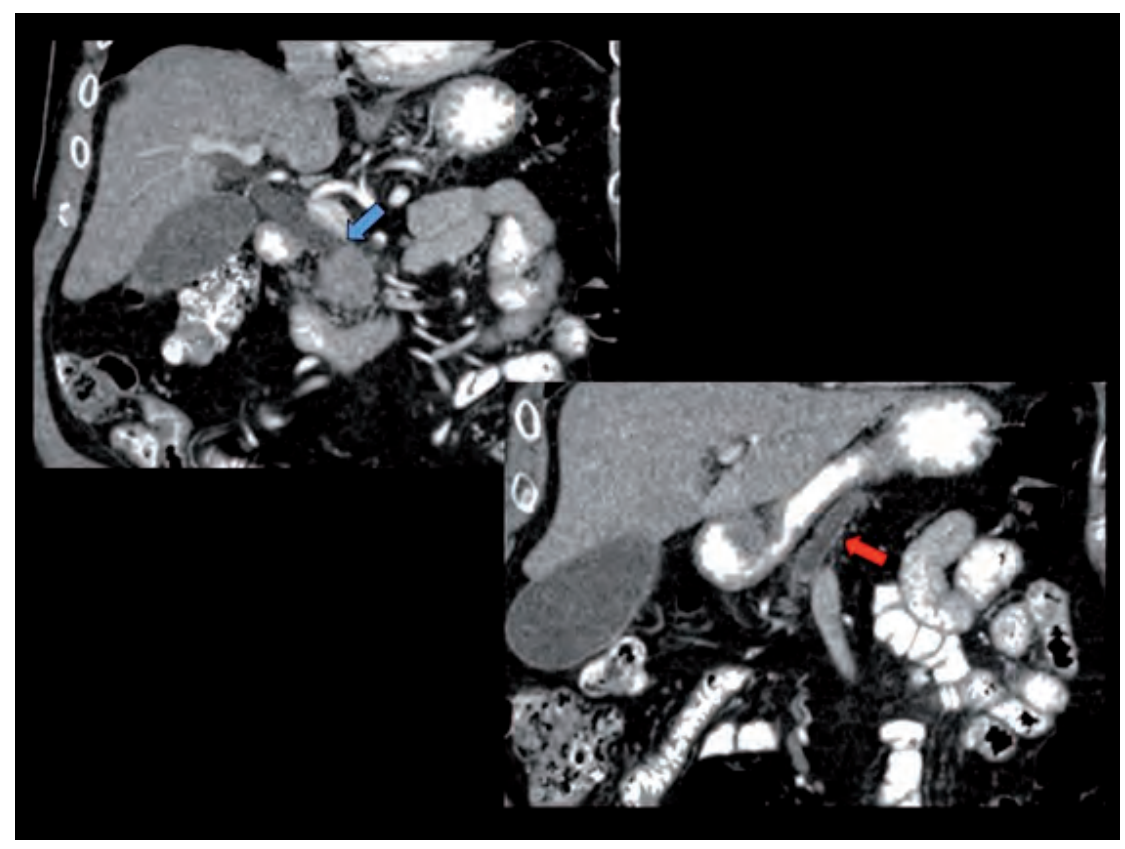

Fig. 5. TC abdomen con contraste intravenoso en el plano coronal: conducto pancreático (imagen inferior) y vía biliar extrahepática dilatados (con terminación abrupta, imagen superior): "signo del doble conducto".

La pancreatitis crónica focal y la pancreatitis autoinmune, son los dos procesos benignos más comúnmente confundidos con cáncer de páncreas en TC o ecografía.

Los pacientes con adenocarcinoma de páncreas, en algunos medios, se someten con frecuencia a una colangiopancreatografía endoscópica retrógrada (CPER) para la colocación de stent biliar previo a realizarse la TC, el cual dificulta la valoración exacta de la localización anatómica de la obstrucción biliar o da lugar a la aparición de cambios inflamatorios locales, que pueden ser confundidos con una lesión neoplásica pancreática.

\section{Estadificación y criterios de resecabilidad}

La TC es la técnica de elección para una correcta evaluación de la extensión local y a distancia. Los valores predictivos positivos (VPP) de la TC para irresecabilidad están entre el 89\% y 100\%, algo menor (76-90\%) para valorar la resecabilidad, siendo las principales limitaciones de la TC en el proceso de estadificación, la presencia de pequeñas lesiones hepáticas y de implantes peritoneales.

\section{$\underline{\text { A. Evaluación vascular }}$}

La infiltración vascular es el factor más crítico del que depende la potencial resecabilidad tumoral.

La invasión arterial es un criterio de irresecabilidad bien aceptado. Sin embargo, la invasión venosa peripancreática, dependerá de su grado y tipo para determinar la resecabilidad

Un sistema de clasificación de infiltración puede basarse en el grado de contigüidad circunferencial del tumor al vaso. Los Criterios de Lu, establecen la probabilidad de infiltración basándose en el porcentaje de contacto con el vaso. Un único contacto no implica infiltración, y por lo tanto, puede realizarse una cirugía con márgenes libres de tumor (Tabla 1). Un contacto (ausencia de plano graso) superior a $180^{\circ}$ o al $50 \%$ de la circunferencia del vaso, es altamente específico de invasión, y por tanto, de irresecabilidad. Por el contrario, cuando el contacto es inferior al 50\%, puede existir o no infiltración, pero esto no debe contraindicar la cirugía (Fig. 6 ,7 y 8). Con esta clasificación, Lu et al obtuvieron unos valores de sensibilidad y especificidad del 84\% y el 98\% respectivamente, y un VPP y Valor predictivo negativo (VPN) del 95\% para evaluar la invasión vascular. ${ }^{8}$ 
Tabla1: Criterios de Lu para evaluar la invasión vascular

\begin{tabular}{|c|c|c|}
\hline GRADOS & $\begin{array}{c}\text { \% de contacto entre el tumor y la } \\
\text { circunferencia del vaso }\end{array}$ & Probabilidad de infiltración \\
\hline 0 & No contacto & No invasión \\
\hline I & $<25 \%$ de circunferencia & invasión posible pero poco probable \\
\hline II & entre $25-50 \%$ & invasión posible pero poco probable \\
\hline III & entre $50-75 \%$ & invasión vascular \\
\hline IV & $>75 \%$ o estenosis & invasión vascular \\
\hline
\end{tabular}
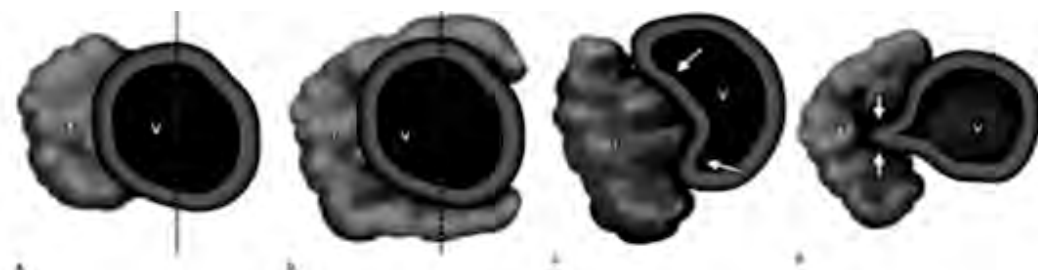

(a) Contacto tumor-vena $\leq 180^{\circ}$ de la circunferencia del vaso, sin deformidad.

(b) Contacto tumor-vena $>180^{\circ}$ de la circunferencia del vaso, sin deformidad.

(c) Contacto tumor-vena $\leq 180^{\circ}$ de la circunferencia del vaso, con deformidad

(flechas).

(d) Deformidad en lágrima (flechas).

Fig. 6. Esquema criterios Lu. Contacto tumor vena.

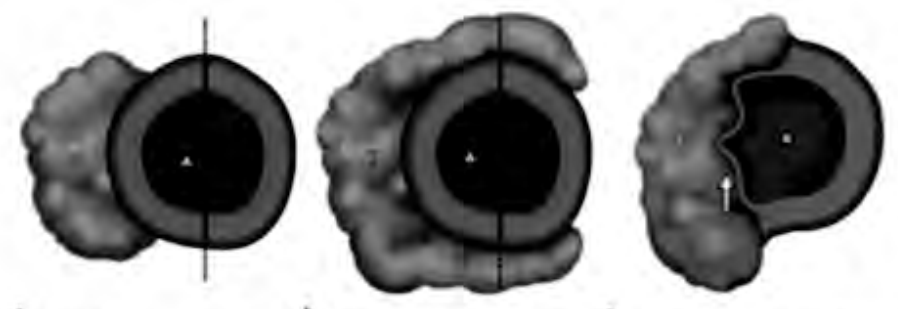

(a) Contacto tumor-arteria $\leq 180^{\circ}$ de la circunferencía del vaso, sin deformidad.

(b) Contacto tumor-arteria $>180^{\circ}$ de la circunferencia del vaso, sin deformidad.

(c) Contacto tumor-arteria con deformidad (flecha).
Fig. 7. Esquema criterios Lu. Contacto tumor arteria.

\section{Invasión venosa:}

Los signos que valoran la resecabilidad incluyen:

a) estenosis e irregularidad de la vena porta (VP) o la vena mesentérica superior (VMS), así como una contigüidad circunferencial del tumor con la vena porta superior a $90^{\circ}$ (Figuras).

b) invasión o trombosis de la VMS o VP.

c) signo de la "lágrima" de la vena mesentérica superior : consiste en una deformidad focal del contorno redondeado de la vena adyacente al tumor en las secciones axiales, como indicativo de invasión venosa. Tiene una sensibilidad del 79-95\%.

d) presencia de circulación colateral: dilatación de pequeñas venas pancreatoduodenales o del tronco gastrocólico, sin otra causa que lo justifique. 

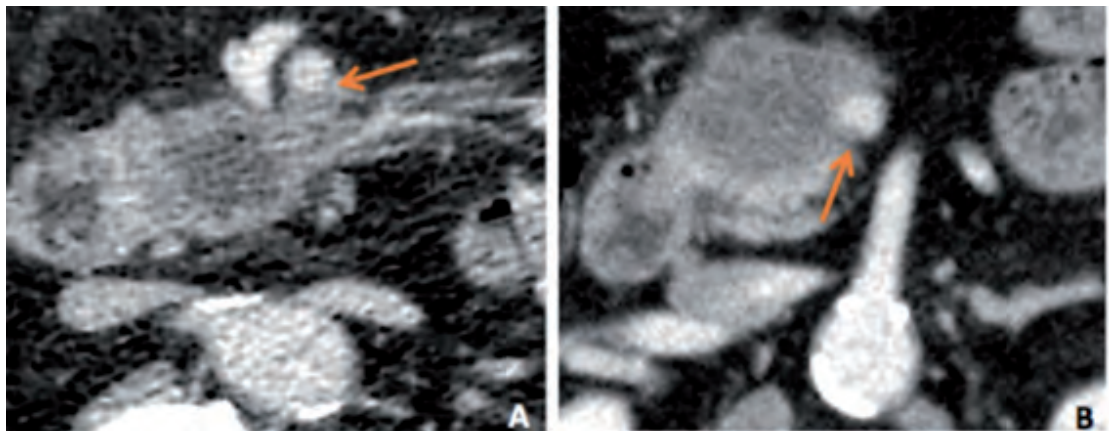

Fig. 8 TCMD de páncreas corte axial. A. Adenocarcinoma en cabeza pancreática que contacta con la vena mesentérica superior (VMS), siendo este contacto inferior al 180 de la circunferencia del vaso. B. ACDP en cabeza pancreática que contacta con la VMS en más de $180^{\circ}$ de su circunferencia, produciendo irregularidad parietal y signo de la lágrima (Flecha).

\section{Invasión arterial:}

La afectación (con pérdida de plano graso entre el tumor y el vaso) de la arteria mesentérica superior (AMS, Fig. 9), tronco celíaco (TC), arteria hepática $(\mathrm{AH})$ ó arteria gastroduodenal proximal, hace al tumor irresecable.

Signos de infiltración arterial:

a) Bandas periarteriales. Se observan como un aumento de la densidad y la trabeculación de la grasa que irradian desde el tumor hasta contactar con el vaso arterial, sin que exista contacto directo entre el tumor y el vaso. Estas bandas pueden representar cambios inflamatorios o desmoplásicos locales, pero se ha demostrado que en el $25 \%$ de los casos implican infiltración arterial. Estas bandas no contraindican por si sola, pero se deben tener en cuenta por la posibilidad de infiltración e irresecabilidad.

b) Manguito perivascular. Es un manguito sólido de densidad de partes blandas que aparece alrededor de las estructuras vasculares, representando extensión tumoral extrapancreática. A veces puede ser la única manifestación del tumor y lo convierte en irresecable cuando infiltra la arteria mesentérica superior o el tronco celíaco.
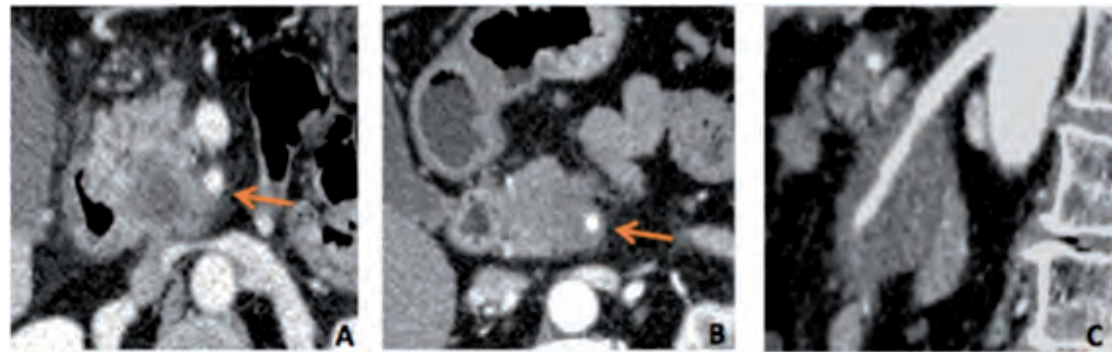

Fig. 9 TCMD abdomen.

A. Adenocarcinoma en cabeza pancreática que contacta con la arteria mesentérica superior (AMS), siendo este contacto inferior a $180^{\circ}$ de la circunferencia del vaso.

B. Adenocarcinoma en cabeza pancreática que rodea por completo la circunferencia de la AMS

C. Irregularidad parietal de la AMS por contacto/infiltración por el tumor.

\section{B. Evaluación extrapancreática}

La evaluación extrapancreática incluye tanto la extensión local como a distancia. La extensión directa a estructuras adyacentes como el estómago, el intestino delgado o el colon/mesocolon, riñones, glándulas suprarrenales, vena cava inferior, aorta o bazo, puede afectar la decisión quirúrgica (fig. 10 ).
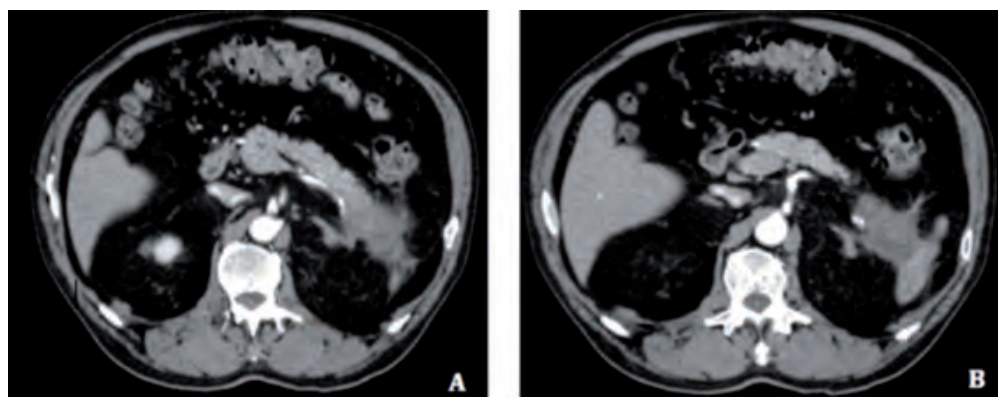

Fig. 10. TCMD cortes axiales con contraste. A y B. Adenocarcinoma localizado en la cola pancreática que contacta con el bazo, infiltrándolo, así como a la vena esplénica. Infiltración de la grasa adyacente al ángulo esplénico del colon. 


\section{C.Evaluación de la invasión perineural}

La invasión perineural se considera en la actualidad uno de los factores pronósticos más importantes en el adenocarcinoma de páncreas. La posibilidad de que las células cancerígenas se propaguen a través del espacio perineural, parece ser una de las principales causas de recurrencia tumoral local tras resecciones pretendidamente curativas.Por otra parte se correlaciona con el dolor posterior (solaralgia) en estos pacientes.

Los principales patrones a valorar en el estudio de la invasión perineural mediante TC, son cambios del tejido graso, en ocasiones sutiles, que incluyen: aumento de densidad difusa e irregular del tejido graso retroperitoneal peripancreático o bien del tejido graso que rodea a la AMS, VMS, tronco celíaco o vena esplénica (Fig. 11).
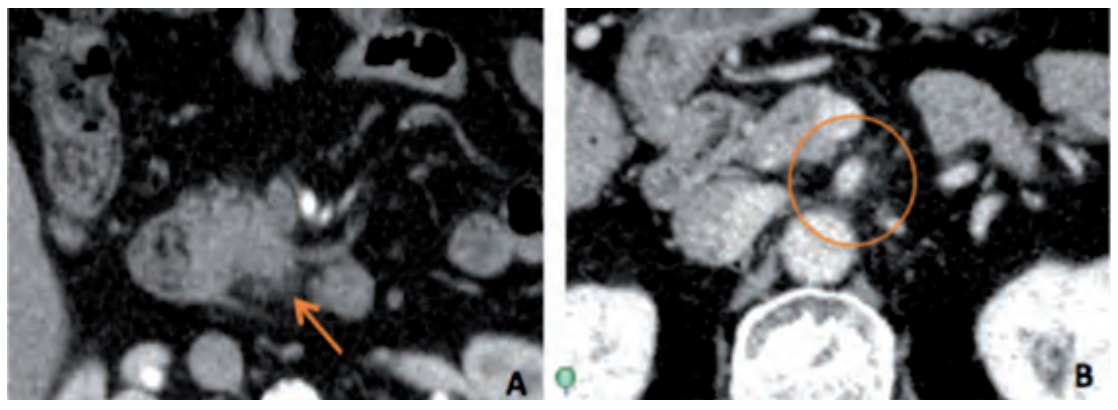

Figura 11. Patrones radiológicos sugestivos de invasión perineural en Adenocarcinoma de páncreas.

A. Contornos indefinidos del margen posterior del proceso uncinado con aumento de densidad irregular de la grasa retropancreática.

B. Aumento de densidad irregular en el espacio graso que rodea a la arteria mesentérica superior.

\section{D.Evaluación ganglionar}

Es baja la precisión diagnóstica de la TC en la determinación de la infiltración tumoral ganglionar, la cual oscila entre el 58\% y el 78\% según las series.

La TC sólo pone de manifiesto la patología ganglionar como un aumento de su tamaño; no es útil para diferenciar tumor o inflamación en los ganglios linfáticos con un tamaño normal. Se considera adenomegalia por TC cuando el diámetro ganglionar es mayor o igual a $10 \mathrm{~mm}$ en el eje corto. $\mathrm{El}$ aumento de tamaño puede deberse a hiperplasia reactiva, infección y/o infiltración tumoral. El tamaño no es una característica discriminatoria entre ganglios linfáticos metastásicos y no metastáticos, además la detección de ganglios metastáticos peripancreáticos tiene una importancia limitada ya que la mayoría se resecan en bloque junto con el tumor. ${ }^{9}$ Por tanto, en pacientes con un tumor resecable por lo demás, la descripción en TC de ganglios peripancreáticos aumentados de tamaño, no debe impedir una resección con intención curativa (fig. 12).

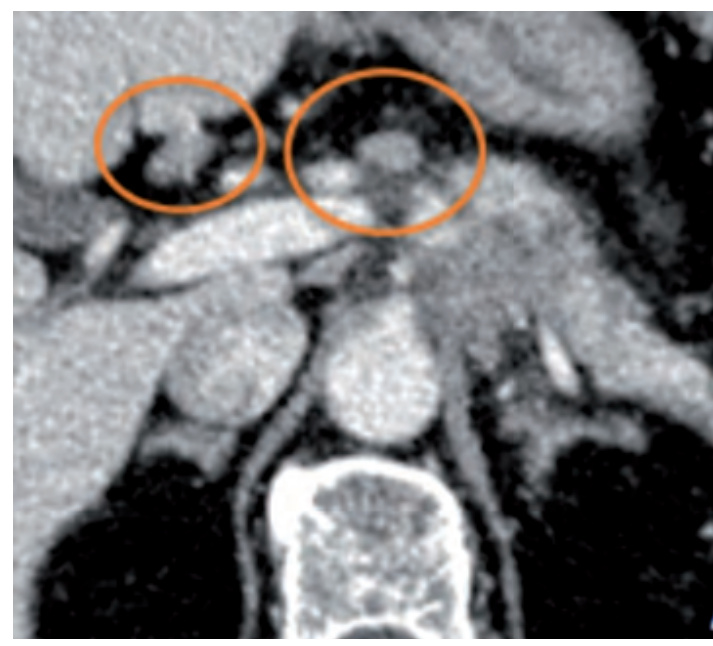

Fig. 12. TCMD corte axial con contraste. Paciente con adenocarcinoma de páncreas. Ganglios peripancreáticos de aspecto inespecífico (eje corto $<1 \mathrm{~cm}$, homogéneos, de contornos bien delimitados).

\section{E. Evaluación de metástasis a distancia}

El adenocarcinoma de páncreas metastatiza más frecuentemente en el hígado, peritoneo, pulmón y hueso.

Los focos metastásicos hepáticos aparecen como áreas de baja densidad en el parénquima hepático realzado, con margen pobremente definido o realce periférico (fig. 13). Las metástasis hepáticas de pequeño tamaño, principalmente implantes peritoneales en la superficie hepática, son las que presentan mayor dificultad para su detección y caracterización mediante las técnicas de imagen. La Resonancia Magnética (RM), principalmente con la fusión de secuencias de difusión y el uso de contraste hepatoespecífico, presenta según algunos estudios, una mayor sensibilidad que la TC en este campo ( $85 \%$ vs $69 \%){ }^{10}$

La presencia de nódulos peritoneales o de ascitis (Fig. 14), en ausencia de otras causas potenciales, sugieren enfermedad diseminada, lo cual contraindica la cirugía. Sin embargo, con frecuencia los implantes tumorales peritoneales de pequeño tamaño, pueden pasar desapercibidos en el estudio de TC. 


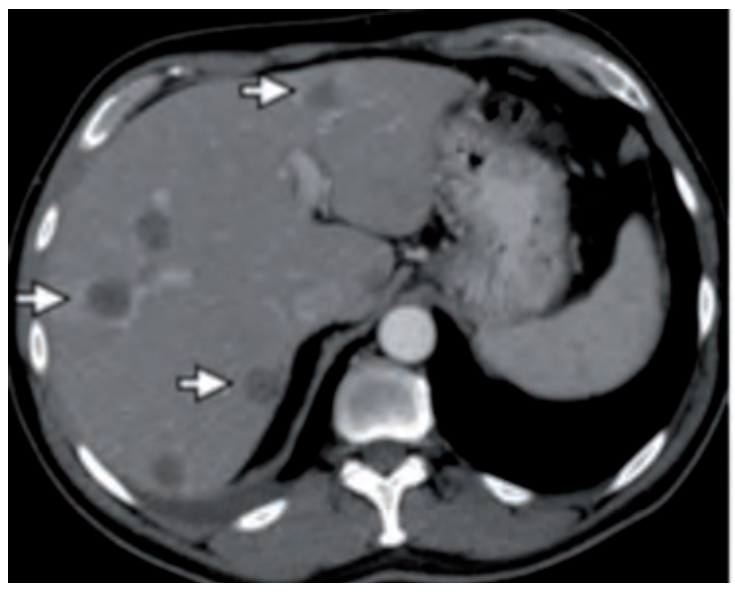

Fig. 13. TC corte axial con contraste intravenoso. Metástasis hepáticas en paciente con masa pancreática. Múltiples nódulos hepáticos con márgenes pobremente definidos y realce completo en anillo.
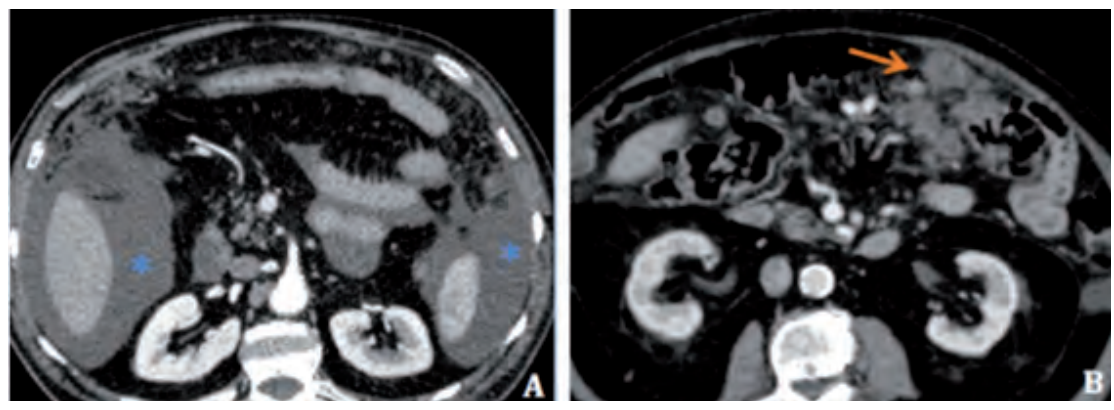

Fig. 14. TCMD abdominal A y B cortes axiales con contraste $\mathrm{i} / \mathrm{v}$

Carcinomatosis peritoneal en paciente portador de adenocarcinoma de páncreas. Presencia de ascitis (asterisco) y nódulos peritoneales y mesentéricos (flecha).

\section{RESONANCIA MAGNETICA (RM)}

La RM ha demostrado ser igualmente sensible y específica que la TC en la estadificación de las neoplasias pancreáticas. Sin embargo, en la mayoría de los centros no suele ser utilizada como método de primera elección, dado su mayor costo y menor disponibilidad. El estudio mediante RM queda reservado para complementar el estudio de TC, en casos de lesiones pancreáticas dudosas, isodensas al parénquima pancreático o para una mejor caracterización de lesiones hepáticas indeterminadas y en pacientes alérgicos al yodo. La RM presenta mayor sensibilidad para detectar tumores de pequeño tamaño o isointensos con el parénquima pancreático, y enfermedad a distancia (metástasis hepáticas pequeñas e implantes peritoneales). ${ }^{11}$ Así como también en aquellos tumores con gran componente quístico. ${ }^{12}$

La resolución de contraste de la RM es superior a la de la TC, sin embargo, la resolución espacial es menor en los estudios de RM que en los actuales estudios de TCMD. Otra limitación de la RM en la detección del adenocarcinoma de páncreas es la importante susceptibilidad a los movimientos respiratorios.

Un protocolo de RM para evaluar tumores pancreáticos incluirá secuencias potenciadas en T1 y T2 sin y con supresión grasa, así como estudios dinámicos tras la administración de gadolinio, difusión y ADC. En los estudios de RM, el tumor presenta una baja señal tanto en las secuencias potenciadas en T1 como en las T2, y como en la TC, las secuencias dinámicas muestran un realce menor que el resto del parénquima. Sin embargo, en escasas ocasiones, pueden mostrarse isointensos, en cuyo caso su identificación puede ser dificultosa. En estos casos las secuencias de difusión pueden ser de utilidad, ya que los adenocarcinomas normalmente presentan una difusión restringida, lo que puede incrementar la probabilidad de detección del tumor. ${ }^{13}$ 


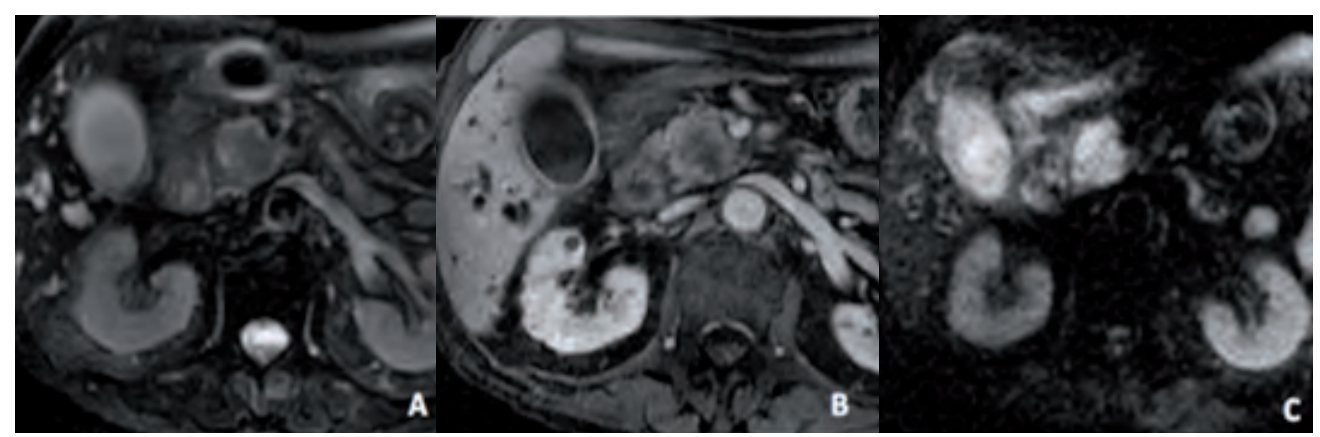

Fig. 15. RM.

A: Secuencia T2 con supresión grasa: lesión heterogénea predominantemente hipointensa en la cabeza pancreática.

B: Secuencia SPGRE 3D (LAVA) con contraste en fase portal. Masa heterogénea con área central de menor realce y contornos irregulares.

C: Secuencia de difusión (factor b: 800) Intenso aumento de señal indicativo de restricción.

La Colangiopancreatografía por RM (CPRM) es útil para evaluar el árbol biliar y conducto pancreático, y determinar el nivel de la obstrucción (Fig. 16). ${ }^{14,15}$

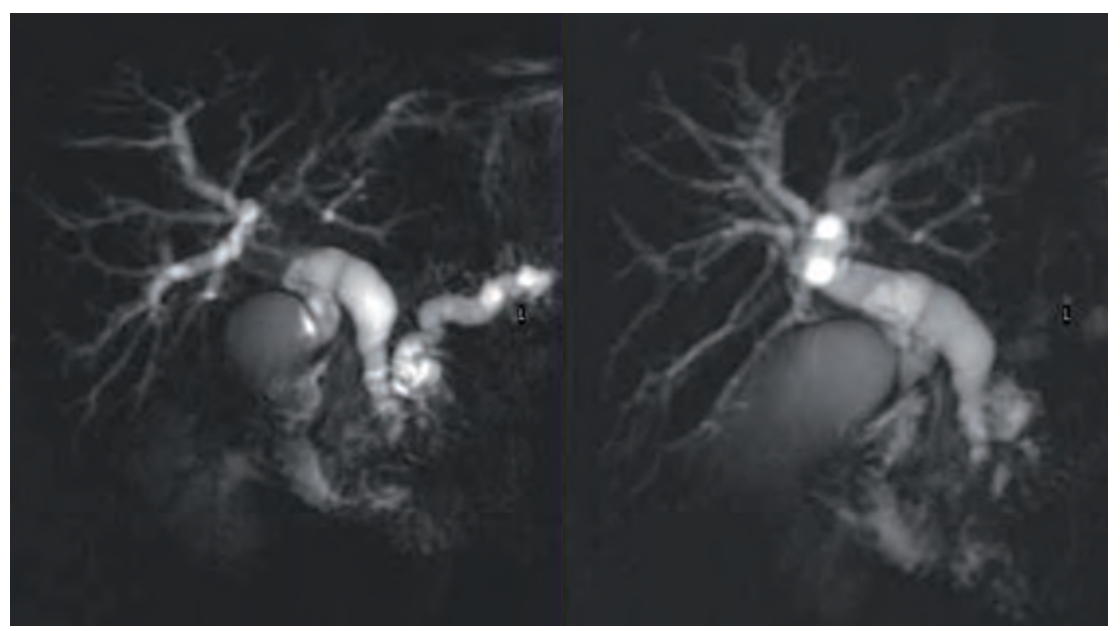

Fig. 16. Colangiorresonancia. Dilatación de la vía biliar intra y extrahepática y del conducto Wirsung debida a un adenocarcinoma de páncreas.

\section{$\mathrm{PET} / \mathrm{TC}$}

El PET/TC posee un papel limitado en la estadificación local del adenocarcinoma pancreático, ya que normalmente es una técnica realizada sin la administración de contraste intravenoso, lo que le confiere una pobre definición espacial del tumor y de su relación con los vasos adyacentes. Sin embargo, entre las utilidades de esta técnica cabe reseñar: los casos de TC no diagnóstica debido a tumores de pequeño tamaño o isodensos al parénquima pancreático, la planificación de biopsia guiada por imagen, o bien, situaciones de PAAF no diagnóstica, en pacientes con sospecha de cáncer de páncreas. Otras indicaciones en pacientes ya diagnosticados: la estadificación tumoral a distancia, el diagnóstico de recurrencia neoplásica y la monitorización de la respuesta terapéutica. ${ }^{5}$

El adenocarcinoma de páncreas normalmente se manifiesta en el PET/TC como un área de aumento de captación de FDG en el interior del páncreas (Fig. 16), sin embargo, en dependencia de la histología del tumor y el grado de respuesta desmoplástica, el adenocarcinoma pancreático puede presentar una baja captación de FDG. ${ }^{15}$ (15)

Entre las principales aplicaciones de la FDG PET/TC, se encuentra el diagnóstico de metástasis hepáticas, peritoneales o a distancia, basándose en la captación de FDG por estas lesiones. Sin embargo, se debe tener en cuenta la posibilidad de falsos negativos en relación con el tamaño (lesiones pequeñas menores de $10 \mathrm{~mm}$ están por debajo de la resolución de la técnica), el tipo histopatológico y grado de diferenciación celular.

En cuanto a la utilidad de la FDG PET/TC en el diagnóstico de recaída tumoral y la monitorización de la respuesta a la quimio-radioterapia, cabe destacar, que los cambios inflamatorios pancreáticos secundarios a cirugía, radioterapia o derivación pancreática, pueden ser causa de captación de FDG. Por ello, para minimizar los resultados falsamente positivos, se recomienda demorar la realización de la PET/TC al menos 6 semanas después de los tratamientos anteriormente citados. ${ }^{5,16}$ 


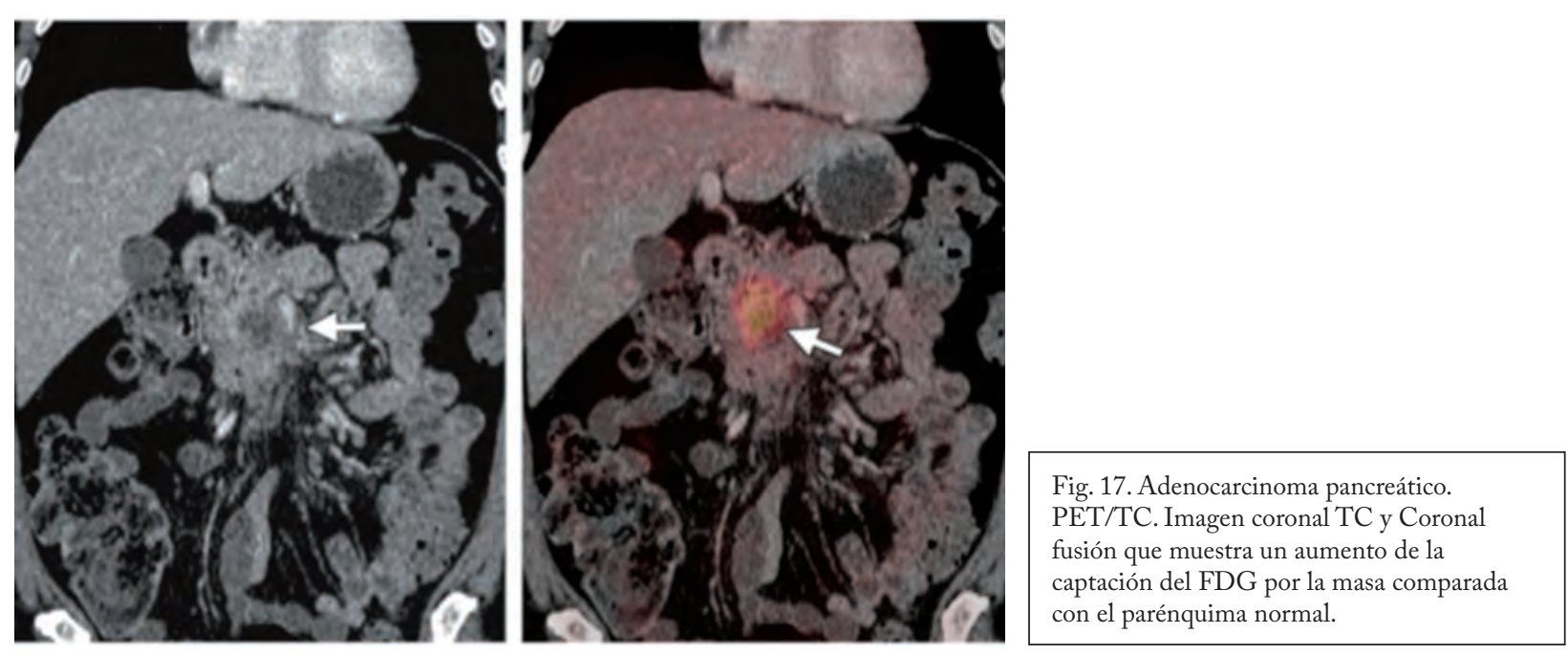

\section{PET/RM}

Recientemente se comenzó la utilización de la fusión de imágenes de FDG/PET y RM en el diagnóstico de las diferentes fases del cáncer pancreático. Cabe destacar con son muy escasos los trabajos publicados y en su gran mayoría, se tratan de fusiones retrospectivas de RM y FDG/PET.

Nagamachi et al, demostraron que la fusion FDG/PET y RM potenciados en T2, tenían mejor precisión que $\mathrm{PET} / \mathrm{TC}$ en la diferenciación de una lesión benigna de una maligna ( $96.6 \%$ vs $86.6 \%{ }^{17}$. Además se mostró más eficaz en identificar la arquitectura interna de las lesiones quísticas, pudiendo diferenciar la naturaleza de las mismas.

También ha mostrado buenos resultados en identificar lesiones, en aquellos pacientes que se presentan únicamente con una dilatación del conducto pancreático y ausencia de tumor en los estudios previos. ${ }^{18}$

El resto de las lineas de investigación, y con resultados prometedores, están entorno al diagnóstico de metástasis hepáticas e implantes peritoneales, así como en el diagnóstico de la recaída tumoral, diferenciándola de cambios estructurales anatómicos producidos por la cirugía. ${ }^{18}$ 


\section{BIBLIOGRAFIA.}

1. Calzado A, Rodríguez R. Imagen por tomografía computarizada. Principios técnicos. En: del Cura JL, Pedraza S, Gayete A, editores. Radiología esencial. Vol 1. Madrid: Panamericana; 2010. p. 16-26.

2. Navarro S, Vaquero E, Maurel J, Bombí J.A, De Juan C, Feliu J et al. Recomendaciones para el diagnóstico, estadificación y tratamiento del cáncer de páncreas (parte I). MedClin 2010; 134(15): 692-702.

3. Ayuso C, Sánchez M, Ayuso JR, et al. Diagnóstico y estadificación del carcinoma de páncreas (I). Radiología. 2006;48(5):273-282.

4. Ayuso C, Sánchez M, Ayuso JR, et al. Diagnóstico y estadificación del carcinoma de páncreas (II) Radiología. 2006;48(5):283-294.

5. Al-Hawary M, Francis IR, Chari ST, et al. Pancreatic Ductal Adenocarcinoma Radiology Reporting Template: Consensus Statement of the Society of Abdominal Radiology and the American Pancreatic Association. Radiology 2014; 270(1): 248-260.

6. Fishman EK, Al-Hawary M, Francis IR, et al. NCCN Guidelines Version 2.2015 Panel Members Pancreatic Adenocarcinoma

7. Cassinotto C, Mouries A, Lafourcade JP, et al. Locally Advanced Pancreatic Adenocarcinoma: Reassessment of Response with CT after Neoadjuvant Chemotherapy and Radiation Therapy. Radiology.2014; 273(1): 108116.

8. Lu DS, Reber HA, Krasny RM, et al. Local staging of pancreatic cancer: criteria for unresectability of major vessels as revealed by pancreatic-phase, thin-section helical CT. AJR Am J Roentgenol 1997; 168(6):14391443.

9. Roche CJ, Hughes ML, Garvey CJ, Campbell F, White DA, Jones L et al. CT and pathologic assessment of prospective nodal staging in patients with ductal adenocarcinoma of the head of the pancreas. Am J Roentgenol 2003; 180(2): 475-480.

10. Valls C, Andía E, Sanchez A, Fabregat J, Pozuelo O, Quintero C et al. Dual-phase helical CT of pancreatic adenocarcinoma: assessment of resectability before surgery. AJR Am J Roentgenol 2002; 178(4): 821-826.

11. Yoon SH, Lee JM, Cho JY, Lee KB, Kim JE, Moon SK et al. Small $(<20 \mathrm{~mm})$ pancreatic adenocarcinomas: analysis of enhancement patterns and secondary signs with multiphasic multidetector CT. Radiology 2011; 259(2): 442-452.

12. Dedushi K, Serbeze Kabashi S, Mucaj S, et al. Imaging Characteristics and Prevalence of Pancreatic Carcinoma in Kosovo During 2011-2015 - Diagnostic Method as Choice. Acta Inform Med. 2016; 24(3): 162-167.

13. Zaheer A, Wadhwa V, Oh J, Fishman EK. Pearls and pitfalls of imaging metastatic disease from pancreatic adenocarcinoma: a systematic review. Clin Imaging 2015; 39(5): 750-758.

14. Arslan A, Buanes T, Geitung JT. Pancreatic carcinoma: MR, MR angiography and dynamic helical CT in the evaluation of vascular invasion. Eur J Radiol 2001; 38(2): 151-159.

15. Motosugi U, Ichikawa T, Morisaka H, Sou H, Muhi A, Kimura K et al. Detection of pancreatic carcinoma and liver metastases with gadoxetic acid-enhanced MR imaging: comparison with contrast-enhanced multi-detector row CT. Radiology 2011; 260(2): 446-453.

16. Sahani DV, Bonaffini PA, Catalano OA, et al. State of art PET/CT of the pancreas: current rol and emerging indications. Radiographic.2012;32(4);1133-1158.

17. Nagamachi S, Nishii R, Wakamatsu H, et al. The usefulness of (18)F-FDG PET/MRI fusion image in diagnosing pancreatic tumor: comparison with (18)F-FDG PET/CT. Ann Nucl Med.2013;27(6):554-563.

18. Paspulati RM, Gupta A. PET/MR Imaging in Cancers of the Gastrointestinal Tract . PET Clin. 2016; 11(4): 403-423. 


\title{
EL ROL DE LA BIOPSIA DIAGNOSTICA EN EL ADENOCARCINOMA DE PANCREAS
}

\author{
Obtener un diagnóstico histólogico en el cáncer de páncreas puede ser dificultoso, en parte por su localización retro- \\ peritoneal que lo hace un órgano de difícil acceso. Por otra parte el tumor esta rodeado de una reacción desmoplásica, \\ que disminuye la sensibilidad de los métodos de punción. A esto se suman las complicaciones vinculadas a los proce- \\ dimientos diagnósticos (pancreatitis, fístula, hemorragia, etc.). \\ La necesidad de una certificación histológica en el cáncer de páncreas, tiene hoy en día indicaciones precisas. \\ En este capítulo, discutiremos: \\ 1) El rol de la biopsia preoperatoria en las lesiones resecables. \\ 2) Su indicación en el paciente con un tumor borderline, que recibirá neoadyuvancia. \\ 3) Su realización en pacientes con tumores irresecables o diseminados que recibirán quimioterapia paliativa.
}

Finalmente, analizaremos los distintos métodos de diagnóstico, su eficacia y complicaciones.

\section{A) Rol de la biopsia en el paciente con lesiones resecables.}

Las Guías Británicas ${ }^{1}$ para el tratamiento del cáncer pancreático, ya recomendaban en el año 2005, que en pacientes con tumores resecables debían evitarse las biopsias transperitoneales.

En 2009 un consenso de expertos norteamericanos ${ }^{2}$ plantea que, "si el paciente es un buen candidato a la cirugía, y la presentación clínica e imagenológica son típicas, debe procederse a la cirugía sin diagnóstico histológico".

En 2010 Levy, $^{3}$ en una revisión monográfica de la Asociación Francesa de Cirugía, concluye que en presencia de un tumor resecable y ausencia de dudas diagnósticas, debe procederse a la cirugía sin necesidad de biopsia, aceptando el bajo riesgo de resecar una lesión benigna.

En 2013, un consenso de expertos del International Study Group of Pancreatic Surgery, ${ }^{4}$ plantea que "en presencia de una masa sólida en el páncreas, sospechosa de malignidad, no es necesaria la biopsia previa a la pancreatectomía".

Las Guías del National Comprehensive Cancer Network en su versión 20155, sugieren no realizar biopsia cuando existe alta sospecha de cáncer pancreático resecable, en pacientes con riesgo quirurgico aceptable.

Por lo tanto, la evidencia actual no recomienda la realización rutinaria de una biopsia preoperatoria en estos pacientes. Los argumentos a favor de esta conducta son: la mejoría en la sensibilidad y especificidad de los métodos imagenológicos, el descenso de las cifras de morbimortalidad de la pancreatectomía (pancreatectomía segura), la presencia de falsos negativos en las biopsias, las posibles complicaciones de los procedimientos de diagnóstico histológico, que pueden además, retrasar la cirugía y con riesgo de implantes peritoneales. ${ }^{2-4,6}$

En conclusión, hoy en día, frente a un paciente con planteo de cáncer pancreático, a priori resecable, cuando existe correlación entre la presentación clínica e imagenológica, no es necesaria la certificación histológica preoperatoria.

La incidencia de lesiones benignas, en pacientes sometidos a pancreatectomía con planteo de cáncer de páncreas, varía según los diferentes reportes entre el 7-11\%.7-11

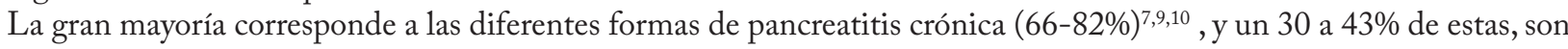
formas de pancreatitis autoinmune. ${ }^{7,9,11}$

La pancreatitis crónica puede tener una presentación clínica, imagenológica y ecoendoscópica muy similar al cáncer pancreático. ${ }^{4,6,8}$

Por otra parte, constituye de por sí, un factor de riesgo para el desarrollo de cáncer de páncreas (4 \% a 20 años de evolución). ${ }^{12}$

Esto ha llevado a que el International Study Group of Pancreatic Surgery, recomiende la pancreatectomía sin necesidad de biopsia, en los pacientes con pancreatitis crónica que desarrollaron una masa sospechosa de malignidad. ${ }^{4}$ 
Distinta debe ser la conducta cuando se sospecha una pancreatitis autoinmune, ya que esta mejorará con la corticoterapia y puede evitarse de esta manera una resección innecesaria.

Debe pensarse en una pancreatitis autoinmune en pacientes jóvenes, con ausencia de repercusión general y cuando existe un contexto de enfermedad autoinmune (fibrosis retroperitoneal, enfermedad inflamatoria intestinal, colangitis esclerosante, sialoadenitis, nefritis intersticial). ${ }^{3,13}$

Existen dos subtipos de pancreatitis autoinmune: la Tipo 1, que se presenta en pacientes añosos, y con alta frecuencia en asiáticos. Se asocia a niveles séricos elevados de IgG4, y a otras enfermedades autoinmunes como la fibrosis retroperitoneal, colangitis esclerosante, sialoadenitis y nefritis intersticial. Su diagnóstico histológico es sencillo, por la presencia de una pancreatitis linfoplasmocitaria esclerosante característica de estas lesiones. ${ }^{3,4,13}$

La tipo 2, prevalece en pacientes más jóvenes, caucásicos y se asocia a enfermedad inflamatoria intestinal. La elevación de IgG4 no es frecuente y el diagnóstico histológico es más difícil, se presenta como lesiones epiteliales granulocíticas (lesiones patognomónicas), con elementos de una pancreatitis idiopática. ${ }^{3,4,13}$

El diagnóstico de pancreatitis autoinmune se basa en la presunción clínica, en la imagenología y en la determinación de niveles de IgG4 en sangre.

En caso de dudas, se recomienda la punción guiada por ecoendoscopía con realización de "core" biopsia, en lugar de una punción aspiración con aguja fina. ${ }^{4}$

La respuesta a cursos cortos de corticoides, puede también ser diagnóstica, ya que existe una alta tasa de respuesta con este tratamiento, superior al $90 \% .^{13}$

\section{B) Rol de la biopsia en el paciente con enfermedad localmente avanzada o diseminada}

En este punto discutiremos la necesidad de confirmación histológica en dos situaciones clínicas diferentes:

\section{1) Paciente con lesión "borderline”, al que se le realizará neoadyuvancia.}

Un consenso de expertos norteamericanos analiza el manejo de las lesiones borderline, y plantea que "previo al inicio de la neoadyuvancia, es mandatorio un diagnóstico tisular". ${ }^{2}$

E1 International Study Group of Pancreatic Surgery ${ }^{4}$, revisa las indicaciones de biopsias previa a las pancreatectomías y concluye, "que antes de comenzar con la quimioterapia o radioquimioterapia neoadyuvante, es mandatoria la confirmación citiológica o histologica de la lesión. (strong recommendation)”.

Las guías del National Comprehensive Cancer Network $^{5}$ en su última actualización, indican la realización de biopsia, en todas las lesiones borderline que serán sometidas a neoadyuvancia.

\section{2) Paciente con enfermedad diseminada o irresecable, que recibirá tratamiento oncológico paliativo.}

Levy et al. $^{3}$ en la revisión monográfica de la Asociación Francesa de Cirugía, plantean "que todos los enfermos con un tumor localmente avanzado o metastásico, deben tener una biopsia antes del tratamiento de quimioterápico o quimiorradiante".

Igual planteo realizan las guías de National Comprehensive Cancer Network. ${ }^{5}$

Por lo tanto, debe realizarse diagnóstico citológico o histológico en todo paciente que recibirá neoadyuvancia y en aquellos con enfermedad claramente irresecable o diseminada, que recibirán tratamientos paliativos.

\section{¿Cómo realizar la biopsia?}

En los pacientes con enfermedad metastásica hepática, confirmando el diagnóstico puede realizarse por punción percutánea ecoguiada o bajo tomografía computada (TC) confirmandose en estos casos no solo la presunción patológica sino tambien el estadio IV. En caso de carcinomatosis, la misma puede confirmarse por laparoscopía. 3,6 
El problema radica en los pacientes con una lesión localmente avanzada, sin metástasis ni carcinomatosis. En ellos, pueden ser utilizados:

- El cepillado mediante colangiopancreaticografía endoscópica retrógrada

- La punción percutánea guiada por imagen (ecografía o tomografía)

- La punción guiada por ecoendoscopía

\section{Cepillado por colangiopancreatografía endoscópica retrógrada (CPER).}

Es un método de diagnóstico citológico que tiene alta especificidad, pero pobre sensibilidad.

La sensibilidad reportada por los diferentes trabajos varía entre un 30 a 54\%, y q la especificidad entre 90 a $100 \% .14,15,16$ Una reciente revisión ${ }^{17}$, estudia la sensibilidad de la citología por CPER en lesiones bilio-pancreáticas (16 trabajos con 1556 pacientes), y encuentra una sensibilidad 41.6\%+/- 3.2\% (99\% CI) con un valor predictor negativo de 58.0\% $+/-3.2 \%$ (99\% CI).

Es por este motivo, que se han desarrollado múltiples pruebas complementarias que buscan mejorar la sensibilidad del procedimiento (inmunohistoquímica, mutaciones, ADNploidia, fluorescencia, etc) con resultados variables y limitados. ${ }^{17}$

Pese a estos pobres resultados, el consenso de expertos del International Study Group of Pancreatic Surgery ${ }^{4}$, propone realizar cepillado durante una CPER para colocación de stent en pacientes con ictericia, ya sea en pacientes con enfermedad diseminada, o por tumores borderline que van a recibir neoadyuvancia.

\section{Punción con aguja percutánea}

La punción percutánea puede ser realizada bajo ecografía o bajo tomografía.

Los defensores de la ecografía, argumentan que se realiza en tiempo real, es más rápida, menos costosa y evita la irradiación que provoca la tomografía. ${ }^{16}$

Habitualmente se utilizan agujas finas (20-25G), que permiten un estudio citológico. Mientras que agujas más gruesas, de entre 14-19G, permiten realizar un estudio histológico completo (core biopsy).

Por el calibre de la aguja, las lesiones deben ser en general, mayores a $2 \mathrm{~cm}$. y estar lejos de estructuras vasculares. ${ }^{17}$

La presencia del citólogo en el momento del procedimiento es de fundamental importancia, ya que aumenta la sensibilidad del estudio. ${ }^{3}$

Las lesiones más accesibles a esta técnica, son las localizadas en cuerpo y cola de páncreas. ${ }^{17}$

En series que incluyen más de 200 pacientes, la sensibilidad de la punción percutánea fue del 81-98\%, y la especificidad fue cercana al 100\%..$^{16,18-20}$

Hartwig ${ }^{17}$ en una revisión de 18 trabajos, encuentra una sensibilidad media del 87\% (rango 45-100\%), especificidad del $100 \%$ y una precisión del 84\% (rango 61-98\%).

El valor predictor negativo fue del 58\% (rango 23-100\%).

Por otra parte, no encuentran diferencias significativas en los resultados con el uso de aguja fina o la "core biopsy". ${ }^{16,17}$

Las complicaciones, incluyen: hemorragia, pancreatitis, fístula pancreática, perforación visceral y abscesos intraabdoinales.

$\mathrm{Su}$ frecuencia es menor al 5\% en las punciones con aguja fina, ${ }^{3,4,16,18,19}$ y las mayores tasas de complicaciones reportadas, están vinculadas a la "core biopsy", o punción con aguja gruesa. ${ }^{17}$

Ha sido descrita la siembra tumoral en el trayecto de la aguja, provocando implantes peritoneales y cutáneos, pero su frecuencia es baja. ${ }^{21}$

Por otra parte, es muy difícil demostrar si el origen de la carcinomatosis está vinculado a la siembra durante la punción, o corresponde a una progresión de la enfermedad. ${ }^{16}$

No se ha demostrado que la punción percutánea, afecte negativamente la sobrevida media los pacientes. ${ }^{22-23}$ 


\section{Punción guiada por ecoendoscopía}

La punción guiada por ecoendoscopía, ha demostrado ser un método útil en el diagnóstico histológico del cáncer de páncreas, y es hoy en día, una herramienta de primera línea.

Hartwig et al ${ }^{19}$ en una revisión sistemática del año 2009, encuentra una sensibilidad del 83\% (rango de 54-95\%), una especificidad del 100\% (rango 71-100\%), una certeza del 88\% (65-96\%) y un valor predictor negativo de $72 \%$, en el diagnóstico histológico guiado por ecoendoscopía.

Un estudio prospectivo realizado por Eloubeidi et al en el 2007, sobre una base de 547 procedimientos, documentó un alto indice de precisión diagnóstica mediante la punción citológica guiada por ecoendoscopía para el cáncer de páncreas. Con una sensibilidad de 95\% (IC del 95\%: 93,2-95,4), especificidad del 92\% (IC del 95\%: 86,6-95,7), valor predictivo positivo del 98\% (IC del 95\%: 97-99), valor predictivo negativo del 80\% (IC del 95\%: 74,9-82,7). La precisión global fue del 94,1\% (IC del 95\%: 92,0-94). Siendo además, un procedimiento seguro. ${ }^{24}$

Recientemente, tres metaanálisis analizan los resultados de la punción por ecoendoscopía, en masas pancreáticas sólidas. $25-27$

Encuentran una sensibilidad del 85-88,6\% y una especificidad del 95,8-99,3\%, en el diagnóstico de malignidad. La mayor incidencia de falsos negativos (15-20\%) se encuentra en pacientes jóvenes con pancreatitis crónica alcohólica. Los resultados falso positivos son extremadamente raros $(<0.1 \%)$ y se han visto en pacientes con pancreatitis auto-inmune en su mayoría.

Los argumentos a favor de esta técnica son: una mejor sensibilidad para valorar lesiones menores de 2-3 cm.28,29, además, permite detectar metástasis ganglionares, pequeñas metástasis hepáticas o nódulos peritoneales, que no fueron reportados por los otros métodos de imagen (TC, RNM) ${ }^{2,28,29,20}$

La ecoendoscopía presenta menos riesgo de producir implantes peritoneales que los métodos de punción percutánea. ${ }^{31}$ Finalmente, permite en el mismo procedimiento, la colocación de stents biliares o neurolísis celíaca. ${ }^{2}$

La punción se realiza a través de la pared del duodeno, en lesiones cefálicas y de la pared gástrica, en lesiones de cuerpo y cola.

Habitualmente se utilizan agujas finas (22-25G), que obtienen muestras para citología. ${ }^{30,32}$

Pueden también realizarse "core" biopsias para un diagnóstico histológico, fundamentalmente cuando se trata de lesiones sospechosas de cáncer asociadas a pancreatitis perilesional, o frente al planteo de otras etiología como linfoma o pancreatitis autoinmune. ${ }^{32}$

El uso de agujas más gruesas (19-20G) o tipo trucut, necesarios para obtener muestras para estudio histológico, encuentra dificultades en lesiones cefálicas o del proceso uncinado, ya que la punción transduodenal requiere de agujas finas, flexibles con capacidad de angulación.

En el caso de las punciones de cuerpo y cola, realizadas desde el estómago, el procedimiento es más seguro.

El uso de dispositivos de mayor calibre, implica por otra parte, un mayor riesgo de complicaciones como el sangrado, y la pancreatitis. $28,30,32$

Se ha demostrado que la presencia del citólogo, al momento de realizar el procedimiento, mejora la sensibilidad del estudio, acorta su duración y disminuye el número de punciones necesarios para hacer el diagnóstico. $27,29,30,32$

Existe consenso, que en ausencia de citólogo en sala, el número de pasajes o punciones necesarios para obtener muestras representativas, debe ser de 5 a 7 para tumores pancreáticos y de 3 a 4 para ganglios peripancreáticos. ${ }^{29,30}$

Buscando mejorar la sensibilidad del procedimiento, se están desarrollando nuevas técnicas: como la administración de contraste, la elastoendoscopía, el DNA análisis y la determinación de mutación K-ras en el material aspirado. ${ }^{29}$

La ecoendoscopía con toma de biopsia, requiere de un alto nivel de entrenamiento. Ya en 2001 la Sociedad Americana de Endoscopía recomendaba, para certificar la competencia, la realización de 150 ecoendoscopías supervisadas (incluyendo 75 de páncreas) y 60 punciones guiadas por ecoendoscopía, de las cuales 25 debían ser pancreáticas. ${ }^{33}$

La Sociedad Europea de Endoscopía en el 2012, plantea que la curva de aprendizaje se completa con un mínimo de 20-30 procedimientos supervisados, de punción pancreática. ${ }^{34}$ Otros trabajos, como el de Mertz, han arribado a conclusiones similares. ${ }^{35}$

La tasa de complicaciones reportada es menor a 3,4\%, las más frecuentes son la pancreatitis y el sangrado. Se han descrito también, perforación duodenal, abscesos, pseudoquistes y pseudoaneurismas. ${ }^{3,19,32,36}$ 
Existen reportes de implantes tumorales en pared gástrica y peritoneo, secundarios a punciones de cuerpo y cola. ${ }^{37-39}$

Sin embargo, estudios que comparan resultados a largo plazo en pacientes sometidos a punción vs no punción, no encuentran diferencias en sobrevida global, ni en la tasa de recurrencia peritoneal. ${ }^{40,41}$

\section{Punción guiada por ecoendoscopía vs punción percutánea}

Existen pocos estudios comparativos entre la punción guiada por ecoendoscopía y la punción percutánea.

En 2006 Horwhat et al, ${ }^{42}$ publican un estudio prospectivo randomizado monocéntrico, que compara ambas técnicas de punción pancreática (43 pacientes con punción percutánea bajo ecografia/TC vs 41 por ecoendoscopía). La ecoendoscopía tuvo mayor sensibilidad ( $84 \%$ vs. $62 \%$ ) y precisión ( $89 \%$ vs. $72 \%$ ), pero la diferencia no fue estadísticamente significativa.

Recientemente otro estudio randomizado multicéntrico con 197 pacientes, compara punción por ecoendoscopía vs punción percutánea ecoguiada. Este trabajo encuentra porcentajes similares de sensibilidad, especificidad, y valor predictivo negativo, pero existe un mayor número de complicaciones con la punción percutánea ecoguiada (5.6\% vs $1,38 \%) \cdot{ }^{43}$

Un estudio retrospectivo que incluye 1050 pacientes, tampoco encuentra diferencias en sensibilidad, especificidad y valor predictivo negativo. Pero determina que para lesiones menores de $3 \mathrm{~cm}$, la ecoendoscopía tiene mayor precisión. ${ }^{44}$

Micames et al, ${ }^{31}$ realizaron un estudio retrospectivo en pacientes que recibieron neoadyuvancia y posterior cirugía por cáncer de páncreas localmente avanzado. En 46 pacientes el diagnóstico se confirmó por punción por ecoendoscopía y en 43 por punción percutánea.

Cuando analiza el desarrollo de carcinomatosis en ambos grupos, encuentra una incidencia significativamente mayor en el grupo de punción percutánea ( $16,3 \%$ vs $2,2 \% ; \mathrm{p}<0.025)$.

Por lo tanto, si bien los trabajos no han demostrado diferencias significativas en sensibilidad, especificidad y valor predictivo negativo, la punción guiada por ecoendoscopía parece tener mayor rendimiento en lesiones menores a $3 \mathrm{~cm}$, menor tasa de complicaciones y menor riesgo de implantes peritoneales.

Por tanto, la punción guiada por ecoendoscopía es el método de elección para el diagnóstico citológico y ocasionalmente histológico de tumores sólidos pancreáticos.

Su uso, cuando está indicada, es recomendado por diferentes guías y consensos de expertos. ${ }^{1-6}$

\section{¿Qué hacer cuando la punción no es concluyente?}

En ocasiones puede ocurrir que el resultado de la punción sea indeterminado o no concluyente.

Esto ocurre en 4,7\% a 9,2\% y es debido a varios factores, el principal es la punción sobre áreas de pancreatitis perilesional. ${ }^{30,32}$ Otros factores implicados son la mala calidad de la muestra obtenida (punción de áreas de necrosis o tumores bien diferenciados), y aspectos técnicos (lesiones localizadas en zonas de difícil acceso, como el cuello o el proceso uncinado, dificultades técnicas, inexperiencia, etc). ${ }^{30,32}$

Varios trabajos han demostrado que la repetición de la punción, en un plazo de 3-4 semanas, permitió aclarar el diagnóstico en $82 \%$ al $92 \%$ de los casos. ${ }^{45-47}$

Como hemos visto las indicaciones de biopsia son distintas, en algunas situaciones se requiere para comenzar un tratamiento de quimioterapia, y en otras situaciones para descartar diagnósticos diferenciales. En este ultimo caso, si el índice de sospecha de malignidad es alto, la conducta más aceptada es repetir la punción por ecoendoscopía, de ser posible en un centro de referencia. $3,6,29,30$

La punción percutánea es un método alternativo, pero teniendo en cuenta el riesgo de complicaciones y de siembra tumoral. ${ }^{5,30}$

Cuando el índice de sospecha de malignidad es bajo, puede aceptarse como alternativa el control clínico e imagenológico evolutivo, siempre con el consentimiento del paciente. ${ }^{30,32}$

Por el contrario, si la segunda biopsia no es concluyente y se ha descartado la pancreatitis autoinmune, persistiendo un alto índice de sospecha de cáncer, en pacientes con lesiones potencialmente resecables, se debe proceder a la resección con confirmación intraoperatoria. ${ }^{5,30}$ 
Si bien hay recomendaciones más que suficientes, sobre la necesidad diagnóstico citológico o histológico para comenzar tratamientos adyuvantes o neoadyuvantes, la realidad indica que esta situación no es siempre posible, seguramente por las dificultades que ofrecen las punciones diagnosticas sobre el páncreas.

Un estudio alemán demostró que no todos los médicos trataban a sus pacientes según las recomendaciones y que se lograba un diagnóstico pretratamiento en el $61 \%$ de los casos. ${ }^{48}$ En tanto que el estudio EUROCARE-4, que registró 93 centros de Europa, encuentra que solo en $63 \%$ de los casos se llegó a un diagnóstico microscópico. ${ }^{49}$

Un reciente estudio holandés con 3321 pacientes recabados entre el 1993 y 2010, documentó un porcentaje de confirmación de 59\%, la mayoría de ellos mediante histología. Dicho porcentaje ha ido en aumento en los últimos años debido a la aparición de la ecoendoscopía y el uso de la citología, a expensas de un mayor número de procedimientos sobre el tumor primario. De todas formas, la mayoría de las muestras se toman de las lesiones metastásicas.

Este estudio concluye, que si bien es deseable contar con una confirmación microscópica del tumor pancreático, antes de incitar el tratamiento, la misma no es posible en un alto porcentaje de casos. Con lo cual quedarían fuera de tratamiento un número importante de pacientes.

Este trabajo culmina afirmando, que la combinación de una masa sospechosa en la imagenología, asociada a perdida de peso, elevación de las bilirrubinas, aumento del CA 19-9, debería ser suficiente, dado que esta combinación llega a porcentajes diagnósticos cercanos al 100\%. ${ }^{50}$ 


\section{BIBLIOGRAFIA}

1. Pancreatic Section of the British Society of Gastroenterology, Pancreatic Society of Great Britain and Ireland, Association of Upper Gastrointestinal Surgeons of Great Britain and Ireland, Royal College of Pathologists, Special Interest Group for Gastro-Intestinal Radiology. Guidelines for the management of patients with pancreatic cancer periampullary and ampullary carcinomas. Gut 2005;54(suppl V):1-16. doi: 10.1136/ gut.2004.057059.

2. Callery MP, Chang KJ, Fishman EK, et al. Pretreatment assessment of resectable and borderline resectable pancreatic cancer: expert consensus statement. Ann Surg Oncol. 2009;16(7):1727-1733.

3. Lévy P. Adenocarcinome pancréatique: quelle est la place biopsie. En Dellpero JR, Paye F, Bachellier P. Cancer du Pancréas. Monographies de L’Assciacion Francaise de Chirurgie. Paris: Anette;2010: p 56-60.

4. Asbun HJ, Conlon K, Fernandez-Cruz L, et al. When to perform a pancreatoduodenectomy in the absence of positive histology? A consensus statement by the International Study Group of Pancreatic Surgery. Surgery. 2014 May;155(5):887-892.

5. Tempero MA, Malafa PM, Asbun H, et al. NCCN clinical practice guidelines in oncology. Pancreatic, adenocarcinoma. Version 2.2015.

6. Fernández JA, Parrilla P. What are the main errors made by surgeons in the management of pancreatic cancer? Cir Esp. 2006;79(4):215-223.

7. Manzia TM, Toti L, Lenci I, et al. Benign disease and unexpected histological findings after pancreaticoduodenectomy: the role of endoscopic ultrasound fine needle aspiration. Ann R Coll Surg Engl.2010;92(4):295-301.

8. de la Fuente SG, Ceppa EP, Reddy SK, et al. Incidence of benign disease in patients that underwent resection for presumed pancreatic cancer diagnosed by endoscopic ultrasonography (EUS) and fine-needle aspiration (FNA).J Gastrointest Surg. 2010;14(7):1139-1142.

9. Hurtuk MG, Shoup M, Oshima Ket al. Pancreaticoduodenectomies in patients without periampullary neoplasms: lesions that masquerade as cancer.Am J Surg. 2010;199(3):372-376.

10. van Heerde MJ, Biermann K, Zondervan PE,et al. Prevalence of autoimmune pancreatitis and other benign disorders in pancreatoduodenectomy for presumed malignancy of the pancreatic head. Dig Dis Sci. 2012;57(9):2458-2465.

11. de Castro SM, de Nes LC, Nio CY, et al. Incidence and characteristics of chronic and lymphoplasmacytic sclerosing pancreatitis in patients scheduled to undergo a pancreatoduodenectomy. HPB (Oxford). 2010;12(1):1521.

12. Lowenfels $\mathrm{AB}, \mathrm{Maisonneuve} \mathrm{P}, \mathrm{Cavallini} \mathrm{G}$, et al.Pancreatitis and the risk of pancreatic cancer. International Pancreatitis Study Group. N Engl J Med 1993;328(20):1433-1437.

13. Matsubayashi H, Kakushima N, Takizawa K, et al. Diagnosis of autoimmune pancreatitis. World J Gastroenterol. 2014; ;20(44):16559-16569.

14. Selvaggi SM. Biliary brushing cytology. Cytopathology. 2004 Apr;15(2):74-79.

15. Volmar KE, Vollmer RT, Routbort MJ, et al.Pancreatic and bile duct brushing cytology in 1000 cases: review of findings and comparison of preparation methods. Cancer 2006;108(4):231-238.

16. Witt BL, Kristen Hilden RN, Scaife C, et al. Identification of factors predictive of malignancy in patients with atypical biliary brushing results obtained via ERCP. Diagn Cytopathol 2013;41(8):682-688.

17. Burnett AS1, Calvert TJ, Chokshi RJ. Sensitivity of endoscopic retrograde cholangiopancreatography standard cytology: 10-y review of the literature. Surg Res. 2013;184(1):304-311.

18. D'Onofrio M, De Robertis R, Barbi E, et al. Ultrasound-guided percutaneous fine-needle aspiration of solid pancreatic neoplasms: 10-year experience with more than 2,000 cases and a review of the literature. Eur Radiol. 2016;26(6):1801-1807.

19. Hartwig W, Schneider L, Diener MK, et al. Preoperative tissue diagnosis for tumours of the pancreas. Br J Surg. 2009;96(1):5-20.

20. Linder S, Blåsjö M, Sundelin P, et al. Aspects of percutaneous fine-needle aspiration biopsy in the diagnosis of pancreatic carcinoma.Am J Surg. 1997;174(3):303-306.

21. David O, Green L, Reddy V, et al. Pancreatic masses: a multi-institutional study of 364 fine-needle aspiration biopsies with histopathologic correlation.Diagn Cytopathol. 1998;19(6):423-427.

22. Bhatia P, Srinivasan R, Rajwanshi A, et al. 5-year review and reappraisal of ultrasound-guided percutaneous transabdominal fine needle aspiration of pancreatic lesions. Acta Cytol. 2008;52(5):523-529.

23. Smith EH. Complications of percutaneous abdominal fine-needle biopsy. Review.Radiology. 1991;178(1):253258.

24. Eloubeidi MA, Varadarajulu S, Desai S, et al. A Prospective Evaluation of an Algorithm Incorporating Routine Preoperative Endoscopic Ultrasound-Guided Fine Needle Aspiration in Suspected Pancreatic Cancer. J Gastrointest Surg. 2007;11(7):813-819.

25. Hewitt MJ, McPhail MJ, Possamai L, et al.EUS-guided FNA for diagnosis of solid pancreatic neoplasms: a meta-analysis. Gastrointest Endosc. 2012;75(2):319-331. 
26. -Puli SR1, Bechtold ML, Buxbaum JL.How good is endoscopic ultrasound-guided fine-needle aspiration in diagnosing the correct etiology for a solid pancreatic mass?: A meta-analysis and systematic review..Pancreas. 2013;42(1):20-26.

27. Hébert-Magee S, Bae S, Varadarajulu S, et al. The presence of a cytopathologist increases the diagnostic accuracy of endoscopic ultrasound-guided fine needle aspiration cytology for pancreatic adenocarcinoma: a meta-analysis.Cytopathology. 2013;24(3):159-171.

28. Hernandez LV, Bhutani MS, Eisner M, et al. Non-surgical tissue biopsy among patients with advanced pancreatic cancer: effect on survival. Pancreas. 2009;38(3):289-292.

29. Dumonceau JM, Polkowski M, Larghi A,et al. Indications, results, and clinical impact of endoscopic ultrasound (EUS)-guided sampling in gastroenterology: European Society of Gastrointestinal Endoscopy (ESGE) Clinical Guideline. Endoscopy 2011;43(10):897-891.

30. Hasan MK1, Hawes RH. EUS-guided FNA of solid pancreas tumors. Gastrointest Endosc Clin N Am. 2012;22(2):155-167.

31. Micames C, Jowell PS, White R. Lower frequency of peritoneal carcinomatosis in patients with pancreatic cancer diagnosed by EUS-guided FNA vs. percutaneous FNA. Gastrointest Endosc. 2003 Nov;58(5):690-695

32. Matsubayashi H, Matsui T, Yabuuchi Y. Endoscopic ultrasonography guided-fine needle aspiration for the diagnosis of solid pancreaticobiliary lesions: Clinical aspects to improve the diagnosis. World J Gastroenterol. 2016;22(2):628-640.

33. Eisen GM, Dominitz JA, Faigel DO, et al. Guidelines for credentialing and granting privileges for endoscopic ultrasound. Gastrointest Endosc 2001;54:811-814.

34. Polkowski M, Larghi A, Weynand B, et al. Learning, techniques, and complications of endoscopic ultrasound (EUS)-guided sampling in gastroenterology: European Society of Gastrointestinal Endoscopy (ESGE) Technical Guideline. Endoscopy 2012; 44: 190-206.

35. Mertz H. The learning curve for EUS-guided FNA of pancreatic cancer. Gastrointest Endosc. 2004;59(1):3337.

36. -Eloubeidi MA, Tamhane A, Varadarajulu S,et al. Frequency of major complications after EUS-guided FNA of solid pancreatic masses: a prospective evaluation. Gastrointest Endosc. 2006 ;63(4):622-629.

37. Paquin SC, Gariépy G, Lepanto L, et al. A first report of tumor seeding because of EUS-guided FNA of a pancreatic adenocarcinoma. Gastrointest Endosc 2005; 61: 610-611.

38. Katanuma A, Maguchi H, Hashigo S,et al. Tumor seeding after endoscopic ultrasound-guided fineneedle aspiration of cancer in the body of the pancreas. Endoscopy 2012;44(Suppl 2):160-161.

39. Chong A, Venugopal K, Segarajasingam D, et al. Tumor seeding after EUS-guided FNA of pancreatic tail neoplasia. Gastrointest Endosc 2011;74:933-935.

40. Ngamruengphong S, Swanson KM, Shah ND, et al. Preoperative endoscopic ultrasound-guided fine needle aspiration does not impair survival of patients with resected pancreatic cancer. Gut. 2015;64(7):1105-1110.

41. Kudo T, Kawakami H, Kuwatani M,et al. Influence of the safety and diagnostic accuracy of preoperative endoscopic ultrasound-guided fine-needle aspiration for resectable pancreatic cancer on clinical performance. World J Gastroenterol. 2014 Apr 7;20(13):3620-3627.

42. Horwhat JD, Paulson EK, McGrath K et al. A randomized comparison of EUS-guided FNA versus CT or US-guided FNA for the evaluation of pancreatic mass lesions. Gastrointest Endosc 2006;63(7): 966-975.

43. Okasha HH, Naga MI, Esmat S, et al.Endoscopic Ultrasound-Guided Fine Needle Aspiration versus Percutaneous Ultrasound-Guided Fine Needle Aspiration in Diagnosis of Focal Pancreatic Masses. Endosc Ultrasound. 2013;2(4):190-193.

44. Volmar KE, Vollmer RT, Jowell PS et al. Pancreatic FNA in 1000 cases: a comparison of imaging modalities. Gastrointest Endosc 2005; 61(7):854-858.

45. Eloubeidi MA, Varadarajulu S, Desai S, et al. Value of repeat endoscopic ultrasound-guided fine needle aspiration for suspected pancreatic cancer. J Gastroenterol Hepatol 2008; 23(4):567-570.

46. Tadic M, Kujundzic M, Stoos-Veic T,et al. Role of repeated endoscopic ultrasound-guided fine needle aspiration in small solid pancreatic masses with previous indeterminate and negative cytological findings. Dig Dis 2008;26(4): 377-382.

47. Suzuki R, Lee JH, Krishna SG, et al. Repeat endoscopic ultrasound-guided fine needle aspiration for solid pancreatic lesions at a tertiary referral center will alter the initial inconclusive result.J Gastrointestin Liver Dis. 2013;22(2):183-187.

48. Boeck S, Bruns CJ, Sargent M, et al. Current oncological treatment of patients with pancreatic cancer in Germany: results from a national survey on behalf of the Arbeitsgemeinschaft Internistische Onkologie and the Chirurgische Arbeitsgemeinschaft Onkologie of the Germany Cancer Society. Oncology 2009;77(1):40-48.

49. De Angelis R, Francisci S, Baili P, et al. The EUROCARE-4 database on cancer survival in Europe: data standardisation, quality control and methods of statistical analysis. Eur J Cancer 2009;45(6):909-930.

50. Bernards N, M. Creemers GJM, Huysentruyt CJ, et. The relevance of pathological verification in suspected pancreatic cancer. Cancer Epidemiology. 2015; 39: 250-255. 


\section{EL ROL DE LA LAPAROSCOPÍA ESTADIFICADORA}

El papel de la laparoscopía estadificadora en el adenocarcinoma de páncreas está destinado fundamentalmente a detectar elementos de incurabilidad, que hayan pasado desapercibidos en los estudios imagenológicos. De esta manera se evitan un número importante de laparotomías innecesarias. ${ }^{1,2}$

Pero su indicación sigue siendo controversial. ¿ Por qué un procedimiento que tiene baja morbilidad y que evita laparotomías innecesarias, no se realiza en forma sistemática?. Su controversia se ha incrementado en los ultimas años debido al aumento y calidad de los estudios imagenológicos, que han mejorado su precision diagnostica. ${ }^{1,2,3}$

Por lo tanto, al momento actual, tenemos defensores y retractores del uso de esta técnica en forma sistemática

En contra del uso de la laparoscopía, se argumenta:

- Que la exploración laparoscópica solo valora la existencia de focos de carcinomatosis y metástasis hepáticas superficiales, sin poder evaluar correctamente el compromiso vascular, ganglionar o lesiones hepáticas profundas. ${ }^{4}$

- El desarrollo de los estudios de imagen, ha permitido mejorar la predicción de resecabilidad en forma sustancial. Con la tomografía multicorte se reportan tasas de sensibilidad de $81-100 \%$, especificidad del 71-100\%, valor predictivo positivo $89-100 \%$ y valor predictivo negativo de $78-100 \% .5,6,7$ Similares tasas se reportan con la resonancia magnética. ${ }^{8}$ A lo que suma el aporte de la ecografía endoscópica, que mejora la sensibilidad diagnóstica.

A favor se argumenta:

- Que los estudios imagenológicos tienen menor sensibilidad en detectar lesiones hepáticas menores a $2 \mathrm{~cm}$, así como focos pequeños de carcinomatosis peritoneal. ${ }^{9}$

- La existencia de un 10 a 25\% de laparotomías innecesarias, con hallazgo intraoperatorio de enfermedad irresecable o diseminada, no diagnosticada previamente..$^{10}$ En pacientes valorados como resecables por los estudios de imagen, la realización de laparoscopía exploradora, determinó la presencia de enfermedad diseminada o irresecable en $13-14 \%{ }^{11,12}$

- Un reciente metaanálisis de Cochrane, analiza el valor diagnóstico de la laparoscopía complementaria a la tomografía, en tumores pancreáticos y periampulares. El estudio incluye 16 trabajos con 1146 pacientes y encuentra que la laparoscopía evitó laparotomías innecesarias en $21 \%$ de los casos. ${ }^{13}$

La ecolaparoscopía ha sido propuesta en un intento por mejorar la detección de lesiones hepáticas profundas, así como el compromiso vascular y ganglionar. ${ }^{14}$

$\mathrm{Su}$ uso requiere alto nivel de entrenamiento en ambas técnicas y disposición del equipamiento.

Un metaanálisis del 2010, revisa el rol de la laparoscopía y la ecografía laparoscópica, en estatificar tumores de páncreas y periampulares. ${ }^{15}$

La sensibilidad para detectar enfermedad inoperable fue del 64\%, y la especificidad del 99\%.

Encuentra que el uso de ambas técnicas, permitió mejorar las tasas de resección del 61 al 80\%. Así mismo, la sensibilidad fue alta para detectar metástasis hepáticas (88\%) y peritoneales (91\%), pero fue menor en detectar la invasión local (58\%)

En 2016, una revisión bibliográfica investiga la precisión de la ecolaparoscopía en determinar resecabilidad en tumores pancreáticos. ${ }^{16}$

Encuentra que la ecolaparoscopía predijo correctamente la resecabilidad en 79\% de los casos, comparado con el 55\% de los estudios imagenológicos.

Cuando se analiza la literatura de los últimos 5 años, que incluye a los modernos tomógrafos multicorte, la diferencia de sensibilidad persistió en favor de la ecolaparoscopía.

Además, la ecolaparoscopía evitó un 33\% de laparotomías innecesarias.

Los riesgos de la laparoscopía estadificadora son bajos, inherentes a toda cirugía laparoscópica exploradora. Si bien los críticos de este estudio argumentan que su uso, implica dos actos anestésico-quirúrgicos, la laparoscopía puede ser realizada en el mismo acto, previo a la pancreatectomía.

El uso selectivo ha sido propuesto para el manejo de diferentes situaciones clínicas. Las guías del National Comprehensive Cancer Network del $2015^{2}$, proponen que "la laparoscopía estadificadora puede ser realizada en pacientes con lesiones resecables,

que tienen un riesgo aumentado de enfermedad diseminada, o en pacientes "borderline"que van a recibir neoadyuvancia”. 
Se han estudiado diferentes criterios que se asocian a enfermedad avanzada o mal pronóstico, a fin de identificar pacientes de riego, que se beneficien de una laparoscopía estadificadora. Dentro de ellos se han estudiado el valor de los marcadores tumorales (CEA y CA 19-9), factores clínicos y paraclínicos (perdida de peso, dolor, performance status, pretina $\mathrm{C}$ reactiva, plaquetopenia, entro otros), tamaño y localización tumoral. Los resultados han sido variables en cuanto a su predicción de enfermedad incurable.

En 2009 Callery et al. ${ }^{3}$ en un consenso de expertos, proponen los siguientes predictores de riesgo para seleccionar candidatos a laparoscopía estadificadora, en enfermedad potencialmente resecable:

- tumores cefálicos mayores de $3 \mathrm{~cm}$

- tumores de cuerpo y cola

- hallazgos dudosos en los estudio de imagen

- niveles elevados de CA 19-9 (mayores a $100 \mathrm{U} / \mathrm{ml}$ )

En el 2016 De Rosa el al ${ }^{17}$, una revisión de 24 estudios, determinó que del análisis de los posibles predicadores de riesgo, los que se asociaron a enfermedad irresecable o incurable, fueron el valor del CA 19-9 por encima de $150 \mathrm{U} / \mathrm{ml}$ y el tamaño tumoral > a $3 \mathrm{~cm}$.

Los mismos autores confeccionan una algoritmo simple de laparoscopía estadificadora en el cáncer de páncreas.(Fig. 1)

El uso de la citología por lavado peritoneal, fue propuesto con la finalidad de aumentar la sensibilidad de la laparoscopía estadificadora. Cuando es positiva y aunque no se evidencien metástasis macroscópicas, tiene valor pronóstico y la misma sobrevida que una enfermedad metastásica. ${ }^{18,19}$

El manual del American Joint Commission on Cancer (AJCC) considera a la citología positiva por lavado peritoneal un $\mathrm{M} 1 .^{20}$

No es clara su indicación y existen quienes no la recomiendan, argumentando que prolonga el tiempo quirúrgico de la laparoscopía e implica posponer la cirugía resectiva, hasta obtener los resultados de la citología. 1,2,14,21

No hay consenso en la realización sistémica o selectiva de una laparoscópica estadificadora en el cáncer de páncreas, una buena práctica sería indicarla al menos, en aquellos pacientes que presenten factores de riesgo de enfermedad diseminada, utilizando los diferentes predicadores estudiados.

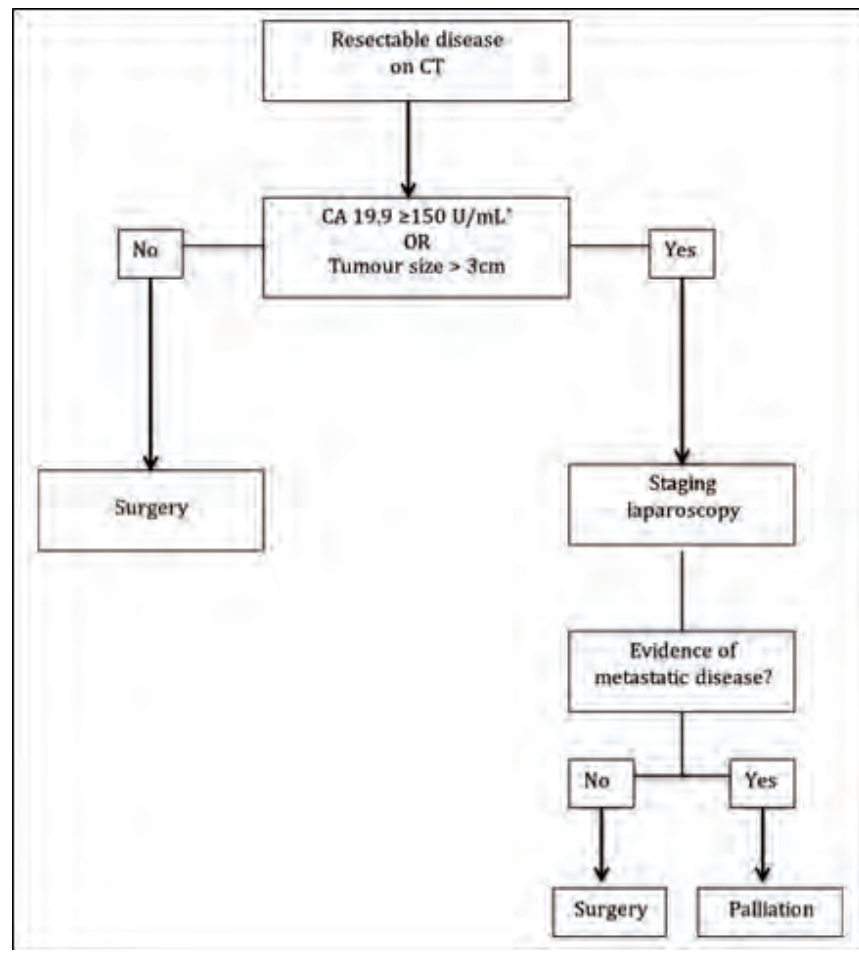

Fig 1. Algoritmo para la realización de una laparoscopia estadificadora selectiva en cáncer de páncreas. Extraído de Da Rosa et al. HBP 2016 (17). 


\section{BIBLIOGRAFIA}

1. Scwarz L, Lesurtel M. Chirurgie palliative de 1'adenocarcinome du pancréas.En Dellpero JR, Paye F, Bachellier P. Cancer du Pancréas. Monographies de L'Assciacion Francaise de Chirurgie. Paris: Anette;2010: p 367-378.

2. Tempero MA, Malafa PM, Asbun H, et al. NCCN clinical practice guidelines in oncology. Pancreatic, adenocarcinoma. Version 2.2015.

3. Callery MP, Chang KJ, Fishman EK,et al. Pretreatment assessment of resectable and borderline resectable pancreatic cancer: expert consensus statement. Ann Surg Oncol. 2009;16(7):1727-1733.

4. Menack MJ, Spitz JD, Arregui ME. Staging of pancreatic and ampullary cancers for resectability using laparoscopy with laparoscopic ultrasound. Surg Endoscopy-Ultrasound Interventional Tech. 2001;15: 1129 - 1134.

5. Zamboni GA, Kruskal JB, Vollmer CM,et al. Pancreatic adenocarcinoma: value of multidetector CT angiography in preoperative evaluation. Radiology. 2007;245(3):770-778.

6. Olivié D, Lepanto L, Billiard JS, et al. Predicting resectability of pancreatic head cancer with multi-detector CT. Surgical and pathologic correlation. JOP. 2007 9;8(6):753-758.

7. Kaneko OF, Lee DM, Wong J, et al. Performance of multidetector computed tomographic angiography in determining surgical resectability of pancreatic head adenocarcinoma. J Comput Assist Tomogr. 2010;34(5):732-738.

8. Fusari M, Maurea S, Imbriaco M. Comparison between multislice CT and MR imaging in the diagnostic evaluation of patients with pancreatic masses. Radiol Med.2010;115(3):453-466.

9. Shrikhande SV, Barreto SG, Goel M, et al. Multimodality imaging of pancreatic ductal adenocarcinoma: a review of the literature. HPB (Oxford). 2012;14(10):658-668.

10. Mayo SC, Austin DF, Sheppard BC,et al. Evolving preoperative evaluation of patients with pancreatic cancer: does laparoscopy have a role in the current era? J Am Coll Surg. 2009 ;208(1):87-95

11. White R, Winston C, Gonen M,et al. Current utility of staging laparoscopy for pancreatic and peripancreatic neoplasms. J Am Coll Surg. 2008 ;206(3):445-50.

12. Maire F, Sauvanet A, Trivin F,et al. Staging of pancreatic head adenocarcinoma with spiral CT and endoscopic ultrasonography: an indirect evaluation of the usefulness of laparoscopy. Pancreatology. 2004;4(5):436-440.

13. Allen VB, Gurusamy KS, Takwoingi Y, et al. Diagnostic accuracy of laparoscopy following computed tomography (CT) scanning for assessing the resectability with curative intent in pancreatic and periampullary cancer. Cochrane Database Syst Rev. 2016 6;7:CD009323.

14. Stefanidis D, Grove KD, Schwesinger WH,et al. The current role of staging laparoscopy for adenocarcinoma of the pancreas: a review. Ann Oncol. 2006;17(2):189-199.

15. Hariharan D, Constantinides VA, Froeling FE,et al. The role of laparoscopy and laparoscopic ultrasound in the preoperative staging of pancreatico-biliary cancers--A meta-analysis. Eur J Surg Oncol. 2010;36(10):941-948.

16. Levy J, Tahiri M, Vanounou T,et al. Diagnostic Laparoscopy with Ultrasound Still Has a Role in the Staging of Pancreatic Cancer: A Systematic Review of the Literature. HPB Surg.;2016: doi 10.1155/2016/8092109.

17. De Rosa A, Cameron IC, Gomez D.Indications for staging laparoscopy in pancreatic cancer.HPB 2016;18:1320.

18. Ferrone CR, Haas B, Tang L,et al. The influence of positive peritoneal cytology on survival in patients with pancreatic adenocarcinoma. J Gastrointest Surg. 2006 ;10(10):1347-1753.

19. Clark CJ, Traverso LW. Positive peritoneal lavage cytology is a predictor of worse survival in locally advanced pancreatic cancer. Am J Surg. 2010;199(5):657-662.

20. Edge S. American Joint Commission on Cancer. Exocrine pancreas. AJCC Cancer Staging Manual, 7th edition, New York, NY: Springer; 2010 .

21. Eskander MF, Bliss LA, Tseng JF. Pancreatic adenocarcinoma.Curr Probl Surg. 2016 ;53(3):107-154. 


\section{MARCADORES TUMORALES EN ADENOCARCINOMA DE PANCREAS}

\section{CA 19-9}

El antígeno carbohidrato 19-9 (CA 19-9) es un epítope o antígeno que forma parte de una glicoproteína, el sialo-lactato-N-fucopentosa.

Es detectado por el anticuerpo monoclonal 1116NS19-9.

Fue descubierto en 1979, como antígeno asociado a carcinoma colo-rectal y posteriormente se lo asoció al cáncer de páncreas. ${ }^{1}$

Hoy en día, es el marcador tumoral más utilizado en cáncer de páncreas y es el único aprobado por la Food and Drug Administration ${ }^{2}$

Los niveles séricos de Ca 19-9 proveen importante información diagnóstica, pronóstica, valoran la respuesta al tratamiento (quirúrgico, quimioterápico) y predicen recurrencia postratamiento.

Sin embargo el CA 19-9 tiene algunas limitaciones:

- La expresión sérica del CA 19-9 depende de la expresión del antígeno del grupo sanguíneo de Lewis. Por lo tanto, los pacientes con fenotipo Lewis negativo no expresan el marcador y se comportan como falsos negativos. Se estima que 5-10\% de la población es fenotipo Lewis negativo. Este porcentaje puede aumentar en la población de raza negra 3,4

- $\quad$ El CA 19-9, puede ser expresado por otros tumores (esófago, estómago, colo-rectal, colngiocarcinoma, hepatocarcinoma) ${ }^{3,4}$

- La ictericia aumenta sus niveles séricos, por lo tanto cualquier condición que genere obstrucción biliar puede elevar su nivel, incluso en patología benigna (coledocolitiásis)

- Otras patologías patologías benignas que pueden elevar el CA 19-9 son: pancreatitis, hepatopatía crónica o insuficiencia renal, generando falsos positivos ${ }^{3,4}$

Estos factores provocan que la sensibilidad y especificidad del CA 19-9 sea subóptima. ${ }^{4}$

Un meta-análisis realizado en 2007 por Goonetilleke y Siriwardena ${ }^{5}$, que incluyó 22 estudios, con un total de 2,283 pacientes con diagnóstico histológico confirmado de cáncer de páncreas, reporta una sensibilidad promedio de $79 \%$ (68\% a $91 \%)$ con una especificidad de $82 \%$ (68\% a 91\%), con un valor predictivo positivo de $72 \%(41 \%$ a $95 \%)$ y un valor predictivo negativo de $81 \%$ (65\% a $98 \%)$.

\section{CA 19-9 como método de screening}

Un marcador "ideal" debe tener alta sensibilidad para detectar la enfermedad en una población asintomática.

Dos trabajos analizaron el rendimiento del CA 19-9 como método de screening.

Kim6 realiza un estudio de masas en Corea en 2004, a 70940 personas asintomáticas se les dosificó CA 19-9 (valor normal hasta $37 \mathrm{U} / \mathrm{mL})$.

En 1063 (1,5\%) que presentaron niveles elevados, solo 4 pacientes tenían un cáncer de páncreas y 1053 fueron falsos positivos. Encuentra un valor predictor positivo de $0.9 \%$.

Chang ${ }^{7}$,en Taiwan, realiza dosificación de CA 19-9 a 5343 pacientes asintomáticos. 385 pacientes (7.2\%) presentaron niveles de CA 19-9 elevados (mayores a $37 \mathrm{U} / \mathrm{mL}$ ) y solo 2 tenían un cáncer de páncreas, a 58 se les diagnosticó otro cáncer (de ellos 13 tenían CA 19-9 elevado) y 325 fueron falsos positivos. Los autores encuentran un factor predictivo positivo solo del $0.5 \%$ y concluyen que el rendimiento del CA 19-9 como método de screening es bajo.

Por lo tanto, el CA 19-9 no ha mostrado beneficio en la detección precoz del cáncer pancreático, cuando se utiliza como método de screening aislado, en población asintomática ${ }^{2,3}$

\section{El CA 19-9 como marcador de estadio de la enfermedad.}

Varios trabajos se han enfocado en determinar si existe correlación entre los niveles séricos preoperatorios de CA 19-9 y el estadío clínico de la enfermedad. ${ }^{8-11}$

Todos ellos encuentran un aumento progresivo de los niveles de CA 19-9 a medida que progresa el estadío. 
Sin embargo, las cifras de CA 19-9 para cada estadío son variables.

Ballehaninna ${ }^{3}$, en una revisión sistemática, encuentra que entre 80 y 90\% de los pacientes con estadíos III y IV tenían niveles séricos de CA19-9 mayores a 100U/ml.

\section{El rol del CA19-9 como predictor preoperatorio de resecabilidad .}

La determinación de la resecabilidad de un cáncer pancreático está determinada por varios factores (clínicos, humorales, imagenológicos).

Varios trabajos se han enfocado en determinar si existe un valor de corte en los niveles de CA19-9, que pueda predecir la presencia de enfermedad avanzada o diseminada y por tanto irresecable. ${ }^{11-17}$

El rango del valor de corte que reportan es amplio y varía entre 92,7 y $352 \mathrm{u} / \mathrm{ml}$. 11-17 Todos los estudios son no randomizados, retrospectivos y con baja casuística Ballehaninna ${ }^{3}$, en su revisión sistemática encuentra que valores de CA 19-9 por debajo de 100U/ml, se correlacionaron con tumores resecables (valor predictor positivo de $41-80 \%$ ), mientras que valores por encima de ese rango, sugieren enfermedad avanzada o metastásica y por tanto irresecable (valor predictor positivo $60-85 \%$ ).

Callery y $\operatorname{col}^{18}$ en un consenso de expertos norteamericanos, proponen predictores de riesgo, que permitirían seleccionar candidatos a laparoscopía preoperatoria, basados en una presunción de enfermedad avanzada o diseminada subclínica. Incluyen como uno de los factores de riesgo a tener en cuenta, niveles de CA 19-9 mayores a $100 \mathrm{U} / \mathrm{ml}$.

\section{CA 19-9 como marcador pronóstico}

Varios estudios han demostrado el valor pronóstico, sobre la sobrevida, de los niveles preoperatorios de CA 19-9.9-24 Todos los trabajos encuentran que los pacientes con niveles preoperatorios normales o bajos de CA 19-9, tienen una sobrevida significativamente mayor que los pacientes con niveles preoperatorios elevados. ${ }^{19-24}$

El valor preoperatorio de CA 19-9 fue identificado como factor pronóstico independiente en el análisis multivariable en varios trabajos. ${ }^{19-24}$

Los diferentes estudios han intentado determinar un valor de corte del nivel de CA 19-9 preoperatorio que marque un quiebre en el pronóstico del paciente. Sin embargo, este valor de corte es controversial y variable según el trabajo, con un rango reportado muy amplio $(37 \mathrm{U} / \mathrm{mL} \text { a } 400 \mathrm{U} / \mathrm{mL})^{19-24}$

Recientemente Bergquist y cols. ${ }^{25}$ realizan una revisión del papel pronóstico del CA 19-9 en la sobrevida del cáncer de páncreas en estadios tempranos (I y II) en Estados Unidos. Se utilizaron datos del National Cancer Data Base del 2010 al 2012. Los pacientes fueron estratificados en dos grupos, según un valor de corte de CA 19-9 de $37 \mathrm{U} / \mathrm{mL}$. Los no secretores fueron analizados por separado.

Se identificaron 28074 pacientes con cáncer pancreático en los que se había dosificado CA 19-9, 10806 pacientes en estadios tempranos. De estos un 8,8\% eran no secretores, un $25 \%$ tuvieron niveles normales de CA $19-9$ y un $66 \%$ tuvieron valores mayores a $37 \mathrm{U} / \mathrm{mL}$

La sobrevida fue significativamente peor, independientemente del estadío, cuando el CA 19-9 estaba elevado.

Los pacientes no secretores tuvieron la misma sobrevida que los pacientes secretores con niveles de CA19-9 normales. En estadios tempranos, los pacientes con CA $19-9$ elevado, tuvieron peor sobrevida a 1, 2 y 3 años (56\% vs $68 \%, 30 \%$ vs $42 \%, 15 \%$ vs $25 \%$ ) comparados con pacientes con niveles normales. Esta diferencia fue estadísticamente significativa $(\mathrm{p}<0.001)$

En base a estos hallazgos los autores plantean que este grupo de pacientes con lesiones tempranas, potencialmente resecables con CA 19-9 elevados pueden beneficiarse de la realización de neoadyuvancia.

\section{El rol del CA 19-9 como marcador de respuesta al tratamiento}

El descenso y normalización de los niveles de CA 19-9 post-pancreatectomía (cuando estaba elevado en preoperatorio), ha sido identificado como un factor de buen pronóstico.

Varios trabajos han demostrado que aquellos pacientes que mantienen elevados los niveles de CA 19-9 en el postoperatorio, tienen menor sobrevida que aquellos en los que se normaliza o desciende $9,11,26,27$

El no descenso de los valores a las 4-6 semanas de la cirugía, debe ser atribuido a la presencia de enfermedad residual o metástasis subclínicas, que determinan un deterioro del pronóstico. $^{3}$ 
La respuesta al tratamiento sistémico puede también ser evaluada con los niveles séricos del CA 19-9.

En los pacientes que reciben neoadyuvancia, el descenso los niveles de CA 19-9 ha sido correlacionado con respuesta favorable. La elevación de los niveles se asoció a progresión de la enfermedad y por consiguiente peor pronóstico, ${ }^{28,29}$ en estos pacientes se recomienda la realización de una laparoscopía diagnóstica, si los estudios de imagen no muestran progresión.

En los pacientes con enfermedad avanzada que reciben quimioterapia, varios trabajos han reportado que el descenso de los niveles de CA 19-9 es predictor de respuesta al tratamiento. ${ }^{30-33}$

Esto no ha podido ser demostrado por otros estudios 34.35

No es claro cuál es el porcentaje de disminución de CA 19-9, que traduce una respuesta al tratamiento sistémico y por consiguiente una mejoría pronóstica.

Este porcentaje es variable en los diferentes trabajos, con rangos que van del 20 al $80 \%$. ${ }^{30-34}$

\section{El CA 19-9 como marcador de recurrencia}

La utilidad del CA 19-9 como indicador precoz de recurrencia ha sido bien estudiada ${ }^{26,36,37}$

Montgomery ${ }^{26}$ encuentra que la elevación mantenida de los niveles de CA 19-9 postratamiento, precede la detección clínico-imagenológica de la recidiva entre 2 semanas y 5 meses (media 3,5 meses).

Hernande $z^{27}$, encuentra que la velocidad del ascenso del CA 19-9, medido cada 4 semanas, es el mejor predictor de recurrencia. En su trabajo evidencia que los pacientes que presentaron recidiva, tuvieron una velocidad de ascenso de $131 \mathrm{U} / \mathrm{ml} / 4$ semanas, comparada con la nula progresión de los pacientes que no presentaban recaída.

\section{Otros marcadores}

A las ya mencionadas limitaciones que posee el CA 19-9 como método diagnóstico, seguimiento, pronóstico, etc. Hay que añadir 2 situaciones que falsean aun más sus valores, por un lado el incremento de su valor en los pacientes ictéri$\cos (67,5 \% \text { de los pacientes con tumores cefalopancreáticos tienen ictericia })^{38}$ y por otro lado la presencia de pacientes Lewis negativos $(5-14 \%) .^{39}$

Esto ha llevado a la búsqueda de otros marcadores que puedan solucionar estas dificultades y puedan completar con el CA 19-9 como biomarcadores. En esta línea surge el interés por el CEA y el CA 125 para el manejo terapéutico del cáncer de páncreas.

Un reciente estudio de casos control sobre un total de 1207 pacientes, encuentra que el CEA y el CA 125 muestran una alta sensibilidad para tumores de páncreas frente a otro biomarcadores, en pacientes Lewis negativos (CEA 63.8\%, CA 125 51.1\%). Su sensibilidad fue mayor en los Lewis negativos que en los positivos y asociados elevan su sensibilidad a $74,5 \%$.

E1 CEA tuvo una mejor correlación para los estadíos precoces y el CA 125 con la enfermedad metastásica. ${ }^{40}$

El aumento del CEA postratamiento esta asociado a un peor pronóstico, incluso en los Lewis positivos. ${ }^{41}$

Por su parte el CA 125 tiene uso limitado para el diagnóstico de cáncer de páncreas, pero asociado a la CA 19-9, consiguen aumentar la sensibilidad diagnóstica. Por otro lado mostró ser un factor de riesgo independiente que puede predecir el pronóstico, su elevación se asoció a enfermedad metastástica y su valor no es influenciado por el nivel de bilirrubina. ${ }^{42}$

Para Luo et al. Los tres biomarcadores, CEA, CA 19-9, CA 125, deben ser solicitados de rutina en todos lo pacientes con diagnóstico o sospecha de cáncer de páncreas. ${ }^{40}$ 


\section{BIBLIOGRAFIA}

1. Koprowski H, Steplewski Z, Mitchell K, et al. Colorectal carcinoma antigens detected by hybridoma antibodies. Somatic Cell Genet. 1979;5(6):957-971 (abstract).

2. $\quad$ Eskander MF, Bliss LA, Tseng JF. Pancreatic adenocarcinoma. Curr Probl Surg. 2016;53(3):107-154.

3. Ballehaninna UK, Chamberlain RS. The clinical utility of serum CA 19-9 in the diagnosis, prognosis and management of pancreatic adenocarcinoma: An evidence based appraisal. J Gastrointest Oncol. 2012 ;3(2):105119

4. Ortiz V, Chapa O, Hernández B, et al. Sensibilidad y especificidad del CA 19-9 para el diagnóstico de neoplasias pancreatobiliares en pacientes con ictericia de origen obstructivo.Cir Gen Mex 2011;33:14-20.

5. Goonetilleke KS, Siriwardena AK. Systemic review of carbohydrate antigen (CA 19-9) as a biochemical marker in the diagnosis of pancreatic cancer. Eur J Surg Oncol 2007; 33: 266-270.

6. Kim JE, Lee KT, Lee JK, et al. Clinical usefulness of carbohydrate antigen 19-9 as a screening test for pancreatic cancer in an asymptomatic population.J Gastroenterol Hepatol. 2004 ;19(2):182-186.

7. Chang CY, Huang SP, Chiu HM, et al.Low efficacy of serum levels of CA 19-9 in prediction of malignant diseases in asymptomatic population in Taiwan. Hepatogastroenterology. 2006;53(67):1-4.

8. Jiang X, Tao HQ, Zou SC. Detection of serum tumor markers in the diagnosis and treatment of patients with pancreatic cancer. Hepatobiliar y Pancreat Dis Int 2004;3:464-468.

9. Ferrone CR, Finkelstein DM, Thayer SP,et al. Perioperative CA 19-9 levels can predict stage and survival in patients with resectable pancreatic adenocarcinoma. J Clin Oncol 2006;24:2897-2902.

10. Kim YC, Kim H J, Park JH, et al. Can preoperative CA 19-9 and CEA levels predict the resectabil it y of patients with pancreatic adenocarcinoma? J Gastroenterol Hepatol 2009;24:1869-1875.

11. Kondo N, Murakami Y, Uemura K, et al. Prognostic impact of perioperative serum CA 19-9 levels in patients with resectable pancreatic cancer. Ann Surg Oncol 2010;17:2321-2329.

12. Schlieman MG, Ho HS, Bold RJ. Utility of tumor markers in determining resectability of pancreatic cancer. Arch Surg. 2003;138(9):951-955.

13. Karachristos A, Scarmeas N, Hoffman JP. CA 19-9 levels predict results of staging laparoscopy in pancreatic cancer.J Gastrointest Surg. 2005 Dec;9(9):1286-1292.

14. Kiliç M, Göçmen E, Tez M,et al. Value of preoperative serum CA 19-9 levels in predicting resectability for pancreatic cancer. Can J Surg. 2006 ;49(4):241-244.

15. Fujioka S, Misawa T, Okamoto T,et al. Preoperative serum carcinoembryonic antigen and carbohydrate antigen 19-9 levels for the evaluation of curability and resectability in patients with pancreatic adenocarcinoma.J Hepatobiliary Pancreat Surg. 2007;14(6):539-544.

16. Maithel SK, Maloney S, Winston C, et al. Preoperative CA 19-9 and the yield of staging laparoscopy in patients with radiographically resectable pancreatic adenocarcinoma.Ann Surg Oncol. 2008;15(12):3512-3520.

17. Zhang S, Wang YM, Su n CD,et al. Clinical value of serum CA 19-9 levels in evaluating resectability of pancreatic carci noma.World J Gastroenterol 2008;14:3750-3753.

18. Callery MP, Chang KJ, Fishman EK,et al. Pretreatment assessment of resectable and borderline resectable pancreatic cancer: expert consensus statement. Ann Surg Oncol. 2009;16(7):1727-1733.

19. Berger AC, Meszoely IM, Ross EA,et al. Undetectable preoperative levels of serum CA 19-9 correlate with improved survival for patients with resectable pancreatic adenocarcinoma.Ann Surg Oncol. 2004;11(7):644649.

20. Smith RA, Bosonnet L, Ghaneh P,et al. Preoperative CA19-9 levels and lymph node ratio are independent predictors of survival in patients with resected pancreatic ductal adenocarcinoma.Dig Surg. 2008;25(3):226232.

21. Waraya M, Yamashita K, Katagiri H,et al.Preoperative serum CA19-9 and dissected peripancreatic tissue margin as determiners of long-term survival in pancreatic cancer. Ann Surg Oncol. 2009;16(5):1231-1240.

22. Distler M, Pilarsky E, Kersting S, et al. Preoperative CEA and CA 19-9 are prognostic markers for survival after curative resection for ductal adenocarcinoma of the pancreas - a retrospective tumor marker prognostic study. Int J Surg. 2013;11(10):1067-1072.

23. Dong Q, Yang XH, Zhang Y,et al. Elevated serum CA19-9 level is a promising predictor for poor prognosis in patients with resectable pancreatic ductal adenocarcinoma: a pilot study. World J Surg Oncol. 2014 2;12:171. doi: 10.1186/1477-7819-12-171.

24. Hartwig W, Strobel O, Hinz U, et al.CA19-9 in potentially resectable pancreatic cancer: perspective to adjust surgical and perioperative therapy. Ann Surg Oncol. 2013;20(7):2188-2196.

25. Bergquist JR, Puig CA, Shubert CR,et al. Carbohydrate Antigen 19-9 Elevation in Anatomically Resectable, Early StagePancreatic Cancer Is Independently Associated with Decreased Overall Survival and an Indication for Neoadjuvant Therapy: A National Cancer Database Study.J Am Coll Surg. 2016;223(1):52-65. 
26. Montgomery RC, Hoffman JP, Riley LB et al. Prediction of recurrence and survival post-resection CA 19-9 values in patients with adenocarcinoma of the pancreas. Ann Surg Oncol 1997; 4: 551-556.

27. Hata S, Sakamoto Y, Yamamoto Y,et al. Prognostic impact of postoperative serum CA 19-9 levels in patients with resectable pancreatic cancer. Ann Surg Oncol. 2012;19(2):636-641.

28. Willett CG, Daly WJ, Warshaw AL. CA 19-9 is an index of response to neoadjunctive chemoradiation therapy in pancreatic cancer. Am J Surg. 1996 ;172(4):350-352.

29. Katz MH, Varadhachary GR, Fleming JB, et al. Serum CA 19-9 as a marker of resectability and survival in patients with potentially resectable pancreatic cancer treated with neoadjuvant chemoradiation. Ann Surg Oncol. $2010 ; 17(7): 1794-801$.

30. Halm U, Schumann T, Schiefke I,et al. Decrease of CA 19-9 during chemotherapy with gemcitabine predicts survival time in patients with advanced pancreatic cancer. Br J Cancer. 2000; 82(5):1013-1016.

31. Maisey NR, Norman AR, Hill A, et al. CA19-9 as a prognostic factor in inoperable pancreatic cancer: the implication for clinical trials. Br J Cancer. 2005; 93(7):740-743.

32. Ko AH, Hwang J, Venook APet al. Serum CA19-9 response as a surrogate for clinical outcome in patients receiving fixed-dose rate gemcitabine for advanced pancreatic cancer. Br J Cancer. 2005; 93(2):195-199.

33. Reni M, Cereda S, Balzano G,et al. Carbohydrate antigen19-9 change during chemotherapy for advanced pancreatic adenocarcinoma.Cancer.2009 15;115(12):2630-2639.

34. Hess V, Glimelius B, Grawe P,et al. CA 19-9 tumour-marker response to chemotherapy in patients with advanced pancreatic cancer enrolled in a randomised controlled trial. Lancet Oncol. 2008 ;9(2):132-138.

35. Wasan HS, Springett GM, Chodkiewicz C,et al. CA 19-9 as a biomarker in advanced pancreatic cancer patients randomised to gemcitabine plus axitinib or gemcitabine alone. Br J Cancer. 2009 6;101(7):1162-11677.

36. Hernandez JM, Cowgill SM, A1-Saadi S, et al. CA 19-9 velocity predicts disease-free survival and overall survival after pancreatectomy of curative intent. J Gastrointest Surg. 2009 Feb;13(2):349-353.

37. Sugiura T, Uesaka K, Kanemoto H, et al. Serum CA19-9 is a significant predictor among preoperative parameters for early recurrence after resection of pancreatic adenocarcinoma.J Gastrointest Surg. 2012 May;16(5):977985.

38. Cwik G, Wallner G, Skoczylas T, et al. Cancer antigens 19-9 and 125 in the differential diagnosis of pancreatic mass lesions. Arch Surg. 2006;141:968-973.

39. Katz MH, Varadhachary GR, Fleming JB, et al. Serum CA 19-9 as a marker of resectability and survival in patients with potentially resectable pancreatic cancer treated with neoadjuvant chemoradiation. Ann Surg Oncol. 2010;17:1794-1801.

40. Luo G, Liu Ch, Guo M, et al. Potential Biomarkers in Lewis Negative Patients With Pancreatic Cancer. Original Article. Ann Surg 2016 ;DOI: 10.1097/SLA.0000000000001741.

41. Kim J, Lee YS, Hwang IK, et al. Postoperative carcinoembryonic antigen as a complementary tumor marker of carbohydrate antigen 19 - 9 in pancreatic ductal adenocarcinoma. J Korean Med Sci. 2015;30:259-263.

42. Chen T, Zhang MG, Xu HX, et al.Preoperative Serum CA125 Levels Predict the Prognosis in Hyperbilirubinemia Patients With Resectable Pancreatic Ductal Adenocarcinoma.Medicine (Baltimore). 2015;94(19):e751. doi: 10.1097/MD.0000000000000751. 


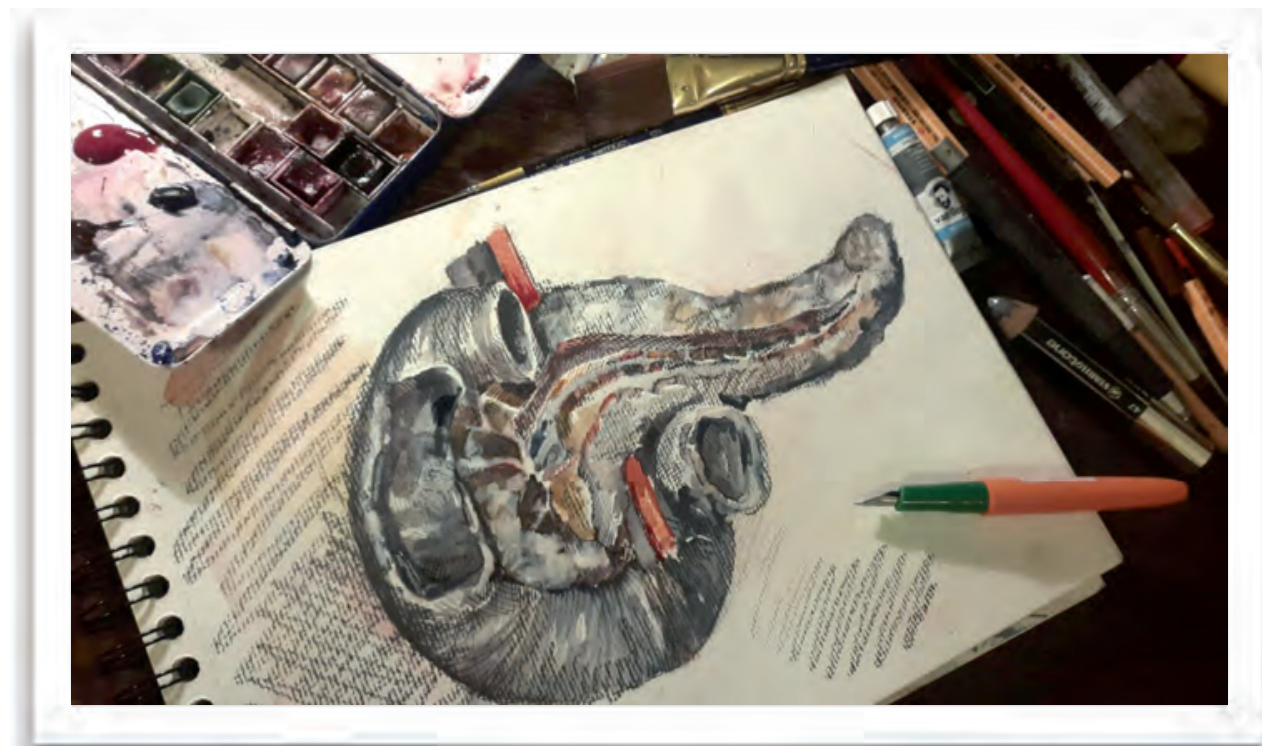

SECCION III

TACTICA

- CONCEPTO TUMOR RESECABLE BORDERLINE

- DRENAJE BILIAR PREOPERATORIO EN EL CANCER CEFALOPANCREATICO

- NEOADYUVANCIA

- ADYUVANCIA

- DUODENOPANCREATECTOMIA CEFALICA

- PANCREATECTOMIA EN ADENOCARCINOMAS DE CUERPO Y COLA DE PANCREAS 


\section{CONCEPTO DE TUMOR RESECABLE BORDERLINE.}

La cirugía continua siendo la única opción pretendidamente curativa para el adenocarcinoma de páncreas, pero su resecabilidad es limitada. Se estima que un $20 \%$ de los pacientes son resecables al momento del diagnóstico, un 50\% se presenta con una enfermedad irresecable metastásica y el restante $30 \%$ con una enfermedad localmente avanzada. ${ }^{1}$ Esto demuestra que las posibilidades de curación son bajas, más aún si tenemos en cuenta que un 10-20\% de los considerados resecables, presentan metástasis al momento de la cirugía.

Antiguamente la resecabilidad se definía en el intraoperatorio, y estaba asociada a resecciones incompletas e insatisfactorias desde el punto de vista oncológico. ${ }^{2}$ Cualquier grado de compromiso vascular, por frecuencia a nivel mesentérico y portal, se consideraba irresecable.

En búsqueda de aumentar la resecabilidad de los tumores pancreáticos, en el contexto del avance de las técnicas quirúrgicas y de cirugía vascular, es que se logran las primeras resecciones tumorales en bloque con reconstrucción vascular. Asada $^{3}$ en 1963 (duodenopancreatectomía con resección de vena porta) y Fortner en 1977, publican sus resultados de resecciones tumorales con reconstrucción vascular exitosa, pero asociado a una alta mortalidad. ${ }^{4}$ No fue hasta los años 90, donde se logran resecciones tumores con reconstrucciones vasculares, comparables a los pacientes sin resección vascular asociada, Allema 51994 y Tseg et al. ${ }^{6} 2004$.

El avance en las técnicas de imagen, junto al inicio de las terapias neoadyuvantes en el adenocarcinoma de páncreas, ha permitido identificar un grupo de pacientes con tumores que no pueden catalogarse como resecables o irresecables. A este grupo Metha los denominó como marginales, por presentar diferentes grados de compromiso vascular. En su trabajo, sometió a tratamiento neoadyuvante a estos pacientes, logrando un "downstaging", mejorando o aumentando su resecabilidad. ${ }^{7}$ Si bien en términos generales la neoadyuvancia no ha mostrado gran impacto en la sobrevida de los pacientes con adenocarcinoma de páncreas, ha permitido convertir pacientes antiguamente considerados como irresecables en resecables, este grupo de tumores es hoy conocido como borderline. ${ }^{8}$

Hasta el momento actual no existe una definición única de tumor borderline. Se trata de un grupo heterogéneo de tumores con compromiso vascular que no pueden catalogarse de resecables o irresecables y su resección conlleva mayor riesgo de márgenes positivos. ${ }^{9}$

Se considera además, que los pacientes con tumores borderline requieren una cirugía más demandante desde el punto técnico, muchas veces asociado a reconstrucciones vasculares y con más riesgo de presentar metástasis ocultas. ${ }^{2}$ Esto le agrega un componente biológico adicional a la definición de borderline, por lo que deben considerarse como tumores más agresivos que los resecables.

Con la llegada de los tomógrafos multicorte de alta resolución y la implementación de los protocolos radiológicos para páncreas, se ha logrado definir la resecabilidad de los tumores de páncreas en aproximadamente el 80\% y el compromiso vascular hasta en un $90 \%$ de los casos. Estos tomógrafos mantienen las limitaciones en diagnosticar metástasis hepáticas o peritoneales pequeñas que están presentes en un $20-30 \%$ de los tumores considerados resecables. ${ }^{10}$ A su vez, estos nuevos métodos de imagen, han permitido documentar diferentes grados de contacto tumoral con el plano vascular, ampliando la gamma de posibles tumores borderline.

Este compromiso vascular ha sido clasificado en grados, que determinarían distinto riesgo de invasión vascular. Se encuentran diferentes clasificaciones como la de Loyer y col. ${ }^{11}$ que divide el grado de contacto tumoral-vascular de la A a la F y la de Lu y col. ${ }^{12}$ que numera del 0 al 4. Las clasificaciones más utilizadas, se basan en tres términos de origen anglosajón y de difícil traducción. Ellos son: "encasement", "abutment" e "involvement", los cuales implican un compromiso vascular distinto.

"Abtument" se refiere a un contacto con el vaso sanguíneo menor a 180 grados y en un segmento corto, menor a $1,5 \mathrm{~cm}$ y no se considera un elemento sensible de invasión vascular.

Se denomina "Encasement" al contacto del tumor con el vaso sanguíneo mayor a 180 grados, es un signo de invasión vascular con una sensibilidad del $84 \%$ y una especificidad de $98 \%$. Si el compromiso es mayor a 270 grados el riesgo se considera del $100 \% .{ }^{13}$

Por último, "involvement o invasión" es un elemento de invasión vascular, puede describirse desde el punto de vista imagenológico como la típica forma de lágrima que adopta el vaso, o la presencia de irregularidades y deformidades de la pared del vaso o trombosis intraluminal. ${ }^{14}$ 


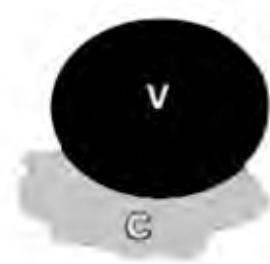

Abutment

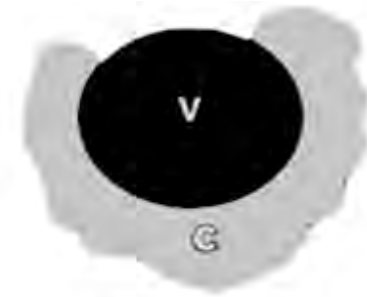

Encasement

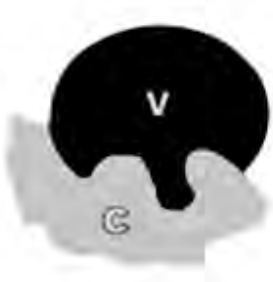

Involvement

Utilizando estos términos, se encuentran en la bibliografía distintas definiciones o clasificaciones de los tumores borderline.

Cuando se analizan, no se evidencian grandes diferencias entre las distintas clasificaciones, se discute si el compromiso venoso mesentérico-portal debe considerarse como borderline o resecable y los diferentes compromisos de la arteria hepática.

De las primeras definiciones anatómica de tumores borderline de páncreas, se encuentra la elaborada por The National Comprehensive Cancer Network (NCCN), en el 2004. ${ }^{15}$ En esta primera definición se toma en cuenta el contacto con la arteria mesentérica, el compromiso venoso mesenterico-portal y el en compromiso de la artera gastroduodenal próximo a la arteria hepática. Incluye dentro de su definición, el compromiso del mesocolon transverso y del propio colon.

En el 2006 Varadhachary et al. del MD Anderson, define como borderline la presencia de tumores con un contacto $\leq$ a 180 grados (abutment) sobre la arteria mesentérica superior, pero con puntos de contacto convexos que mejoren las posibilidades de resección. El tumor puede rodear la arteria hepática (encasement) en el origen de la arteria gastroduodenal, pero debe ser pasible de reconstrucción. En cuanto al compromiso venoso, el tumor rodea, comprime y obstruye un segmento corto, pasible de reconstrucción (involvement). En esta definición no se encuentra el compromiso del mesocolon ni colon. ${ }^{16}$

En el 2008 la Asociación Americana Hepatobiliopancreática, convocó a una conferencia sobre le cáncer de páncreas resecable y borderline, con el fin de realizar precisiones sobre los mismos . La conferencia fue co-patrocinada por la Sociedad de Patología Quirúrgica, la Sociedad de Cirugía del Tracto Alimentario, el M.D. Anderson Cancer Center y el Comité Directivo del Simposio Gastrointestinal (AHPBA/SSO/SSAT). Allí se definió a los tumores borderline como aquellos que no tenían metástasis a distancia, un compromiso más o menos extenso de la vena mesentérica superior y vena porta, que puede ir desde una pérdida de plano a una infiltración, incluso con un pequeño trombo intraluminal, pero que permitan su resección y reparación vascular.

Un compromiso de la arteria gastroduodenal hasta el origen en la arteria hepática, la cual puede contactar sin extenderse al tronco celíaco. En este consenso no se cuenta como borderline la reconstrucción de la arteria hepática. Por último, se considera borderline, un contacto menor a la mitad de la circunferencia de la arteria mesentérica superior $(<180$ grados $) .{ }^{17}$

Recientemente The Alliance for Clinical Trials in Oncology (Alliance A021101) ${ }^{18}$, surge en 2013 con su trabajo piloto para evaluar la respuesta al FOLFIRINOX. Este grupo encuentra la necesidad de consensuar definiciones para los tumores borderline. Proponen que los pacientes borderline deben tener al menos una de las siguientes características radiológicas: contacto del tumor con la vena porta o mesentérica superior mayor a 180 grados o una oclusión reconstituible. Contacto con la arteria mesentérica superior menor a 180 grados. Compromiso de la arteria hepática común reconstituible en un segmento corto. Y contacto menor a 180 grados con el tronco celíaco.

En el 2015 se presenta una nueva guía de la NCCN con una nueva clasificación.

En tanto el Consenso Europeo de la International Study Group of Pancreatic Surgery (ISGPS), comunica que su definición es compatible con la de la NCCN. ${ }^{19}$ 
Tabla 1: Clasificaciones de Tumores Borderline

\begin{tabular}{|c|c|c|c|c|c|}
\hline Anatomía & NCCN 2015 & $\begin{array}{l}\text { AHPBA/ } \\
\text { SSAT/SSO }\end{array}$ & MD.Anderson & ISGPS & Alliance \\
\hline $\begin{array}{l}\text { Vena } \\
\text { mesentérica } \\
\text { superiory } \\
\text { vena porta }\end{array}$ & $\begin{array}{l}\text { "involvement". } \\
\text { Incluye } \\
\text { trombosis de } \\
\text { un pequeño } \\
\text { segmento. }\end{array}$ & $\begin{array}{l}\text { "abutment", } \\
\text { "encasment", } \\
\text { "involvement", } \\
\text { Reconstituible }\end{array}$ & $\begin{array}{l}\text { "Involvement" } \\
\text { Incluye oclusión } \\
\text { Reconstituible }\end{array}$ & $\begin{array}{l}\text { "involvement” } \\
\text { Incluye oclusión } \\
\text { Reconstituible }\end{array}$ & $\begin{array}{l}\text { Contacto tumor- } \\
\text { vaso } \geq 180 \\
\text { grados. } \\
\text { Reconstituible }\end{array}$ \\
\hline $\begin{array}{l}\text { Arteria } \\
\text { mesentética } \\
\text { superior }\end{array}$ & "Abutment" & "Abutment" & "Abutment" & "Abutment" & "Abutment" \\
\hline $\begin{array}{l}\text { Arteria } \\
\text { Hepática } \\
\text { Común }\end{array}$ & $\begin{array}{l}\text { "Abutment" o } \\
\text { sector corto de } \\
\text { "encasement" }\end{array}$ & $\begin{array}{l}\text { "Abutment" o } \\
\text { Sector corto de } \\
\text { "encasement" }\end{array}$ & $\begin{array}{l}\text { Sector corto de } \\
\text { "encasement"/ } \\
\text { "abutment" }\end{array}$ & $\begin{array}{l}\text { "Abutment" o } \\
\text { Sector corto de } \\
\text { "encasement" }\end{array}$ & $\begin{array}{l}\text { Invasion vascular } \\
\text { corta } \\
\text { Reconstituible }\end{array}$ \\
\hline $\begin{array}{l}\text { Tronco } \\
\text { celíaco }\end{array}$ & $\begin{array}{l}\text { No "abutment" } \\
\text { o "encasement" }\end{array}$ & $\begin{array}{l}\text { No "abutment"/ } \\
\text { "encasement" }\end{array}$ & $\begin{array}{l}\text { No "abutment" o } \\
\text { "encasement" }\end{array}$ & $\begin{array}{l}\text { No "abutment" o } \\
\text { "encasement" }\end{array}$ & $\begin{array}{l}\text { Contacto } \\
\text { tumor-vaso } \\
<180 \text { grados }\end{array}$ \\
\hline
\end{tabular}

A esta clasificación anatomo-radiológica, se le agregan componentes biológicos y clínicos que determinan que un tumor considerado resecable desde el punto de vista anatómico, pueda ser considerado borderline.

E1 MD Anderson prepone la siguiente subclasificación:

- Borderline Tipo A, definido por su clasificación anatómica.

- Borderline Tipo B, son aquellos pacientes que siendo radiologicamente resecables, presentan elementos que hacen sospechar una enfermedad avanzada desde el punto sistémico, como por ejemplo la sospecha de N1 radiológico, sospecha de micrometástasis y la presencia de un CA 19-9 > $1000 \mathrm{u} / \mathrm{ml}$.

- Borderline Tipo C: son aquellos pacientes que presentan un status performance marginal que impide la ci rugía o la presencia de comorbildades reversibles que condicionan la oportunidad operatoria. ${ }^{20}$

Dentro de las características de un bajo performance status se destacan, la fatiga y anorexia que puede ser producida por la ictericia así como también el descenso de peso, el dolor, la edad y la necesidad de ingresos hospitalarios. ${ }^{21}$

Como queda de manifiesto, no hay una definición única y precisa de tumores borderline y las clasificaciones pueden ser difíciles de implementar, incluso 2 autores pueden considerar distinto a un mismo tumor.

Del análisis de las diferentes clasificaciones y de la evolución de las mismas nos surgen una serie de interrogantes y conclusiones.

No nos podemos quedar únicamente en que los tumores borderline, son aquellos que tienen comprometida su resección R0, cuando aún se discute el valor de las resecciones R1.

Tampoco en el punto de las resecciones vasculares, cuando algunas clasificaciones toman la resección venosa como parte de los tumores resecables.

Sumado a la dificultad en la evaluación imagenológca de la respuesta de los tumores borderline a la neoadyuvancia.

Además se han sumado los elementos biológicos y clínicos que han complejizado aún más la clasificación.

Por ello, sin desconocer la importancia que tiene aumentar la tasa de resecciones de los tumores pancreáticos, consiguiendo un mayor número de resecciones R0, así como el beneficio de las resecciones vasculares con fin de ampliar los márgenes oncológicos. Creemos que más que una definición anatómica de los tumores borderline, debemos manejar el concepto borderline.

Estos tumores son más agresivos, con mayor riesgo de enfermedad sistémica, asociado a un declive en el perfomance status.

La neoadyuvancia no solo busca aumentar la resecabilidad y mejorar los márgenes de resección, sino también tratar precozmente las micrometástasis y conocer el potencial evolutivo, seleccionado aquellos pacientes que realmente se beneficiaran de una cirugía más demandante, asociada a morbimortalidad elevada y un mal pronóstico. ${ }^{21}$ 


\section{BIBLIOGRAFIA}

1. SEER Cancer Statistics Factsheets: Pancreas Cancer. National Cancer Institute. Bethesda, MD, http://seer. cancer.gov/statfacts/html/pancreas.html . Accessed March 3, 2014.

2. Evans DB, George B, Tsai S. Non-metastatic Pancreatic Cancer: Resectable, Borderline Resectable, and Locally Advanced-Definitions of Increasing Importance for the Optimal Delivery of Multimodality Therapy. Ann Surg Oncol.2015; 22(11):3409-3413.

3. Asada S, Itaya H, Nakamura K, et al. Radical pancreatoduodenectomy and portal vein resection. Report of two successful cases with transplantation of portal vein. Arch Surg 1963;87:609-613.

4. Fortner JG, Kim DK, Cubilla A, et al. Regional pancreatectomy: en bloc pancreatic, portal vein and lymph node resection.Ann Surg. 1977;186(1):42-50.

5. Allema JH, Reinders ME, van Gulik TM, et al. Portal vein resection in patients undergoing pancreatoduodenectomy for carcinoma of the pancreatic head.Br J Surg. 1994;81(11):1642-1646.

6. Tseng JF, Raut CP, Lee JE, et al. Pancreaticoduodenectomy with vascular resection: margin status and survival duration. J Gastrointest Surg. 2004;8(8):935-949.

7. Mehta VK, Fisher G, Ford JA, e al. Preoperative chemoradiation for marginally resectable adenocarcinoma of the pancreas. J Gastrointest Surg. 2001;5(1):27-35.

8. Lopez NE, Prendergast C, Lowy AM. Borderline resectable pancreatic cancer: Definitions and management. World J Gastroenterol 2014; 20(31): 10740-10751.

9. Katz MH, Crane CH, Varadhachary G. Management of borderline resectable pancreatic cancer. Semin Radiat Oncol 2014; 24(2): 105-112.

10. Horton KM, Fishman EK. Adenocarcinoma of the pancreas: CT imaging. Radiol Clin N Am 2002;40(6):12631272.

11. Loyer EM, David CL, Dubrow RA, et al. Vascular involvement in pancreatic adenocarcinoma: reas- sessment by thin-section CT. Abdom Imaging 1996; 21(3):202-206.

12. Lu DS, Reber HA, Krasny RM, et al. Local staging of pancreatic cancer: criteria for unresectability of major vessels as revealed by pancreatic-phase, thin-section helical CT. AJR Am J Roentgenol 1997; 168(6):14391443.

13. Mullapudi B, Hawkes PJ, Patel A, Are C, Misra S. Borderline Resectable Pancreatic Cancer.Indian J Surg Oncol 2015; 6(1):63-68.

14. Pietryga JA, Morgan DE. Imaging preoperatively for pancreatic adenocarcinoma. J Gastrointest Oncol. 1015;6(4):343-357.

15. National Comprehensive Cancer Network (NCCN) Practice Guidelines for Pancreatic Cancer. Available at: http:// www.nccn.org. 2004.

16. Varadhachary GR, Tamm EP, Abbruzzese JL, et al. Borderline resectable pancreatic cancer: definitions, management, and role of preoperative therapy. Ann Surg Oncol 2006; 13 (8): 1035-1046.

17. Callery MP, Chang KJ, Fishman EK, et al. Pretreatment assessment of resectable and borderline resectable pancreatic cancer: expert consensus statement. Ann Surg Oncol 2009;16(7):1727-1733.

18. Katz MHG, Marsh R, Herman JH, et al. Borderline Resectable Pancreatic Cancer: Need for Standardization and Methods for Optimal Clinical Trial Design.Ann Surg Oncol. 2013; 20(8):2787-2795.

19. Bockhorn M, Uzunoglu FG, Adham M, et al. Borderline resectable pancreatic cancer: A consensus statement by the International Study Group of Pancreatic Surgery (ISGPS).Consensus. Surgery. 2014; 155(6):977-988.

20. Tzeng CD, Fleming JB, Lee JE, et al. Defined Clinical Classifications Are Associated with Outcome of Patients with Anatomically Resectable Pancreatic Adenocarcinoma Treated with Neoadjuvant Therapy. Ann Surg Oncol (2012) 19(6):2045-2053.

21. Katz MH, Pisters PW, Evans DB, et al. Borderline resectable pan- creatic cancer: the importance of this emerging stage of disease. J Am Coll Surg 2008; 206 (5): 833-846. 


\section{DRENAJE BILIAR PREOPERATORIO EN EL CANCER CEFALOPANCREATICO}

En este capítulo, nos referiremos al drenaje biliar preoperatorio en pacientes portadores de un adenocarcinoma de páncreas, potencialmente resecable.

Discutiremos su indicación, vía de realización, tipo de drenaje a utilizar y duración del mismo.

\section{¿Está indicado su uso rutinario?}

La localización cefalopancreática es la más frecuente en los tumores malignos del páncreas, y por lo tanto la ictericia obstructiva es su forma de presentación habitual.

La ictericia mantenida afecta órganos y mecanismos fisiológicos, provocando falla renal, disfunción cardíaca ${ }^{1}$, injuria hepática ${ }^{2}$, alteraciones de la coagulación ${ }^{3}$ y la inmunidad ${ }^{4}$.

Se ha demostrado también la aparición de un síndrome de respuesta inflamatoria sistémica, mediado por endotoxinas ${ }^{5}$ y el agravio de la mucosa intestinal con disfunción absortiva y traslocación bacteriana6.

Todas estas alteraciones fisiopatológicas son reversibles luego de restablecido el flujo bilio-enteral.

Por esta razón, inicialmente se interpretó que el drenaje biliar, precediendo la pancreatectomía, mejoraría el estado general del paciente disminuyendo la morbimortalidad de la cirugía.

Es así, que la colocación previa a la duodenopancreatectomía, de un drenaje biliar se convirtió, inicialmente, en una práctica corriente.

En una revisión americana, a 2573 pacientes se le realizó una duodenopancreatectomía con intención curativa, en $52,7 \%$ de los casos se colocó un drenaje biliar preoperatorio. ${ }^{7}$

En una encuesta de la Asociación Francesa de Cirugía del 2010, (sobre un total de 1399 pacientes sometidos a pancreatectomía cefálica o total), se colocó un drenaje biliar preoperatorio en $33 \%$ de los casos. ${ }^{8}$

Sin embargo, el beneficio teórico de la colocación de un drenaje preoperatorio, no ha podido ser comprobado en la práctica.

Ya en 1982 Hatfield, no encuentra beneficios en la morbimortalidad operatoria, con la colocación de drenaje biliar preoperatorio, pero si una significativa morbilidad vinculada al drenaje biliar (estudio prospectivo randomizado en el que se colocaba drenaje transparietohepático). ${ }^{9}$

En 2002 Sewnath, ${ }^{10}$ publica un meta-análisis evaluando la eficacia del drenaje preoperatorio (transparietohepático (TPH) y/o endoscópico) vs cirugía de inicio, se incluían 5 estudios randomizados y 18 estudios de cohortes, comprendidos en el lapso de 1966 a 2001.

La mortalidad fue similar en los 2 grupos, $16 \%$ drenaje biliar preoperatorio vs $14 \%$ cirugía de inicio.

Pero la morbilidad fue significativamente mayor cuando se realizó drenaje biliar (57\% vs 42\%) y la estadía hospitalaria fue también significativamente mayor en el grupo de pacientes con drenaje biliar primario (42 vs 24 días).

La tasa de mortalidad y de complicaciones, de los procedimientos de drenaje, fue elevada, $5 \%$ y $27 \%$ respectivamente. El estudio concluye que no es recomendable el uso de drenaje biliar preoperatorio de forma sistemática.

En 2010 van der Gaag, ${ }^{11}$ publica un estudio randomizado multicéntrico holandés (14 centros), que incluía pacientes con tumores cefalopancreáticos potencialmente resecables. Se randomizaron pacientes a los que se le realizó colangiopancreatografía endosópica retrograda (CPER) con colocación de stent plástico vs cirugía de inicio.

Fueron incluidos 196 pacientes, la diferencia en cuanto a la morbilidad global no fue estadísticamente significativa, $37 \%$ en grupo de cirugía vs $47 \%$ en grupo de CPER, la mortalidad fue similar $4 \%$ vs $9 \%$.

Pero las complicaciones graves fueron significativamente mayores en el grupo de CPER 74\% vs 39\%, así como la tasa de reingreso con el drenaje biliar primario.

El estudio concluyó, que debido a la mayor incidencia de complicaciones graves, no era recomendable el uso de drenaje biliar primario de forma rutinaria

Un estudio de seguimiento de este mismo grupo ${ }^{12}$, encuentra que el drenaje preoperatorio genera un retraso significativo en la cirugía (1 vs 5 semanas), pero no determina diferencias significativas en la sobrevida de los pacientes (12,2 vs 12,7 meses) 
Más recientemente, Qiu en 2011, realiza un meta-análisis ${ }^{13}$ de 14 estudios retrospectivos, que comparaban el efecto del drenaje biliar preoperatorio sobre la morbi-mortalidad, en pacientes con ictericia obstructiva de causa maligna (1826 pacientes en total).

El estudio no discrimina en la selección la topografía de la obstrucción, e incluye drenaje transparietohepático y endoscópico.

Este, no encuentra diferencias significativas en mortalidad, ni en la tasa de fuga biliar, ni pancreática, retraso de la evacuación gástrica o absceso intrabdominal. Pero encuentra diferencia significativa en la tasa de infección parietal.

El estudio concluye que el drenaje biliar preoperatorio, no disminuye la mortalidad ni la morbilidad postoperatoria, y por lo tanto no debe ser utilizado de forma rutinaria.

Fang $^{14}$ realiza un meta-análisis para Cochrane en 2012, en el que incluye seis estudios randomizados controlados, comparando morbi-mortalidad del drenaje biliar preoperatorio vs cirugía.

El estudio incluye tanto patología benigna como maligna y se realizan drenajes por vía transparietohepática (TPH) y por CPER.

No se encuentran diferencias en la mortalidad, pero la morbildad del drenaje biliar preoperatorio es significativamente mayor.

No hay diferencias en la estadía hospitalaria.

El estudio concluye, que no hay evidencia para refutar o apoyar el drenaje biliar preoperatorio, pero este puede aumentar la tasa de efectos adversos y por lo tanto no es recomendable su uso rutinario.

Finalmente Sun ${ }^{15}$, en un meta-análisis publicado en 2014, analiza 14 trabajos con un total de 2248 pacientes.

Los trabajos incluidos comparan morbimortalidad del drenaje preoperatorio mediante colocación de stent vs no drenaje, en pacientes sometidos a pancreatectomía cefálica. La gran mayoría de las causas fueron tumores periampulares, pero también incluyeron patologías benignas que requirieron duodenopancreatectomía.

No encuentra diferencias significativas entre ambos grupos, en mortalidad, morbilidad global, ni en la tasa de infecciones cutáneas, abscesos intra-abdominales, fístula pancreática, fuga biliar o retardo en vaciamiento gástrico.

Sin embrago, el estudio encuentra que cuanto la duración del drenaje preoperatorio fue menor a 4 semanas, la morbilidad fue significativamente mayor en el grupo de pacientes drenados (7 vs $23 \%$ ), mientras que cuando el drenaje se realizó por 4 o más semanas, previas a la cirugía, la morbilidad fue similar.

Por lo tanto no tenemos al día de hoy evidencia que avale la necesidad de realizar drenaje biliar preoperatorio de forma rutinaria.

\section{¿Existen indicaciones para realizar drenaje biliar preoperatorio?}

La Sociedad Europea de Endoscopía ${ }^{16}$, recomienda en sus guías terapéuticas, la colocación de drenaje biliar preoperatorio, en pacientes con tumores potencialmente resecables, cuando:

- Existe una urgencia (colangitis)

- Prurito intenso

- En pacientes potencialmente resecables, que presentan desnutrición severa o patologías médicas reversibles que retrasan la cirugía.

- En pacientes candidatos a neoadyuvancia (recomendaciones grado A).

Similares recomendaciones realizan un trabajo monográfico de la Asociación Francesa de Cirugía y revisiones recientes, ${ }^{17,18}$ quienes plantean como otra indicación, niveles muy elevados de bilirrubinemia.

\section{¿Cuál es el nivel de bilirrubinemia por encima del cual está indicado colocar un drenaje biliar preoperatorio?}

Van der Gaag' ${ }^{11}$, fija como criterio de exclusión en su trabajo, cifras de bilirrubinas mayores a $14.6 \mathrm{mg} / \mathrm{dl}$.

Recientemente Sauvanet ${ }^{18}$, presenta un estudio multicéntrico retrospectivo francés, en el que se revisan 1200 pacientes sometidos a pancreatectomía cefálica o total por adenocarcinoma de páncreas. (Se excluían los pacientes a los que se había colocado stent por colangitis o necesidad de neoadyuvancia).

El estudio encuentra que cifras de bilirrubinemias mayores a $14.6 \mathrm{mg} / \mathrm{dl}$ aumentan el riesgo de transfusiones intraoperatorias.

Cifras mayores a $17.5 \mathrm{mg} / \mathrm{dl}$ aumentan de forma significativa la tasa de complicaciones severas.

Cuando analiza el efecto sobre la sobrevida, encuentra que cifras por encima de $17.5 \mathrm{mg} / \mathrm{dl}$ la afectan negativamente a largo plazo. 
La colocación de stent biliar no afecta la morbilidad ni la sobrevida.

Por lo tanto, concluye que la colocación de un stent biliar previo a pancreatectomía por adenocarcinoma pancreático, está indicado en casos de ictericia severa.

\section{¿Cual es el método más apropiado de drenaje?}

La respuesta a esta pregunta es materia de debate.

Las opciones con que contamos incluyen: el drenaje transparietohepático, y las opciones endoscópicas (drenaje naso-biliar, y los stents, plásticos o metálicos auto-expandibles)

No existen estudios randomizados que comparen estos métodos de drenaje en pacientes con tumores de páncreas potencialmente resecables.

El uso del drenaje biliar preoperatorio, ha ido en aumento en las 2 últimas décadas. pero esto ha sido a expensas de un mayor uso de la vía endoscópica. ${ }^{7,19}$

El uso del drenaje por vía transparietohepática se ha mantenido estable (12 - 17\% en la revisión de Jenkins). ${ }^{7}$

Speer $^{20}$, en un estudio randomizado que comparaba colocación de stent endoscópico vs transparietohepático, en pacientes irresecables, encontró que el abordaje endoscópico era significativamente mejor en la resolución de la ictericia, con menor morbimortalidad, fundamentalmente en pacientes con obstrucción distal.

Las morbimortalidad esta asociada a hemorragia, bilirragia e infección cutánea.

Trabajos recientes encuentran que el abordaje transparietohepático tiene mejores resultados en cuanto a la velocidad de resolución de la ictericia y mejor relación costo beneficio. ${ }^{21,22}$

Sin embargo, se ha reportado que el abordaje transparietal, se asocia con peor pronóstico a largo plazo, comparado con el abordaje endoscópico. ${ }^{19,23}$

Esto está asociado a una mayor tasa de implantes peritoneales ${ }^{19} \mathrm{y}$ hepáticos ${ }^{23}$, por siembras en el trayecto del catéter.

Por lo tanto, el uso del drenaje transparietohepático, en el preoperatorio de los tumores de páncreas potencialmente resecables, estaría indicado ante la falla de los abordajes endoscópicos. ${ }^{24}$

Prácticamente no existe mención en la literatura actual, sobre el uso del drenaje nasobiliar en este grupo de pacientes Solo un trabajo compara drenaje nasobiliar vs stent endoscópico y no encuentra diferencias significativas en cuanto a complicaciones y permeabilidad del drenaje. ${ }^{25}$

\section{¿Stent plástico o autoexpandible?}

Múltiples estudios randomizados y metaanálisis comparan stents plásticos vs autoexpandibles, en la paliación por tumores pancreáticos irresecables. ${ }^{26-29}$

Todos ellos muestran que el éxito en la colocación del stent y la tasa complicaciones son similares, pero la permeabilidad a largo plazo es superior en los stents metálicos autoexpandibles.

Existen múltiples estudios retrospectivos comparativos, que demuestran la eficacia del stent autoexpandible, en cuanto a mayor duración de la permeabilidad, con la consiguiente menor tasa de episodios de colangitis y recambio de stent. ${ }^{30-33}$

Adams ${ }^{33}$, encuentra una tasa de complicaciones 7 veces mayor, y un aumento por tres de la internación en pacientes con stent plástico. El tiempo transcurrido entre la colocación del stent y la aparición de la complicación fue 5 veces más largo en el grupo de stent metálico (200 vs 44 días)

Los estudios muestran que la tasa de obstrucción con repetición de la CPER, cuando se colocó stent plástico fue de 39 a 55\% (seguimiento 56 a 117 días), contra una tasa menor a 7\% en el stent metálico. (seguimiento de 104 a 120 días). . $^{31,33-39}$

Esto cobra jerarquía en el grupo de pacientes a los que se les va a realizar neoadyuvancia, ya que se debe asegurar una permeabilidad prolongada del stent, asegurando un correcto drenaje biliar, en pacientes que recibirán drogas hepatotóxicas, evitando la aparición de colangitis, en un paciente que estará inmunodeprimido.

La duración promedio de la neoadyuvancia y el tiempo de recuperación previo a la cirugía es de 5-6 meses. ${ }^{36}$ En esta situación el stent autoexpandible, ha mostrado su mejor eficacia. ${ }^{33,34,37}$ 
La Sociedad Europea de Endoscopía, recomienda en sus guías, la colocación de stents autoexpandibles en pacientes que se van a ser sometidos a neoadyuvancia (Recomendación grado C)

Cuando el drenaje es necesario por corto tiempo, no hay diferencias en la morbimortalidad entre stens plásticos y metálicos a 30 días, por lo que el uso de stents plásticos es recomendado. (Recomendación grado A) ${ }^{16}$. Dentro de ellas se prefiere los de polietileno por sobre las de teflón. ${ }^{16}$

Inicialmente se planteó que los stent metálicos autoexpandibles (fundamentalmente los stents no forrados, no removibles) podían generar alteraciones inflamatorias en la pared de la vía biliar, interfiriendo en la disección y afectando el nivel de sección proximal de la vía biliar, complicando la pancreatectomía. ${ }^{30}$

Sin embargo, la aparición de stents más cortos (de 4-6 cms), que quedan incluidos en la pieza y de stents forrados, que pueden ser retirados en la cirugía, han permitido minimizar estos riesgos.

Varios trabajos no encuentran complicaciones intra ni postoperatorias vinculadas a la colocación previa del stents metálicos..$^{30-32,35-37}$

Solo un trabajo reporta mayor tasa de infecciones cutáneas en el grupo de stent metálico y un mayor tiempo operatorio. ${ }^{38}$

El mismo estudio, encuentra que la presencia previa de stent metálico, no afecta la posibilidad de resecciones R038.

El otro punto controversial es el mayor costo de los stent metálicos.

Existen múltiples estudios que realizan análisis de costo-beneficio, entre los diferentes tipos de stent, fundamentalmente en pacientes a los que se les realiza tratamiento paliativo de la ictericia.

El costo promedio de un stent metálico es prácticamente 20 veces mayor que el de un stent plástico. ${ }^{39,40}$ Pero se debe analizar el costo global, valorando los gastos que se generan en días de internación, y en repetición de endoscopías, vinculados a la menor duración de la permeabilidad del stents plástico.

Tanto el trabajo de $\mathrm{Yeoh}^{41}$, como el metaanálisis de $\mathrm{Moss}^{42}$, encuentran que en la paliación mayor a 4 meses, los costos del stent metálico son menores o similares (dependiendo del valor de la CPER adicional).

Si trasladamos este análisis de costo-beneficio al grupo de pacientes a los que se les realiza drenaje preoperatorio, parece lógico pensar que en los drenajes de corta duración (por ejemplo por colangitis), la relación se vuelca hacia los stent de plástico.

Distinta es la situación de los pacientes en los que la indicación es por neoadyuvancia, ya que en ellos el tiempo de drenaje será de 5-6 meses.

En un reciente estudio prospectivo randomizado43, los autores analizan la eficacia y la relación costo beneficio del stent plástico y de las prótesis autoexpandibles, cubiertas y no cubiertas, en pacientes potencialmente resecables, a los que se les realizó neoadyuvancia. Este estudio no encuentra diferencias en los costos del tratamiento, con cualquiera de los tres tipos de stent.

El stent autoexpandible forrado mostró: mayor duración de permeabilidad y menos días de retraso en el tratamiento neoadyuvante.

\section{En pacientes que recibirán neoadyuvancia, eel stent autoexpandible, debe ser cubierto o no cubierto?}

Existen múltiples trabajos enfocados en comparar ambos tipos de stent, fundamentalmente en pacientes que recibirán neoadyuvancia o paliación de la enfermedad.

La causa de obstrucción de la prótesis no cubierta, es el crecimiento tumoral a través de la pared del stent, el forrado no sufre esta complicación pero tiene una tasa mucho más alta de migración, y puede ocluirse por la formación de una lámina de barro en su pared, (similar a lo ocurre en los stent plásticos). A su vez, ambos pueden ocluirse por crecimiento tumoral en los extremos del dispositivo.

Se han desarrollado prótesis parcialmente cubiertas que tienen resultados intermedios. ${ }^{161}$

La revisión de la bibliografía muestra resultados ambiguos.

Los ensayos randomizados controlados tienen resultados contradictorios, en algunos se encuentra mayor permeabilidad en stent no cubierto ${ }^{44}$, en otros la mayor duración se produce con stent cubierto ${ }^{45,46}$, y en otros, resultados similares. ${ }^{47}$ Los metaanálisis recientes, también muestran resultados disímiles, mientras unos no encuentran mayores beneficios del stent cubierto y no lo recomiendan por la tasa mayor de migración ${ }^{48}$, otros determinan la superioridad del stent cubierto por su mayor permeabilidad. ${ }^{49}$ 
Finalmente otro metaanálisis mas reciente, no encuentra diferencias entre ambos tipos de stent, en cuanto a duración de la permeabilidad y tasa de disfunción. Si el beneficio de poder remover el stent forrado, en el caso de oclusión. ${ }^{50}$

Por lo tanto al momento actual, no se ha podido definir qué tipo de stent autoexpandible es el más recomendable.

\section{¿Cuál debe ser la duración óptima del drenaje biliar preoperatorio?}

Una vez indicado el drenaje biliar preoperatorio, se debe discutir cual debe ser su duración.

Se excluyen de esta discusión los pacientes que se realizaran neoadyuvancia, en los que la cirugía se realiza luego de completado el tratamiento oncológico.

La adecuada recuperación de la función hepática y de los efectos sobre otros órganos que produce la hiperbilirrubinemia, depende de los niveles de bilirrubina alcanzados y del tipo de drenaje utilizado.

Estudios experimentales muestran que el tiempo necesario para que el hígado recupere su normal funcionamiento, es de 4 a 6 semanas. ${ }^{51}$

¿Es este el tiempo que debemos esperar para operar al paciente? Es sabido que a mayor duración del drenaje, aumentan los riesgos de complicaciones vinculadas al mismo, como ser la inflamación local de la vía biliar y el riesgo de colonización bacteriana. ${ }^{24}$

El estudio randomizado de Van der Gaag ${ }^{11}$, fija la duración del drenaje preoperatorio entre 4 a 6 semanas, basado en la evidencia experimental

Un reciente metaanálisis ${ }^{15}$ revisa la duración reportada de los drenajes preoperatorios. En 7 de 10 estudios se realizaron drenajes por más de 4 semanas y el tiempo máximo fue 6 semanas.

El estudio compara la morbimortalidad vinculada a la duración del drenaje con respecto al grupo de pacientes no drenados y encuentra que cuando el drenaje fue menor a 4 semanas, la morbilidad fue significativamente mayor.

Cuando la duración del drenaje fue mayor a 4 semanas, la morbilidad fue similar al grupo de pacientes no drenados.

Concluye entonces, que de realizarse drenaje, éste debe mantenerse por más de 4 semanas

En contra de estos reportes, un estudio reciente comparativo no randomizado ${ }^{52}$, divide a los pacientes en 2 grupos según la duración del drenaje (mayor y menor a 2 semanas).

Encuentra que si bien la morbimortalidad de la cirugía fue similar, la morbilidad fue menor en los pacientes drenando por menos de 2 semanas.

Concluye que el drenaje por menos de 2 semanas es más apropiado.

Por lo tanto, cuál debe ser la duración del drenaje, es motivo de controversia, y no ha podido ser definida, la mayoría de los estudios realizan drenajes entre 4 y 6 semanas.

\section{Drenaje biliar e infección}

La instrumentación de la vía biliar con la posterior colocación de stents, produce contaminación bacteriana de la misma.

Varios trabajos en los que se realizan bilicultivos intraoperatorios, muestran una tasa de bilicultivos positivos significativamente mayor, en los pacientes a los que se le drenó la vía biliar en el preoperatorio, en comparación a los no drenados, $(58-89 \%$ vs $14-26 \%) .53-57$

Un porcentaje elevado de esos bilicultivos muestran flora polimicrobiana $(57-71 \%)^{53,55}$.

Los gérmenes más frecuentemente aislados, fueron: enterococo y bacilos gram negativos (Klebsiella, Enterobacter y Escherichia coli) $)^{53,54,57}$.

Cuando los pacientes presentaron complicaciones infecciosas (absceso intra-abdominal, infección cutánea), se aislaron los mismos gérmenes que se habían detectado el bilicultivo, en el 71 al 89\% de los casos ${ }^{53-55}$.

Un reciente trabajo japonés ${ }^{56}$, encuentra que cuando hay bilicultivos positivos, existen diferencias significativas en las resistencias a los antibióticos, según se haya realizado o no drenaje preoperatorio.

Los gérmenes aislados en bilicultivos de pacientes que tuvieron drenaje preoperatorio, tienen mayor resistencia a los antibióticos usados rutinariamente como profilácticos de la cirugía (cefazolina), con sensibilidad del $91 \%$ en pacientes no drenados y $45 \%$ en los drenados. 
Esto se atribuye al uso de antibióticos profilácticos durante la colocación del stent, y a los sucesivos episodios colangitis, que seleccionan poblaciones resistentes.

Cortes $^{57}$ realiza un estudio en que analiza la morbilidad de la duodenopancreatectomía, dividiendo a los pacientes en 2 grupos (bilicultivo positivo y negativo), encontrando que la morbilidad global y las complicaciones infecciosas fueron significativamente mayores en el grupo de pacientes con bilicultivos positivos.

Estos hallazgos están en sintonía, con otros estudios que encuentran vinculación entre la contaminación biliar, por el drenaje preoperatorio y la mayor tasa de complicaciones infecciosas postoperatorias ${ }^{53-55}$.

Sin embargo Sudo ${ }^{56}$, no encuentra diferencias en la morbilidad global, ni en la tasa de complicaciones infecciosas postoperatorias. La explicación planteada, es el uso de diferentes planes antibióticos, (Cefazolina en el grupo de pacientes no drenados y Cefoperazona en el grupo de pacientes drenados). Lo que está basado en el reconocimiento de las diferentes sensibilidades a los antibióticos de cada grupo.

Por lo tanto, se debe reconocer al grupo de pacientes que recibieron drenaje preoperatorio, como un grupo de riesgo para las complicaciones infecciosas y deben diseñarse planes antibióticos específicos ${ }^{8,56,57}$.

\section{Conclusiones}

- El uso de drenaje biliar preoperatorio en el cáncer cefalopancreático, no está indicado de forma rutinaria

- Existen indicaciones específicas: colangitis, co-morbilidades que retrasen la cirugía, cifras elevadas de bilirrubina, e indicación de neoadyuvancia

- La vía de elección es la endoscópica, el abordaje transparietohepático, solo está indicado ante su falla.

- Cuando la duración del drenaje sea corta, se recomienda el uso de stents plásticos.

- La duración del drenaje es controversial, se tiende a aceptar que debe ser de entre 4 a 6 semanas. (se excluyen los pacientes que recibirán neoadyuvancia).

- Cuando se realiza drenaje por indicación de neoadyuvancia, deben colocarse stents autoexpandibles, el tipo de drenaje (forrado, no forrado o parcialmente forrado), no está definido.

- La realización del drenaje aumenta la infección biliar y el riesgo de complicaciones infecciosas, esto debe ser tenido en cuenta en el manejo antibiótico peri-operatorio 


\section{BIBLIOGRAFIA.}

1. Wadei HM, Mai ML, Ahsan N, Gonwa TA. Hepatorenal sybdrome: pathopysioloy and management. Clin J Am Soc Nephrol. 2006 Sep;1(5):1066-1079.

2. Pauli-Magnus C, Meier PJ. Hepatocellular transporters and cholestasis. J Clin Gastroenterol. 2005;39(4): 103110.

3. Papadopoulos V, Filippou D, Manolis E, Mimidis K. Haemostasis impairment in patients with obstructive jau dice. JGastrointestin Liver Dis 2007; 16(2): 177-186.

4. Nehéz L, Andersson R. Compromise of immune function in obstructive jaundice. Eur J Surg. 2002;168(6):315328.

5. Padillo FJ, Cytokines and acute-phase response markers derangements in patients with obstructive jaundice. Hepatogastroenterology 2001; 48(38):378-381.

6. Assimakopoulos SF, Vagianos CE, Charonis A, et al. Intestinal failure in obstructive jaundice. World J Gastroenterol. 2005;11(24):3806-3807.

7. Jinkins LJ, Parmar AD, Han Y,et al. Current trends in preoperative biliary stenting in patients with pancreatic cancer. Surgery 2013; 154(2): 179-189.

8. Regimbeau JM, Adenocarcinome de la têté du pancréas et ictère obstructif place du drainage biliaire preoperatoire. En Dellpero JR, Paye F, Bachellier P. Cancer du Pancréas. Monographies de L'Assciacion Francaise de Chirurgie. Paris: Anette;2010: p 75-79.

9. Hatfield AR,Tobias R, Terblanche J, et al. Preoperative external biliary drainage in obstructive jaundice. A prospective controlled clinical trial. Lancet. 1982;2(8304); 896-899.

10. Sewnath ME,Karsten TM, Prins MH, et al. A meta-analysis on the efficacy of preoperative biliary drainage for tumors causing obstructive jaundice. Ann Surg. 2002;236(1):17-27.

11. Van der Gaag, NA, Rauws EA, van Eijck CH, et al. Preoperative biliary drainage for cancer of the head of the pancreas. N Engl J Med. 2010;362(2):129-137.

12. Eshuis WJ,van der Gaag NA, Rauws EA. Therapeutic delay and survival after surgery for cancer of the pancreatic head with or without preoperative biliary drainage. Ann Surg 2010; 252(5): 840-849.

13. Qiu YD, Bai JL, Xu FG, Ding YT. Effect of preoperative biliary drainage on malignant obstructive jaundice: a meta-analysis.World J Gastroenterol 2011; 17(3):391-396

14. Fang Y, Gurusamy KS, Wang Q. Pre-operative biliary drainage for obstructive jaundice. Cochrane Database Syst Rev 2012; (9): CD005444. doi:10.1002/14651858.CD005444.pub3

15. Sun C, Yang G, Li Z, Tzec CM. A meta-analysis of the effect of preoperative biliary stenting on patients with obstructive jaundice. Medicine (Baltimore) 2014; 93(26): e189. doi: 10.1097/MD.0000000000000189.

16. Dumonceau J,Tringali A, Blero D,et al."Biliary stenting: indications, choice of stents and results: European Society of Gastrointestinal Endoscopy (ESGE) clinical guideline,"Endoscopy. 2012; 44(3); 277-298.

17. Sugiyama H, Tsuyuguchi T, Sakai Y, et al. Current status of preoperative drainage for distal biliary obstruction. World J Hepatol. 2015;7(18):2171-2176.

18. Sauvanet A, Boxer M, Paye F, et al. Severe Jaundice Increases Early Severe Morbidity and Decreases Long-Term Survival after Pancreaticoduodenectomy for Pancreatic Adenocarcinoma. J Am Coll Surg. 2015;221(2):380389.

19. Uemura K, Murakami Y, Satoi S, et al. Impact of Preoperative Biliary Drainage on Long-Term Survival in Resected Pancreatic Ductal Adenocarcinoma: A Multicenter Observational Study. Ann Surg Oncol. 2015;22(3):1238-1246.

20. Speer AG, Cotton PB, Russell RC, et al. Randomised trial of endoscopic versus percutaneous stent insertion in malignant obstructive jaundice. Lancet 1987;2(8550):57-62.

21. Park SY, Park CH, CHO SB, el al. What is appropriate procedure for preoperative biliary drainage in patients with obstructive jaundice awaiting pancreaticoduodenectomy? Surg Laparosc Endosc Percutan Tech. 2011;21(5):344-348.

22. Hong SK, Jnag JY, Hang MJ, et al. Comparison of clinical outcome and cost-effectiveness after various preoperative biliary drainage methods in periampullary cancer with obstructive jaundice. J Korean Med Sci. 2012;27(4):356-362

23. Strom TJ, Klapman JB, springiest GM, et al. Comparative long-term outcomes of upfront resected pancreatic cancer after preoperative biliary drainage. Surg Endosc. 2015;29(11):3273-3281.

24. Lai EC, Lay SH, Lay WY. The current status of preoperative biliary drainage for patients who receive pancreaticoduodenectomy for periampullary carcinoma: a comprehensive review.Surgeon. 2014;12(5):290-296

25. Sugiyama H, Tsuyuguchi T, Sakai Y, et al. Preoperative drainage for distal biliary obstruction:endoscopic stenting or nasobiliary drainage? Hepatogastroenterology 2013; 60(122): 231-234.

26. Moss AC, Morris E, Mac Mathuna P. Palliative biliary stents for obstructing pancreatic carcinoma.Cochrane Database Syst Rev. 2006 Apr 19;(2):CD004200. 
27. Piñol V, Castells A, Bordas JM, et al. Percutaneous self-expanding metal stents versus endoscopic polyethylene endoprostheses for treating malignant biliary obstruction: randomized clinical trial. Radiology. 2002;225(1):27-34

28. Kaassis M, Boyer J, Dumas R, et al. Plastic or metal stents for malignant stricture of the common bile duct? Results of a randomized prospective study. Gastrointest Endosc. 2003;57(2):178-182.

29. Soderlund C, Linder S. Covered metal versus plastic stents for malignant common bile duct stenosis: a prospective, randomized, controlled trial. Gastrointest Endosc. 2006;63(7):986-995.

30. Wasan SM, Ross WA, Stearkel GA, Lee JH. Use of expandable metallic biliary stents in resectable pancreatic cancer. Am J Gastroenterol 2005;100(9):2056-2561.

31. Decker C, Christen JD, Phadnis MA, et al . Biliary metal stents are superior to plastic stents for preoperative biliary decompression in pancreatic cancer. Surg Endosc 2011;25(7):2364-2367.

32. Singal AK, Ross WA, Guturu P, et al. Self-expanding metal stents for biliary drainage in patients with resectable pancreatic cancer: single-center experience with 79 cases. Dig Dis Sci. 2011;56(12):3678-3684.

33. Adams MA, Anderson MA, Myles JD, et al. Self-expanding metal stents (SEMS) provide superior outcomes compared to plastic stents for pancreatic cancer patients undergoing neoadjuvant therapy. J Gastrointest Oncol 2012;3(4):309-313.

34. Boulay BR, Gardner TB, Gordon SR. Occlusion rate and complications of plastic biliary stent placement in patients undergoing neoadjuvant chemoradiotherapy for pancreaticcancer with malignant biliary obstruction.J Clin Gastroenterol 2010;44(6):452-455

35. Mullen JT, Lee JH, Gomez HF, et al. Pancreaticoduodenectomy after placement of endobiliary metal stents. J Gastrointest Surg. 2005;9(8):1094-1104

36. Tol JA, awn Hooft JE, Timmer R, et al. Metal or plastic stents for preoperative biliary drainage in resectable pancreatic cancer. Gut. 2015. doi: 10.1136/gutjnl-2014-308762.

37. Aadam AA, Evans DB, Khan A, Oh Y, Due K. Efficacy and safety of self-expandable metal stents for biliary decompression in patients receiving neoadjuvant therapy for pancreatic cancer: a prospective study. Gastrointest Endosc 2012;76(1):67-75.

38. Cavell LK, Allen PJ, Vinoya C, et al. Biliary self-expandable metal stents do not adversely affect pancreaticoduodenectomy. Am J gastroenterol. 2013;108(7):1168-1173.

39. Barkun AN, Adam V, Martel M, et al. Partially covered self-expandable metal stents versus polyethylene stents for malignant biliary obstruction: A cost-effectiveness analysis. Can J Gastroenterol Hepatol 2015;29(7):377383.

40. Moy BT, Brik JW. An Update to Hepatobiliary Stents. Journal of Clinical and Translational Hepatology. 2015;3(1)67-77.

41. Yeoh KG,Zimmerman MJ, Cunningham JT, Cotton PB. Comparative costs of metal versus plastic biliary stent strategies for malignant obstructive jaundice by decision analysis. Gastrointest Endosc 1999;49(4):466-471.

42. Moss AC, Morris E, Leyden J, Mac Mathuna P. Do the benefits of metal stents justify the costs? A systematic review and meta-analysis of trials comparing endoscopic stents for malignant biliary obstruction. Eur J Gastroenterol Hepatol. 2007 ;19(12):1119-1124.

43. Gardner TB, Spangler CC, Byanova KL, et al. Cost Effectiveness and Clinical Efficacy of Biliary Stents in Patients Undergoing Neoadjuvant Therapy for Pancreatic Adenocarcinoma in a Randomized Controlled Trial. Gastrointest Endosc. 2016;84(3):460-466.

44. Lee SJ, Kim MD, Lee MS, et al. Comparison of the efficacy of covered versus uncovered metallic stents in treating inoperable malignant common bile duct obstruction: a randomized trial. J Vasc Interv Radiol. 2014;25(12):1912-1920.

45. Isayama $\mathrm{H}$, Komatsu $\mathrm{Y}$, Tsujino $\mathrm{T}$, et al. A prospective randomised study of "covered" versus"uncovered" diamond stents for the management of distal malignant biliary obstruction. Gut. 2004;53(5):729-734.

46. Kitano M, Yamashita Y, Tanaka K, et al. Covered self-expandable metal stents with an anti-migration system improve patency duration without increased complications compared with uncovered stents for distal biliary obstructioncaused by pancreatic carcinoma: a randomized multicenter trial. Am J Gastroenterol. 2013;108(11):1713-1722.

47. Telford JJ, Carr-Locke DL, Baron TH, et al. A randomized trialcomparing uncovered and partially covered self-expandable metal stents in the palliation of distal malignant biliary obstruction. Gastrointestinal endoscopy. 2010; 72(5):907-194.

48. Almadi MA, Barkun AN, Martel M. No benefit of covered vs uncovered self-expandable metal stents in patients with malignant distal biliary obstruction: a meta-analysis. Clin Gastroenterol Hepatol. 2013;11(1):2737.

49. Saleem A, Laggett CL, Murad MH, Baron TH. .Meta-analysis of randomized trials comparing the patency of covered and uncovered self-expandable metal stents for palliation of distal malignant bile duct obstruction Gastrointest Endosc. 2011;74(2):321-327. 
50. Li J, Li T, Sun P, et al. Covered versus Uncovered Self- exandable Metal stents for Managing Malignant Distal BiliaryObstruction: A Meta-Analysis. PLoS One. 2016;11(2):e0149066. doi: 10.1371/journal.pone.0149066.

51. Koyama K, Takagi Y, Ito K, Dato T. Experimental and clinical studies on the effect of biliary drainage in obstructive jaundice. Am J Surg 1981;142(2):293-299.

52. Son JH, Kim J, Lee SH, et al. The optimal duration of preoperative biliary drainage for periampullary tumors that cause severe obstructive jaundice. Am J Surg 2013;206(1):40-46.

53. Povoski SP, Karpeh MS, Conion KC, et al. Preoperative biliary drainage: impact on intraoperative bile cultures and infectious morbidity and mortality after pancreaticoduodenectomy.J Gastrointest Surg 1999;3(5):496-505.

54. Limongelli P, Pal M, Bansi D, et al. Correlation between preoperative biliary drainage, bile duc contamination, and postoperative outcomes for pancreatic surgery. Surgery 2007;142(3):313-318.

55. Lermite E, Pessaux P, Teyssedou C, et al. Effect of preoperative endoscopic biliary drainage on infectious morbidity after pancreatoduodenectomy: a case-control study. Am J Surg. 2008;195(4):442-446.

56. Sudo T, Murakami Y, Uemura K, et al. Perioperative antibiotics covering bile contamination prevent abdominal infectious complications after pancreatoduodenectomy in patients with preoperative biliary drainage. World J Surg. 2014 ;38(11):2952-2959.

57. Cortes A, Sauvanet A, Bert F, et al. Effect of bile contamination on immediate outcomes after pancreaticoduodenectomy for tumor. J Am Coll Surg. 2006; 202/(1):93-99. 


\section{NEOADYUVANCIA}

Los avances en las técnicas quirúrgicas y en las terapias oncológicas, han determinado mejoras en la sobrevida de la mayoría de los cánceres en las últimas 3 décadas. El adenocarcinoma de páncreas escapa a esta situación y se estima que se convertirá en la segunda causa de muerte por cáncer para el año 2030.

¿Cuáles son las razones de estos malos resultados?. Se destacan, la ausencia de una clínica específica que permita un diagnóstico temprano, la presencia de una biología tumoral agresiva, la característica quimiorresistencia de estos tumores y la demandante técnica quirúrgica. ${ }^{1}$

Las mejoras en términos de sobrevida del adenocarcinoma de páncreas, se han visto luego de la inclusión de la terapia adyuvante, pero los resultados siguen siendo malos con sobrevidas medias entorno a los 20 meses.

Luego de una resección pretendidamente curativa, seguida de un tratamiento adyuvante (quimioterapia y radioterapia), el $75 \%$ presentará recaída local y el $50 \%$ metástasis a distancia. ${ }^{2}$

Es por ello, que se buscan alternativas terapéuticas que mejoren estos resultados y allí la neoadyuvancia aparece como una opción prometedora.

Al momento del diagnóstico el 10 al 20\% de los adenocarcinoma de páncreas son resecables, el 40 a $50 \%$ son metastásicos y el resto se trata de una enfermedad localmente avanzada.

Es de destacar, que aquellos considerados resecables de inicio, presentan en un 10 a $20 \%$ de los casos enfermedad metastásica al momento de la cirugía. ${ }^{3}$

El grupo de pacientes con enfermedad localmente avanzada, es el que presenta mayor interés en el campo de la neoadyuvancia. Puede dividirse en 2 subgrupos, aquellos considerados borderline y los irresecables no metastásicos. Las diferencias entre ambos se basa en el mayor o menor compromiso sobre vasos mesentéricos, pedículo hepático, tronco celíaco y compromiso aorto-cavo.

A su vez, los tumores borderline pueden ser considerados aquellos tumores resecables que se benefician de un tratamiento neoadyuvante. Siguiendo la sigla $\mathrm{ABC}$ son aquellos que:

- A: por su anatomía y sus relaciones vasculares tienen un riesgo aumentado de resecciones R1 y R2.

- B: Biológicos, aquellos con mayores probabilidades de metástasis ocultas por presentar un CA 19-9 > 200 U/ml.

- C:Co-morbilidades, aquellos que por su condición general o performance status, deben ser evaluados y selecionados para una cirugía.

Los primeros estudios, que incluían en conjunto a los pacientes con enfermedad localmente avanzada, mostraron que el 30\% se convertían a una enfermedad resecable luego de un tratamiento neoadyuvante, obteniendo sobrevidas comparables al grupo inicialmente resecable. 4 Actualmente, los estudios que se centran exclusivamente en los tumores borderline, documentan un índice de respuesta mayor, que pueden llegar a 60\%, con resecciones R0 del 90\%. Mientras que los considerados localmente avanzados o irresecables no metastásicos, presentan un índice de resección de $23 \%$ y resecciones R0, algo menores que el borderline de 70-77\%, con el uso de nuevos fármacos. ${ }^{5}$

El tratamiento de neoadyuvancia consigue, también, un descenso del estadío (downstaging) mediante su efecto sobre el tumor, las adenopatías, y el compromiso perineural y linfático.

Existen diversos grados de respuesta que dependen de la propia biología tumoral, de los fármacos utilizados y de la asociación o no de radioterapia.

Hay diferentes clasificaciones de respuesta tumoral a la neoadyuvancia, por ejemplo la diseñada por Evans, quien los divide en 3 grupos: Grado I con destrucción de menos de 10\% de células tumorales, grado IIa entre 10 a 50\% de destrucción celular tumoral, IIb de 51 a $90 \%$ y III con menos del 10\% de células tumorales viables. ${ }^{6}$ Existen otros scores como el elaborado por el MD Anderson y el Colegio Americano de Patólogos (CAP). ${ }^{7}$ (Tabla 1.)

El metaanálisis de Gillen documentó una respuesta completa en 3.9\% de los pacientes, una respuesta parcial de 29.1\%, una estabilidad lesionan de $43.9 \%$ y una progresión en un $20.3 \%$ de los pacientes. ${ }^{4}$

Con el uso de nuevos fármacos y combinaciones aumenta el número de respuestas completas, con cifras que van desde el 1.3 al $7 \% .^{8}$ 
Tabla 1: Scores de respuesta tumoral a la neoadyuvancia

\begin{tabular}{|l|c|}
\hline \multicolumn{1}{|c|}{ Grados de regresión tumoral } & Definición \\
\hline CAP & Sin tumor viable. (Respuesta completa) \\
\hline 0 & Marcada respuesta. (Escasas células neoclásicas residuales) \\
\hline 1 & Respuesta moderada. (Células residuales y fibrosis) \\
\hline 3 & Respuesta pobre. (Extenso tumor residual) \\
\hline MD. Anderson Cancer Center & Respuesta completa \\
\hline IV & $<10 \%$ de células tumorales viables \\
\hline III & Destrucción del $51-90 \%$ de células tumorales \\
\hline IIb & Destrucción de 10-50\% de células tumores \\
\hline IIa & $<10$ o ausencia de destrucción de células tumorales \\
\hline I & \\
\hline
\end{tabular}

Extraído de Chun et al. Histopathologic tumor response after induction chemotherapy and stereotactic body radiation therapy for borderline resectable pancreatic cancer. (6)

Las diferencias en el porcentaje de respuesta completa de los reportes analizados, puede vincularse a las distintas formas de procesamiento de las piezas de anatomía patológica.

Zhao en su estudio, mostró una respuesta completa en 2,5\% de pacientes, asociado a mejor sobrevida y tiempo libre de enfermedad, frente a los que presentaban respuestas menores. ${ }^{8}$

A pesar del incremento logrado en las respuestas con el uso de las nuevas terapias, la mitad de estos pacientes presentará una recaída hepática o peritoneal al año, surgiendo el concepto de que se trata, en realidad, de una enfermedad sistémica de inicio. ${ }^{9}$

La neoadyuvancia ha demostrado disminuir el número de adenopatías positivas frente aquellos operados de inicio (35\% vs $79 \%)$, así como también, un menor compromiso perineural y linfático. ${ }^{10}$

El uso de la neoadyuvancia no se asoció a mayor índice de complicaciones quirúrgicas, frente a los pacientes sometidos a cirugía de inicio. ${ }^{11}$ Un reciente metaanálisis, no muestra diferencias en la morbimortalidad de las resecciones pancreáticas (falla de sutura, sepsis, sangrados, fístulas, etc.) en los pacientes resecables o borderline. En cambio, los pacientes considerados irresecables, tienen un aumento de la morbimortalidad en las resecciones, pero en rangos considerados aceptables. ${ }^{12}$ Este conjunto de pacientes no tiene grupo control de comparación y se asocia a cirugías más complejas, con mayor frecuencia de resecciones vasculares, que explicarían estos niveles de morbimortalidad más elevados. A su vez, la terapia neoadyuvante se asoció a un menor índice de fístula pancreática, probablemente vinculada a la presencia de un páncreas mas duro y con menor secreción, luego de la terapéutica. ${ }^{13}$

El otro aspecto a considerar a la hora de elección de neoadyuvancia, es la toxicidad que produce.

La misma varía de acuerdo a los fármacos utilizados y sus combinaciones. La terapia en base a gemcitabina (con paclitaxel) ha demostrado ser una combinación bien tolerada en el tratamiento del cáncer de páncreas, con grados aceptables de mielosupresión y neuropatía periférica, por eso es más utilizada en pacientes de mayor edad. El uso de la gemcitabina como único fármaco, ha caído en desuso por los bajos resultados en este tipo de paciente.

En cuanto al FOLFIRINOX, sus buenos resultados documentados, deben ser balanceados con la alta toxicidad que produce. Esta combinación presenta altos grados de toxicidad tanto hematológicos como no hematológicos, neutropenia $45 \%$, neutropenia febril $5.4 \%$, trombocitopenia $9.1 \%$ y diarrea $12.1 \% .^{14}$

Cabe aclarar que estos resultados son extrapolaciones de trabajos con pacientes en estadío IV, y que estos tratamientos neoadyuvantes son utilizados en pacientes más jóvenes y con un buen performance status.

Por lo tanto, la realización de la neoadyuvancia parece ser un tratamiento seguro en los pacientes con buen performance status y no implicaría un aumento del riesgo quirúrgico.

El conocimiento de la respuesta a la neoadyuvancia resulta esencial para determinar la estrategia terapéutica, sobre todo en tumores localmente avanzados. Para los pacientes con enfermedad resecable, esta valoración puede ser difícil en ausencia de enfermedad medible.

Siguiendo al Colegio Médico de Wisconsin los criterios para evaluar la respuesta son clínicos (desaparición del dolor, y el status performance), tomográficos y serológicos (CA 19-9)..$^{15}$

La imagenología convencional ha sido ineficaz en determinar la respuesta a los tratamientos neoadyuvantes en el adenocarcinoma de páncreas. En el análisis tomográfico se toma en cuenta el tamaño y volumen tumoral, y su estrecha 
relación con los vasos sanguíneos. No obstante, en pacientes que se ha logrado resecciones R0 con buenas respuestas histológicas, menos del $2 \%$ presentaron cambios imagenológicos luego de la neoadyuvancia. ${ }^{16}$

Incluso con los tomógrafos multicorte y la aplicación de los criterios RECIST, no se han logrado resultados para valorar la respuesta a la neoadyuvancia.

La razón de esta dificultad radica en las características morfológicas del adenocarcinoma de páncreas, que esta rodeado de un estroma fibroso que no desaparece con la neoadyuvancia.

En aquellos casos que presentan una disminución del tamaño tumoral, a pesar de no mostrar cambios en sus relaciones vasculares, se logran índices de resecciones R0 mayores.

Por lo tanto, la tomografía no ha sido eficaz en valorar la respuesta a la neoadyuvancia, su dificultad radica en la incapacidad de diferenciar tumor viable, fibrosis y necrosis. ${ }^{17}$

La resonancia, si bien es útil por su mayor precisión en la detección de metástasis hepáticas, tampoco ha aportado buenos resultados para valorar las respuestas producidas por la neoadyuvancia.

Los regímenes en base a FOLFIRINOX han despertado interés en cuanto a la respuesta imagenológica que producirían, dado los buenos resultados patológicos documentados.

Recientemente un estudio del Memorial Sloan Kettering Cancer Center de Nueva York, vio que los pacientes sometidos a esta terapia, con cambios imagenológicos mayores al 30\%, se asociaban a altos indices de resección y R0. ${ }^{18}$

Igualmente los resultados en este sentido han sido contradictorios y otros estudios no evidenciaron cambios imagenológicos, que hicieran suponer los hallazgos quirúrgicos encontrados. ${ }^{19}$ Los estudios de imagen infravaloran los efectos de la neoadyuvancia sobre el tumor pancreático.

E1 PET surge como una alternativa alentadora para evaluar la respuesta a la neoadyuvancia. Se ha demostrado que el descenso del SUV se asoció a una respuesta patológica. Choi mostró que un descenso del SUV mayor a 50\% se asoció a un $100 \%$ de resecabilidad..$^{20}$

Además las respuestas documentadas por el PET son mas precoces en el tiempo, que las visualizadas por la tomografía. ${ }^{21}$

Por lo tanto, la utilización de las imágenes tomográficas de "restaging", no debe contraindicar una cirugía exploratoria, salvo que evidencien una progresión de la enfermedad que contraindique la resección y cambie la estrategia quirúrgica.

Dentro de los criterios serológicos se han utilizado las variaciones del CA 19-9. Sus valores pre-tratamiento bajos, han demostrado ser un marcador pronóstico útil en los

pacientes con adenocarcinoma de páncreas, en todas las etapas de la enfermedad. En tanto, sus variaciones post-tratamiento se vincularon a la respuesta.

En el marco de la neoadyuvancia, los valores iniciales bajos de CA 19-9 pretratamiento, se asociaron a una mayor tasa de resección y mejor sobrevida. Igualmente, este hecho no significa que aquellos que presentan elevados niveles de CA 19-9, no puedan completar el tratamiento y obtener buenos resultados quirúrgicos.

Con respecto a la valoración de la respuesta al tratamiento sucede algo similar. Aquellos que presentan buena respuesta tienen más posibilidades de resección y mejor sobrevida, pero no implica que aquellos que no presentaron cambios o incrementen el valor de CA 19-9, no puedan ser sometidos con éxito a una cirugía. ${ }^{22}$

$\mathrm{Al}$ igual que ocurre con la imagenología, las variaciones del CA 19-9 y los cambios histológicos tienen mayor concordancia en los pacientes con cáncer de páncreas localmente avanzados que con los tumores resecables.

El estudio de Boone evidenció que las disminuciones mayores del $90 \%$ se asociaron a un mayor número de respuestas completas (29\%) y un descenso del 50\% con una aumento de la sobrevida en este tipo de pacientes. ${ }^{23}$

Por otro lado, casi un $15 \%$ presenta incremento del CA 19-9 y de ellos, la mitad tiene enfermedad metastásica. ${ }^{24}$

Por lo tanto, frente a un paciente con aumento del CA 19-9, luego de un tratamiento de neoadyuvancia, debe profundizarse en los estudios imagenológicos (RNM o PET) así como la realización de una una laparospcopía estadificadora, a fin de evidenciar una progresión lesional metastásica no evidente. ${ }^{25}$

De lo analizado se concluye, que luego de culminada la neoadyuvancia, se justifica la exploración quirúrgica en aquellos pacientes potencialmente resecables, mientras no evidencien una progresión lesional ni un ascenso marcado del CA 19-9 y mantengan un buen performance status.

El uso de la quimioterapia (asociada o no a radioterapia) neoadyuvante en el adenocarcinoma de páncreas, se basa en algunos entonces en preceptos racionales. 
- Entender la enfermedad como sistemática de inicio, y de esta forma buscar el tratamiento precoz de las micrometástasis.

- Se ha documentado una mejor adhesión a los tratamientos neoadyuvantes, alrededor del $90 \%$ completan la primera etapa del tratamiento, que es superior al $60 \%$ de los que cumplen los tratamientos adyuvantes. ${ }^{26}$

- Obtener una disminución del tamaño tumoral y aumentar el número de resecciones R0, así como una disminución de las adenopatías positivas y de los implantes durante la cirugía. ${ }^{27}$

- Conocer el potencial evolutivo de la enfermedad, un 20-30\% de pacientes progresan bajo el tratamiento, no siendo candidatos a cirugía. ${ }^{3}$

- La realización de quimiorradioterapia en regiones y tumores no abordados quirúrgicamente, logrando tratamientos más efectivos y con menor toxicidad. ${ }^{28}$

Dentro de las críticas al uso de la neoadyuvancia, se encuentra la posibilidad de progresión de la enfermedad local, perdiendo la oportunidad de resección.

Los estudios que analizaron esta "window of opportunity", no demostraron esta teoría, ya que menos del $2 \%$ presenta progresión exclusivamente local durante el tratamiento..$^{29}$

Otra de las críticas, es la necesidad de colocación de stent transtumorales en los pacientes ictéricos, para disminuir la hepatotoxicidad de los fármacos. Este procedimiento no exento de riesgos, incluye además, la posibilidad de colangitis y recambio de las prótesis durante la evolución del tratamiento.

Por ultimo, la realización de neoadyuvancia requiere diagnostico citológico o histológico pre-tratamiento, aumentando el riesgo de complicaciones.

Siguiendo estos preceptos racionales, analizaremos el uso de la neoadyuvancia en las diferentes etapas del adenocarcinoma de páncreas.

\section{PACIENTES CON ENFERMEDAD RESECABLE DE INICIO}

El fundamento en la realización de neoadyuvancia en pacientes con adenocarcinoma de páncreas resecable, se basa en el tratamiento de las micrometástasis, en obtener mayores resecciones R0 y en el downstaging.

El interés por el tratamiento de las micrometástasis se debe, como ya fue mencionado, al alto porcentaje de recaída metastásica luego de la resección curativa.

Hasta un 15\% de los pacientes desarrollan metástasis en el postoperatorio temprano, se postula que el stress quirúrgico asociado a la inmunosupresión y al aumento de los factores de crecimientos derivados de la cirugía, serian responsables del crecimiento de lesiones preexistentes ocultas. ${ }^{30}$

Otro aspecto importante en el uso de neoadyuvancia en los tumores resecables, radica en el alto porcentaje de resecciones R1 o con márgenes positivos. Si bien los estudios de Imagen permiten definir con bastante precisión qué tumores serán resecables, existen diferencias entre estos hallazgos y los quirúrgicos.

El análisis de Wolff documentó márgenes positivos entre el 37\% al 50\% de las piezas de resección estudiadas de tumores previamente resecables. ${ }^{30}$ Se plantea que la interpretación de las imágenes así como la experiencia del cirujano influyen es estos resultados.

Varios estudios han mostrado los beneficios de las terapias neoadyuvantes sobre estos parámetros mencionados. (Tabla 2).

No existen protocolos únicos de tratamiento en lo que respecta a los fármacos y asociaciones a utilizar, así como el uso o no de radioterapia.

El esquema estudiado por Evans, que consistía en la realización de Gemcitabina asociada a dosis fraccionadas de radioterapia de hasta $50 .{ }^{4} \mathrm{~Gy}$, mostró ser un tratamiento seguro, con baja toxicidad, $11 \%$ de resecciones R1 y sobrevidas medias de 30 meses. ${ }^{15}$ Varadhachary asoció Cisplatino y mostró resultados similares con resecciones R1 de 4\%. Christians $^{31}$ sobre 69 pacientes con enfermedad resecable, a los cuales se le realizó neoadyuvancia con cistpaltino/ gemcitabina más radioterapia, documentó 33\% de pacientes N1 y 97\% de resecciones R0.

Cuando se comparó grupo con neoadyuvancia vs grupo con cirugía, se evidenció una mejoría de la sobrevida en los primeros, sin significación estadística, pero con menor número de adenopatías positivas (downstaging). ${ }^{32}$

Hay un creciente interés en el estudio de la neoadyuvancia en este tipo de pacientes, con buenos resultados, pero con escaso número de reportes. Pero hasta el momento los metaanálisis (Gillen, Andriulli, Xu), no han mostrado beneficios en cuanto a sobrevida y tiempo libre de enfermedad. ${ }^{4,33}$ Cuestionando el real valor de las resecciones R0 y las adenopatías positivas, sobre la sobrevida de estos pacientes. 
Actualmente las guías NCCN, no recomiendan el uso de neoadyuvancia en los pacientes con tumores resecables de páncreas. ${ }^{34}$

En ausencia de evidencia, no estaría indicada de inicio esta modalidad terapéutica en los pacientes con tumores resecables. Pero podría plantearse en pacientes considerados de riesgo como los que presentan tumores mayores de $3 \mathrm{~cm}$, un CA 19-9 mayor a 1000 y la presencia de adenopatías imagenologicamente positivas. ${ }^{35}$

Faltan estudios con series mas grandes de pacientes para concluir sobre los beneficios de esta terapéutica, en este grupo de pacientes.

Actualmente las lineas de investigación fases II/III apuntan a valorar los resultados con planes de FOLFORINOX y Gemcitabina con Nab-paclitaxel (NEOANAX y NEOPAFOX), entre otras asociaciones.

Tabla 2: Estudios seleccionados de neoadyuvancia en adenocarcinoma de páncreas resecable.

\begin{tabular}{|c|c|c|c|c|}
\hline Estudio & Tipo & $\mathbf{N}$ de pacientes & Terapia & Resultados \\
\hline $\begin{array}{c}\text { Talamonti et al. } \\
2006\end{array}$ & Fase II & 20 & Gemcitabina + RT & $\begin{array}{c}\text { Resección 85\%. R0 94\%. } \\
\text { SV. Media } 26 \text { meses }\end{array}$ \\
\hline $\begin{array}{c}\text { Evans et al. } \\
2008\end{array}$ & Fase II & 86 & Gemcitabina + RT & $\begin{array}{c}\text { Resecciones } 71 \% \text {. R0 89\% } \\
\text { SV media } 34 \text { meses }\end{array}$ \\
\hline $\begin{array}{l}\text { Heinrich et al. } \\
2008\end{array}$ & Fase II & 28 & Gemcitabina + cisplat & $\begin{array}{c}\text { Resección 89\%. R0 80\% } \\
\text { SV media } 26.5 \text { meses }\end{array}$ \\
\hline $\begin{array}{l}\text { Varadhachary et.al } \\
2008 \\
\end{array}$ & Fase II & 90 & $\begin{array}{c}\text { Gemcitabina + cisplat } \\
+ \text { RT }\end{array}$ & $\begin{array}{c}\text { Resección 66\%. R0 96\% } \\
\text { SV media } 28.3 \text { meses }\end{array}$ \\
\hline $\begin{array}{l}\text { O'Reilly et al. } \\
2014\end{array}$ & Fase II & 38 & Gemcitabina + Oxalip & $\begin{array}{c}\text { Resección } 71 \% \text {. R0 74\% } \\
\text { SV media } 27.2 \text { meses. }\end{array}$ \\
\hline $\begin{array}{c}\text { Christians et al. } \\
2016\end{array}$ & Fase II & 69 & $\begin{array}{c}\text { Gemcitabina o cisplat } \\
+ \text { RT }\end{array}$ & $\begin{array}{c}\text { Resecciones } 87 \% \text {. R0 97\% } \\
\text { SV media } 31.5 \text { meses }\end{array}$ \\
\hline
\end{tabular}

Extraído de Li D.Adjuvant and Neoadjuvant Therapy for Pancreatic Cancer.

\section{TUMORES BORDER-LINE}

Independientemente de la clasificación utilizada, los tumores borderline son aquellos que implican un aumento en la posibilidad de resecciones incompletas. ${ }^{36}$

Bajo el concepto documentado, pero aún discutido, de que las resecciones R1-R2 se asocian a un peor pronóstico,37 es que la neoadyuvancia reviste gran interés en este grupo de pacientes.

Las premisas que sustentan la utilización de la neoadyuvancia en los tumores borderline son: mayor posibilidad de metástasis ocultas en tumores en teoría más agresivos, mayor posibilidad de resecciones incompletas, cirugías mas complejas y con mayor número de resecciones venosas. ${ }^{3} \mathrm{~A}$ su vez, los pacientes con tumores borderline que no se resecan, presentan una sobrevida similar a los inoperables con una media de 8-12 meses. ${ }^{38}$

A pesar de estas premisas, no hay consenso en la utilización de la neoadyuvancia en los tumores borderline. Hay autores que recomiendan su realización en pacientes con compromiso venoso extenso, frente a un compromiso vascular arterial o de órganos

vecinos en forma masiva. En este contexto, otros autores, basan en scores de riesgo la selección de pacientes candidatos a neoadyuvancia. Uno de los más conocidos es el Score de Glasgow modificado, que toma en cuenta mediadores inflamatorios, asociados o no al CA 19-9.39

En cambio, la guía NCCN plantea el uso sistemático de neoadyuvancia en todos los pacientes con riesgo de presentar bordes de resección positivos. ${ }^{34}$

Al igual que lo que sucede en los tumores resecables, no hay consenso en la terapéutica a utilizar, en sus fármacos y combinaciones, así como la asociación o no de radioterapia.

Los protocolos más utilizados, se basan en un tratamiento sistémico de inducción por 2 meses y de no presentar progresión o metástasis, continuar con un tratamiento quimiorradiante. ${ }^{3}$

Tradicionalmente los planes utilizaban 5FU o Gemcitabina asociado o no a radioterapia. Con estas combinaciones se consiguen aproximadamente un $30 \%$ de resecciones en los tumores localmente avanzados. 
El primer estudio prospectivo fue aportado por Metha, ${ }^{40}$ en tumores conocidos como marginales, por el compromiso vascular que presentaban. Se utilizó 5FU más radioterapia, consiguiendo un $60 \%$ de resecciones, todas con margen negativo. Concluye que este tratamiento es seguro, genera un downstaging y se asocia a una sobrevida media de 30 meses, similar a los tumores resecables de inicio. A partir de allí, se han desarrollado múltiples estudios con diferentes combinaciones de fármacos y radioterapia, con porcentajes de resecciones, que oscilan entre 30-60\%. (Tabla 3)

Luego de demostrado el beneficio del FOLFIRINOX para los paciente con adenocarcinoma de páncreas metastásico, ${ }^{41}$ surge el interés de su utilización en todas las etapas de la enfermedad.

Cristians $^{42}$ es uno de los primeros en publicar sus resultados con esta asociación farmacológica y tumores localmente avanzados, en pacientes con buen performance status. Este estudio evidenció 67\% de resecciones, todas R0, con toxicidad y complicaciones quirúrgicas aceptables.

Muchas series han reproducidos estos datos, llegando en algunos casos a mostrar resecciones del 80\% con 100\% de R0. ${ }^{43}$

Tabla 3: Series de pacientes border-line bajo tratamiento de neoadyuvancia.

\begin{tabular}{|l|c|c|c|}
\hline & N pacientes & Resecabilidad & Sobrevida (meses) \\
\hline KATZ, 2012 & 129 & $66 \%$ & 33 \\
\hline CHRISTIANS, 2014 & 18 & $67 \%$ & 22 \\
\hline ROSE, 2014 & 64 & $48 \%$ & 22 \\
\hline PANICCIA, 2015 & 18 & $94 \%$ & NO REPORTADO \\
\hline KATZ, 2015 & 23 & $68 \%$ & 18 \\
\hline KIM, 2016 & 26 & $77 \%$ & NO REPORTADO \\
\hline
\end{tabular}

Extraído de Coveler et al. (35).

El estudio prospectivo Alliance A02110144 utilizando 4 ciclos de FOLFIRINOX de inducción, seguido de radioterapia más capecitabina, mostró 63\% de resección con 93\% de R0 y 13\% de respuesta completa. El índice de toxicidad, para este estudio fue de 64\%, con una sobrevida media de 21.7 meses. Hay un gran interés en los resultados obtenidos con estas asociaciones de fármacos, en pacientes con un buen performance estatus, si bien se asocian a mayor toxicidad.

De lo analizado, la realización de la neoadyuvancia en los tumores borderline tiene dos importantes aportes, por un lado el aumento del número de resecciones y el tratamiento de la enfermedad local, y por otro el tratamiento sistémico precoz. A la luz de los resultados, cuestionamos el valor real de las resecciones $\mathrm{R} 0$ y la disminución de los $\mathrm{N}+$, dado que no han mejorado la sobrevida global, consolidando el concepto de que se trata de una enfermedad sistémica de inicio. Se requieren estudios con más series de casos para poder sacar conclusiones de los diferentes protocolos terapéuticos y sus beneficios.

\section{ENFERMEDAD LOCAL IRRESECABLE DE INICIO.}

El tratamiento de la enfermedad local irresecable puede ser entendido como quimiorradiante exclusivo y es abordado en el capítulo de tratamientos paliativos.

En este grupo de pacientes la sobrevida es baja con una media de aproximadamente 10 meses.

Sin embargo existe un grupo de pacientes con enfermedad irresecable, que tienen buena respuesta al tratamiento sistémico y se vuelven resecables. 
Tabla 4: Series de neoadyuvancia en pacientes irresecable.

\begin{tabular}{|l|c|c|c|}
\hline \multicolumn{1}{|c|}{ ESTUDIO } & N de pacientes & Resecabilidad & Sobrevida (meses) \\
\hline Dean, 2016 & 42 & $19 \%$ & 27 \\
\hline Sadot, 2015 & 101 & $30 \%$ & 26 \\
\hline Nitsche 2015 & 14 & $29 \%$ & 31 \\
\hline Marthey, 2015 & 77 & $36 \%$ & 22 \\
\hline James 2014 & 22 & $46 \%$ & No reportado \\
\hline Faris 2013 & 22 & $23 \%$ & No reportado \\
\hline Gunturu 2013 & 16 & $13 \%$ & No reportado \\
\hline Kharofa 2012 & 12 & $58 \%$ & No reportado \\
\hline Lowry, 2012 & 19 & $5 \%$ & No reportado \\
\hline
\end{tabular}

Varios estudios han mostrado beneficios de estos tratamientos que finalmente se convierten en neoadyuvantes, debido a las respuestas conseguidas.

Hoseim ${ }^{45}$ con un tratamiento de FOLFIRINOX seguido de un tratamiento quimiorradiente, mostró $50 \%$ de resecciones y 80\% de R0, para tumores irresecables de inicio, con una toxicidad grado 3-4 de 40\%.

La revisión de Coveler, muestra que el uso de FOLFIRINOX o Nab-paclitaxel asociado a la gemcitabina logra 20 a $40 \%$ de respuesta radiológica, con 20 a $44 \%$ de resecabilidad y un 60-80\% de resecciones R0, con sobrevidas de 30 meses. $^{35}$

Boone mostró cifras bajas de resección del 15\% con resecciones R0 de 50\%. ${ }^{46}$

El estudio de Massachussets, mostró una downstaging en pacientes con enfermedad localmente avanzada, con 35\% de ganglios positivos en los sometidos a neoadyuvancia, frente a 79\% de los resecables inicialmente. Concluyó que luego de neoadyuvancia en tumores borderline e irresecables, se logran resecciones R0 y sobrevidas similares a los pacientes resecables de inicio. ${ }^{10}$

Estos datos alentadores, se presentan en series de muy pocos casos. Pero en definitiva, se demuestra que los pacientes con tumores irresecables presentan cierta respuesta a la neoadyuvancia, con las nuevas combinaciones farmacológicas. Se logran índices de resección de un 20-40\%, con sobrevidas similares a los pacientes resecables de inicio. Igualmente no hay consenso sobre el tratamiento de estos pacientes, son series con resultados muy diversos y deben ser considerados para pacientes seleccionados, en el marco de ensayos clínicos y en centros de referencia. (Tabla 4). 


\section{BIBLIOGRAFIA.}

1. He J, Page AJ, Weiss M,et al. Management of border- line and locally advanced pancreatic cancer: where do we stand? World J Gastroenterol 2014;20(9):2255-2266.

2. Hishinuma S, Ogata Y, Tomikawa M, et al. Patterns of recurrence after curative resection of pancreatic cancer, based on autopsy findings. J Gastrointest Surg. 2006;10(4):511-518.

3. Fathi A, Christians KK, George B, Ritch PS, Ericsson BA, Tolat P, Johnston FM, Evans DB, Tsai S.Neoadjuvant therapy for localized pancreatic cancer: guiding principles. J Gastrointest Oncol 2015;6(4):418-429.

4. Gillen S, Schuster T, Meyer zum Büschenfelde C, Friess H, Kleeff J: Preoperative/neoadju- vant therapy in pancreatic cancer: a system- atic review and meta-analysis of response and resection percentages. PLoS Med 2010; 7: e1000267. doi: 10.1371/journal.pmed.1000267.

5. Rombouts SJ, Walma MS, Vogel JA, van Rijssen LB, Wilmink JW, Mohammad NH, van Santpoort HC, Quintus Molenaar I, Besselink MG. Systematic Review of Resection Rates and Clinical Outcomes After FOLFIRINOX-Based Treatment in Patients with Locally Advanced Pancreatic Cancer.Ann Surg Oncol. doi: $10.1245 / \mathrm{s} 10434-016-5373-2$.

6. Evans DB, Rich TA, Byrd DR, et al. Preoperative chemoradiation and pancreaticoduodenectomy for adenocarcinoma of the pancreas. Arch Surg. 1992; 127(11):1335-9.

7. Chuong MD, Frakes JM, Figura N, et al. Histopathologic tumor response after induction chemotherapy and stereotactic body radiation therapy for borderline resectable pancreatic cancer. J Gastrointest Oncol 2015;7(2):221-227.

8. Zhao Q, Rashid A, Gong Y, et al. Pathologic complete response to neoadjuvant therapy in patients with pancreatic ductal adenocarcinoma is associated with better prognosis. Ann Diagn Pathol. 2012;16(1):29-37.

9. Lee SH, Kang CM, Kim H, et al. Pathological Complete Remission of Pancreatic Cancer Following Neoadjuvant Chemoradiation Therapy; Not the End of Battles. Medicine (Baltimore). 2015 Dec;94(52):e2168. doi: 10.1097/MD.0000000000002168.

10. Ferrone CR, Marchegiani G, Hong TS, et al. Radiological and surgical implications of neoadjuvant treatment with FOLFIRINOX for locally advanced and borderline resectable pancreatic cancer. Ann Surg. 2015;26(1):1217.

11. Cooper AB, Parmar AD, Riall TS, et al. Does the use of neoadjuvant therapy for pancreatic adenocarcinoma increase postoperative morbidity and mortality rates? J Gastrointest Surg. 2015;19(1):80-86.

12. Verma V, MD, Li J, MD, Lin Ch. Neoadjuvant Therapy for Pancreatic Cancer Systematic Review of Postoperative Morbidity, Mortality, and Complications. Am J Clin Oncol 2016;39(3):302-313.

13. Takahashi H, Ogawa H, Ohigashi H, et al. Preoperative chemoradiation reduces the risk of pancreatic fistula after distal pancreatectomy for pancreatic adenocarcinoma. Surgery 2011;150(3):547-56.

14. Evans DB, Erickson BA, Ritch P: Borderline resectable pancreatic cancer: definitions and

the importance of multimodality therapy. Ann Surg Oncol 2010;17(11):2803-2805.

15. Evans DB, George B, Tsai S. Non-metastatic pancreatic cancer: resectable, borderline resectable, and locally advanced-definitions of increasing importance for the optimal delivery of multimodality therapy. Ann Surg Oncol. 2015;22(11):3409-3413.

16. Katz MH, Fleming JB, Bhosale P, et al. Response of borderline resectable pancreatic cancer to neoadjuvant therapy is not reflected by radiographic indicators. Cancer. 2012;118 (23):5749-5756.

17. Dholakia AS, Hacker-Prietz A, Wild AT, et al. Resection of borderline resectable pancreatic cancer after neoadjuvant chemoradiation does not depend on improved radiographic appearance of tumor-vessel relationships.J Radiat Oncol. 2013.2(4):413-425.

18. Sadot E, Telem DA, Cohen L, et al. FOLFIRINOX Induction Therapy for Stage 3 Pancreatic Adenocarcinoma. Ann Surg Oncol. 2015; 22(11):3512-3521.

19. Ferrone CR, Marchegiani G, Hong TS, et al. Radiological and Surgical Implications of Neoadjuvant Treatment With FOLFIRINOX for Locally Advanced and Borderline Resectable Pancreatic Cancer. Ann Surg. 2015 Jan;261(1):12-17.

20. Choi M, Heilbrun LK, Venkatramanamoorthy R, et al. Using $18 \mathrm{~F}$-fluorodeoxyglucose positron emission tomography to monitor clinical outcomes in patients treated with neoadjuvant chemo-radiotherapy for locally advanced pancreatic cancer. Am J Clin Oncol. 2010; 33(3):257-261.

21. Wang XY, Yang F, Jin CH, et al. Utility of PET/CT in diagnosis, staging, assessment of resectability and metabolic response of pancreatic cancer.World J Gastroenterol 2014; 20(42): 15580-15589.

22. Katz MHG., Varadhachary GR, Fleming JB, et al. Serum CA 19-9 as a Marker of Resectability and Survival in Patients with Potentially Resectable Pancreatic Cancer Treated with Neoadjuvant Chemoradiation. Ann Surg Oncol. 2010; 17(7):1794-1801.

23. Boone BA, Steve J, Zenati MS, et al. Serum CA 19-9 Response to Neoadjuvant Therapy is Associated with Outcome in Pancreatic Adenocarcinoma.Ann Surg Oncol 2014; 21:4351-4358. 
24. Aldakkak M, Christians KK, Krepline AN, et al. Pre-treatment carbohydrate antigen 19-9 does not predict the response to neoadjuvant therapy in patients with localized pancreatic cancer. HPB (Oxford). 2015;17(10):942952.

25. Maithel SK, Maloney S, Winston C, et al. Preoperative CA 19-9 and the yield of staging laparoscopy in patients with radiographically resectable pancreatic adenocarcinoma.Ann Surg Oncol. 2008 ;15(12):3512-3520.

26. Raigani S, Ammori J, Julian K, et al. Trends in the Treatment of Resectable Pancreatic Adenocarcinoma.J Gastrointest Surg. 2014; 18(1): 113-123.

27. Willett CG, Lewandrowski K, Warshaw AL, et al. Resection margins in carcinoma of the head of the pancreas. Implications for radiation therapy. Ann Surg 1993;217(2):144-148.

28. Evans DB, Rich TA, Byrd DR, et al. Preoperative chemoradiation and pancreaticoduodenectomy for adenocarcinoma of the pancreas. Arch Surg 1992;127(11):1335-1339.

29. Tsai S, Evans DB. Therapeutic Advances in Localized Pancreatic Cancer. JAMA Surg. 2016; 151(9):862-868.

30. Wolff RA, Varadhachary GR, Evans DB. Adjuvant therapy for adenocarcinoma of the pancreas: analysis of reported trials and recommendations for future progress. Ann Surg Oncol 2008; 15(10): 2773-2786.

31. Christians KK, Heimler JW, George B, et al. Survival of patients with resectable pancreatic cancer who received neoadjuvant therapy.Surgery. 2016;159(3):893-900.

32. Casadei R, Di Marco M, Ricci C, et al. Neoadjuvant Chemoradiotherapy and Surgery Versus Surgery Alone in Resectable Pancreatic Cancer: A Single-Center Prospective, Randomized, Controlled Trial Which Failed to Achieve Accrual Targets.J Gastrointest Surg. 2015; 19(10):1802-1812.

33. Xu CP, Xue XJ, Liang N, et al. Effect of chemoradiotherapy and neoadjuvant chemoradioth erapy in resectable pancreatic cancer: a systematic review and meta-analysis. J Cancer Res Clin Oncol. 2014(4);140:549-559.

34. Tempero MA, Malafa MP, Behrman SW, et al. Pancreatic adenocarcinoma, version 2.2014: featured updates to the NCCN guidelines. J Natl Compr Canc Netw. 2014;12:1083-1093.

35. Coveler AL, Herman JM, Simeone DM, et al. Localized Pancreatic Cancer: Multidisciplinary Management. Am Soc Clin Oncol Educ Book. 2016;35:217-226.

36. Lopez NE, Prendergast C, Lowy AM. Borderline resectable pancreatic cancer: Definitions and management. World J Gastroenterol 2014; 20(31): 10740-10751.

37. Sohn TA, Yeo CJ, Cameron JL, et al. Resected adenocarcinoma of the pancreas-616 patients: results, outcomes, and prognostic indicators. J Gastrointest Surg 2000; 4(6): 567-579.

38. Wolfgang CL, Herman JM, Laheru DA, et al. Recent progress in pancreatic cancer. CA Cancer J Clin. 2013; 63(5): 318-348.

39. Hackert T, Ulrich A, Büchler MW. Borderline resectable pancreatic cancer.Cancer Letters 2016; 375 (2): 231237.

40. Mehta VK, Fisher G, Ford JA, et al. Preoperative chemoradiation for marginally resectable adenocarcinoma of the pancreas. J Gastrointest Surg. 2001;5(1):27-35.

41. Conroy T, Desseigne F, Ychou M, et al. FOLFIRINOX versus gemcitabine for metastatic pancreatic cancer. New Engl J Med 2011;364(19):1817-1825.

42. Christians KK, Tsai S, Mahmoud A, et al. Neoadjuvant FOLFIRINOX for borderline resectable pancreas cancer: a new treatment paradigm? Oncologist. 2014;19(3):266-274.

43. Paniccia A, Edil BH, Schulick RD, et al. Neoadjuvant FOLFIRINOX application in borderline resectable pancreatic adenocarcinoma: a retrospective cohort study, Medicine (Baltimore).2014; 93(27): e198. doi: 10.1097/ MD.0000000000000198.

44. Katz MHG, Shi Q Ahmad SA, et al. Preoperative modified FOLFIRINOX followed by chemoradiation for borderline resectable pancreatic cancer: initial results from Alliance trial A021101. J Clin Oncol. 2015;33(15);(suppl; abstr 4008).

45. Hosein PJ, MacIntyre J, Kawamura C, et al. A retrospective study of neoadjuvant FOLFIRINOX in unresectable or borderline-resectable locally advanced pancreatic adenocarcinoma. BMC Cancer 2012;12:199. doi: 10.1186/1471-2407-12-199.

46. Boone BA, Steve J, Krasinskas AM, et al. Outcomes with FOLFIRINOX for Borderline Resectable and Locally Unresectable Pancreatic Cancer. J Surg Oncol. 2013; 108(4): 236-241. 


\section{ADYUVANCIA}

\section{¿TIENE BENEFICIOS EL TRATAMIENTO ADYUVANTE EN EL ADENOCARCINOMA DE PANCREAS?}

El adenocarcinoma de páncreas se encuentra en el cuarto lugar como causa de muerte por cáncer, y ocupará la segunda posición para el año 2030.

La sobrevida del cáncer de páncreas a 5 años ronda el 5-7\%, (pudiendo llegar al 20\% en centros de alto volumen) con una tasa de recaída local de 50 a $80 \%$ y de aparición de metástasis de hasta un $70 \%{ }^{1}$

Estos datos, junto a los malos resultados quirúrgicos en términos de sobrevida a largo plazo, demuestran el interés por estudio de las terapias adyuvantes. El valor de las mismas está bien establecido en términos de prolongar la sobrevida y disminuir la recurrencia. ${ }^{2}$

Hoy en día, no hay dudas sobre el beneficio de las terapias adyuvantes en el adenocarcinoma de páncreas, tanto en la sobrevida, como en el tiempo libre de enfermedad. Los buenos resultados se han visto en tumores de páncreas resecados, así como en el localmente avanzado y/o metastásico. En estos dos últimos casos, no se trataría de una adyuvancia sino de un tratamiento paliativo.

Las preguntas que nos surgen son: ¿Qué pacientes se benefician del tratamiento adyuvante? ¿En base a qué tratamientos se realiza? ¿Quimoterapia, radioterapia o quimiorradioterapia? ¿Cuándo iniciar el tratamiento luego de la cirugía?

Para una mejor compresión del tema debemos realizar un análisis histórico de los principales trabajos científicos. Uno de los primeros artículos que analiza el efecto de la quimioterapia (QT) en el tratamiento del cáncer de páncreas es el de Mallinson, publicado en $1980 .^{3}$ En esa época la sobrevida para esta patología era del $1 \%$ a los 5 años. Este estudio demostró mejoría en la sobrevida media de pacientes con tumores irresecables pasando de 9 a 44 semanas. A pesar de no tratarse de un tratamiento adyuvante, se demostró el beneficio de la QT en prolongar la sobrevida.

En 1985 Kaiser $^{4}$ y colaboradores mostraron los primeros resultados de lo que 2 años más adelante se publicará con el nombre de GITSG (gastrointestinal tumor study group). En esta primera etapa se publicó un estudio prospectivo randomizado de 43 pacientes, que se dividieron en un grupo con tratamiento y un grupo control.

Todos los pacientes fueron sometidos a una resección pancreática previa. El tratamiento adyuvante se basó en la asociación de radioterapia $(\mathrm{RT})$ y QT en base a 5-fluoracilo $(5 \mathrm{FU})$. El resultado fue contundente, mostró una mejoría en la sobrevida de los pacientes tratados con una media de 20 meses vs 11 meses en el grupo control. El estudio fue abandonado por los claros resultados.

En 1987 se publicó el estudio GITSG 5 que utilizó el trabajo de Kaiser, al cual se sumaron 30 pacientes randomizados al grupo de tratamiento. Se replicó lo observado en el estudio anterior, logrando sobrevidas de $40 \%$ a los 2 años y $20 \%$ a los 5 años, mejorando los resultados de los pacientes tratados únicamente con cirugía.

Es un trabajo criticado por el bajo número de pacientes así como lo obsoleto del método radiante, pero ha sido el punto de partida y comparación con otros estudios.

En 1993 un estudio noruego ${ }^{6}$ randomizó 61 pacientes que los dividió en 2 grupos, uno control y otro con QT. Se utilizaron drogas como Adriamicina, 5FU y mitomicina $\mathrm{C}$ (MMC), en pacientes con tumores de páncreas resecados. Los resultados también mostraron beneficios de los tratamientos adyuvantes por sobre los no tratados. Con sobrevidas medias de 23 meses vs 11 meses, y sobrevida a 2 años de 43\% vs 32\%. Solo 13 pacientes culminaron los 6 ciclos, y se evidenció un alto índice de toxicidad.

Posteriormente se publicaron otros estudios no randomizados, como el de Neoptolemos ${ }^{7}$ y el de $\mathrm{Yeo}^{8}$, con resultados contradictorios, que no pudieron reproducir los resultado de GITSG.

Esto impulsó a la European Organization for Research and Treatment of Cancer (EORTC) ${ }^{9}$, a realizar el segundo estudio prospectivo randomizado sobre el beneficio de la adyuvancia en el cáncer de páncreas. Este trabajo contó con más de 200 pacientes en los que se realizó una duodenopancreatectomía (DPC) por tumores periampulares. Posteriormente fueron randomizados en 2 grupos, uno de tratamiento con quimiorradioterapia (QRT) y otro control, similar al estudio GITSG.

El EORTC no mostró diferencias significativas en el tiempo libre de enfermedad, ni en la sobrevida. Tampoco los resultados fueron significativos cuando se tomaron en cuenta solo los tumores pancreáticos, con sobrevidas medias de 17.4 vs 12.6 meses ( $\mathrm{p}=0.099)$. Este estudio concluyó que el tratamiento con QRT no debe considerase el estándar en los pacientes con tumores periampulares resecados, a pesar de ser seguro y bien tolerado.

Se le adjudicaron 2 críticas iniciales, se incluyeron todos los tumores periampulares y las dosis de quimioterapia con 5FU fueron menores que en el estudio GITSG.

Mas adelante en el $2006^{10}$ se revisó nuevamente éste estudio y se demostró un error estadístico. Aplicando un nuevo modelo, el EORTC evidenció una mejora en la sobrevida en forma significativa, con porcentajes a 2 años de $37 \%$ vs $23 \%$ en favor al grupo tratado $(\mathrm{p}=0.049)$. 
La discusión sobre las terapias adyuvantes continúa, en el año 2002 un estudio japonés no evidenció mejoría en la sobrevida ni el tiempo libre de enfermedad. Demostró además, un alto indice de toxicidad con la combinación de 5FU y MMC. Pero éste estudio fue considerado de bajo peso estadístico. ${ }^{9}$

Las dudas continuaban y en el año 2004 aparece otro de los estudios principales el ESPAC-1.11 Este trabajo prospectivo y randomizado fue innovador en su diseño y dividió a los pacientes en 4 grupos. El primero sin tratamiento adyuvante, el segundo con adyuvancia en base a 5FU, un tercer grupo con QRT y un último grupo con QRT más QT de mantenimiento. Luego los comparó en 2 sub grupos QRT vs no QRT y QT vs no QT. Se concluyó que había una mejoría en la sobrevida de los pacientes que recibían QT frente a los que no recibían, con una media de 20.1 meses vs 15.5 meses respectivamente, y sobrevidas a 2 y 5 años de $40 \%$ y $20 \%$ respectivamente para el grupo con QT vs 30\% y $8 \%$ en el grupo de no QT. Todas éstas diferencias son estadísticamente significativas. En cambio los resultados con QRT no fueron buenos y no mostraron beneficios. Este estudio también tuvo criticas como la realizada por Morris ${ }^{12}$ que considera subóptima la dosis de RT realizada, así como lo complejo del análisis y la difícil interpretación de datos En esta línea, un metaanálisis de la British Journal of Cancer del $2005^{13}$ se propuso determinar si la QT y la QRT adyuvantes tenían impacto en la sobrevida. Concluyó que hay una mejora en la sobrevida media con el uso de QT de 13.5 meses a 19 meses, y una sobrevida a los 2 y 5 años de $38 \%$ y $28 \%$ para los tratados con QT frente a $19 \%$ y $12 \%$ de los controles respectivamente. Tampoco mostró beneficios con la QRT al igual que ESPAC-1.

En el año 2007 una revisión de la American College of Surgeons sobre su base de datos de 301033 pacientes con adenocarcinoma, divididos en 2 períodos de tiempo, también demostró el beneficio de la QT sobre el tratamiento quirúrgico exclusivo (OR, 0,83;95\% CI, 0.79-0.88 [P<0.001]). ${ }^{14}$

En ese mismo año se publica otro estudio prospectivo randomizado de gran impacto llamado CONKO-001..$^{15}$ Luego de los trabajos publicados en 1997 donde se mostraron las ventajas de la gemcitabina como adyuvante en el cáncer de páncreas, ${ }^{16} \mathrm{CONKO}-001$ fue el primer estudio a gran escala en utilizar éste fármaco como quimioterápico adyuvante. Un total de 368 pacientes operados por un adenocarcinoma de páncreas, de 88 centros de Alemania y Austria, se randomizaron en 2 grupos, uno con tratamiento adyuvante con gemcitabina y otro sin tratamiento.

El análisis de este estudio, en cuanto al tiempo libre de enfermedad, mostró mejoría estadísticamente significativa para el grupo con gemcitabina frente al grupo control.

En cuanto a la sobrevida, en la primera publicación, hay un aumento en favor del grupo con gemcitabina, pero el mismo no era estadísticamente significativo, con un media de supervivencia de 22.1 vs 20.2 meses ( $\mathrm{p}=0.061$ ). Al cierre de la primera edición se empezó a ver que las curvas de sobrevida de ambos grupos se separaban con el tiempo.

Por lo tanto, parecía muy probable que la diferencia en la supervivencia global entre los grupos fuera estadísticamente significativa con un seguimiento más prolongado. Este estudio fue cerrado en setiembre del año 2012 y en los resultados finales se comprobaron las suposiciones iniciales, una mejoría de la sobrevida global de $24 \%$ para el grupo tratado. Con sobrevida a los 5 años de $20.7 \%$ vs $10.4 \%$ y a los 10 años de $12.2 \%$ vs $7.7 \%(\mathrm{p}=0.01)$.

Este estudio proporcionó evidencia nivel 1 del beneficio de los tratamientos adyuvantes en el cáncer de páncreas.

En el año 2008 se publicaron 2 estudios que apoyaron los tratamientos adyuvantes en el cáncer de páncreas, un análisis del Johns Hopkins Hospita $1{ }^{17}$ y un estudio retrospectivo de la Clínica Mayo. ${ }^{18}$ Se utilizaron tratamientos adyuvantes con QRT y los compararon con grupos controles, ambos mostraron una mejoría en la sobrevida estadísticamente significativa en favor de los tratamientos adyuvantes.

Si bien existen estudios que no han demostrado la utilidad de los tratamientos adyuvantes en el cáncer de páncreas, los mismos han sido considerados de bajo peso estadístico. Existe evidencia suficiente de que los tratamientos adyuvantes mejoran el tiempo libre de enfermedad y la sobrevida global por encima del $20 \%$ frente a los grupos controles.

La guía NCCN ${ }^{19}$ propone, para los pacientes resecados, adyuvancia con la combinación de QRT en base a gemcitabina o 5FU antes y después del tratamiento radiante. En el caso de realizar quimioterapia exclusiva la gemcitabina o la combinación 5FU-leucovorin son los fármacos de primera línea.

Se recomienda empezar el tratamiento adyuvante entre la cuarta y octava semana luego de la cirugía, pero la misma es igualmente efectiva hasta las 12 semanas. Lo importante es completar todos los ciclos de tratamiento (ESPAC-3). ${ }^{20}$ Hoy las nuevas lineas de investigación se basan en el rol de las combinaciones de quimioterápicos, el uso de terapias biológicas, el papel de la quimiorradioterapia y de la inmunoterapia.

\section{¿QUIMIOTERAPIA O QUIMIORRADIOTERAPIA?}

El uso de la quimiorradioterapia es controversial, en cuanto a resultados, toxicidad y beneficios sobre la quimioterapia. En los estudios analizados se demuestra una tendencia a la quimiorradioterapia en la escuela americana y de la quimioterapia exclusiva, en la europea. 
Como fue mencionado, el primer estudio prospectivo randomizado que evidenció las ventajas de la QRT sobre el tratamiento quirúrgico exclusivo fue el GITSG. ${ }^{5}$ En él se utilizó una dosis de radioterapia de 40 Gy en 2 sesiones de 20 Gy en conjunto con $5 \mathrm{FU}$ y posterior mantenimiento con el mismo fármaco. Éste estudio mostró resultados excelentes con una sobrevida media de 20 meses frente a 11 meses de los que no recibieron tratamiento.

El EORTC ${ }^{9}$ también utilizó dosis de radioterapia de 40 Gy, asociado a 5FU pero sin dosis de mantenimiento. En su primer análisis la quimiorradioterapia mostró mejoría no significativa en la sobrevida, y en su re análisis del año 2006, en cambio, demostró que esa mejoría era estadísticamente significativa.

Estos estudios fueron criticados por su bajo número de casos, escaso tiempo de seguimiento y lo obsoleto del método radiante.

El ESAPC- $1^{12}$ que comparó grupos con quimiorradioterapia con grupos sin quimiorradioterapia, no mostró beneficio en la sobrevida con el uso de quimiorradioterapia, sino un efecto deletéreo de la misma en términos de sobrevida y tiempo libre de enfermedad. Concluye que el retraso en el inicio de la quimioterapia sería la causa de tales resultados. Este estudio no escapó a las críticas sobre el bajo número de pacientes y la baja adhesión al tratamiento radiante.

Los cambios en los métodos de radioterapia, el uso de planificación mediante tomografías 3D, entre otros, han permitido delimitar mejor los campos de tratamiento, logrando dosis más altas y con menor toxicidad. En los avances en éste campo es donde se busca mejorar los resultados de la QRT.

En la publicación del Johns Hopkins Hospita ${ }^{17}$ del 2008, se compararon los resultados del uso o no de quimiorradioterapia adyuvante. En el grupo de tratamiento se utilizaron dosis más altas de radioterapia de hasta 50 Gy con 5FU concomitante y de mantenimiento. El estudio mostró una adhesión al tratamiento de un $80 \%$. La sobrevida media tuvo un aumento significativo en el grupo con QRT vs controles (21 vs 14.6 meses). También mostró un claro beneficio en los pacientes con adenopatías positivas y margen positivo.

En el mismo año la Clínica Mayo ${ }^{18}$ publicó un artículo similar con 466 pacientes, donde 274 fueron sometidos a QRT adyuvante con una dosis media de 50,4 Gy luego de una resección R0. Ésta revisión también mostró una mejoría en la sobrevida estadísticamente significativa con el tratamiento de QRT, pero el beneficio fue mayor en los pacientes con factores de riesgo como ser adenopatías positivas o alto grado histológico.

En el $2010^{21}$ ambas instituciones publican un trabajo para demostrar los beneficios de la QRT adyuvante sobre el tratamiento quirúrgico exclusivo. En éste estudio la $\mathrm{QRT}$ se basó en $5 \mathrm{FU}$ y radioterapia con acelerador lineal a dosis medias de $50.4 \mathrm{~Gy}$.

En el grupo con QRT se vio una mejoría en la sobrevida media de 21.1 vs 15.5 meses frente a los controles.

Debido al beneficio demostrado de la gemcitabina, se comenzó a probar asociaciones de QRT con dicho fármaco. Es así que en el año 2008 se presenta el estudio realizado por Radiation Therapy Oncology Group (RTOG 97-04), ${ }^{22}$ quien comparó el tratamiento de $\mathrm{QRT}$ con $5 \mathrm{FU}$ y gemcitabina, ambos grupos recibieron $50.4 \mathrm{~Gy}$ de radioterapia. Éste estudio mostró una mejoría en la sobrevida con gemcitabina sobre el $5 \mathrm{FU}$ pero asociado a mayor toxicidad sobre todo hematológica. Con el pasar de los años se realizó en el 2011 una nueva revisión del RTOG 97-04, donde se documentó más baja toxicidad sin diferencias en la sobrevida en los 2 grupos y una baja tasa de recaída local.23

La discusión sobre la QRT se centra en su toxicidad documentada. El estudio francés de Chauffert ${ }^{24}$, primer estudio en comparar QRT vs QT luego de 20 años, mostró un aumento en la toxicidad gastrointestinal y hematológica con la QRT. Este trabajo no mostró mejoría en la sobrevida con el uso de QRT con dosis de 60 Gy.

En diferentes centros se continuó comparando los beneficios de la QRT sobre la QT exclusiva como tratamiento adyuvante. Éstos estudios no siempre son comparativos dado el diferente uso de fármacos, dosis radiantes y estadíos de la enfermedad.

Un consenso de expertos americanos en el 2009 concluye que tanto la QRT o la QT exclusiva son estrategias válidas como tratamiento adyuvante, pero la radioterapia no asociada a QT no es aceptada. ${ }^{25}$ Los mayores beneficios del uso de QRT se ven en pacientes con tumores localmente avanzados o irresecables, ${ }^{26}$ pero asociados a una mayor toxicidad por utilizar dosis altas de radioterapia cercanas a $60 \mathrm{~Gy}^{27}$

Estos resultados no aplican para los cánceres de páncreas resecados, donde no habría beneficio con el uso de QRT adyuvante. ${ }^{28}$ Salvo en las resecciones tipo R1 y R2, donde parecería haber mejores resultados. ${ }^{29}$

La reciente publicación del estudio LAP 07, mostró cierto beneficio de la QRT en cuanto a evitar la progresión de la enfermedad localmente avanzada, pero sin cambios en la sobrevida global. ${ }^{30}$

La realización de QRT o QT exclusiva como adyuvancia en el cáncer de páncreas no esta definida y siguen en curso estudios que intentan responder esta pregunta como el RTOG 0848.

$\mathrm{La}$ QRT tiene sus beneficios en los tumores localmente avanzados o irresecables, no correspondiendo a una adyuvancia sino más bien a un tratamiento paliativo. La otra indicación de la QRT por sobre la QT, parecería ser en aquellos pacientes resecados con riesgo de recidiva, por ejemplos en las resecciones R1. El mayor beneficio radica en evitar la recurrencia local y no tanto en la sobrevida. 
El retraso en el inicio de la QT terapéutica estaría en la base de los malos resultados de la QRT. ${ }^{31}$

Sin duda hubo un cambio con la implementación de nuevas técnicas de radioterapia disminuyendo la toxicidad de la misma. La expectativa está centrada en que los diferentes métodos radiantes logren altas concentraciones con la mínima toxicidad posible. En ésta línea se encuentra el uso de radioterapia intraoperatoria, estereotáxica, así como la radioterapia guiada por Robot (CyberKnife). ${ }^{32}$

Las guías de NCCN recomiendan su uso asociado a QT (5FU o gemcitabina) como tratamiento adyuvante a dosis de 45-46Gy, como primera línea para el cáncer de páncreas resecado, como parte del arsenal terapéutico. ${ }^{19}$

\section{¿HAY BENEFICIOS EN LA REALIZACIÓN DE QUIMIOTERAPIA EN LOS PACIENTES N0?}

Hoy se acepta el beneficio de la adyuvancia en todos los estadíos del cáncer de páncreas. Sin embargo, muchos estudios demuestran las ventajas de la adyuvancia solo en los pacientes con factores de riesgo de recaída tumoral (grado histológico, resecciones R1, adenopatías positivas, entre otras). No recomendando el uso sistemático de adyuvancia en pacientes en estadío I y II. ${ }^{14}$

Es así que los estudios del Johns Hopkins Hospital ${ }^{17}$ y de la Clínica Mayo, ${ }^{18}$ ambos en el año 2008, no mostraron beneficios en la sobrevida en los pacientes N0. Dos años después en su publicación en conjunto, ambas instituciones muestran mejoría de la sobrevida estadísticamente significativa, en el tratamiento de los estadíos I y II. Concluyen que el beneficio de la adyuvancia es independiente del estadío ganglionar. ${ }^{21}$

Lo racional en el uso de adyuvancia está basado en la alta recurrencia local y a distancia, presumiblemente por la presencia de micrometástasis luego de la resección, o por considerarlo una enfermedad sistémica de inicio. ${ }^{16}$

Biliroma ${ }^{14}$ utilizó el registro de The National Cancer Data Base (NCDB), considerado uno de los más grandes del mundo, y mostró el beneficio de la adyuvancia en los estadíos I y II resecados. También el JSAP-02 mostró la mejoría en la sobrevida con el uso de quimioterapia adyuvante en los estadíos I y II.

Una reciente revisión de la American College demuestra también el beneficio del uso de adyuvancia en los pacientes N0. ${ }^{31}$

Hay evidencia suficiente para el uso de adyuvancia en los estadíos I y II resecados de adenocarcinoma de páncreas. Además, en los últimos años hay un aumento en el uso de la quimioterapia adyuvante, en cifras que llegan a un $250 \%$. No ha ocurrido lo mismo con la QRT que presenta una disminución de un 40\% en su uso como terapia adyuvante. A pesar de este aumento del uso de QT adyuvante, hay de un tercio a dos tercios de los pacientes en estadío I y II sin recibir tratamiento. Dentro de las causas se destacan las complicaciones postoperatorias, la aparición de metástasis, problemas psicosociales, negación por parte del paciente y el desconocimiento. ${ }^{33}$

A pesar de que su uso no se ha universalizado, está demostrado el beneficio de la terapia adyuvante en el cáncer de páncreas en estadío I y II. Su indicación se basa en la presencia de micrometástasis y en un concepto Fishereano de considerar al cáncer de páncreas como una enfermedad sistémica de inicio.

\section{¿HACIA DONDE APUNTAN LOS NUEVOS ESTUDIOS DE LAS TERAPIAS ADDYUANTES?}

Las nuevas líneas de investigación buscan mejorar los resultados obtenidos hasta ahora en el cáncer de páncreas. Se destacan el rol de la combinación de fármacos, la asociación con terapias biológicas e inmunoterapia y las mejoras en el tratamiento radiante.

Desde los estudios de Burry, donde se demostró el beneficio de la gemcitabina en la adyuvancia del cáncer de páncreas, el mismo se ha convertido en el tratamiento estándar. En base a él, se han realizado y se realizan estudios comparativos con otras drogas o asociaciones. La fluorpirimidina S-1 ha mostrado beneficios desde el estudio JASPAC $-01^{34}$, y desde allí se han documentado otros trabajos que apoyan su uso junto a la gemcitabina en el cáncer de páncreas ${ }^{35}$.

Está en curso el estudio ESAPC-4 que valora la sobrevida de la capecitabina asociada a la gemcitabina frente al uso de gemcitabina sola.

El erlotinib (un inhibido del receptor del factor de crecimiento epidérmico) ha mostrado su beneficio asociado con la gemcitabina en el cáncer de páncreas localmente avanzado y metastásico.

Actualmente se está desarrollando el CONKO-005 quien compara los resultados de erlotinib más gemcitabina vs gemcitabina sola. Similar situación sucede con el nab-paclitaxel quien mostró su beneficio en estadíos avanzados y actualmente, se está viendo su beneficio como tratamiento adyuvante en el estudio APACT. ${ }^{2}$ 
Luego de la gemcitabina el plan conocido como FOLFIRINOX ha presentado el mayor impacto en el tratamiento del cáncer de páncreas avanzado. Hay expectativa de su uso en estadíos precoces a pesar de su alta toxicidad. Está en curso el estudio PRODIGE 24/ACCORD 24, que compara la adyuvancia con gemcitabina vs FOLFIRINOX. ${ }^{36}$ El grupo francés UNICANCER, está en la misma línea y presentará sus resultados con el uso de FOLFIRNOX adyuvante. Esta terapia debe ir destinada a pacientes con un buen performance status.

La radioterapia avanza en encontrar la forma en mejorar los resultados y disminuir su toxicidad. Está en curso el RTOG 0848 que compara la adyuvancia de QRT vs QT. Así como otras asociaciones con quimioterápicos como el FOLFIRINOX (CONKO-7) o con gemcitabina-nab-paclitaxel (LAPACT). ${ }^{37}$

También se avanza en las diferentes formas de RT como la intraoperatoria, estereotáxica, externa, entre otras.

Las terapias blanco moleculares no han mostrado aún resultados alentadores, a pesar de que el beneficio teórico existe. La asociación erlotinib es aceptada por sus resultados. Se han realizado ensayos con bevacizumab, cetuximab, trastuzumab entre otros, pero sin mostrar mejoras en los resultados. ${ }^{38}$ Se estudiaron en asociación con RT, Arnoletti publica resultados en fase I, del cetuximab como radiosensibilizador. ${ }^{39}$

Como ya fue mencionado en otro capitulo, el adenocarcinoma de páncreas se compone de un estroma denso producido por una reacción desmoplásica. Ese estroma está compuesto en un 50\% por células inflamatorias e inmunológicas, generando un ambiente inmunosupresor que permite el desarrollo y la quimiorresistencia característica de este tumor. Es en este sentido que la inmunoterapia ha presentado interés científico en revertir esta inmunomodulación negativa. Se han diseñado drogas que intentan bloquear estos mecanismos de control, así como vacunas que estimulen a las células inmunológicas.

Se diseñaron varios tipos de vacunas (while-cell, pépticas, y ADN), donde se destacan la GUAX y la Algenpantucel L, sus mejores resultados han sido asociado a otras drogas inmunoestimulantes o quimioterápicos clásicos.

También se ha intentado estimular la acción de macrófagos y CD8+, entre otras células inmunológicas. Se ha utilizado interferón y sustancias que degraden el ácido hialurónico que permitan una mayor penetración de la gemcitabina por ejemplo.

Estas líneas de investigación aún no han mostrado los resultados esperados, pero se reconocen grandes avances hasta el momento.

En la combinación de los diversos agentes clásicos y terapias inmunológicas que logren inhibir las vías de señalización, así como la inmunosupresión local, logrando estimular a las células de la inmunidad, estará la clave del tratamiento de ésta enfermedad. ${ }^{37}$

\section{EN SUMA:}

- La sobrevida a 5 años del adenocarcinoma de páncreas, en términos de porcentajes, sigue siendo baja. La cirugía es la modalidad terapéutica que presenta las mejores chances de curación, pero los resultados no han variado en forma importante, en los últimos 20 años. Es allí donde los tratamientos adyuvantes han tenido impacto mejorando la sobrevida global y el tiempo libre de enfermedad.

- El beneficio de las terapias adyuvantes, está presente en todos los estadíos de la enfermedad incluso en aquellos con adenopatías negativas ( $\mathrm{N} 0)$.

- No se ha podido definir aún, si la QT es superior a la QRT y hay estudios en curso que intentaran contestar la interrogante. Del análisis realizado parecería ser mas seguro el uso de la $Q T$ exclusiva y reservar la QRT para los pacientes con riesgo de recaída local. Si bien ambas terapias son aceptadas como primera linea tratamiento adyuvante.

- Los tratamientos adyuvantes deben realizarse entre las 4 y 8 semanas postoperatorio, con un margen de seguridad de hasta 12 semanas. Los planes de primera linea se basan en gemcitabina y $5 \mathrm{FU}$-Leucovorin.

- En el uso de nuevas drogas (FOLFIRINOX) y sus diferentes combinaciones, así como los avances en radioterapia, en inmunoterapia y en terapias blanco moleculares, es donde está centrada la expectativa en mejorar los resultados de ésta patología. 


\section{BIBLIOGRAFIA.}

1. Siegel R, Ma J, Zou Z, et al. Cancer statistics, 2014. CA Cancer J Clin 2014;64(1): 9-29.

2. Li D, O’Reilly EM. Adjuvant and Neoadjuvant Therapy for Pancreatic Cancer.Surg Oncol Clin N Am. 2016;25: 311-326.

3. Mallinson CN, Rake MO, Cocking JB, et al. Chemotherapy in pancreatic cancer: results of a controlled, prospective, randomised, multicentre trial. British Medical Journal. 1980; 281(6255): 1589-1591.

4. Kalser MH, Ellenberg SS: Pancreatic cancer. Adjuvant combined radiation and chemotherapy following curative resection. Arch Surg 1985;120(8): 899-903.

5. Further Evidence of Effective Adjuvant Combined Radiation and Chemotherapy Following Curative Resection of Pancreatic Cancer. Gastrointestinal tumor study group. Cancer. 1987;59(12):2006-2010.

6. Bakkevold KE, Arnesj\$ B, Dahl O, et al. Adjuvant Combination Chemotherapy (AMF) Following Radical Resection of Carcinoma of the Pancreas and Papilla of Vater Results of a Controlled, Prospective, Randomised Multicentre Study. EurJ Cancer 1993; 29(5):698-703.

7. Neoptolemos JP, Baker P, Johnson CD, et al. Adjuvant radiotherapy and follow on chemotherapy in patients with pancreatic cancer. Results of the UK Pancreatic Cancer Group study (UKPACA-1). GI Cancer 1998; 2:235-245.

8. Yeo CJ, Abrams RA, Grochow LB, et al. Pancreaticoduodenectomy for pancreatic carcinoma: postoperative adjuvant chemoradiation improves survival. A prospective, single-institution experience. Ann Surg 1997; 225:621-633.

9. Klinkenbij1 JH, Jeekel J, Sahmoud T, et al. Adjuvant radiotherapy and 5-fluorouracil after curative resection of cancer of the pancreas and periampullary region: phase III trial of the EORTC gastrointestinal tract cancer cooperative group. Ann Surg. 1999;230(6):776-782.

10. Garofalo MC, Regine WF, Tan MT. On statistical reanalysis, the EORTC trial is a positive trial for adjuvant chemoradiation in pancreatic cancer. Ann Surg. 2006;244(2):332-333.

11. Neoptolemos JP, Stocken DD, Friess H, et al. A randomized trial of chemoradio- therapy and chemotherapy after resection of pancreatic cancer. N Engl J Med 2004;350:1200-1210.

12. Morris SL, Beasley M, Leslie M. Chemotherapy for pancreatic cancer. N Engl J Med. 2004; 350(26): 27132715.

13. Stocken DD, Büchler MW, Dervenis C, et al. Meta-analysis of randomised adjuvant therapy trials for pancreatic cancer. British Journal of Cancer 2005; 92(8): 1372 - 1381.

14. Bilimoria KY, Bentrem DJ, Ko CY, et al. Multimodality therapy for pancreatic cancer in the U.S.: utilization, outcomes, and the effect of hospital volume. Cancer. 2007;110(6):1227-1234.

15. Oettle H, Post S, Neuhaus $\mathrm{P}$, et al. Adjuvant chemotherapy with gemcitabine vs observation in patients undergoing curative-intent resection of pancreatic cancer: a randomized controlled trial. JAMA 2007;297(3):267277.

16. Burris HA , Moore MJ, Andersen J, et al. Improvements in survival and clinical benefit with gemcitabine as first-line therapy for patients with advanced pancreas cancer: a randomized trial.J Clin Oncol.1997;15(6):24032413.

17. Herman JM, Swartz MJ, Hsu CC, et al. Analysis of Fluorouracil-Based Adjuvant Chemotherapy and Radiation After Pancreaticoduodenectomy for Ductal Adenocarcinoma of the Pancreas: Results of a Large, Prospectively Collected Database at the Johns Hopkins Hospital.J Clin Oncol. 2008; 26(21): 3503-3510.

18. Corsini MM, Miller RC, Haddock MG, et al. Adjuvant Radiotherapy and Chemotherapy for Pancreatic Carcinoma: The Mayo Clinic Experience (1975-2005). J Clin Oncol. 2008; 26(21):3511-3516.

19. Tempero MA, Malafa MP, Asbun H, et al. NCCN clinical practice guidelines in oncology. Pancreatic, adenocarcinoma. Version 2.2015

20. Valle JW, Palmer D, Jackson R, et al. Optimal duration and timing of adjuvant chemotherapy after definitive surgery for ductal adenocarcinoma of the pancreas: ongoing lessons from the ESPAC-3 Study. J Clin Oncol. 2014;32(6): 504-512.

21. Hsu CC, Herman JM, Corsini MM, et al. Adjuvant Chemoradiation for Pancreatic Adenocarcinoma: The Johns Hopkins Hospital-Mayo Clinic Collaborative Study. Ann Surg Oncol 2010; 17(4):981-990.

22. Regine WF, Winter KA, Abrams RA, et al. Fluorouracil vs Gemcitabine Chemotherapy Before and After Fluorouracil-Based Chemoradiation Following Resection of Pancreatic Adenocarcinoma. A Randomized Controlled TrialA Randomized Controlled Trial.JAMA. 2008;299(9):1019-1026.

23. Regine WF, Winter KA, Abrams RA, et al. Fluorouracil-based Chemoradiation with Either Gemcitabine or Fluorouracil Chemotherapy after Resection of Pancreatic Adenocarcinoma: 5-Year Analysis of the U.S. Intergroup/RTOG 9704 Phase III Trial. Ann Surg Oncol. 2011;18(5):1319-1326. 
24. Chauffert B, Mornex F, Bonnetain F, et al. Phase III trial comparing intensive induction chemoradiotherapy (60 Gy, infusional 5-FU and intermittent cisplatin) followed by maintenance gemcitabine with gemcitabine alone for locally advanced unresectable pancreatic cancer. Definitive results of the 2000-01 FFCD/SFRO study. Annals of Oncology 2008;19(9):1592-1599.

25. Abrams RA, Lowy AM, O’Reilly EM, Wolff RA, Picozzi VJ, Pisters PWT. Combined Modality Treatment of Resectable and Borderline Resectable Pancreas Cancer: Expert Consensus Statement. Ann Surg Oncol. 2009;16 (7):1751-1756.

26. Loehrer PJ, Feng Y, Cardenes H, et al. Gemcitabine Alone Versus Gemcitabine Plus Radiotherapy in Patients With Locally Advanced Pancreatic Cancer: An Eastern Cooperative Oncology Group Trial. J Clin Oncol 2011; 29(31):4105-4112.

27. Chen Y, Sun XJ, Jiang TH, et al. Combined radiochemotherapy in patients with locally advanced pancreatic cancer: A meta-analysis. World J Gastroenterol 2013; 19(42): 7461-7471.

28. Martin LK, Luu DC, Li X, et al. The Addition of Radiation to Chemotherapy does not Improve Outcome When Compared to Chemotherapy in the Treatment of Resected Pancreas Cancer: The Results of a Single-Institution Experience.Ann Surg Oncol. 2014 ; 21(3): 862-867.

29. Habermehl D, Brecht IC, Bergmann F, et al. Adjuvant radiotherapy and chemoradiation with gemcitabine after R1 resection in patients with pancreatic adenocarcinoma. World Journal of Surgical Oncology. 2015; 13:149-156.

30. Hammel P, Huguet F, van Laethem JL, et al. Effect of Chemoradiotherapy vs Chemotherapy on Survival in Patients With Locally Advanced Pancreatic Cancer Controlled After 4 Months of Gemcitabine With or Without Erlotinib.The LAP07 Randomized Clinical Trial.JAMA. 2016;315(17):1844-1853.

31. Parikh AA, Maiga A, Bentrem D, et al. Adjuvant Therapy in Pancreas Cancer: Does It Influence Patterns of Recurrence?.J Am Coll Surg 2016; 222(4):448-456.

32. Eskander MF, Bliss LA, Tseng JF. Pancreatic Adenocarcinoma.Current Problems in Surgery 2016; 53(3):107154.

33. Raigani S, Ammori J, Julian K, et al. Trends in the Treatment of Resectable Pancreatic Adenocarcinoma.J Gastrointest Surg. 2014; 18(1): 113-123.

34. Maeda A, Boku N, Fukutomi A, et al. Randomized Phase III Trial of Adjuvant Chemotherapy with Gemcitabine versus S-1 in Patients with Resected Pancreatic Cancer: Japan Adjuvant Study Group of Pancreatic Cancer (JASPAC-01).Jpn J Clin Oncol 2008;38(3)227-229.

35. Sudo K, Nakamura K, Yamaguchi T. S-1 in the treatment of pancreatic cancer. World J Gastroenterol. 2014;20(41):15110-15118.

36. Marsh RDW, Talamonti MS, Katz MH, et al. Herman JM.Pancreatic cancer and FOLFIRINOX: a new era and new questions.Cancer Medicine 2015, 4(6):853-863.

37. Chiorean EG, Coveler LA.Pancreatic cancer: optimizing treatment options, new, and emerging targeted therapies.Drug Design, Development and Therapy 2015;9: 3529-3545.

38. Valsecchi ME, Díaz-Cantón E, De la Vega M, et al. Recent Treatment Advances and Novel Therapies in Pancreas Cancer: A Review.J Gastrointest Canc. 2014; 45(2):190-201.

39. Arnoletti JP, Frolov A, Eloubeidi M, et al. A phase I study evaluating the role of the anti-epidermal growth factor receptor (EGFR) antibody cetuximab as a radiosensitizer with chemoradiation for locally advanced pancreatic cancerCancer. Chemother Pharmacol. 2011;67(4):891-7. 


\section{DUODENOPANCREATECTOMIA CEFALICA.}

Los avances en las técnicas quirúrgicas y en los tratamientos perioperatorios han producido un descenso en la mortalidad de la duodenopancreatectomía cefálica (DPC), la misma es menor 5\%, sobre todo en los centro de referencia. Sin embargo, la morbilidad de este procedimiento sigue siendo elevada y ronda el 30-50\%, incluso en los centro de alto volumen. ${ }^{1}$ Dentro de las complicaciones se destacan la fístula pancreática, el retraso en el vaciamiento gástrico (RVG), el sangrado y los abscesos. Todos ellos pueden requerir, según su severidad, la realización de diversos estudios y procedimientos que aumentan los costos, prolongan la estadía hospitalaria, retrasan el inicio de la adyuvancia y deterioran la calidad de vida del paciente.

Realizaremos una revisión histórica de las principales técnicas quirúrgicas de la DPC y sus variantes, así como las discrepancias entre las diferentes formas de reconstrucción, que buscan disminuir la alta morbilidad de este procedimiento.

\section{¿PANCREATICOYEYUNOSTOMÍA o PANCREATICOGASTROSTOMÍA?}

Las primeras descripciones históricas de la DPC han sido erráticas y difíciles de documentar. Como surge de la revisión histórica realizada por el Prof. Dr. Raul Praderi, y que fuera publicada en el Congreso Uruguayo de Cirugía del 1999, la primera DPC se le adjudica al italiano Alessandro Codivilla en 1898, en un paciente que sobrevivió 28 días. Posteriormente Walter Kausch en 1909 en Berlin, resecó la cabeza del páncreas y el paciente vivió 9 meses. ${ }^{2}$

Posteriormente le siguieron otras descripciones de resecciones pancreáticas, hasta que Allen O. Whipple realizó su primera DPC por un tumor ampular en 1935, otorgándole el nombre a este procedimiento. Por aquel entonces, realizaba una cirugía en 2 tiempos, con el cierre del munón pancreático (fig.1). ${ }^{3}$ Este autor continuó el estudio de esta cirugía, y ya para el año 1940 la realizaba en un solo tiempo, gracias a la uso de la vitamina K. Para mediados de los años cuarenta publica sus 5 años de experiencia, donde se destaca la confección de una coledocoyeyunostomía, abandonado la anastomosis a la vesícula biliar que realizaba previamente. ${ }^{4}$

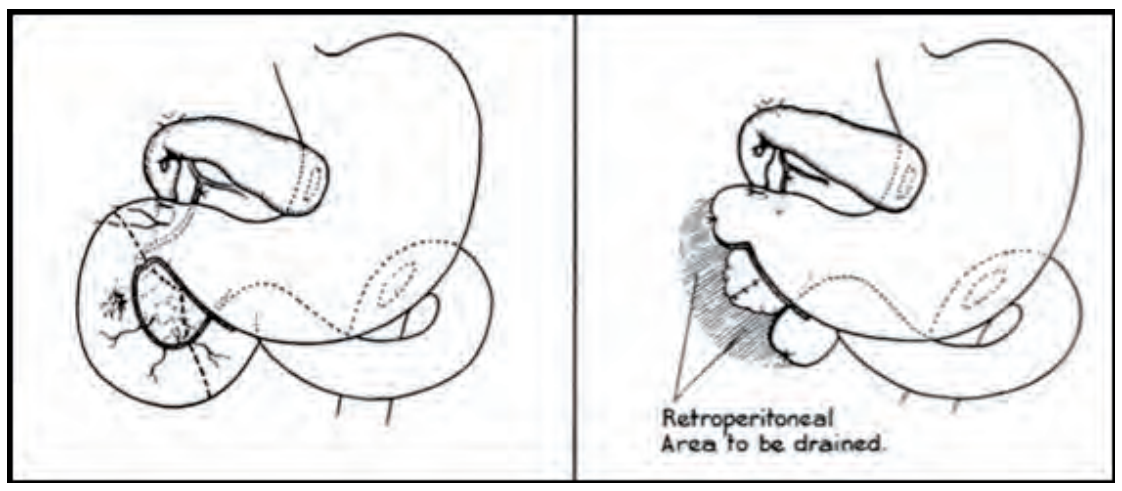

FIGURA 1: Reseccion en 2 tiempos

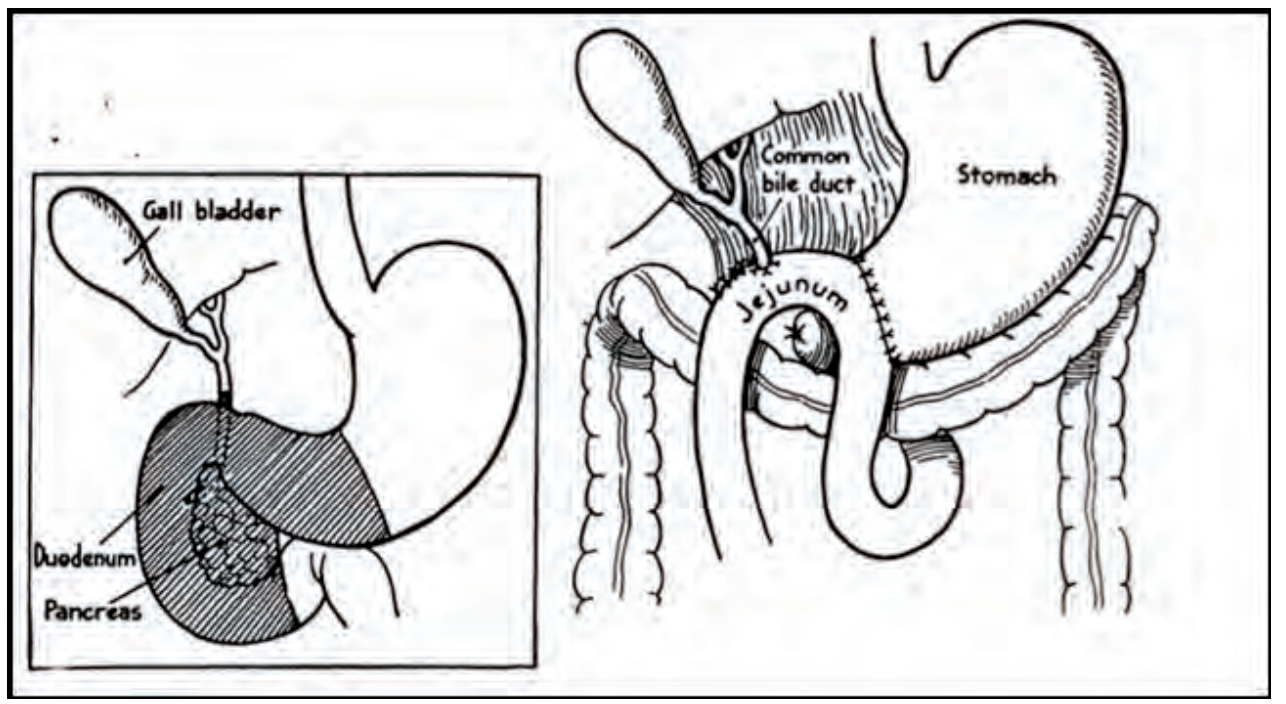

FIGURA 2. Técnica de Whipple en 1 tiempo con coledocoyeyunostomía.

Extraído de articulo original. ${ }^{4}$ 
En los comienzos de la cirugía de resección cefalopancreática se postulaba no realizar anastomosis al páncreas remanente con el tubo digestivo. Los argumentos utilizados eran:

1) Mayor índice de falla de sutura por activación de enzimas pancreáticas, 2) la posibilidad de vivir sin jugos pancreáticos, 3) realizada la anastomosis, en un alto porcentaje, se produce estenosis el conducto pancreático.

Cattell en cambio, entiende que es indispensable el drenaje del conducto pancreático, no solo por su utilidad en la digestión de las grasas, sino también porque la falla del cierre del muñón pancreático determina complicaciones y en algunos casos la muerte de los pacientes.

Bajo estos conceptos, Child en 1941 documenta la primera pancreaticoyeyunostomía, la describe como termino-terminal invaginante.

Posteriormente, el propio Cattell recomienda la anastomosis directa del conducto pancreático con el yeyuno, en este caso termino-lateral. Propone además, que si el diámetro del conducto pancreático es pequeño, se debe realizar de una sutura capsulo-yeyeunal denominada como "necrosante".

Finalmente en 1946, Whipple que ya realizaba su cirugía en un tiempo, anastomosa el conducto pancreático con el yeyuno mediante la utilización de un tubo de goma. Esta anastomosis había sido documentada previamente por Varco en el año 1945.

A la fecha actual, se han descrito más de 70 variaciones de pancreaticoyeyunostomías, que pueden agruparse en termino-terminales o termino laterales, inaviginantes o ducto-mucosa, en un plano o en dos planos, etc. Pero en definitiva, todas son modificaciones de las descritas por Cattell, Child y Whipple (Fig. 3). ${ }^{5}$

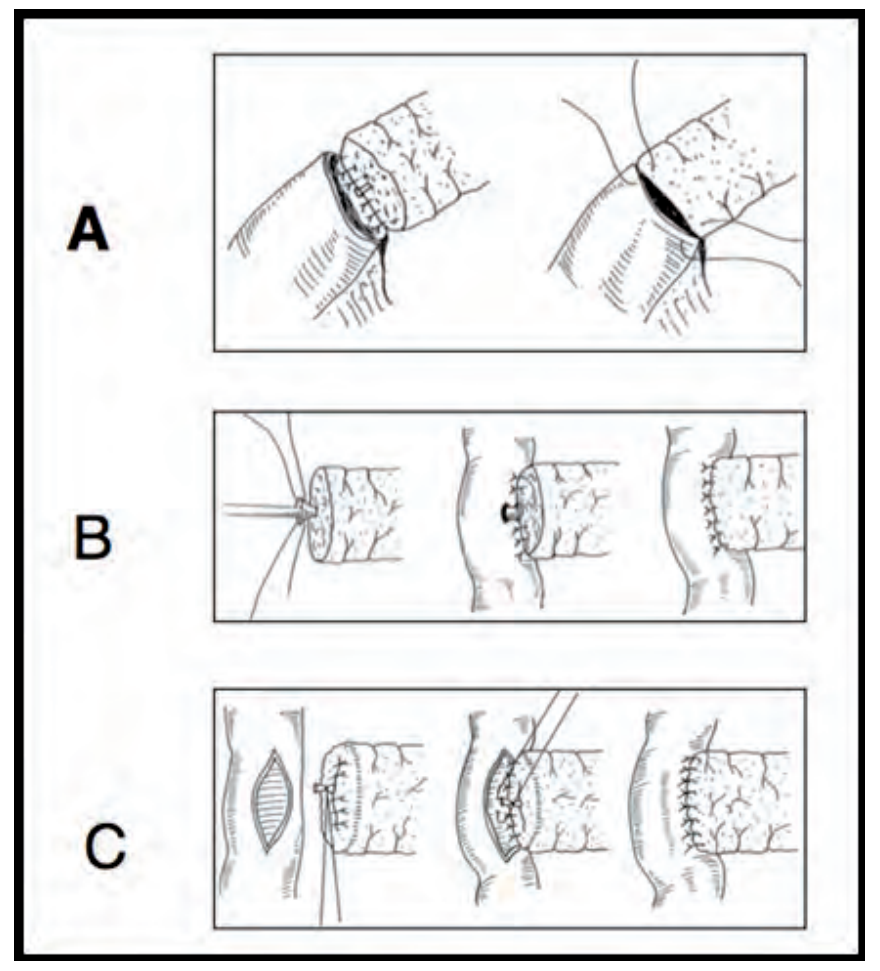

\author{
FIGURA 3: Pancreaticoyeyunostomías. \\ A: Pancreaticoyeyunostomía de Child, termino-terminal. \\ Invaginante 1941 \\ B: Pancreaticoyeyunostomía de Cattell termino-lateral. \\ Ducto-mucosa 1943 \\ C: Pancreaticoyeyunostomía de Varco y Whipple termino- \\ lateral. 1945. \\ Extradito de Kakita A. (5)
}

Con la popularización del procedimiento descrito por Whipple, se comenzó a ver una alto índice de complicaciones asociadas a la falla de la pancreaticoyeyunostomía (fístula pancreática). Este hecho, despierta en Wells el interés por otro tipo de derivación pancreática, la pancreaticogastrostomía. Basado en la teoría de la activación de las enzimas pancreáticas en el yeyuno, con la consiguiente digestión de la sutura de la pancreaticoyeyunostomía. Basado en este concepto realiza un procedimiento experimental en 7 perros, con buenos resultados durante el seguimiento. ${ }^{6}$

En el año 1952 este autor publica 3 casos de duodenopancreatectomías con pancreaticogastrostomía, concluyendo que este procedimiento es más seguro que la pancreaticoyeyunostomía. ${ }^{7}$ Dicha anastomosis ya había sido documentada por Waugh y Clagett en $1946 .^{8}$

Desde los inicios de la DPC, la sutura pancreática ha sido considerada el "talon de Aquiles" de esta cirugía. La fuga pancreática puede determinar la aparición de una fístula pancreática $(\mathrm{PF})$ o colecciones, y posteriormente, sangrados, RVG y sepsis. Aumentando de esta manera la morbilidad y mortalidad del procedimiento. ${ }^{9}$ En centros de alto volumen se estima que la FP se produce en $14 \%$ de los $\operatorname{casos}^{10}$, con oscilaciones entre el $10 \%$ y $28,5 \%{ }^{11}$

La International Study Group en el 2005 definió a la FP como la salida de cualquier líquido que presenta una dosificación de amilasa 3 veces superior a su valor sérico, luego del tercer día de postoperatorio. ${ }^{12}$ Además la clasificó en grados de severidad A,B,C. (Tabla 1) 
Los pacientes con FP grado C, presentan una alta tasa de reintervenciones (70\%), mayor incidencia de falla multiorgánica (68\%), y una mayor mortalidad (32\%), que las FP grados A y B. Además, su presencia retrasa o impide la realización de la adyuvancia. ${ }^{13}$

Los dos elementos de mayor riesgo para la producción de una FP, son la presencia de un páncreas blando y un conducto pancreático principal < a $3 \mathrm{~mm}$. de diámetro. Otros elementos identificados son la presencia de tumores ampulares o quísticos y la pérdida sanguínea mayor a $1000 \mathrm{ml}$ durante la cirugía. ${ }^{14}$

Callery y col. ${ }^{15}$ realizaron una estratificación del riesgo para la producción de una FP, de acuerdo a diferentes características del paciente y del procedimiento.(Tabla 2).

Un valor mayor o igual a 10 se asocia a un aumento en la posibilidad de fístula pancreática.

Tabla 1: Grados de severidad de FP.

\begin{tabular}{|l|c|c|c|}
\hline \multicolumn{1}{|c|}{ CARACTERITICAS } & GRADO A & GRADO B & GRADO C \\
\hline Signos de enfermedad sistémica & NO & SI & SI \\
\hline Requirió tratamiento ? & NO & Si & SI \\
\hline Evidencia ECO o TC & NO & SI & SI \\
\hline Drenaje persistente > 3 semanas & NO & SI & SI \\
\hline Signos de infección & NO & SI & SI \\
\hline Readmisión & NO & SI & SI \\
\hline Sepsis & NO & NO & SI \\
\hline Reoperación & NO & NO & SI \\
\hline Muerte & NO & NO & SI \\
\hline
\end{tabular}

Extraído de ISGP 2005. (12).

$\mathrm{ECO}=$ Ecografía

$\mathrm{TC}=$ Tomografía computada.

Tabla 2: Estratificación del riesgo de la FP.

\begin{tabular}{|l|c|c|}
\hline \multicolumn{1}{|c|}{ FACTOR DE RIESGO } & PARAMETRO & PUNTOS \\
\hline \multirow{2}{*}{ TEXTURA GALDULAR } & FIRME (6-10) & 0 \\
& BLANDO (1-5) & 2 \\
\hline \multirow{3}{*}{ PATOLOGIA } & CANCER PANCREAS o & 0 \\
& PANCREATITIS & \\
& TUMOR DE AMPOLLA o & 1 \\
& CANCER DE DUODENO & \\
\hline DIAMETRO DEL & $\geq 5 \mathrm{~mm}$ & 0 \\
CONDUCTO & $4 \mathrm{~mm}$ & 1 \\
& $3 \mathrm{~mm}$ & 2 \\
& $2 \mathrm{~mm}$ & 3 \\
\hline PERDIDA SANGUINEA & $\leq 1 \mathrm{~mm}$ & 0 \\
& $\leq 400 \mathrm{ml}$ & 1 \\
& $401-700 \mathrm{ml}$ & 3 \\
\hline
\end{tabular}

Extraído de Callery y col. (15).

La pancreaticoyeyunostomía es históricamente la forma de sutura mas utilizando en la DPC, pero los índices de FP documentada hacen surgir el interés por otras variantes de esta anastomosis, por ejemplo la pancreaticogastrostomía o modificaciones de la propia pancreaticoyeyunostomía.

Desde el punto de vista teórico, la pancreaticogastrostomía muestra ciertos beneficios. Se presenta como una sutura técnicamente sencilla, por la proximidad anatómica entre el páncreas y la pared posterior de estomago. ${ }^{16}$ Además, la pared gástrica es gruesa y ricamente vascularizada permitiendo una sutura más firme y segura. ${ }^{17}$

La pancreaticogastrostomía requiere un menor número de suturas y produce la inactivación de las enzimas pancreáticas por el PH gástrico, evitando el efecto teórico de la digestión de la sutura. Por otra parte, la SNG permite degravitar las secreciones pancreáticas, logrando menor contacto de las enzimas con la sutura.

Esto se contrapone al concepto teórico de que las enteroquinasas intestinales activan las enzimas pancreáticas, pudiendo determinar la digestión de la pancreaticoyeyunostomía y la posterior fístula pancreática. ${ }^{18}$ 
Se plantea también, que la gastroyeyunostomía se asocia a menor indice de fístula biliar, por menor contacto de esta sutura con las enzimas pancreática activadas.

En cambio, se propone como efectos adversos de la pancreaticogastrostomía un mayor índice de sangrado gastrointestinal $^{19}$, una mayor insuficiencia pancreática exógena, asociada a una estenosis del conducto pancreático y a una inhibición de las enzimas pancreáticas en un medio ácido. ${ }^{20}$

Los metaanálisis previos al 2008 aproximadamente, no mostraron diferencias entre estos dos tipos de anastomosis. ${ }^{21}$ En 2013 aparecen 2 estudios prospectivos randomizados que muestran un descenso en la incidencia de fístula pancreática con la realización de una pancreaticogastrostomía. El trabajo de Topal y col. ${ }^{22}$ en Bélgica, documentó $19.8 \%$ de FP moderada o severa en los pacientes con pancreaticoyeyunostomía, frente al 8\% de los pacientes con pancreaticogastrostomía. Esta diferencia fue independiente del diámetro del Wirsung, con un 10,2 \% de fístulas en ductos mayores de $3 \mathrm{~mm}$ en pancreticoyeyunostomías y de $2.86 \%$ en gastroyeyunostomías.

En el mismo sentido Figueras et al. ${ }^{23}$ mostraron en más de 100 pacientes, que hay una disminución del riesgo de FP, estadísticamente significativa, con la realización de pancreaticogastrostomía luego de la realización de una DPC.

Estos artículos estimularon la realización de otros trabajos que han confirmado estos resultados.

Los recientes metaanálisis de Tewari et al. ${ }^{24}$ en 2010, y en 2015, WeiTao Que et al..$^{25}$ en 2015, Liu et al. ${ }^{26}$ en 2015 y Menahem et al. en $2015^{27}$, han demostrado menor índice de FP y de menor gravedad en los pacientes sometidos a una pancreaticogastrostomía, frente aquellos sometidos a una pancreaticoyeyunostomía luego de una DPC. Asociado además, a menor estadía hospitalaria, pero sin variaciones en la mortalidad ni en otras morbilidades (sangrados, fístula biliar, RVG, alteraciones en la secreción exógena o endógena pancreática).

Este hecho, la ausencia de diferencias en la morbilidad y en la mortalidad entre ambos procedimientos, alertó a otros autores que han cuestionado estos metaanálisis, a la búsqueda de una explicación de estos resultados. Sus críticas radican en la heterogeneidad de la población analizada, las diferentes técnicas de pancreaticoyeyunostomías empleadas y la omisión en la documentación de factores de riesgo de FP como el diámetro del Wirsung y la textura del páncreas. Un reciente metaanálisis del 2016, intentó homogeneizar los grupos y no encontró diferencias en la tasa de FP con la utilización de una pancreaticogastrostomía o una pancreaticoyeyunostomía. Tampoco encontró diferencias en la morbilidad ni mortalidad luego de una DPC. ${ }^{28}$

Por lo tanto, aún no esta definido si la pancreaticogastrostomía tiene menor índices de FP y de otras complicaciones frente a una pancreaticoyeyunostomía. Se cree que en la valoración de la situación local, textura y movilidad del páncreas, así como del tamaño del conducto pancreático, deberán ser dirigidos los próximos estudios comparativos a fin de dilucidar esta problemática. ${ }^{29}$

$\mathrm{Si}$ bien todo parece indicar que la pancreaticogastrostomía tiene menor índice de FP, hasta tanto los resultados sean contundentes, la experiencia del cirujano y la técnica a la que esté habituado, deben primar en la decisión quirúrgica. La pancreaticogastrostomía sería más sencilla de realizar y reproducible.

Los páncreas considerados de mayor riesgo de fístula, parecen beneficiarse de la realización de una pancreaticogastrostomía. ${ }^{30}$

\section{¿PANCREATECTOMÍA CON PRESERVACION PILÓRICA O NO?}

La conservación o no de la región antropilórica durante una DPC puede determinar la aparición de alteraciones funcionales, asociadas a la técnica utilizada. Se destacan las derivadas del síndrome postgastrectomía (dumping, reflujo alcalino, úlceras de neoboca, síndrome de asa aferente, diarreas, perdida de peso) y el RVG.

Otros dos aspectos a tener en cuenta a la hora de comparar los procedimientos, son el oncológico (margen de sección) y los perioperatorios (duración de la cirugía y pérdidas sanguíneas).

La duodenopancreatectomía con preservación pilórica (DPCP) fue introducida por Watson en 1944¹ , en la resección de un tumor de la ampolla de vater. Pero fueron Traverso y Longmire quienes popularizaron la técnica a fines de la década del setenta y principios de los ochenta. En su primera publicación ${ }^{32}$, sometieron a una DPCP a 2 pacientes, uno por pancreatitis crónica y el otro por un tumor de duodeno. Mediante esta técnica, se buscaba disminuir el síndrome postgastrectomía evidenciado con la duodenopancreatectomía clásica (DPCc), los resultados en este sentido fueron favorables.

Una siguiente publicación en 1980 de los mismos autores, describe la experiencia de 18 pacientes con pancreatectomía y conservación pilórica. Su técnica consistía en preservar el píloro y los primeros uno a tres cm de duodeno, con una posterior reconstrucción duodeno-yeyuynal, termino-lateral, transmesocolónica. En esta serie no se documentaron pacientes con síndrome postgastrectomía con el uso de esta técnica, ni la presencia de úlceras gástricas en el seguimiento de 8 pacientes. ${ }^{33}$ (Fig. 4). 


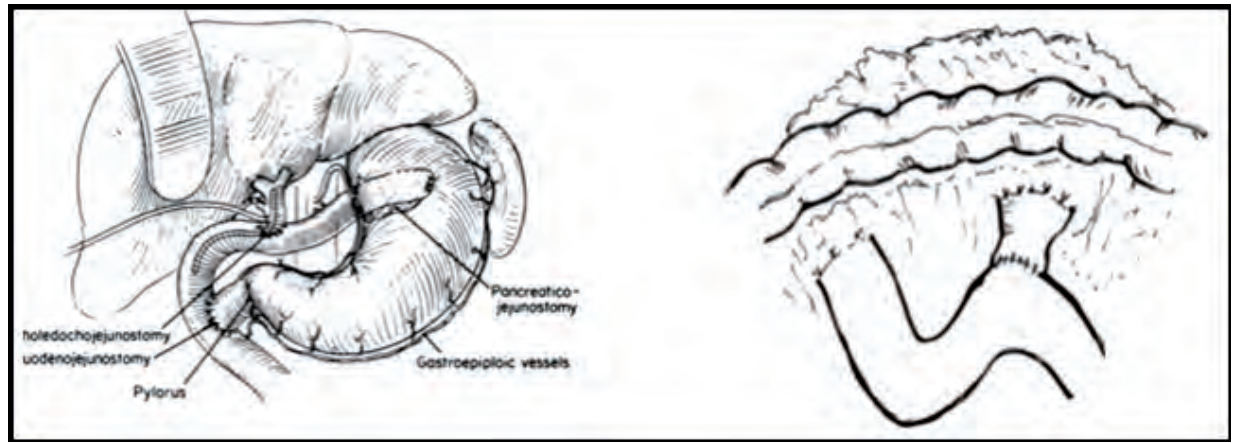

FIGURA 4.

Duodenopancreatectomía con conservación pilórica (DPCP). Anastomosis

transmesocolónica.

Extraído Traverso et al.

Articulo original. (33).

La DPCP no mostró diferencias oncológicas ni en la mortalidad operatoria cuando se comparó con la DPCc. ${ }^{34}$ Una vez documentado que ambos procedimientos son comparables desde el punto de vista oncológico, no modificando la mortalidad, surge el interés por demostrar que DPCP disminuye la morbilidad de la DPCc, la cual ronda el 40\%.

Los análisis iniciales mostraron que la DPCP disminuye el sangrado intraoperatorio y la necesidad de transfusiones, así como también se asoció a menor tiempo quirúrgico. ${ }^{35}$

A su vez Wenger et al., mediante un cuestionario de seguimiento, documentaron que la DPCP se asocia a una mejor calidad de vida, desde el punto de vista funcional gastrointestinal que la DPCc. ${ }^{36}$

Por otro lado Büchler et al. demostraron en su estudio prospectivo, que la preservación pilórica se asocia a mayor ganancia de peso postoperatoria, mejor tolerancia a la glucosa y mayor secreción de insulina. ${ }^{37}$

Pero la DPCP no está exenta de complicaciones funcionales y Warshaw documentó que solo 1 de 8 pacientes sometido a esta cirugía, pudo recobrar la vía oral en los primeros 10 días de postoperatorio. Fue una de las primeras publicaciones en mencionar que esta cirugía producía un $\mathrm{RVG} .{ }^{38}$

Esta compilación tuvo controversias desde el inicio de su análisis, mientras unos la consideran propia de la DPCP ${ }^{39}$, otros como Seiler, proponen que es la DPCc la que presenta mayor RVG. ${ }^{35}$

Mientras tanto, el estudio prospectivo randomizado multicéntrico de Tran et al ${ }^{40}$ del 2004, no mostró diferencias en el tiempo de vaciamiento gástrico cuando comparó los dos procedimientos, además concluyó que el RVG sería secundaria a otra complicación concurrente intraabdominal (sangrado, fístula pancreática o absceso), más que a la técnica empleada. Tampoco demostró diferencias en el tiempo operatorio, en la pérdida de sangre, en complicaciones metabólicas, en pérdida de peso, en cuanto a resecciones oncológicas, ni en la mortalidad, así como tampoco en la sobrevida global. Concluyendo que ambos procedimientos son comparables.

Cabe destacar, que la mayoría de los pacientes analizados en estos estudios, presentan una patología benigna, en general una pancreatitis crónica.

Especial atención merece la revisión sistemática Cochrane del $2014^{41}$ que analizó 6 estudios prospectivos randomizados. En esta, se realizó un análisis comparativo de sobrevida, mortalidad y morbilidad entre la DPCP y la DPCc, en pacientes con cáncer de páncreas o tumores periampulares. Los resultados sobre resecciones oncológicas, mortalidad quirúrgica y sobrevida, no mostraron diferencias significativas en ambos grupos. En cuanto a la morbilidad, tampoco hubo diferencias en la incidencia de fístula pancreática, fístula biliar, sangrado postoperatorio, reoperaciones ni estadía hospitalaria. Para valorar la calidad de vida, se tomaron en cuenta la pérdida del apetito, la presencia de náuseas, vómitos, diarrea y ganancia de peso, las cuales tampoco mostraron diferencias entre ambos procedimientos.

Mientras tanto, evidenció un mayor tiempo quirúrgico en el procedimiento de Whipple clásico (MD -68.26, 95\% CI -105.7 to $-30.83 ; \mathrm{P}<0.0004 ; \mathrm{I}^{2}=67.5 \%$ ) y un mayor sangrado intraoperatorio (MD $-0.76,95 \% \mathrm{CI}-0.96$ to -0.56 ; $\mathrm{P}<0.00001)$, pero sin una diferencia en la reposición hemática entre ambos grupos. Cabe aclarar, que del análisis del tiempo operatorio surge una heterogeneidad moderada en cuanto los datos utilizados.

Por ultimo, el RVG no mostró diferencias significativas entre los procedimientos analizados, pero en base a una heterogeneidad alta de los datos, sobre todo por las diferentes clasificaciones utilizadas por los distintos trabajos. La cirugía con conservación pilórica mostró un 29\% de gastroparesia (RVG), frente a $24.5 \%$ de aquellos sometidos a la cirugía de Whipple clásica, (OR 2.35, 95\% CI 0.72 to 7.61 ; P de 0.16 ; 12 = 75.6\%).

La actual revisión Cochrane del 2016, no modifica estas conclusiones previas. ${ }^{42}$

Hasta el momento no hay datos concluyentes que evidencien que la conservación pilórica o no, produzcan impacto en la morbilidad o en la sobrevida a largo plazo, durante la realización de una duodenopancreatectomía.

El retardo en el vaciamiento gástrico o gastroparesia post-duodenopancreatectomía es una de las complicaciones mas frecuentes de dicha cirugía. Se presenta en un $20-40 \%$ de los casos y se asocia a un deterioro de la calidad de vida y un retraso en el inicio de la terapia adyuvante. ${ }^{43}$ 
Se caracteriza por la presencia de vómitos, necesidad de sonda nasogástrica (SNG), intolerancia a los alimentos y consiguiente dificultad en el restablecimiento de la vía oral.

Desde su reconocimiento, se han implementado diversas tácticas para disminuir su incidencia. En el 2007 el International Study Group of Pancreatic Surgery consensuó una definición, que ha permitido actualmente comparar los diferentes estudios que analizan esta complicación (Tabla 3). ${ }^{44}$

Tabla 3: Clasificación de Retraso del Vaciamiento Gástrico.

\begin{tabular}{|c|c|c|c|}
\hline CARACTERITICAS & GRADO A & GRADO B & GRADO C \\
\hline $\begin{array}{c}\text { Requerimiento SNG } \\
\text { (días postoperatorio) o } \\
\text { reintroducción }\end{array}$ & SNG 4-7 días & SNG 7-14 días & SNG + 14 días \\
\hline $\begin{array}{c}\text { Incapacidad de tolerar } \\
\text { alimentos (días) }\end{array}$ & 7 & 14 & 21 \\
\hline $\begin{array}{c}\text { Distensión gastrica o } \\
\text { vómitos }\end{array}$ & SI/NO & SI & SI \\
\hline Uso de proquinetícos & SI/NO & SI & SI \\
\hline
\end{tabular}

Dentro de las causas que se describen en la génesis del RVG se destaca, un defecto en la inervación y vascularización del sector antropilórico durante la DPC, a los que se le suma los efectos producidos por otras complicaciones intercurrentes (FP, fístula biliar, sangrados, abscesos) y las variantes técnicas utilizadas como la anasotmosis gastro o duodenoyeyyunal, la posición retrocólica de asa de ascenso, la gastrectomía más o menos extensa y la disminución de la producción de hormonas gastrointestinales, entre otras. ${ }^{43,45}$

Hasta el momento, no hay datos concluyentes de que DPc tenga menor incidencia de RVG que la DPCP.

Kawai et al. en el 2011, proponen una nueva técnica quirúrgica en la cual resecó solo el píloro, preservando mas del 95\% del estómago, así como la irrigación e inervación de la región antropilórica. ${ }^{46}$ Este autor realizó un estudio prospectivo randomizado de 139 paciente, comparando las resecciones con preservación pilórica vs resección pilórica. El estudio mostró que la técnica con resección pilórica tuvo menos indice de RVG, estadísticamente significativa, frente a la técnica con preservación pilórica $(4,5 \%$ vs $17,5 \%, \mathrm{P}=0.0244)$. (Fig.5).

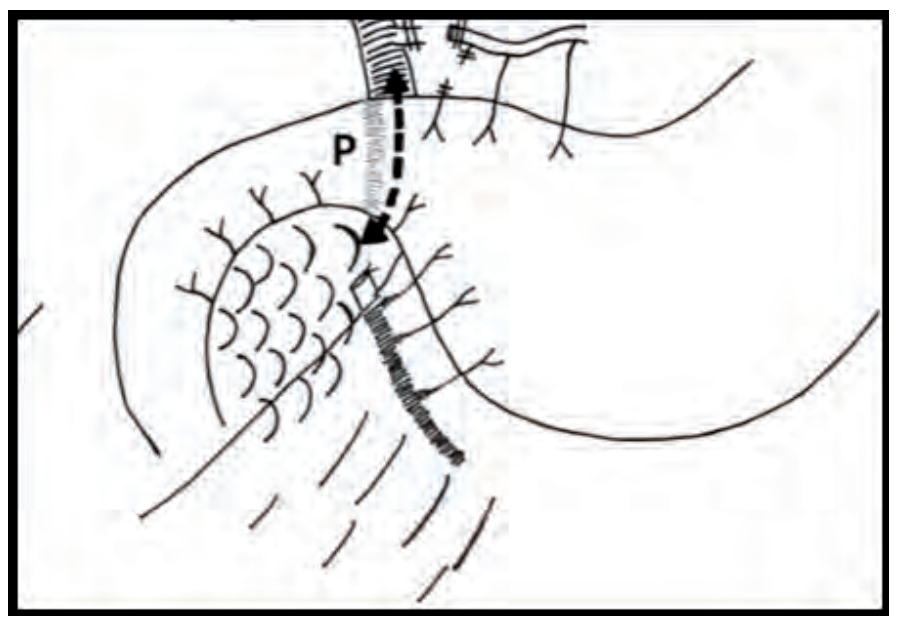

FIGURA 5. Técnica de Kwai, de resección pilórica y preservación gástrica.

Extraído de Kwai y col. (46).

En el seguimiento a dos años este mismo grupo, mostró que la resección pilórica mantiene los resultados en cuanto RVG frente a la preservación pilórica. Además, documentó una mejora en la recuperación del peso vinculado a una mejor alimentación, sin aumento de los elementos de un síndrome postgastrectomía. Demostró también, que la malnutrición empeora el RVG, por lo cuál, aquellos con una gastroparesia precoz entran en un círculo vicioso, empeorando la sintomatología por las dificultades en la alimentación. ${ }^{47}$

Un metaanálisis de 804 pacientes confirmó los hallazgos de Kawai y documentó que la cirugía con resección pilórica presenta menor RVG, estadísticamente significativa, que con la cirugía de conservación pilórica. ${ }^{48}$

Otro metaanálisis de 2599 pacientes, homogeneizó la población, retirando variables tales como la diabetes, uso de fármacos, compilaciones postoperatorias, entre otras, que influyen en la aparición del RVG. Luego comparó todas las técnicas que resecan el píloro como la técnica de Whipple clásica y aquella que reseca únicamente el píloro, frente a la 
cirugía de conservación pilórica. Demostró, que la resección pilórica con mayor preservación gástrica se asoció a menor índice de gastroparesia. Aunque sus resultados deben tomarse con precaución, dado el escaso número de trabajos con esta técnica. ${ }^{49}$

Otras diferentes técnicas quirúrgicas y de reconstrucción se han empleado a fin de disminuir el RVG. El asa diseñada por Braun, para la gastroyeyunostomia, evita algunas complicaciones del síndrome postgastrectomía como el reflujo alcalino, así como el síndrome de asa aferente. Esta reconstrucción fue utilizada también para disminuir el RVG producida por la DPC. Una revisión del $2014^{50}$ comparó diversas formas de anastomosis duodenoyeyunales, se utilizaron asas cortas (distancia entre hepaticoyeyunostomía y anastomosis duodenoyeyunal de $20 \mathrm{~cm}$ ) y asas largas (distancia de 50-60 cm). Así como un ascenso precólico o retrocólico del asa de duodenoyeyunostomía, asociado o no a la realización de un asa de Braun.

Esta revisión concluyó que la utilización de un asa yeyunal larga, de unos 50-60 cm, entre la hepáticoyeyunostomía y la duodenoeyunostomía, por pasaje precólico y la realización de un asa de Braun, se asoció a un menor índice RVG, con un porcentaje de 4,5\%. Desde el punto de vista teórico, la fijación de la región antropilórica que se produce por el pasaje a través del mesocolon, puede determinar obstrucción o angulación del duodeno con la consiguiente distensión gástrica. Con un asa larga, todo el contenido pasa por cualquiera de las ramas hacia abajo por declive, evitando la angulación y el síndrome de asa aferente. El apoyo del asa de Braun permite el drenaje de jugo pancreático y biliar hacia el yeyuno, evitando su pasaje por la a través del estómago. (Fig. 6)

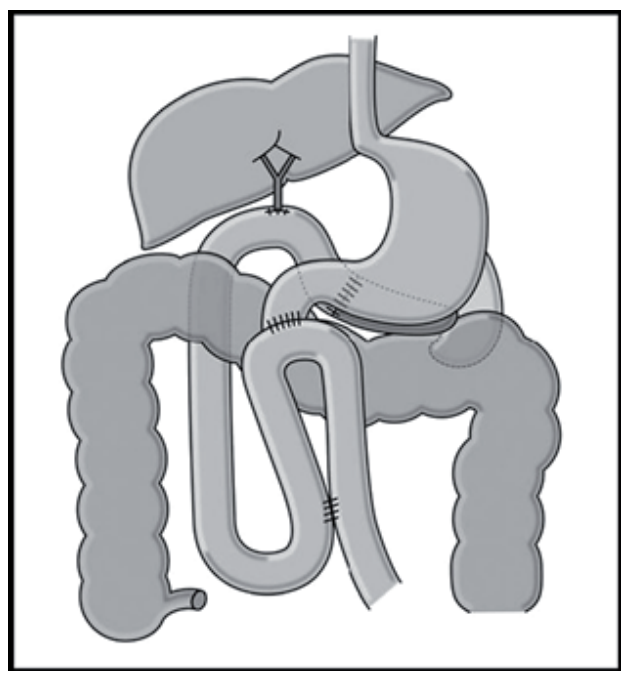

Figura 6. Esquema de anastomosis duodeno-yeyunal, precólica, con asa de Braun asociada.

Extraído de Cordesmeyer et al. (50)

Otros autores han mostrado los beneficios del uso del asa de Braun en el descenso en el RVG.

Hochwald et al. ${ }^{51}$ reportaron $7 \%$ vs. $31 \%$ ( $\left.\mathrm{P}=0.003\right)$, Nikfarjam et al. ${ }^{52}$

$4.2 \%$ vs. $35 \%,(\mathrm{P}=0.008), \mathrm{Xu}$ et al. $536.7 \%$ vs. $26.87 \%,(\mathrm{P}<0.001)$.

Hwang et $\mathrm{a}^{54}$ realizaron en el 2016 , el primer estudio prospectivo randomizado que valora el papel del asa de Braun, en la mejoría del retardo en el vaciamiento gástrico.

Este estudio randomizó 60 pacientes y determinó una mejora en el retardo del vaciamiento gástrico en aquellos en los que se realizó un asa de Braun 3.3\% vs. 23.3\% ( $\mathrm{P}=0.052)$.

La posición de ascenso del asa yeyunal para la reconstrucción de la anastomosis duodeo-yeyunal o gastroyeyunal, también es tema de debate. Cordesmeyer el al..$^{50}$, obtuvieron menor índice de retardo en el vaciamiento gástrico con el uso de un asa precólica, argumentando que evita el anclaje y la angulación que se produce en el mesocolon, así como también lo aleja de las suturas precedentes que son causa, muchas veces, de producción del RVG.

No todos los estudios muestran beneficios con el uso del ascenso precólico, un metaanálsis del 2016 que analizó 6 estudios controlados y randomizados con un total de 588 pacientes, no mostró beneficios con esta técnica, pero sus resultados deben ser tomados con cautela por la heterogeneidad de nivel moderado que presentaron los datos. (6 RCTs, 588 pacientes, OR $0.60,95 \%$ CI $\left.0.31-1.16, Z=1.52, \mathrm{p}=0.13, \mathrm{I}^{2}=56 \%\right) .55$

Si bien no existe aún la evidencia suficiente, del análisis de los resultados surge que habría una mejoría en el RVG con el ascenso precólico, así también lo demuestra en su metaanálisis Hanna ${ }^{45}$ de 5712 pacientes, donde mostró un beneficio estadísticamente significativo con la realización de un DPC con gasterectomía sub total y gastroyeyunostomía precólica. 
Por último, también se investigó si el diámetro de la duodenoyeynuostomía o de la gastroyeynuostomía, influyen en la aparición o no del RVG. Uno de los primeros estudios en documentar esta variable fue el de Walters y col. en 2015, donde comparó una duodenoyeyuonostomía (4 cm de diámetro), gastroyeyunostomía (4-5 cm de diámetro) y gastroyeyunostomia larga ( $9 \mathrm{~cm}$ de diámetro). Los resultados mostraron, que utilizar una anastomosis digestiva larga disminuye no solo la incidencia de RVG, sino también su severidad.

El retardo en el vaciamiento gástrico es una complicación frecuente, que genera morbilidad y retrasa el inicio de la adyuvancia. Su génesis es multifactorial y están implicados la alteración en la inervación e irrigación del sector antropilórico y la presencia de complicaciones intercurrentes (fistula pancreática, colecciones, fistula biliar, sangrados). Hay resultados alentadores con la resección pilórica exclusiva para evitar su aparición. Recientes estudios mostraron que la realización de una anastomosis larga (gastroyeyunal), sobre un asa aferente larga, en una posición precólica y asociada a un asa de Braun, ha disminuido de forma estadísticamente significativa, la aparición de esta complicación.

\section{LINFADENECTOMIA STANDART O LINFADENECTOMIA EXTENDIDA.}

La alta tasa de recaída local luego de una pancreatectomía pretendidamente curativa por cáncer, llevó al interés por el estudio de las linfadenectomías realizadas. Esta recaída se produce a pesar de confirmar márgenes negativos en la pieza de resección e incluso luego de una pancreatectomía total. Por lo cual, la diseminación linfática cobró especial atención.

Los datos aportados por Cubilla en 1978, que mantiene aún su vigencia, evidenciaron que la diseminación linfática está presente en aproximadamente el $90 \%$ de los casos y que se produce sobre ganglios ubicados, preferentemente en los sectores supraduodenopancreático, retroduodenopancreático e infraduodenopancreatico, para los tumores de cefá$\operatorname{licos} .{ }^{57}$

En el estudio de Ishikawa et al. se compararon 2 grupos de pacientes, durante 2 periodos de tiempo, que fueron sometidos a duodenopancreatectomía cefálica por cáncer. En el grupo 1 (1971 a 1981) de 32 pacientes, se realizaron duodenopancreatectomía con resección de ganglios del grupo pilórico, superior cefálico, coledociano, anterior cefalopancreático, posterior cefalopancreático, inferior cefálico y por último mesentérico superior.

El grupo 2 (1981 a 1986) se le suma a la resección descrita para el grupo 1, los grupos ganglionares corporales superior e inferior, cólico medio, hepático común, tronco celíaco y paraaórticos.

Este estudio mostró una sobrevida a 3 años del 13\% para el grupo 1 vs el 38\% para el grupo 2 con p<0,05. Con un descenso del riesgo a morir por recurrencia local de $67 \%$ a $16 \%$ en favor del grupos 2 p $<0.05$.

$\mathrm{Si}$ bien este estudio concluye, que en pacientes con tumores menores a $4 \mathrm{~cm}$ se recomienda la resección ganglionar extendida, manifiestan que no consiguen el control a distancia de la enfermedad. ${ }^{58}$

En la misma línea a fines de los ochenta, otro grupo japonés compara pacientes con resecciones radicales, donde se incluyen ganglios yuxtaregioneales y resecciones no radicales como la duodenopancreatectomía estándar. En él, también se encontró un beneficio con la realización de las linfadenectomías extendidas y concluye que las mismas son indispensables para conseguir la cura en el cáncer de páncreas. ${ }^{59}$ Aunque este estudio tiene un sesgo, un mayor porcentaje de los pacientes sometidos a resecciones extendidas eran N- (50\% para resecciones extendidas vs 35\% para DPC estándar), por lo cual este estudio debe ser tomado con cautela.

En el 2007 se realizó un metaanálisis que compara la duodenopancreatectomía con linfadenectomía estándar vs la linfadenectomía extendida. Contó con 5 estudios no randomizados y 4 prospectivos randomizados, con resultados contradictorios.

De los resultados del metaanálisis se evidenció que la extension de la linfadenectomía no afectó la sobrevida global. Si bien la morbilidad y mortalidad del procedimiento fueron similares, el grupo con linfadenectomía extendida presentó mayor retardo en el vaciamiento gástrico, diarrea y desnutrición. El número de ganglios obtenidos fue mayor en el grupo con linfadenectomía extendida.

Este metaanálisis encuentra que la información disponible es muy heterogénea y que no se pueden sacar conclusiones definitivas, pero dado que no hay cambios en la sobrevida se recomienda la realización de una linfadenectomía estándar y reservar a la extendida para ensayos clínicos, dado la morbilidad que produce. ${ }^{60}$

Los pocos trabajos prospectivos randomizados, con en un bajo número de pacientes, concluyen que la linfadenectomía extendida se asocia a mayor tiempo operatorio, mayor pérdida sanguínea, mayor número de ganglios resecados, mayor 
morbilidad (diarrea y retardo en el vaciamiento gástrico), pero con deterioro en la calidad de vida y sin mejoría de la sobrevida. ${ }^{61-66}$

La heterogeneidad de los estudios por las diferencias en los vaciamientos ganglionares, las técnicas quirúrgicas empleadas, la selección de los pacientes, así como la realización o no de terapia adyuvante, llevó a la necesidad de definir algunos criterios para el estudio del tema.

Es así, que se llevó a cabo en el Consenso de la International Study Group on Pancreatic Surgery (ISGPS) ${ }^{67}$ las definiciones y precisiones sobre las linfadenectomías en el cáncer de páncreas, basados en una búsqueda bibliográfica. Lo primero que se comparó y definió fueron las linfadenectomías estándar y la extendida. Se utilizó como base, la nomenclatura japonesa de los grupos ganglionares para el cáncer de páncreas. ${ }^{68}$ (Fig 7)

La linfadenectomía estándar incluye la resección de los grupos 5, 6, 8a, 12b1, 12b2, 12c, 13a, 13b, 14a, 14b, 17a, $17 \mathrm{~b}$. (Fig 8).

Mientras que las linfadenectomías extendidas son variables y pueden incluir desde los grupos 9, 15,16, incluso para algunos autores el 10 y 11 .

El consenso concluye que ningún estudio prospectivo randomizado ha mostrado beneficios de la linfadenectomía extendida y que la misma se asoció a mayor índice diarrea crónica y pérdida de peso.

Este trabajo, encuentra necesario la resección del grupo 14, a la derecha de la arteria mesentérica, lugar de asiento de gran parte de la recidiva local, además considera que durante una correcta resección del proceso uncinado, este grupo queda incluido.

Capítulo aparte merece el grupo para-aórtico N16, su compromiso es un factor de riesgo negativo en cuanto a sobrevida. No hay consenso en si debe incluirse en la linfadenectomía estándar y algunos consideran que de ser positivo, en una biopsia extemporánea, no debe completarse la duodenopancreatectomía.

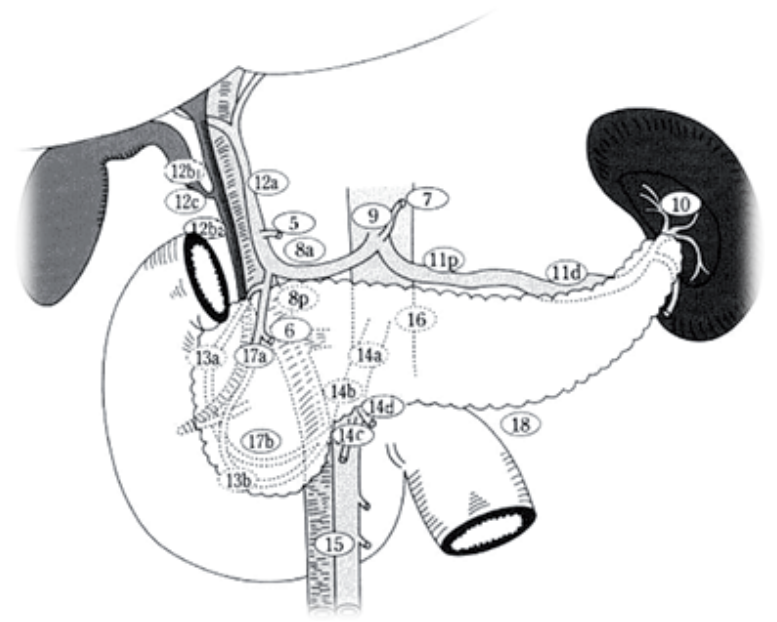

Figura 7. Estaciones ganglionares de la escuela Japonesa. Extraído de Tol J et al. Surgery 2014;15(3):591- 600. (67).

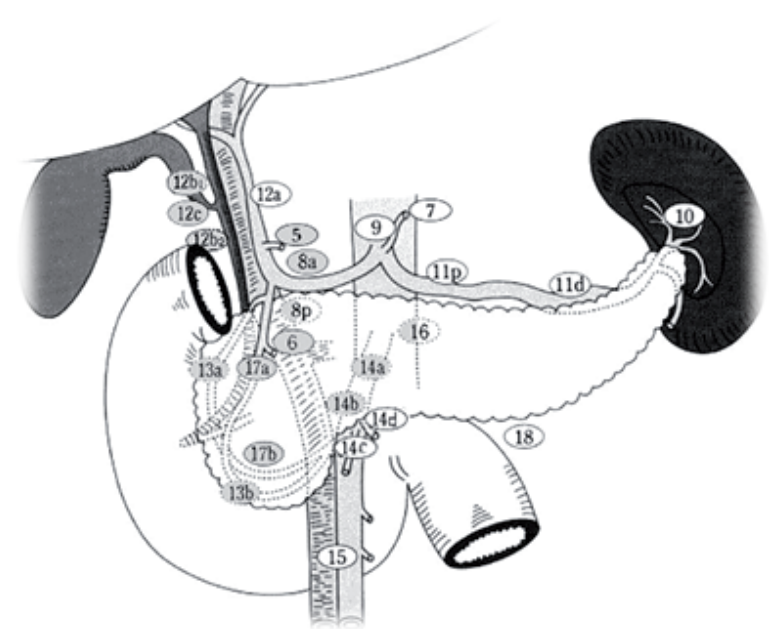

Figura 8. Linfadenectomía estándar.

Extraído de Tol J et al. Surgery 2014;15(3):591- 600. (67). 
Un reciente metaanálisis ${ }^{69}$, demuestra también que la linfadenectomía extendida conlleva un mayor tiempo operatorio, mayor necesidad de transfusiones sanguíneas y mayor índice de complicaciones.

La presencia de diarrea se asoció a la mayor disección de la arteria mesentérica superior. Además la linfadenectomía extendida no mostró mejoría sobre la sobrevida global. Por otro lado, se propone que el manipuleo que provoca la linfadenectomia extendida, se asocia a un mayor riesgo de diseminación de células tumorales.

Por último, otro metaanálisis del $2015^{70}$, toma en cuenta 5 estudios prospectivos randomizados, con un total de 546 participantes, a 276 se les practicó un vaciamiento extendido y a 270 una linfadenectomía estándar. El procedimiento extendido no mostró mejoría en la sobrevida $(\mathrm{HR}=0.88,95 \%(\mathrm{CI})=075-1.03 ; \mathrm{P}=0.11)$, con una heterogeneidad no significativa $\left(\mathrm{P}=0.92 ; \mathrm{I}^{2}=0 \%\right)$.

Hay un mayor recuento ganglionar en el vaciamiento extendido sobre el estándar, pero asociado a una morbilidad mayor $(\mathrm{RR}=1.23 ; 95 \% \mathrm{CI}=1.01-1.50 ; \mathrm{P}=0.004)$, con una heterogeneidad de los datos no significativa $(\mathrm{P}=0.35$; $\left.\mathrm{I}^{2}=9 \%\right)$.

En cambio, no se encontró un mayor tiempo operatorio ni mayor necesidad de transfusiones sanguíneas con el procedimiento extendido.

La diarrea crónica y la desnutrición se asociaron a la disección de 360 grados de la arteria mesentérica superior, con la consiguiente denervación y no así con las disecciones menores.

Por otra parte, hay controversias sobre el factor pronóstico del N1, mientras algunos lo encuentran un factor pronóstico negativo, otros no evidencian modificaciones en la sobrevida a largo plazo entre la presencia de un N1 o un N0. Se especula que aquellos que no encuentran diferencias entre N0 y N1, se basan en una recolección baja de ganglios durante la linfadenectomía y se perderían aquellos ganglios metastásicos, considerandose una linfadenectomía no representativa. $^{71,72}$

Hoy en día, se define que aproximadamente entre 12 y 16 ganglios son aceptados para una correcta estratificación. ${ }^{71}$

Slidell et al. ${ }^{73}$ encontraron que cuando el N0 se basaba en el análisis de 11 ganglios, la sobrevida media era de 16 meses, mientras que si se basaba en 12 ganglios, la sobrevida asciendía a 26 meses ( $<$ < 0,01). Por lo cual, un mínimo de 12 ganglios deben ser evaluados para una correcta estadificación (HR 0.68, 95\% CI 0.52-0.90; P = .006).

La evidencia actual sugiere que la presencia de N1 se asocia a un peor pronóstico y a un descenso en la sobrevida global. E1 N1 aumenta de riesgo de muerte por cáncer $(\mathrm{HR}=1.44,95 \% \mathrm{CI}: 1.33-1.55 ; \mathrm{P}<.001)$ y presenta una sobrevida media de 12 meses vs 18 meses del N0.73

Malleo et al. ${ }^{71}$ encuentran cifras superiores de sobrevida, pero siempre mayor en los pacientes N0 comparado con los N1 (55 meses vs 30 meses).

Se ha estudiado la relación ganglios positivos sobre ganglios totales (Lymph node ratio [LNR]), el número total de ganglios comprometidos, así como la localización de los mismos, como posibles factores pronósticos.

Slidell et al. ${ }^{73}$ encuentran que LNR < a 0,2 se asocia a un mejor pronóstico que si es > 0,4 (15 meses vs 10 meses de sobrevida media). Y que cada $10 \%$ de ascenso del LNR hay un descenso en la sobrevida de $9 \%(\mathrm{HR}=1.09,95 \% \mathrm{CI}$ : $1.07-1.11 ; \mathrm{P}<.001)$.

Mientras tanto, Riediger et al. ${ }^{72}$ considera al LNR un factor de riesgo independiente que afecta la sobrevida global, con un punto de corte de $\mathrm{LNR} \geq 0,3$. En tanto Zhan et al. ${ }^{74}$ encuentran que la sobrevida cae en forma significativa con un LNR es $>0,2$.

Por su parte el trabajo de Malleo et al. ${ }^{71}$ encuentra que el número de ganglios comprometidos se asoció más con la sobrevida que el LNR. Encontró que mientras la sobrevida media fue de 29 meses si tenía un ganglio metastásico, era de 9 meses si habían más de 8 ganglios comprometidos.

Otro de los puntos interesantes es que la localización de los ganglios comprometidos puede tener implicancias pronósticos. Dentro de los más estudiados se encuentra el grupo de la mesentérica superior (grupo 14), donde él mismo es considerado un factor pronóstico independiente. ${ }^{71}$

La pregunta es ¿cual es la trascendencia clínica de estos datos?. El mejor conocimiento sobre la estadificación y pronóstico del paciente con cáncer de páncreas, permite una mejor selección de los tratamientos, para un grupo de pacientes que ya de por sí tienen baja sobrevida. De esta forma, pacientes con ganglios positivos de grupo 14 quizá no sean candidatos a una cirugía y se beneficiarían de un tratamiento de neoadyuvancia inicial, o que el valor de LNR determine o no la realización de terapias adyuvantes.

La disección linfática extendida no esta justificada, dado que no cambia la sobrevida y esta asociado a un aumento de la morbilidad. Se necesita un mínimo de 16 ganglios para una correcta estadificación.

La relación de ganglios positivos sobre ganglios totales, el número total de ganglios comprometidos, así como su localización, han sido estudiados como factores de riesgo independiente que tienen implicancias en la sobrevida. 
En el 2007 Gockel et al. ${ }^{75}$ describen una region anatómica denominada mesopáncreas, sitio de asiento de la mayoría de las recaídas locales. Estos datos son concordantes con la alta tasa de resecciones R1 que presenta el borde medial y posterior de las piezas de duodenopancreatectomía. (60-80\%).

Esta región, no aceptada por todos como anatómica, nace de conceptos embriológicos de plegamientos de fascias, que derivan del mesogástrio posterior. Se encuentra por detrás de la cabeza del páncreas y enmarcado entre los vasos mesentéricos y la aorta. Hay diferentes descripciones y extensiones de la región. Adham et al. ${ }^{76}$ realizan una definición simplista de la region, como "el triángulo del mesopáncreas", delimitado por la cara posterior de la porta y la emergencia de la arteria mesentérica superior y el tonco celíaco, de la aorta abdominal. Mientras tanto Wu, lo describe como una region divida por el proceso uncinado con un mesopáncreas anterior y otro posterior. ${ }^{77}$

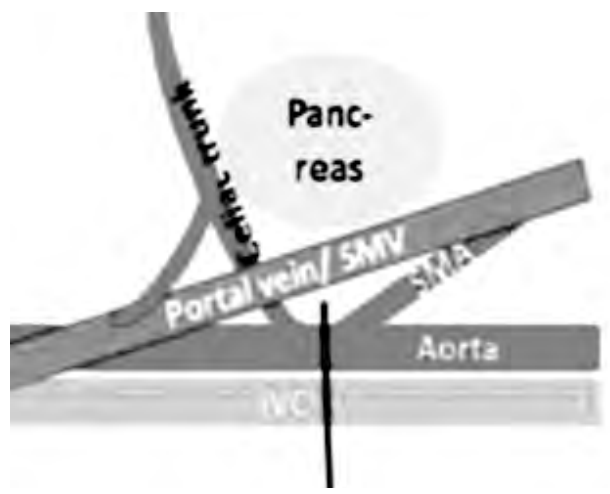

Figura 8. Esquema del “triángulo del mesopáncreas" Extraído de Wu et al. (77).

El mesopáncreas comprende un tejido celular que contiene nervios, vasos y ganglios. En su interior, inmerso en un tejido conjuntivo se encuentra el plexo nervioso cefalopancreático, la arteria pancreático duodenal inferior, venas yeyunales, arterias yeyunales y ganglios paraaóritcos grupo $16 \mathrm{a} 2,16 \mathrm{~b} 1 .^{78}$

Siguiendo los preceptos de Heald del "Holy plane" para el cáncer de recto, Kawabata et al. describe la escisión total del mesopáncreas buscando disminuir la recidiva local. A partir de allí, se han diseñado diversas tácticas de resección del mesopáncreas, por ejemplo, el abordaje arterial inicial o abordajes posteriores, así como también diversos niveles de resección. ${ }^{79}$

Los niveles de resección se basan en una mayor o menor extensión de la disección sobre la arteria mesentérica, siendo el nivel 1 una resección mas limitada y el nivel 3, una disección hasta la adventicia de una hemicircunferencia de la arteria mesentérica superior. Esta última conlleva la resección de los ganglios del grupo $16 .^{78}$

La resección completa de esta región denominada mesopáncreas podría disminuir la incidencia de recurrencia local, dado el alto porcentaje de resecciones completas que produce (R0 93\% vs 60\%). ${ }^{77,79}$

Pero la utilización de los conceptos de Heald y la comparación entre mesorrecto y mesopáncreas, parece no ser adecuada y tiene sus detractores.

Un reciente estudio en cadáveres destacó las diferencias conceptuales entre ambas estructuras y resecciones.

El mesopáncreas no tiene limites definidos como el mesorrecto, mientas en este último están bien definidas las estructuras y separadas de sus nervios autonómicos, dentro del mesopáncreas se encuentran vasos, nervios, y tejido linfático. La escisión mesorrectal total esta estandarizada y puede ser evaluada su calidad por la anatomía patológica, hecho que no sucede en la resección del mesopáncreas.

Los depósitos tumorales del recto estarían, en su mayoría, confinados al mesorrecto, mientras que hay depósitos ganglionares en el cáncer de páncreas fuera de su meso. ${ }^{80}$

Por lo cual, aquellos preceptos oncológicos utilizados para la escisión mesorrectal total, no pueden ser aplicados al páncreas y es posible que no se logren los mismos resultados.

Una de las cuestiones importantes, es si la escisión total del mesopáncreas debe considerarse parte de la linfadenectomía. La resección del mesopáncreas incluye más que una resección linfática, ya que comprende un tejido celuloadiposo, que además contiene el plexo nervioso y pedículos vasculares. Por otro lado, incluye los ganglios del grupo 16, que iría en contra de las recomendaciones de una linfadenectomía estándar que no la incluye. ${ }^{77}$

En cuanto al beneficio de la resección del mesopáncreas, los datos iniciales no evidenciaron mayor tiempo operatorio, mayor sangrado o mayor mortalidad. Esta claro su beneficio aumentando las resecciones R0, pero no hay datos en cuanto al beneficio en la sobrevida, falta seguimiento a largo plazo para valorar su impacto. ${ }^{77}$ 


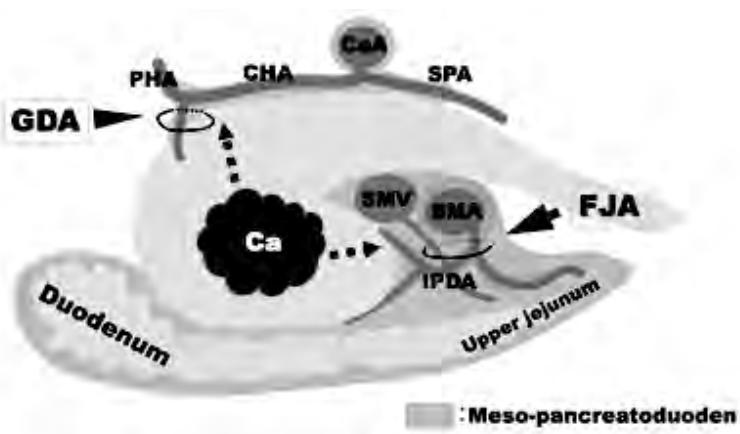

Figura 9. Esquema del mesopáncreas. FJA (primer pedículo yeyunal) calve en la disección del mesopáncreas.

Extraído de Kawabata, et al. EJSO 2016; 42: 689-705.

\section{RESECCION VENOSA DURANTE LA DUODENOPANCREATECTOMÍA CEFÁLICA}

La primera pancreatectomía con reconstrucción venosa fue descrita por primera vez por Moore et al. en $1951 .{ }^{81}$ Luego le siguieron los conocidos trabajos de Fortner de resecciones extendidas, pero asociadas a una morbimortalidad elevada. No fue hasta los años 90 donde se reportan casos de pancreatectomías con reconstrucción venosa y resultados comparables a dicha cirugía pero sin resección vascular. ${ }^{82}$

Durante décadas el compromiso venoso fue considerado como parte de una enfermedad irrsecable. Los avances en las técnicas quirúrgicas ha permitido la realización de duodenopancreatectomías con resultados similares a las resecciones sin compromiso vascular.

Hoy se considera a los tumores pancreáticos con compromiso venoso, como tumores borderline, y se propone la realización de una cirugía resectiva de inicio, si el compromiso es tal, que permita su reconstrucción vascular.

Tseg el al..$^{83}$, en su estudio retrospectivo del MD Anderson, se pregunta si las resecciones venosas por cáncer, en el transcurso de una duodenopancreatectomía, se asocian a igual sobrevida que la duodenopancreatectomía estándar. Y por otro lado, si este procedimiento se asocia a una mayor morbimortalidad. Sobre un total de 291 duodenopancreatectomías por cáncer de páncreas, a 110 (38\%) se le realizó resección venosa y posterior reconstrucción. Cuando se comparó la resección venosa frente al tratamiento estándar, se vio un aumento en la pérdida sanguínea en la cirugía con compromiso venoso, pero sin aumentar la mortalidad del procedimiento, ni el índice de complicaciones mayores, así como tampoco la estadía hospitalaria.

La sobrevida media fue similar, 23.4 meses para aquellos que requirieron resección venosa y de 26,5 meses para la duodenopancreatectomía estándar $(\mathrm{p}=0,18)$.

En el análisis multivariable, la resección venosa no se asoció a un deterioro de la sobrevida $\mathrm{HR}=1.1, \mathrm{P}=0.499$.

Estos resultados fueron apoyados por el metaanálisis de Zhou et al., donde se analizaron 19 publicaciones no randomizadas, con un total de 2247 pacientes, de los cuales 661 requirió una resección venosa. Aquí se documentó un mayor tiempo quirúrgico y una mayor pérdida de sangre en los pacientes con resección venosa frente a los que no la requirieron, sin diferencias en la morbilidad ni mortalidad postoperatoria.

Tampoco mostró diferencias en la sobrevida a 1,3 y 5 años. ${ }^{84}$

El metaanálisis de Yu et al., no solo apoya estos resultados, sino que evidencia mayor número de resecciones R0 con la cirugía de resección vascular. ${ }^{85}$

El consenso de la International Study Group of Pancreatic Surgery (ISGPS) del 201486, define los tipos de resecciones venosas en cuatro categorías. (Fig 10) :

- Tipo 1: Resección parcial con venorrafia

- Tipo 2: Resección parcial con reparación mediante parche.

- Tipo 3: Resección de un segmento de vena, con reparación borde a borde.

- Tipo 4: Resección de un segmento, con interposición de una prótesis o cualquier otro material, que requiera 2 suturas. 


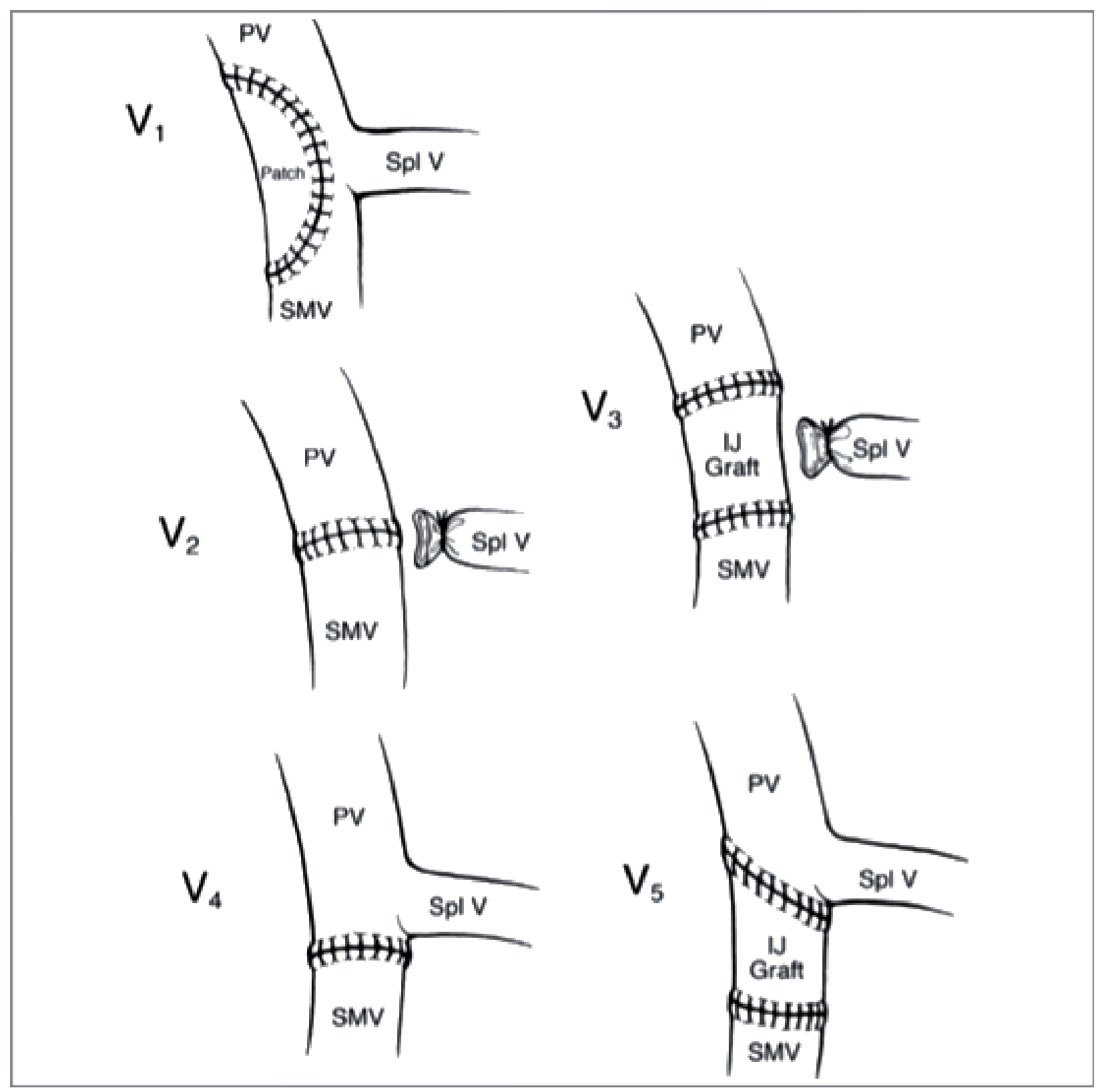

Figura 10. Esquema de las diferentes resecciones venosas y sus posibles reconstrucciones. Extraído de Eskander MF et al. (98).

Este consenso concluye que las reconstrucciones venosas son seguras en manos experimentadas y que debe practicarse a todos los pacientes que lo requieran a fin de lograr una resección R0.

Si bien la información disponible hasta el momento concluye que las resecciones venosas son seguras y logran índices de sobrevida similares a aquellos que no la requieren, en centros de alto volumen. El debate se reinstala al demostrar que si la infiltración venosa se confirma desde el punto de vista histológico, la sobrevida cae y se acerca a la sobrevida media de los pacientes en tratamiento paliativo.

La sobrevida media de los pacientes con resecciones vasculares es de 17 meses, pero cuando se confirma la infiltración desde el punto de vista histológico cae a 12 meses. ${ }^{87}$

Un reciente estudio multicéntrico francés con 469 pacientes, mostró que aproximadamente el 50\% de los pacientes con resección venosa mostraban efectivamente infiltración vascular. Con una sobrevida media de 31 meses para los que no presentaron infiltración histológica y de 15.5 meses para los que si presentaron.

Encontró que esta invasion es un factor de mal pronóstico, además se asoció a un mayor número de ganglios positivos, corroborando la hipótesis que la infiltración venosa no solo se da por cercanía anatómica de las estructuras, sino que se vincula a un comportamiento más agresivo de estas lesiones. ${ }^{88}$ 
Datos similares muestra Mierke et al..$^{89}$ en su trabajo sobre 244 resecciones por cáncer. Aquellos que requirieron resección venosa, en aproximadamente el $30 \%$ se documentó una infiltración histológica. En cuanto al análisis de sobrevida, hubo diferencias entre los grupos analizados, los pacientes sin resección tuvieron una sobrevida media de 20 meses, los que requirieron resección venosa, pero sin compromiso histológico, 16.1 meses y aquellos con resección venosa y confirmación histológica de infiltración 11,9 meses ( $\mathrm{p}=0.01$ ). Además el compromiso venoso se mostró como un factor de riesgo independiente en cuanto la disminución del tiempo libre de enfermedad y en la aparición de metástasis.

Un reciente metaanálisis de la British Journal of Surgery del 2016, compara los resultados de las duodenopancreatectomías con resección venosa, por sospecha de infiltración de la misma y DPC sin resección venosa. Sobre un total de 27 estudios y 9005 pacientes, se demostró que la resección venosa se asoció a un descenso de la sobrevida a 1,3 y 5 años, con una sobrevida de media de 14.3 meses vs 19.5 meses de los pacientes con DPC sin resección ( $\mathrm{p}=0.063$ ). Concluye que la resección venosa se asocia a una mayor mobimortalidad del procedimiento y a un peor pronóstico. ${ }^{90}$

Nos parece interesante la conclusión del trabajo de Lapshyn et al., que considera que en los estudios de imagen estará la clave en identificar aquellos pacientes con compromiso venoso real y se deberán dirigir los futuros estudios a fin de mejorar la precision sobre este compromiso vascular, dado que esos pacientes no se benefician de una abordaje quirúrgico de inicio ("upfront surgery"), sino de una neoadyuvancia. ${ }^{91}$

\section{RESECCION ARTERIAL MAYOR DURANTE LA DUODENOPANCREATECTOMIA.}

La resección arterial durante una duodenopancreatectomía por cáncer de páncreas parece ser menos controversial. Si bien algunos estudios de cohorte mostraron que dichas resecciones parecen ser seguras, los datos actuales no parecen apoyarlos por la morbilidad que producen. ${ }^{92}$

El metaanálisis de Molberg et al. ${ }^{93}$ sobre 26 estudios, con un total de 2609 pacientes, 366 con resecciones arteriales, mostró ser una cirugía más prologanda, con mayor pérdida sanguínea y asociada a mayor estadía hospitalaria.

A su vez, se asoció a una mayor morbilidad operatoria, número de reintervenciones y una mortalidad 5 veces mayor que aquellos que no requirieron resección arterial.

Estas resecciones arteriales no mejoraron la sobrevida global ni los aspectos oncológicos, con una mayor incidencia de muerte al año, estadísticamente significativa $\left(\mathrm{OR}=0.49 ; 95 \% \mathrm{CI}, 0.31-0.78 ; \mathrm{P}=0.002 ; \mathrm{I}^{2}=35 \%\right)$.

Al igual que lo que sucede con el compromiso venoso, la infiltración de la arteria se asocia a un peor pronóstico a pesar de haber conseguido una resección R0, con una sobrevida media de 18 meses cuando el compromiso es perinueral y de 9 meses cuando se demuestra la infiltración arterial $(\mathrm{p}=0.002) .{ }^{94}$

El consenso de International Study Group of Pancreatic Surgery (ISGPS), concluye que no hay buena evidencia de que las resecciones arteriales, en el contexto de una duodenopancreatectomía, sean beneficiosas en términos de sobrevida y por otro lado se asocian a una mayor morbimortalidad.

Recomienda que si durante la exploración quirúrgica se confirma el compromiso arterial, se debe abandonar la intención pretendidamente curativa y continuar con un tratamiento paliativo. ${ }^{86}$

La evidencia actual sugiere tener una actitud más conservadora frente a tumores cefalopancreáticos con compromiso arterial. Pero los avances en cirugía han impulsado a algunos cirujanos a su realización. En el mejor conocimiento de la biología tumoral podría estar la clave que justifique las resecciones arteriales a futuro. Hoy en día, estas resecciones debieran reservarse para centros de alto volumen, con concentración de pacientes, equipo multidisciplinario y en el contexto de estudios clínicos. ${ }^{95}$

\section{DUODENOPANCREATECTOMÍA MINIMAMENTE INVASIVA.}

Los beneficios de la cirugía mínimamente invasiva sobre la patología oncológica abdominal ya están probados. Si bien al inicio la realización de una DPC por un cáncer de páncreas presentaba cierto escepticismo, por el tiempo quirúrgico, las posibles morbilidades así como también por el riesgo oncológico, hoy en día en centros de alto volumen, se muestra como una cirugía factible, segura y oncológica. Se han descrito resecciones duodenopancreáticas por cáncer por vía laparoscópica con buenos resultados y en el 2007 se comenzó con la realización por cirugía robótica, que adicionó el beneficio de la visión estereoscópica, la magnificación, la estabilidad y la ergonomía. ${ }^{96}$ 
La primera duodenopancreatectomía laparoscópica con éxito fue descrita por Ganger y Pomp en 1993, la misma fue realizada a una mujer de 30 años, por una pancreatitis crónica. ${ }^{97}$ De allí en más, basados en los beneficios conocidos de la cirugía laparoscópica y en el desarrollo tecnológico de esta vía de abordaje, es que crecen las técnicas mínimamente invasivas para el tratamiento del cáncer de páncreas. Tal es así, que entre el año 2010 y 2011, hay un incremento de un $45 \%$ en el uso de estas técnicas. ${ }^{98}$

Pero, a pesar de estos avances y los buenos resultados, se sigue cuestionando el valor real de esta cirugía mediante técnicas mini-invasivas, restando determinar si estos beneficios son superiores al tiempo quirúrgico y los costos.

Se estima que la curva de aprendizaje para la duodenopancreatectomía laparoscópica es de 10 procedimientos, mientras que para la cirugía robótica la cifra es variable, con 20 casos se disminuye la pérdida sanguínea y el índice de conversión, con 40 desciende el índice de fístula pancreática y con 80 procedimientos el tiempo operatorio.

A medida que se ha ganando experiencia en los centros especializados y de la mano de cirujanos entrenados, los resultados de estas técnicas han mejorado, siendo similares en cuanto a morbilidad y mortalidad a la duodenopancreatectomía laparotómica.

Se ha ido disminuyendo el tiempo quirúrgico en los abordajes mínimamente invasivos. ${ }^{99}$ Por ejemplo en el estudio de Kim et al, quien divide la curva de aprendizaje en tres periodos, documentó un descenso de 3 horas entre el primer período y el tercer período ( $9.8 \mathrm{hs}$ a $6.6 \mathrm{hs}) .{ }^{100}$

En cuanto a los resultados publicados de DPC laparoscópica, se destaca el estudio de Senthilnathan et al, una de las primeras grandes series publicadas, con 150 procedimientos, 130 de ellos por adenocarcinoma. El tiempo promedio de este procedimiento para este estudio fue de 310 minutos, la pérdida sanguínea de $110 \mathrm{ml}$, el tiempo de internación de 8 días, y una morbilidad de 29,7\%. Desde el punto de vista oncológico presentaron $9.23 \%$ de márgenes positivos, una recolección de 18 ganglios en promedio y la sobrevida a 5 años fue de $29.42 \%$ con una sobrevida media de 33 meses. ${ }^{101}$

Un reciente estudio analítico de 492 duodenopancreatectomías laparoscópicas, mostró 13\% de conversion, un tiempo promedio del procedimiento de 452 minutos, y una perdida sanguínea de $369 \mathrm{ml}$ en promedio. En cuanto a la morbilidad mostró $13 \%$ de fístula pancreática, $8,6 \%$ de retardo en el vaciamiento gástrico y una mortalidad de $2.3 \%$.

Desde el punto de vista oncológico, las resecciones ganglionares oscilaron entre 14 y 23 ganglios y las resecciones R0 entre 77 y $100 \% .^{102}$

Este mismo estudio además comparó los resultados entre la cirugía laparoscópica y la cirugía abierta. Encontrando una menor pérdida sanguínea, menor tiempo de estadía hospitalaria y un mejor recuento ganglionar con el procedimiento laparoscópico.

Desde este mismo punto, Croome et al. ${ }^{103}$ mostraron un mayor tiempo de sobrevida libre de progresión en favor del abordaje mini-invasivo, pero con una sobrevida global similar.

Kendrick et al también encuentran ventajas oncológicas de la cirugía laparoscópica cuando se comparó con la cirugía abierta. Sobre un total de 108 DPC laparospcópicas y 214 DPC abiertas, documentó un mayor retraso en el inicio de la terapia adyuvante en los pacientes de cirugía abierta (12\%). ${ }^{95}$

Una revisión sistemática de duodenopancreatectomías mínimamente invasivas que incluyo 1028 procedimientos (75\% laparoscópicas y 25\% robóticas), muestra un índice de conversión de 9.1\%, tiempo operatorio entre 287 y 657 minutos. Una media de ganglios resecados de 17.1 y de resecciones R0 de $91.6 \%$.

La morbilidad global fue de $35.9 \%$, la fístula pancreática se presentó en un $17 \%$ y la mortalidad fue $2.2 \% .{ }^{104}$

Este estudio concluye, que el abordaje mínimamente invasivo ha mostrado ser seguro y oncologicamente aceptable, en centros especializados y en cirujanos con experiencia en cirugía laparoscópica. Algunas cuestiones quedan por definir como la sustentabilidad económica, sobre todo con el Da Vinci, y la reproducibilidad de la técnica.

\begin{tabular}{|c|c|c|c|c|c|c|c|}
\hline Author, Year & Technique & $\begin{array}{l}N(\text { (Total)/N } \\
\text { (Malignant) }\end{array}$ & $E B L(m L)$ & $\begin{array}{l}\text { Operative } \\
\text { Time (min) }\end{array}$ & $\begin{array}{l}\text { Fistula Rate } \\
\text { (Grade C) }\end{array}$ & Mortality Rate & $\begin{array}{l}\text { Oncalogic Outcomes } \\
\text { (RO Rate, } L N \text { ) }\end{array}$ \\
\hline Gulilianotti et al, 2010 & Robot & $60 / 45$ & 394 & 421 & $31.6 \%$ & $3 \%$ & $90 \%, 18$ \\
\hline Kim et al, 2013 & Laparoscopic & $100 / 12$ & - & 474 & $6 \%$ & - & $100 \%, 13$ \\
\hline Palanivelu, 2015 & Laparostopic & $150 / 130$ & 110 & 310 & $8.5 \%$ & $0 \%$ & $90.8 \%, 18$ \\
\hline Zureikat," (last 120 cases) 2015 & Robot & $200 / 166$ & 250 & 417 & $6.9 \%$ & 3.35 & $91.4 \%, 26$ \\
\hline
\end{tabular}

Figura 11. Tabla comparativa de estudios con abordaje mínimamente invasivos.

Extraído de Magge D, et al. (96). 


\section{BIBLIOGRAFIA}

1. Hariharan D, Saied A, Kocher HM. Analysis of mortality rates for pancreatic cancer across the world. HPB 2008;10(1):58-62.

2. Praderi RC. Cien años de Cirugía Pancreática.Conferencia dictada en el 50 Congreso Uruguayo de Cirugía.Noviembre de 1999.

3. Whipple AO, Parsons WB, Mullins CR.Treatment of carcinoma the ampulla of vater.Ann Surg. 1935 Oct; 102(4): 763-779.

4. Whipple AO. Pancreaticoduodenectomy for Islet Carcinoma : A Five-Year Follow-Up.Ann Surg. 1945;121(6):847-852.

5. Kakita A, Yoshida M, Takahashi T. History of pancreaticojejunostomy in pancreaticoduodenectomy: development of a more reliable anastomosis technique.J Hepatobiliary Pancreat Surg. 2001; 8(3):230-237.

6. Wells CA, Annis D. Experimental pancreaticogastrostomy. Lancet. 1949 Jan 15;1(6542):97-99.

7. Wells C, Shepherd JA, Gibbon N.Pancreaticogastrostomy. Lancet. 1952;1(6708):588-589.

8. Waugh JM, Clagett OT. Resection of the duodenum and head of the pancreas for carcinoma. Surgery. 1946;20:224-232.

9. Oussoultzoglou E, Bachellier P, Bigourdan JM, et al. Pancreaticogastrostomy decreased relaparotomy caused by pancreatic fistula after pancreaticoduodenectomy compared with pancreaticojejunostomy. Arch Surg 2004; 139(3):327 - 335.

10. Addeo P, Delpero JR, Paye F, et al. Pancreatic fistula after a pancreatico- duodenectomy for ductal adenocarcinoma and its association with morbidity: a multicentre study of the French Surgical Association. HPB (Oxford). 2014;16(1):46-55.

11. Bassi C, Butturini G, Molinari E, et al. Pancreatic fistula rate after pancreatic resection. The importance of definitions. Dig Surg 2004;21(1):54-59.

12. Bassi C, Dervenis C, Butturini G, et al. Postoperative pancreatic fistula: an international study group (ISGPF) definition. Surgery. 2005;138(1):8-13.

13. Matthew T. McMillan, Charles M. VollmerJr, et al.The Characterization and Prediction of ISGPF Grade C Fistulas Following Pancreatoduodenectomy. J Gastrointest Surg. 2016: 20(2):262-276.

14. Pratt WB, Callery MP, Vollmer CM. Risk prediction for development of pancreatic fistula using the ISGPF classification scheme. World J Surg 2008;32(3):419-428.

15. Callery MP, Pratt WB, Kent TS, et al. A prospectively validated clinical risk score accurately predicts pancreatic fistula after pancreatoduodenectomy. J Am Coll Surg. 2013;216(1):1-14.

16. Delcore R, Thomas JH, Pierece GL, et al. Pancreatogastrostomy: a safe drainage procedure after pancreatoduodenectomy. Surgery 1990;108(4):641-647.

17. Leibermann MD, Kilburn H, Lindsey M, et al. Relation of perioperative deaths to hospital volume among patients undergoing pancreatic resection for malignancy. Ann Surg 1995;222(5):638-645.

18. Aranha GV, Hodul P, Golts E, et al. A comparison of pancreaticogastrostomy and pan- creaticojejunostomy following pancreaticoduodenectomy. J Gastrointest Surg. 2003;7(5):672-682.

19. Fabre JM, Arnaud JP, Navarro F, et al. Results of pancreatogastrostomy after pancreatoduodenectomy in 160 consecutive patients. Br J Surg. 1998;85(6):751-775.

20. Pessaux P, Aube C, Lebigot J, et al. Permeability and functionality of pancreaticogastrostomy after pancreaticoduodenectomy with dynamic magnetic resonance pancreatography after secretin stimulation. J Am Coll Surg. 2002;194(4):454-462.

21. Zhou Y, Yu J, Wu L, et al. Meta-analysis of pancreaticogastrostomy versus pancreaticojejunostomy on occurrences of postoperative pancreatic fistula after pancreaticoduodenectomy. Asian Journal of Surgery 2015; 38(3): 155-160.

22. Topal B, Fieuws S, Aerts R, et al. Pancreaticojejunostomy versus pancreaticogastrostomy reconstruction after pancreaticoduodenectomy for pancreatic or periampullary tumours: a multicentre randomized trial. Lancet Oncol 2013;14(7):655-662.

23. Figueras J, Sabater L, Planellas $\mathrm{P}$, et al. Randomized clinical trial of pancreaticogastrostomy versus pancreaticojejunostomy on the rate and severity of pancreatic fistula after pancreaticoduodenectomy. Br J Surg. 2013; 100(12):1507- 1605.

24. Tewari M, Hazrah P, Kumar V, et al. Options of restorative pancreaticoenteric anastomosis following pancreaticoduodenectomy: A review.Surgical Oncology. 2010;19(1): 17-26.

25. Que WT, Fang HB, Yan B, et al. Pancreaticogastrostomy versus pancreaticojejunostomy after pancreaticoduodenectomy: a meta-analysis of randomized controlled trials. Am J Surg. 2015;209 (6):1074-1082.

26. Liu BF, Chen JM, Geng W, et al. Pancreaticogastrostomy is associated with significantly less pancreatic fistula than pancreaticojejunostomy reconstruction after pancreaticoduodenectomy: a meta-analysis of seven randomized controlled trials. HPB. 2015;17(2):123-130. 
27. Menahem B, Guittet L, Mulliri A, et al. Pancreaticogastrostomy Is Superior to Pancreaticojejunostomy for Prevention of Pancreatic Fistula After Pancreaticoduodenectomy. An Updated Meta-analysis of Randomized Controlled Trials. Ann. Surg.2015; 261(5): 882-887.

28. Crippa S, Cirocchi R, Randolph J, et al. Pancreaticojejunostomy is comparable to pancreaticogastrostomy after pancreaticoduodenectomy: an updated meta-analysis of randomized controlled trials. Langenbecks Arch Surg. 2016: 401(4):427-437.

29. Guerrini GP, Fausi G. Should we consider pancreaticogastrostomy the best method of reconstruction after pancreaticoduodenectomy?.EJSO. 219; 42(2): 315-316.

30. Hallet J, Zih FSW, Deobald RG, et al. The impact of pancreaticojejunostomy versus pancreaticogastrostomy reconstruction on pancreatic fistula after pancreaticoduodenectomy: meta-analysis of randomized controlled trials. Review article.HPB. 2015; 17(2): 113-122.

31. Watson K. Carcinoma of ampulla of Vater successful radical resection. Br J Surg 1944;31(124):368-373.

32. Traverso LW, Longmire WP Jr. Preservation of the pylorus during pancreaticoduodenectomy. Surg Gynecol Obstet 1978;146(6):959-462.

33. Traverso LW, Longmire WP. Preservation of the pylorus in pancreaticoduodenectomy.Ann Surg. 1980;192(3):306-310.

34. Pitt HA, Grace PA. Cancer of the pancreas. Pylorus-preserving resection of the pancreas. Baillieres Clin Gastroenterol. 1990;4(4):917-930.

35. Seiler CA, Wagner M, Sadowski C, et al. Randomized prospective trial of pylorus-preserving vs. classic duodenopancreatectomy (Whipple procedure): initial clinical results. J Gastrointest Surg. 2000;4(5):443-452.

36. Wenger FA, Jacobi CA, Haubold K, et al. Gastrointestinal quality of life after duodenopancreatectomy in pancreatic carcinoma. Preliminary results of a prospective randomized study: pancreatoduodenectomy or pyloruspreserving pancreatoduodenectomy. Chirurg 1999;70(12): 1454-1459.

37. Biichler MW, Friess H, Miiller MW, et al. Randomized Trial of Duodenum-Preserving Pancreatic Head Resection Versus Pylorus- Preserving Whipple in Chronic Pancreatitis. Am J Surg. 1995;169(1):65-69.

38. Warshaw AL, Torchiana DL. Delayed gastric emptying after pylorus-preserving pancreaticoduodenectomy. Surg Gynecol Obstet. 1985;160(1):1-4.

39. Lin PW, Shan YS, Lin YJ, Hung CJ.Pancreaticoduodenectomy for pancreatic head cancer: PPPD versus Whipple procedure. Hepatogastroenterology. 2005;52(65):1601-1604.

40. Tran KT, Smeenk HG, van Eijck CH, et al. Pylorus preserving pancreaticoduodenectomy versus standard Whipple procedure: a prospective, randomized, multicenter analysis of 170 patients with pancreatic and periampullary tumors. Ann Surg. 2004;240(5):738-745.

41. Diener MK, Fitzmaurice C, Schwarzer G, et al. Pylorus-preserving pancreaticoduodenectomy (pp Whipple) versus pancreaticoduodenectomy (classic Whipple) for surgical treatment of periampullary and pancreatic carcinoma.Cochrane Database Syst Rev. 2014;(11).doi: 10.1002/14651858.CD006053.pub5.

42. Hüttner FJ, Fitzmaurice C, Schwarzer G, et al. Pylorus-preserving pancreaticoduodenectomy (pp Whipple) versus pancreaticoduodenectomy (classic Whipple) for surgical treatment of periampullary and pancreatic carcinoma.Cochrane Database Syst Rev. 2016; 16;2.doi: 10.1002/14651858.CD006053.pub6.

43. Helmink BA, Snyder RA, Idrees K. et al. Advances in the Surgical Management of Resectable and Borderline Resectable Pancreas Cancer. Surg Oncol Clin N Am. 2016; 25(2): 287-310.

44. Wente MN, Bassi C, Dervenis C, et al. Delayed gastric emptying (DGE) after pancreatic surgery: a suggested definition by the International Study Group of Pancreatic Surgery (ISGPS). Surgery 2007;142(5):761-768.

45. Hanna MM, Gadde R, Allen CJ, et al. Delayed gastric emptying after pancreaticoduodenectomy. Research review.J Surg Res. 2016;202(2):380-388.

46. Kawai M, Tani M, Hirono S, et al. Pylorus Ring Resection Reduces Delayed Gastric Emptying in Patients Undergoing Pancreatoduodenectomy. A Prospective, Randomized, Controlled Trial of Pylorus-Resecting Versus Pylorus-Preserving Pancreatoduodenectomy. Ann Surg. 2011;253(3):495-501.

47. Kawai M, Tani M, Hirono S, et al. Pylorus-Resecting Pancreaticoduodenectomy Offers Long-Term Outcomes Similar to Those of Pylorus-Preserving Pancreaticoduodenectomy: Results of a Prospective Study.World J Surg. 2014 38(6):1476-1483.

48. Zhou Y, Lin L, Wu L, et al. A case-matched comparison and meta-analysis comparing pylorus-resecting pancreaticoduodenectomy with pylorus-preserving pancreaticoduodenectomy for the incidence of postoperative delayed gastric emptying. HPB. 2015;17(4): 337-343.

49. Wu W, Hong H, Fu L, et al. The Effect of Pylorus Removal on Delayed Gastric Emptying after Pancreaticoduodenectomy: A Meta- Analysis of 2,599 Patients. PLoS One. 2014;9(10):e108380. doi: 10.1371/journal. pone. 0108380 .

50. Cordesmeyer S, Lodde, Zeden K, Kabar I, et al. Prevention of Delayed Gastric Emptying After Pylorus-Preserving Pancreatoduodenectomy with Antecolic Reconstruction, a Long Jejunal Loop, and a Jejuno-Jejunostomy. J Gastrointest Surg. 2014; 18(4):662-673. 
51. Hochwald SN, Grobmyer SR, Hemming AW, et al. Braun enteroenterostomy is associated with reduced delayed gastric emptying and early resumption of oral feeding following pancreaticoduodenectomy. J Surg Oncol. 2010;101(5):351-355.

52. Nikfarjam M, Houli N, Tufail F, et al. Reduction in delayed gastric emptying following non-pylorus preserving pancreaticoduodenectomy by addition of a Braun enteroenterostomy. JOP. 2012;13(5):488-496.

53. Xu B, Meng H, Qian M, et al. Braun enteroenterostomy during pancreaticoduodenectomy decreases postoperative delayed gastric emptying. Am J Surg. 2015;209(6):1036-1042.

54. Hwang HK, Lee SH, Han DH, et al. Impact of Braun anastomosis on reducing delayed gastric emptying following pancreaticoduodenectomy: a prospective, randomized controlled trial. J Hepatobiliary Pancreat Sci. 2016;23(6):364-372.

55. Joliat GR, Labgaa I, Demartines N, et al. Effect of Antecolic versus Retrocolic Gastroenteric Reconstruction after Pancreaticoduodenectomy on Delayed Gastric Emptying: A Meta-Analysis of Six Randomized Controlled Trials.Dig Surg. 2016;33(1):15-25.

56. Walters. DM, Shada AL, LaPar JD, et al. Long Gastrojejunostomy Is Associated With Decreased Incidence and Severity of Delayed Gastric Emptying After Pancreaticoduodenectomy. Pancreas 2015; 44(8): 1273-1279.

57. Cubilla A., Fortner J., Fitzgermal PJK. Lymph node involvement in carcinoma of the head of the pancreatic area. Cancer 1978; 41(4):880-887.

58. Ishikawa O, Ohhigashi $\mathrm{H}$, Sasaki $\mathrm{Y}$, et al. Practical usefulness of lymphatic and connective tissue clearance for the carcinoma of the pancreas head.Ann Surg. 1988;208(2):215-220.

59. Manabe T, Ohshio G, Baba N, et al. Radical pancreatectomy for ductal cell carcinoma of the head of the pancreas. 1989;64(5):1132-1137.

60. Michalski CW, Kleeff J, Wente MN, et al. Systematic review and meta-analysis of standard and extended lymphadenectomy in pancreaticoduodenectomy for pancreatic cancer.British Journal of Surgery 2007; 94(3): 265-273.

61. Pedrazzoli S, DiCarlo V, Dionigi R, et al. Standard versus extended lymphadenectomy associated with pancreatoduodenectomy in the surgical treatment of adenocarcinoma of the head of the pancreas. Ann Surg 1998;228(4):508-517.

62. Yeo CJ, Cameron JL, Sohn TA, et al. Pancreaticoduodenectomy with or without extended retroperitoneal lymphadenectomy for periampullary adenocarcinoma: comparison of morbidity and mortality and short-term outcome. Ann Surg 1999;229(5):613-614.

63. Yeo CJ, Cameron JL, Lillemoe KD, et al. Pancreaticoduodenectomy with or without distal gastrectomy and extended retroperitoneal lymphadenectomy for periampullary adenocarcinoma, part 2: randomized controlled trial evaluating survival, morbidity, and mortality. Ann Surg 2002;236(3):355-366.

64. Riall TS, Cameron JL, Lillemoe KD, et al. Pancreaticoduodenectomy with or without distal gastrectomy and extended retroperitoneal lymphadenectomy for periampullary adenocarcinoma-part 3: update on 5-year survival. J Gastrointest Surg 2005;9(9):1191-1204.

65. Farnell MB, Pearson RK, Sarr MG, et al. A prospective randomized trial comparing standard pancreatoduodenectomy with pancreatoduodenectomy with extended lymphadenectomy in resectable pancreatic head adenocarcinoma. Surgery 2005;138(4):618-630.

66. Nimura Y, Nagino M, Takao S, et al. Standard versus extended lymphadenectomy in radical pancreatoduodenectomy for ductal adenocarcinoma of the head of the pancreas: long-term results of a Japanese multicenter randomized controlled trial. J Hepatobiliary Pancreat Sci 2012;19(3):230-241.

67. Tol J, Gouma DJ, Bassi C.Definition of a standard lymphadenectomy in surgery for pancreatic ductal adenocarcinoma: A consensus statement by the International Study Group on Pancreatic Surgery (ISGPS). Surgery 2014; 156(3): 591-600.

68. Japan Pancreas Society. Classification of pancreatic carci- noma. 2nd English ed. Tokyo: Kanehara \& Co. Ltd; 2003.

69. Orci LA, Jeremy Meyer J, Commessure Ch, el al. A meta-analysis of extended versus standard lymphadenectomy in patients undergoing pancreatoduodenectomy for pancreatic adenocarcinoma.HPB 2015; 17(7): 565-572.

70. Dasari BVM, Pasquali S, Vohra RS, et al. Extended Versus Standard Lymphadenectomy for Pancreatic Head Cancer: Meta-Analysis of Randomized Controlled Trials. J Gastrointest Surg. 2015; 19(9):1725-1732.

71. Malleo G, Maggino L, Capelli P, et al. Reappraisal of Nodal Staging and Study of Lymph Node Station Involvement in Pancreaticoduodenectomy with the Standard International Study Group of Pancreatic Surgery Definition of Lymphadenectomy for Cancer.J Am Coll Surg. 2015; 221(2): 367-379.

72. Riediger H, Keck T, Wellner U, et al. The Lymph Node Ratio is the Strongest Prognostic Factor after Resection of Pancreatic Cancer. J Gastrointest Surg 2009;13(7):1337-1344. 
73. Slidell MB, Chang DC, Cameron JL, et al. Impact of Total Lymph Node Count and Lymph Node Ratio on Staging and Survival after Pancreatectomy for Pancreatic Adenocarcinoma: A Large, Population-Based Analysis. Ann. Surg. Oncol. 2008; 15(1):165-174.

74. Zhan HX, Xu JW, Wang L, et al. Lymph node ratio is an independent prognostic factor for patients after resection of pancreatic cancer. World J Surg Oncol 2015;13:105. doi: 10.1186/s12957-015-0510-0.

75. Gockel I, Domeier M, Wollscheck T, et al. Resection of the mesopancreas (RMP): a new surgical classification of a known anatomical space.

World J Surg Oncol.2007;5:44.DOI: 10.1186/1477-7819-5-44.

76. Adham M, Singhirunnusorn J. Surgical technique and results of total mesopancreas excision (TMpE) in pancreatic tumors. Eur J Surg Oncol 2012;38(4):340-345.

77. Cao Z, Xu J, Shao Q, el al. Surgical treatment of pancreatic head cancer: concept revolutions and arguments. Chin J Cancer Res. 2015;27(4):392-396.

78. Inoue Y, Saiura A, Yoshioka R, et al. Pancreatoduodenectomy With Systematic Mesopancreas Dissection Using a Supracolic Anterior Artery-first Approach.Ann Surg. 2015;262(6):1092-1101.

79. Chowdappa R, Challa VR.Mesopancreas in Pancreatic Cancer: Where do We Stand - Review of Literature. Indian J Surg Oncol 2015; 6(1):69-74.

80. Peparini N, Caronna R, Chirletti P.The "meso" of the rectum and the "meso" of the pancreas: similar terms but distinct concepts in surgical oncology. Hepatobiliary Pancreat Dis Int. 2015;14(5):548-551.

81. Moore GE, Sako Y, Thomas LB. Radical pancreaticoduodenectomy with resection and reanastomosis of the superior mesenteric vein. Surgery 1951;30(3):550-553.

82. Allema JH, Reinders ME, van Gulik TM, et al. Portal vein resection in patients undergoing pancreatoduodenectomy for carcinoma of the pancreatic head.Br J Surg. 1994;81(11):1642-1646.

83. Tseng JF, Raut CP, Lee JE, et al. Pancreaticoduodenectomy with vascular resection: margin status and survival duration. J Gastrointest Surg. 2004;8(8):935-949.

84. Zhou Y, Zhang Z, Liu Y, et al. Pancreatectomy Combined with Superior Mesenteric Vein-Portal Vein Resection for Pancreatic Cancer: A Meta-analysis.World J Surg. 2012; 36(4):884-891.

85. Yu XZ, Li J, Fu DL, et al. Benefit from synchronous portal-superior mesenteric vein resection during pancreaticoduodenectomy for cancer: a meta-analysis. Eur J Surg Oncol. 2014;40(4):371-378.

86. Bockhorn M, Uzunoglu FG, Adham M, et al. Borderline resectable pancreatic cancer: A consensus statement by the International Study Group of Pancreatic Surgery (ISGPS).Consensus. Surgery 2014; 155(6):977-988.

87. Beltrame V, Gruppo M, Pedrazzoli S, et al. Mesenteric-Portal Vein Resection during Pancreatectomy for Pancreatic Cancer. Gastroenterol Res Pract. 2015:659730. doi: 10.1155/2015/659730.

88. Ramacciato G, Nigri G,Petrucciani N, et al.Pancreatectomy with Mesenteric and Portal Vein Resection for Borderline Resectable Pancreatic Cancer: Multicenter Study of 406 Patients. Ann Surg Oncol. 2016;23(6):20282037.

89. Mierke F, Hempel S, Distler M, et al. Impact of Portal Vein Involvement from Pancreatic Cancer on Metastatic Pattern After Surgical Resection.Ann Surg Oncol. 2016.DOI 10.1245/s10434-016-5515-6 .

90. Giovinazzo F, Turri G, Katz MH, et al. Meta-analysis of benefits of portal-superior mesenteric vein resection in pancreatic resection for ductal adenocarcinoma. Br J Surg. 2016;103(3):179-191.

91. Lapshyn H, Bronsert P, Bolm L, et al. Prognostic factors after pancreatoduodenectomy with en bloc portal venous resection for pancreatic cancer. Langenbecks Arch Surg. 2016; 401(1):63-69.

92. Fujii T, Yamada S, Murotani K,et al. Inverse Probability of Treatment Weighting Analysis of Upfront Surgery Versus Neoadjuvant Chemoradiotherapy Followed by Surgery for Pancreatic Adenocarcinoma with Arterial Abutment. Medicine (Baltimore). 2015 Sep;94(39):e1647. doi: 10.1097/MD.0000000000001647.

93. Mollberg N, Rahbari NN, Koch M, et al. Arterial Resection During Pancreatectomy for Pancreatic Cancer. A Systematic Review and Meta-Analysis.Ann Surg. 2011;254(6):882-893.

94. Bachellier P, Rosso E, Lucescu I, et al. Is the need for an arterial resection a contraindication to pancreatic resection for locally advanced pancreatic adenocarcinoma? A case-matched controlled study. J Surg Oncol 2011;103(1): 75-84.

95. Vicente E, Quijano I, Ielpo E. Arterial resection for pancreatic cancer:a modern surgeon should change its behavior according to the new therapeutic options. G Chir. 2014; 35(1/2): 5-14.

96. Magge D, Zureikat A, Hogg M, et al.Minimally Invasive Approaches to Pancreatic Surgery.Surg Oncol Clin N Am. 2016; 25: 273-286.

97. Gagner M., Pomp A.Laparoscopic pylorus-preserving pancreatoduodenectomy. Surg. Endosc. 1994; 8(5):408410.

98. Eskander MF, Bliss LA., Tseng JF. Pancreatic adenocarcinoma.Current Problems in Surgery.2016; 53(3):107154.

99. Helmink BA, Snyder RA, Idrees K, et al. Advances in the Surgical Management of Resectable and Borderline Resectable Pancreas Cancer.Surg Oncol Clin N Am 2016; 25(2): 287-310. 
100. Kim SC, Song KB, Jung YS, et al. Short-term clinical outcomes for 100 consecutive cases of laparoscopic pylorus-preserving pancreatoduodenectomy:improvement with surgical experience. Surg Endosc 2013;27(1):95103.

101. Senthilnathan P, Gurumurthy SS, Palanivelu C, et al. Long-term results of laparo- scopic pancreaticoduodenectomy for pancreatic and periampullary cancer- experience of 130 cases from a tertiary-care center in South India. J Laparoendosc Adv Surg Tech A 2015;25(4):295-300.

102. Merkow J, Paniccia A, Edil BH.Laparoscopic pancreaticoduodenectomy: a descriptive and comparative review.Chin J Cancer Res 2015;27(4):368-375.

103. Croome KP, Farnell MB, Que FG, et al. Total laparoscopic pancreaticoduodenectomy for pancreatic ductal adenocarcinoma: oncologic advantages over open approaches? Ann Surg 2014;260(4):633-638; discussion 638640.

104. Liao CH, Wu YT, Liu YY, et al. Systemic Review of the Feasibility and Advantage of Minimally Invasive Pancreaticoduodenectomy. World J Surg 2016; 40(5):1218-1225. 


\section{PANCREATECTOMÍA EN ADENOCARCINOMAS DE CUERPOY COLA DEL PANCREAS}

Debido a su localización y lo inespecífico de su sintomatología inicial, los tumores de cuerpo y cola tienen habitualmente un diagnóstico tardío.

Si a esto le sumamos que su localización es menos frecuente que la cefálica, la casuística publicada es mucho menor que la referida a la duodenopancreatectomía.

En una revisión francesa del $2010^{1}$ solo 10 a 22\% de los adenocarcinomas de cuerpo y cola de páncreas fueron resecables.

Sin embargo, la demostración que las pancreatectomías ensanchadas y las resecciones vasculares del eje celíaco con o sin reconstrucción son factibles, han permitido aumentar las tasas de resecabilidad.

El desarrollo de la cirugía mínimamente invasiva (laparoscópica, robótica) y la demostración de que su realización es segura y satisfactoria desde el punto oncológico, ha generado la realización de un importante número de estudios en este sentido.

\section{Criterios de irresecabilidad.}

No existen dudas de que elementos de incurabilidad como la presencia de metástasis hepáticas, carcinomatosis y compromiso ganglionar a distancia, son elementos que contraindican la resección. ${ }^{2-4}$

En cuanto al compromiso del eje venoso mesentérico-portal, existe consenso entre expertos que la oclusión por trombosis o invasión tumoral directa, no pasible de reconstrucción, es un elemento de irresecabilidad. ${ }^{2-5}$

En cambio la invasión o el contacto del tumor con la arteria mesentérica superior, mayor a $180^{\circ}$, es considerado como criterio de irresecabilidad en todos los consensos. ${ }^{2-5}$

Por la localización corporocaudal y lo avanzado de las lesiones al momento del diagnóstico, el compromiso del tronco celíaco y sus ramas es frecuente. En general todos los consensos aceptan que el contacto del tumor mayor a 180o con el tronco celíaco y una invasión extensa de la arteria hepática común, lo hacen irresecable. ${ }^{2-5}$

En tanto el compromiso de la arteria esplénica no afecta la resecabilidad, ya que queda incluida en la pieza de esplenopancreatectomía

Sin embargo, en un esfuerzo por aumentar la resecabilidad y la tasa de resecciones R0, algunos centros, fundamentalmente japoneses, ${ }^{6,7}$ han desarrollado la técnica de pancreatectomía distal con resección del tronco celíaco, modificando la técnica de Appleby (gastrectomía con resección en bloque del tronco celíaco). ${ }^{8}$

Discutiremos sus aspectos técnicos, y sus resultados más adelante.

\section{Pancreatectomía izquierda o distal, estándar.}

La técnica quirúrgica de pancreatectomía distal por adenocarcinoma de páncreas, está hoy en día bien estandarizada. La cirugía incluye la resección en bloque del cuerpo y la cola del páncreas, con los vasos esplénicos y el bazo.

Este es el procedimiento estándar, aceptado por diferentes guías y consensos de expertos. ${ }^{4,9}$

E1 International Study Group for Pancreatic Surgery ${ }^{9}$, incluye dentro de la definición de pancreatectomía estándar la resección, cuando es necesario, de la fascia de Gerota y/o sectores grasos del mesocolon transverso, sin incluir resección colónica.

En cuanto a los estudios de la diseminación ganglionar en el cáncer de páncreas distal, los mismos son escasos. Un estudio japonés de los años 90 encontró que las cadenas más afectadas eran la de la arteria esplénica, la arteria hepática, el tronco celíaco, la arteria mesentérica superior y los grupos para-aórticos. ${ }^{10}$

Un estudio posterior ${ }^{11}$, encuentra que los ganglios más frecuentemente afectados, son los grupos 8 (cadena hepática), 11 (arteria esplénica), 14 (arteria mesentérica ) y 16 (latero-aórticos), siguiendo la clasificación de la Japanese Pancreas Society. ${ }^{12}$

El International Study Group for Pancreatic Surgery ${ }^{13}$, utiliza la clasificación de grupos ganglionares de la Japanese Pancreas Society, y en un trabajo de consenso propone que el vaciamiento ganglionar estándar, en el adenocarcinoma ductal de cuerpo y cola de páncreas, debe incluir (Fig1.):

- grupo 10 (hilio esplénico)

- grupo 11 (arteria esplénica)

- grupo 18 (borde inferior del páncreas)

- el grupo 9 (tronco celíaco) se sugiere cuando la lesión está localizada en el cuerpo del páncreas. 


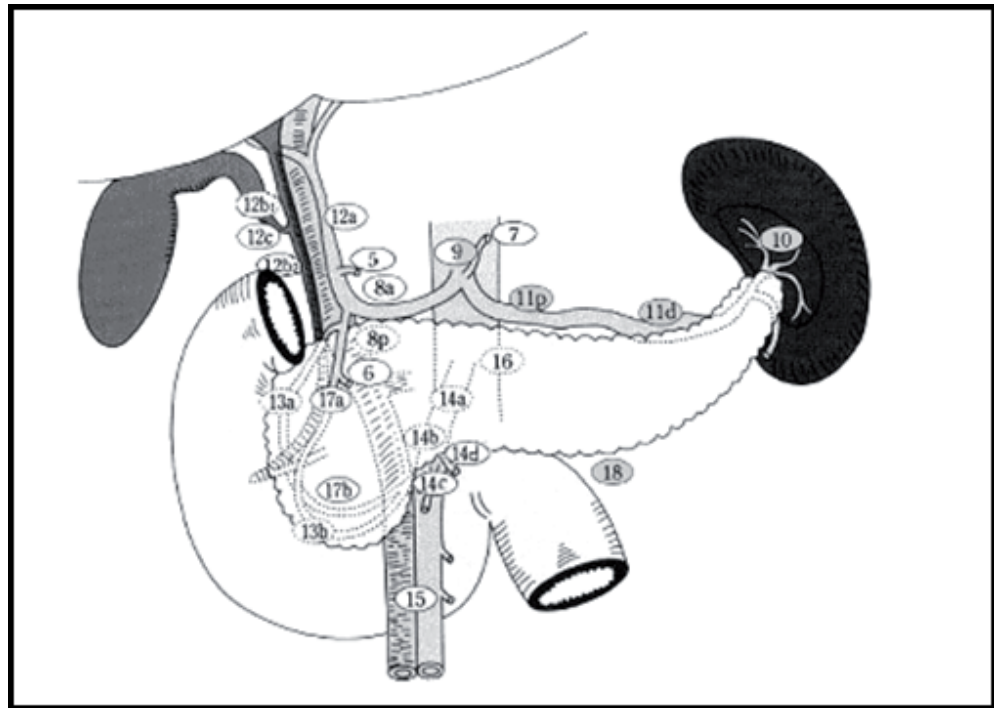

Fig 1. Vaciamiento ganglionar estándar en adenocarcinoma de cuerpo y cola de páncreas. En gris los ganglios a resecar. Extraído de Tol Ja. Surgery. 2014 Sep;156(3):591600. (13)

El compromiso ganglionar es un factor pronóstico reconocido.

El número mínimo de ganglios que deben ser resecados para poder realizar una correcta estadificación, varía en la bibliografía entre $12-15$ ganglios. ${ }^{14,15}$

El consenso del International Study Group for Pancreatic Surgery ${ }^{13}$, plantea un número mayor o igual a 15 ganglios. Sin embargo, el uso de neoadyuvancia, puede disminuir el número de ganglios identificados por el patólogo16 y en esta situación, un número menor a 15 ganglios puede ser aceptado. ${ }^{13}$

La forma más exacta de evaluar el significado pronóstico del compromiso ganglionar es controversial.

Se ha planteado estimarlo según el número total de ganglios resecados, el promedio de ganglios positivos sobre el total de ganglios resecados (lymph node ratio) o por el número absoluto de metástasis ganglionares identificadas Los valores de corte, para el cambio de pronóstico utilizando el Lymph node ratio (LNR), varían de 0,2 a 0,4. ${ }^{15,17,18}$

El número de ganglios positivos, también es un factor pronóstico demostrado, el valor de corte a partir del cual la sobrevida cae de forma radical, varía según los estudios entre 2 y 3 ganglios metastásicos. ${ }^{18-20}$ La mayoría de los estudios que analizan estos factores pronósticos se originan de pacientes a los que se les realizó una duodenopancreatectomía.

Un reciente estudio retrospectivo de 77 pacientes sometidos a pancreatectomía distal por adenocarcinoma pancreático, analiza el valor pronóstico del compromiso ganglionar. ${ }^{21}$

En el análisis univariado, el N1 tuvo valor pronóstico ( $\mathrm{pN} 0$ vs $\mathrm{pN} 1: 17.5$ vs 7.9 meses, $\mathrm{P}=0.001$ ), lo mismo que el Lymph node ratio LNR (<0.08 vs $\geq 0.08: 17.5$ vs 4.4 meses, $\mathrm{P}<0.001)$

El número de ganglios positivos, también mostró valor pronóstico, cuando el $\mathrm{N}=0$ la sobrevida media fue de 17 meses, mientras que si el $\mathrm{N}+\geq 2$ cae a 6.4 meses, similar sobrevida de los pacientes no resecados.

En el análisis multivariable, el número absoluto de ganglios metastásicos fue identificado como factor independiente de pronóstico oncológico.

En otro estudio similar ${ }^{22}$ con 85 pacientes, el análisis multivariado revela que la presencia de 5 o más ganglios positivos y un LNR de 0.2, fueron factores pronósticos independientes de sobrevida.

En cuanto a los vaciamientos ganglionares extendidos, si bien trabajos japoneses de los años 80 reportaron beneficios en la sobrevida ${ }^{23,24}$, estos resultados no pudieron ser demostrados en estudios randomizados posteriores. ${ }^{25-30}$

Diferentes metaanálisis ${ }^{31-33}$, que incluyen muchos de estos estudios randomizados, no encuentran beneficios en la sobrevida, y si un aumento del tiempo operatorio, de pérdidas sanguíneas, así como una mayor morbilidad postoperatoria vinculada a una mayor incidencia de diarrea y pérdida de peso.

En base a estos resultados el International Study Group for Pancreatic Surgery ${ }^{13}$, no recomienda los vaciamientos ganglionares extendidos a los grupos 8 (arteria hepática), 14 (arteria mesentérica) y 16 (para-aórticos), al realizar una pancreatectomía izquierda por adenocarcinoma. 


\section{Pancreato-esplenectomía Anterógrada Radical Modular(RAMPS)}

La "Radical antegrade modular pancreatosplenectomy"(RAMPS) descrita por Strasberg y cols en 2003 ${ }^{34}$, fue propuesta con la finalidad de disminuir la tasa de margen posterior positivo y asegurar un completo vaciamiento ganglionar de la región. El mismo autor plantea que no debe ser considerada una resección ampliada.

A diferencia del abordaje clásico, la disección se realiza de derecha a izquierda, con una sección inicial de cuello del páncreas y los vasos esplénicos. El plano de disección posterior incluye la resección de la fascia renal anterior o de Gerota y camina por el espacio perirrenal. En este punto los autores describen 2 variantes: si el tumor no invade la cápsula pancreática por su cara posterior, realizan la que denominan RAMPS anterior, en la que se conserva la glándula suprarrenal izquierda.

Si por el contrario, el tumor esta exteriorizado, la suprarrenal es resecada en bloque con la pieza, a esta variante la denomina: RAMPS posterior. Fig2.

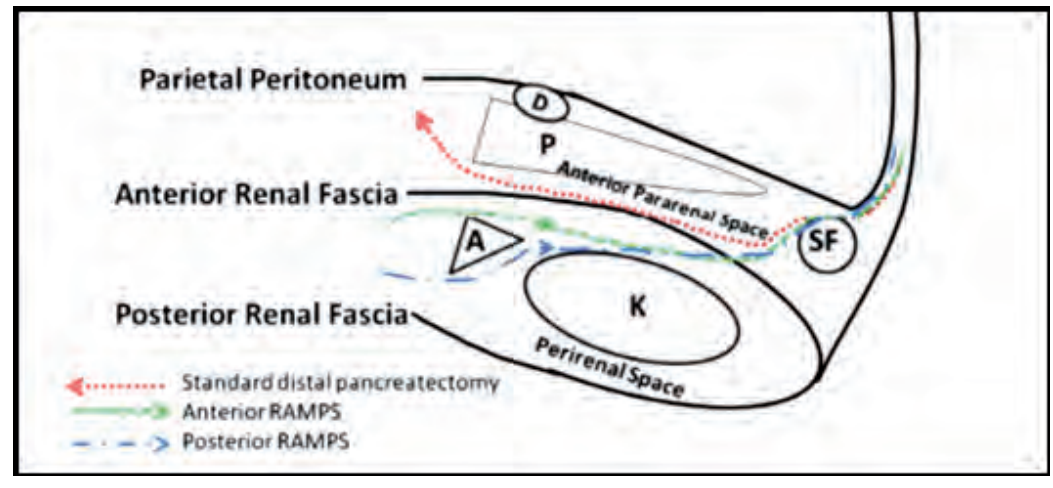

Fig 2. Variantes de resecciones RAMPS. Línea roja resección estándar, línea verde RAMPS anterior, línea azul RAMPS posterior.

Extraído de Strasberg et al.Cancer J. 2012; 18(6):562-570.36

Se presentan resultados con esta técnica quirúrgica sobre 47 pacientes, (RAMPS anterior en 32 y en 15 pacientes RAMPS posterior). En 23 casos la resección fue ampliada a otros órganos.

El tiempo medio operatorio fue de 243 minutos, el número de ganglios resecados 18 y la tasa de resecciones R0 de $89 \%$. La morbilidad fue de $66 \%$ y la mortalidad a 30 días $0 \%$.

La sobrevida media fue de 25,9 meses y la sobrevida a 5 años $35 \% \cdot{ }^{35,36}$

La tabla 1, muestra los resultados de estudios comparativos entre RAMPS y pancreatoesplenctomía estándar. Todos los trabajos son retrospectivos, y algunos incluyen tumores diferentes a adenocarcinomas.

Los resultados muestran, que con esta técnica el número de ganglios resecados fue mayor, lo mismo que la tasa de resecciones R0, no hubo diferencias significativas en cuanto a la duración de la cirugía ni en las pérdidas sanguíneas.

Tabla 1: RAMPS vs Pancreatoesplenctomía estándar

\begin{tabular}{|c|c|c|c|c|c|c|c|c|}
\hline \multicolumn{2}{|c|}{} & ganglios & $\begin{array}{c}\text { R0 } \\
(\%)\end{array}$ & $\begin{array}{c}\text { Perdida } \\
\text { sanguinea } \\
(\mathrm{ml})\end{array}$ & $\begin{array}{c}\text { Tiempo } \\
\text { operatorio } \\
\text { (minutos) }\end{array}$ & $\begin{array}{c}\text { Tasa } \\
\text { complicaciones } \\
(\%)\end{array}$ & $\begin{array}{c}\text { mortalidad } \\
\text { Sobrevida } \\
\text { Media } \\
\text { (meses) }\end{array}$ \\
\hline $\begin{array}{c}\text { Trottman } \\
(37)\end{array}$ & RAMPS & 11 & 10 & - & 300 & 55 & 0 & - \\
\cline { 2 - 10 } $\begin{array}{c}\text { Park } \\
(38)\end{array}$ & PDS & 4 & 85 & - & 292 & 50 & 0 & - \\
\hline \multirow{2}{*}{$\begin{array}{c}\text { Abe } \\
(39)\end{array}$} & RAMPS & 14 & 89 & 323 & 210 & 18 & 0 & 24 \\
\cline { 2 - 10 } & PDS & 20 & 81 & 400 & 185 & 22 & 0 & 15 \\
\hline
\end{tabular}

La tasa de complicaciones fue similar. En cuanto a los resultados a largo plazo si bien parece haber una tendencia a una mayor sobrevida con el RAMPS, la misma no fue estadísticamente significativa.

Una reciente revisión sistemática y metaanálisis ${ }^{40}$ revisa 13 artículos, con un total de 354 pacientes. Encuentra que el RAMPS tiene una tasa de resecciones R0 del $88 \%$, un número medio de ganglios resecados de 21, con una morbilidad del 40\%, sin mortalidad. Reporta una sobrevida global a 5 años de $37 \%$. 
Cuando compara el procedimiento con la cirugía estándar, encuentra que el RAMPS se asoció con menor pérdida sanguínea, mayor número de ganglios resecados y mayor tasa de R0.

Sin embargo, todos los trabajos son retrospectivos y con bajo número de pacientes, por lo cual el beneficio de esta técnica deberá ser avalado por estudios randomizados.

\section{Pancreatectomías extendidas.}

Bajo el término de pancreatectomías extendidas, se incluyen las resecciones de estructuras vasculares y órganos adyacentes al páncreas, que han sido invadidas por el tumor.

El consenso del International Study Group for Pancreatic Surgery ${ }^{13}$, en un intento por unificar criterios, enumera las estructuras que al ser resecadas definen una "pancreatectomía extendida " en los tumores de cuerpo y cola de páncreas:

- Cualquier tipo de resección gástrica

- Colon y/o estructuras vasculares principales del mesocolon transverso (cólica media o izquierda)

- Intestino delgado

- Glándula suprarrenal izquierda.

- Riñón izquierdo

- Diafragma

- Hígado (cuando la resección es por invasión directa, no debe ser incluida la resección de metástasis)

La resección debe ser en bloque.

La ampliación de la resección en el páncreas, por margen de sección positivo en la extemporánea, no debe interpretarse como pancreatectomía extendida.

$\mathrm{El}$ consenso, define que la resección de estructuras vasculares también debe interpretarse como pancreatectomía extendida, estas son:

- la vena porta, vena mesentérica superior y mesentérica inferior

- la arteria hepática, tronco celíaco y arteria mesentérica superior

\section{Pancreatectomías distales extendidas a órganos vecinos.}

Por su localización y por lo tardío de su diagnóstico, las lesiones de cuerpo y cola de páncreas invaden, muchas veces, estructuras vecinas.

$\mathrm{El}$ análisis de los resultados de las pancreatectomías extendidas a órganos vecinos, es difícil por lo inhomogéneo de los reportes. Muchos estudios analizan de forma conjunta pancreatectomías cefálicas y distales, por otra parte en algunos se incluyen resecciones por distintos tipos de tumores, metástasis e incluso patología benigna

En la tabla 2 se presentan los resultados de distintas series de pancreatectomías extendidas

Los datos sugieren que se asocian a una mayor tasa de complicaciones, pero la mortalidad perioperatoria es similar. Todos muestran un mayor tiempo operatorio, mayores pérdidas sanguíneas y una estadía hospitalaria y en cuidados intensivos significativamente más prolongada. ${ }^{13,41-46}$ 
Tabla 2: Resultados sobre pancreatectomías extendidas a órganos vecinos.

\begin{tabular}{|c|c|c|c|c|c|c|c|}
\hline \multirow{2}{*}{ Autor } & \multirow{2}{*}{$\begin{array}{c}\mathbf{N}^{0} \\
\text { Total/extendidas }\end{array}$} & \multicolumn{2}{|c|}{ Mortalidad (\%) } & \multicolumn{2}{|c|}{ Morbilidad (\%) } & \multicolumn{2}{|c|}{ Sobrevida } \\
\hline & & $S$ & $\mathrm{E}$ & S & E & $\mathrm{S}$ & $\mathrm{E}$ \\
\hline $\begin{array}{l}\text { Sasson (41) } \\
2002\end{array}$ & $\begin{array}{c}116 / 37 \\
6 \text { P.distal } \\
25 \mathrm{DPC} \\
5 \text { T,total } \\
\end{array}$ & 1,7 & 2,7 & 35 & 39 & $\begin{array}{l}\text { Media } 26 \text { m } \\
16 \% \text { a } 5 \text { años }\end{array}$ & $\begin{array}{l}\text { Media } 16 \mathrm{~m} \\
9,5 \text { a } 5 \text { años }\end{array}$ \\
\hline $\begin{array}{l}\text { Shoup (42) } \\
2003 \\
\end{array}$ & $\begin{array}{c}57 / 22 \\
\text { Pancreas distal } \\
\end{array}$ & 0 & 0 & $\begin{array}{l}0 \% \\
\text { relap }\end{array}$ & $\begin{array}{l}9 \% \\
\text { relap }\end{array}$ & $\begin{array}{l}\text { Media } 16 \mathrm{~m} \\
22 \% \text { a } 5 \text { años }\end{array}$ & $\begin{array}{l}\text { Media } 9 \mathrm{~m} \\
8 \% \text { a } 5 \text { años }\end{array}$ \\
\hline $\begin{array}{l}\text { Kleeff (43) } \\
2007\end{array}$ & $\begin{array}{c}302 / 109 \\
\text { Pancreas distal }\end{array}$ & 0 & 5,5 & 23 & 32 & - & - \\
\hline $\begin{array}{l}\text { Hartwig (44) } \\
2009\end{array}$ & $\begin{array}{c}101 / 101 \\
21 \text { P. distal } \\
60 \text { DPC } \\
20 \text { P.total }\end{array}$ & 1,5 & 3,5 & 25 & 35 & Media 23m & Media $18 \mathrm{~m}$ \\
\hline $\begin{array}{l}\text { Burdelski (45) } \\
2011\end{array}$ & $\begin{array}{l}55 / 55 \\
\text { DPC }\end{array}$ & 4 & 7 & 37 & 69 & Media 18m & Media 16m \\
\hline
\end{tabular}

Los órganos más frecuentemente incluidos en las resecciones extendidas, son el colon y el estómago, seguidos por la glándula suprarrenal y el riñón. La resección de hígado, diafragma e intestino son más raras. ${ }^{41,43,44,46}$

El efecto de la resección de cada órgano específico sobre la morbi-mortalidad no ha podido ser establecido por los insuficientes datos registrados. ${ }^{13}$ Pero la resección colónica ${ }^{42}$ y la nefrectomía ${ }^{45}$ han sido asociadas en diferentes trabajos con una mayor tasa de complicaciones.

Por otro lado, dos trabajos encuentran que la morbilidad aumenta de forma proporcional al número de órganos resecados. $^{44,45}$

Los resultados de sobrevida a largo plazo, sugieren que la pancreatectomía extendida a otros órganos tiene resultados similares a la estándar. ${ }^{13,41,42,44,45}$

Los resultados de sobrevida a 5 años de las resecciones ensanchadas, son mejores que los de tratamientos paliativos con quimioterapia o radio-quimioterapia por enfermedad localmente avanzada. ${ }^{13}$

\section{Resecciones extendidas a los ejes arteriales.}

La localización corporo-caudal y lo avanzado de las lesiones al momento del diagnóstico, hacen que el compromiso del tronco celíaco y sus ramas sea frecuente, la arteria mesentérica superior también puede estar comprometida.

\section{Pancreatectomía distal con resección en bloque del tronco celíaco \\ (Técnica de Appleby modificada)}

En general todos los consensos aceptan que el contacto del tumor mayor a $180^{\circ}$ con el tronco celíaco y una invasión extensa de la arteria hepática común, lo hacen irresecable. ${ }^{2-5}$

Sin embargo en un esfuerzo por aumentar la resecabilidad y la tasa de resecciones R0, centros japoneses desarrollaron la técnica de pancreatectomía distal con resección en bloque del tronco celíaco. ${ }^{6}$

Este procedimiento, es una adaptación de la técnica descrita por Appleby en 1953, para el cáncer gástrico avanzado, en la que realizaba una gastrectomía con resección en bloque del tronco celíaco. ${ }^{8}$

La base fisiológica de este procedimiento, en el que no se realiza reconstrucción arterial, se basa en la observación de pacientes con oclusión ateromatosa del tronco celíaco, en los que el flujo arterial hepático se mantiene por las arcadas pancreático-duodenales. 
En la figura 2 se ejemplifica como el flujo hepático se mantiene a través de la arcada pancreático-duodenal (anterior y posterior), por flujo retrógrado desde la arteria mesentérica superior hacia la arteria gastroduodenal y hepática propia. La irrigación gástrica, se ve afectada por la desaparición de la coronaria estomáquica y el flujo desde la esplénica a través de los vasos cortos. El flujo arterial se mantiene a través del mismo circuito de las pancreático duodenales a través de la gastroduodenal y la gastroepiploica derecha.

Es una técnica de alta complejidad, que se realiza en pocos centros especializados.

Una revisión del 2015 basada en el American College of Surgeons-National Surgical Quality Improvement Program (ACS-NSQIP), muestra que en un período de 14 meses, se realizaron en 43 instituciones 822 pancreatectomías distales, pero solo en 20 casos $(2,4 \%)$ se realizó resección en bloque del tronco celíaco. ${ }^{47}$

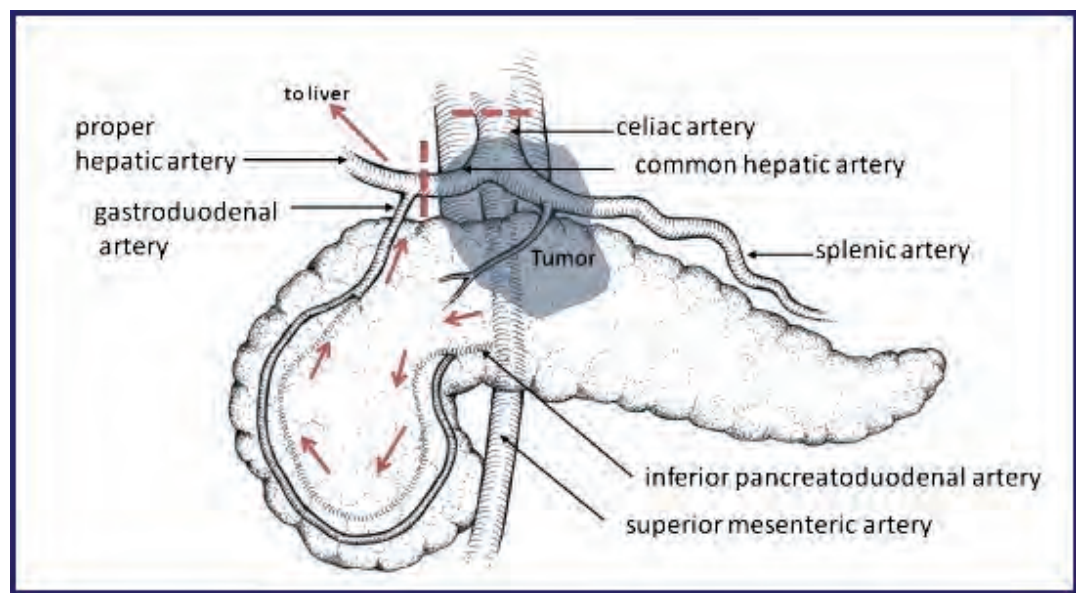

Fig. 2. Modelo de suplencia vascular de arteria hepática, luego de la resección

del tronco celíaco a través de la arcada

pancreático-duodenal.

Extraído de Strasberg (36).

Sus resultados son controversiales y se la asocia con una mayor morbilidad quirúrgica (por isquemia hepática y/o gástrica), un mayor índice de sangrado y tiempo operatorio.

Por otra parte, se la ha vinculado con morbilidad alejada, por la aparición de diarrea y malnutrición por pérdida del plexo celíaco.

Los resultados oncológicos también son debatidos y deben ser comparados con el paciente que recibe tratamiento oncológico paliativo y con la pancreato-esplenectomía estándar

Los reportes son todos retrospectivos y con bajo número de casos.

El trabajo con mayor cantidad de pacientes, incluye 42 casos en un período de 10 años. ${ }^{48}$

Tres revisiones sistemáticas ${ }^{49-51}$ recientes, analizan los resultados de este procedimiento. Dos de ellas analizan 19 trabajos y otra 18 , incluyen entre 203 y 240 pacientes.

Una de las revisiones que asocia un metaanálisis ${ }^{49}$, encuentra que la duración media de la cirugía y las pérdidas sanguíneas fueron significativamente mayores que la pancreatectomía distal estándar (tiempo medio de cirugía 375 minutos, pérdida sánguínea media $1320 \mathrm{ml}$ ). En un 11,5\% de los casos se realizó reconstrucción arterial, y en un 33\% hubo resección venosa del eje mesentérico-portal (esta incidencia de resección venosa fue significativamente mayor que en la pancreatectomía distal estándar).

La tasa de reintervenciones fue $9.7 \%$

Las resecciones R0 reportadas varian entre $72,7 \%$ y 74\%, las cuales son similares a las reportadas en la pancreatectomía estándar. ${ }^{49,50}$

La mortalidad varió entre $3 \%$ y $6,7 \%{ }^{49-51}$ y la morbilidad global documentada en los tres estudios varió entre 27 y 50,2\%. ${ }^{49-51}$ Mientras tanto, la tasa de fístula pancreática documentada fue de 28-31\%, similar a cirugía estándar. ${ }^{49-51}$

En cuanto a las complicaciones isquémicas, 2 trabajos reportan cifras globales entre $6 \%$ y $9 \%{ }^{50-51}$, mientras la revisión de Gong et al. las desglosa por órgano: gastropatía isquémica 12\%, hepática grave (infarto, falla hepática, absceso) 5,4\%, hepática leve (alteración de AST y ALST transitorias) 40\%, isquemia de la vesícula biliar 7,3\%. ${ }^{49}$

Los estudios también analizan el valor de la embolización preoperatoria y no encuentran diferencias en las tasas de isquemia entre los pacientes con oclusión arterial previa y los no embolizados. ${ }^{49-50}$

La tasa de diarrea crónica documentada fue de 37\% para el trabajo de Gong. ${ }^{49}$

Cuando se analizan los resultados a largo plazo, estas revisiones reportan tasas de sobrevida media que varía de 14 a 24 meses. $^{49,51}$

Gong $^{49}$ concluye por su parte, que la sobrevida de este procedimiento complejo es similar a la de la pancreatectomía estándar, pero mejor que la de los pacientes no resecados que recibieron exclusivamente tratamiento oncológico paliativo. 


\section{Resecciones extendidas al eje venoso mesentérico portal.}

Los aspectos teóricos y resultados de las resecciones venosas, ya han sido discutidos en el capítulo de duodenopancreatectomía.

En la localización corporocaudal, este eje venoso está afectado con menos frecuencia.

\section{Pancreatectomía distal oncológica por cirugía mínimamente invasiva.}

En los últimos años la pancreatectomía distal laparoscópica ha sido utilizada para el tratamiento de lesiones benignas y borderline de cuerpo y cola de páncreas.

Todos los reportes son retrospectivos y no existen estudios randomizados comparativos con la cirugía abierta.

Seis metaanálisis y revisiones sistemáticas recientes (que incluyen patología benigna y maligna), demuestran que la pancreatectomía laparoscópica, es un procedimiento seguro comparable con la cirugía abierta..$^{52-57}$

En todos, el abordaje laparoscópico tuvo una internación más corta y una reinstalación más precoz de la vía oral. ${ }^{52-57}$ La duración de la cirugía fue mayor en el grupo laparoscópico en dos estudios ${ }^{53,55}$ y la tasa de conversión fue del $0-30 \% .^{52-57}$

En cuanto a la morbilidad, tres trabajos documentaron ventajas con el abordaje laparoscópico ${ }^{52-54}$, mientras los restantes no mostraron diferencias estadísticamente significativas. ${ }^{55-57}$

La tasa de fistula pancreática fue similar entre ambos grupos y ningún estudio encuentra diferencias en la mortalidad. ${ }^{52-57}$

La seguridad y eficacia oncológica de los abordajes mínimamente invasivos es materia de debate. Hay varios trabajos que han analizado las diferencias oncológicas de ambos procedimientos.

Kooby et al..$^{58}$ en un estudio multicéntrico compara retrospectivamente resultados oncológicos de pancreatectomía distal abierta y laparoscópica (212 pacientes, 23 por laparoscopía). No encuentra diferencias en la tasa de resecciones R0 (laparotómico 73.9\% vs laparoscópico 65.7\%), número de ganglios resecados ni sobrevida media (16 meses para ambos grupos).

Otros estudios monocéntricos recientes arriban a similares hallazgos..$^{59-61}$

En 2015 Adam el al. ${ }^{62}$ comparan los resultados de pancreatectomías distales abiertas y por cirugía mínimamente invasiva, realizadas en 215 centros norteamericanos. (datos obtenidos del National Cancer Database).

El estudio revisa 1733 pacientes, 535 (31\%) operados por cirugía mínimamente invasiva y 1198 (69\%) por cirugía abierta.

Encuentran similares tasas de resecciones R0, al igual que el número de ganglios resecados.

La tasa de readmisón a 30 días fue similar, pero la estadía medía fue menor en el grupo de pacientes sometidos a cirugía mínimamente invasiva.

En 2015 Ricci et al. realizan un revisión sistemática y metaanálisis, comparando pancreatectomía distal convencional y laparoscópica por adenocarcinoma de páncreas. El estudio incluye 5 trabajos, con 261 pacientes (69\% convencional, $31 \%$ laparoscópico). Encuentran que la tasa de resección R0 fue similar entre los 2 grupos (laparotómico 86.3\% vs laparoscópico $80.7 \%, \mathrm{P}=0.53)$ y el número medio de ganglios resecados fue comparable $(\mathrm{P}=0.33)$.

Sin embargo, en cuanto al tamaño tumoral, el grupo de cirugía laparoscópica presentó casos de tumores de menor diámetro, comparado con los de cirugía abierta $(\mathrm{P}=0.04)$.

La pancreatectomía distal laparoscópica tuvo un tiempo operatorio más prolongado $8280.9 \pm 62.9$ vs. $237.3 \pm 70.2$ min, $\mathrm{P}=0.04)$, menor pérdida sanguínea $(335.1 \pm 228.1$ vs. $611 \pm 574.5 \mathrm{ml} \mathrm{P=0.01)} \mathrm{y} \mathrm{menor} \mathrm{estadía} \mathrm{hospitalaria}(5.3$ \pm 2.5 vs. $10.6 \pm 8.6$ días $\mathrm{P}<0.001)$.

En cuanto a la morbimortalidad global, la tasa de fístula pancreática y el número de pacientes reoperados, fueron similares en ambos grupos y no hubo diferencias en cuanto a la sobrevida a largo plazo $(\mathrm{P}=0.32) .{ }^{63}$

En 2016 una revisión Cochrane compara pancreatectomía distal y laparoscópica por cáncer. ${ }^{64}$ Analiza 12 estudios retrospectivos con 1579 (394 por vía laparoscópica y 1182 por vía laparotómica).

Esta revisión no encuentra diferencias en mortalidad ni morbilidad, con tasas de fístula similares, pero la estadía hospitalaria fue más corta para el grupo laparoscópico. 
Desde el punto de vista oncológico, el margen positivo se evidenció en $14.3 \%$ de los pacientes del grupo de cirugía laparoscópica (49/333) y de 18.4\% para el grupo de cirugía abierta (208/1133).

En general se acepta que la pancreatectomía mínimamente inasiva está indicada en lesiones no exteriorizadas, con la fascia de Gerota intacta y a una distancia mínima del tronco celíaco de 1 a $2 \mathrm{~cm} .{ }^{65}$

Por lo tanto, si bien la evidencia parece indicar que son métodos comparables, los estudios deben ser realizados en pacientes comparables desde el punto de vista oncológico, con tamaño y localización tumoral similares.

Deberemos esperar el resultado de estudios randomizados, con un seguimiento a largo plazo.

La cirugía robótica también ha sido utilizada con éxito en el tratamiento de lesiones corporocaudales de páncreas ${ }^{66} \mathrm{y}$ en este sentido, algunos estudios la han comparado con la cirugía laparoscópica.

Butturini ${ }^{67}$ en un estudio prospectivo monocéntrico, compara pancreatectomía laparoscópica y robótica por cáncer, no encontrando diferencias en la tasa de conversión, duración de la estadía hospitalaria, tasa de fístula, ni en los resultados oncológicos (similar tasa de R0 y número de ganglios resecados). La cirugía robótica tuvo una duración más prolongada y el costo del procedimiento fue mayor.

Gavriilidis en un reciente metaanálisis ${ }^{68}$, compara los resultados de la cirugía robótica vs laparoscópica en pancreatectomía distal, y encuentra que la cirugía robótica tuvo mayor duración, con una internación más corta y la tasa de conversiones fue similar

No hubo diferencias en la mortalidad ni tasa de fístula, pero el grupo de cirugía robótica tuvo una tasa significativamente mayor de reingresos.

Zhou en otro metanálisis ${ }^{69}$, encuentra que la cirugía robótica tuvo mayor duración que la laparoscópica, pero en los demás parámetros comparados: tasa de conversión, morbimortalidad, tasa de fístula, tasa de resección R0 y número de ganglios resecados, no hubo diferencias significativas. Tampoco encuentra diferencias en el costo de ambos procedimientos.

\section{El problema de la fístula pancreática.}

En la pancreatectomía distal la complicación más frecuente es la aparición de una fístula pancreática postoperatoria, originada en la línea de sección pancreática.

El International Study Group on Pancreatic Fístula (ISGPF) la definió en 2005: "como la salida de fluido, que presenta una dosificación de amilasa 3 veces superior a su valor sérico, luego del tercer día de postoperatorio" ${ }^{70}$

También realizo una clasificación de su severidad, en tres niveles (A,B y C). Tabla 3.

Su incidencia es de $20-40 \%^{71-73}$ (71-73) y puede desencadenar otras complicaciones como abscesos intrabdominales, hemorragias tardías por erosión vascular, infección cutánea y desnutrición. Pese a los desarrollos técnicos, su incidencia no ha podido ser disminuida.

Varias técnicas de cierre del muñón pancreático han sido propuestas, buscando mejorar los resultados: cierre manual, uso de grapadoras, combinación de ambas, cierre sobre malla, colas biológicas, parches serosos o pancreatoyeyunostomias sobre el muñón pancreático. ${ }^{71}$

Las dos técnicas más utilizadas son el cierre manual (con o sin cierre por separado del conducto de Wirsung) y la sección con grapadora mecánica. 
Tabla 3: Grados de severidad de FP. Extraído de ISGP 2005. (70).

\begin{tabular}{|l|c|c|c|}
\hline \multicolumn{1}{|c|}{ CARACTERITICAS } & GRADO A & GRADO B & GRADO C \\
\hline Signos de enfermedad sistémica & NO & SI & SI \\
\hline Requirió tratamiento ? & NO & SI & SI \\
\hline Evidencia ECO oTC & NO & SI & SI \\
\hline Drenaje persistente $>$ 3 semanas & NO & SI & SI \\
\hline Signos de infección & NO & SI & SI \\
\hline Readmisión & NO & SI & SI \\
\hline Sepsis & NO & NO & SI \\
\hline Reoperación & NO & NO & SI \\
\hline Muerte & NO & NO & \\
\hline
\end{tabular}

$\mathrm{ECO}=$ Ecografía $/ \mathrm{TC}=$ Tomografía computada

En 2011, un estudio multicéntrico randomizado europeo (DISPACT) ${ }^{73}$, comparó ambas técnicas de cierre. El estudio incluyó 21 centros especializados, 450 pacientes fueron randomizados (221 stapler y 229 cierre manual), no habiendo diferencias en la tasa de fístula, el uso del stapler presentó 32\% (56 de 177) de fístula pancreática y la técnica manual $28 \%$ (49 of 175 ; OR $0 \cdot 84,95 \%$ CI $0 \cdot 53-1 \cdot 33$; p=0 56 ). Tampoco hubo diferencias en la severidad de la fistula.

Los autores concluyen que el uso de grapadora no disminuye la incidencia de fístula.

Tres revisiones sistemáticas con metaanálisis tampoco encuentra diferencias en la tasa de fístula comparando cierre manual o mecánico. ${ }^{72,74,75}$

Solo el metaanálisis de $\mathrm{Zhang}^{76}$, encuentra una menor incidencia de fístula utilizando grapadora.

El uso de la grapadora debe ser adaptado a las características anatómicas, cuando el páncreas es grueso y fibroso, el stapler puede provocar desgarros, sangrados y aumentar el riesgo de fístula. ${ }^{71}$

El uso de la somatostatina y sus análogos ha sido propuesto desde los años 90 , con la finalidad de disminuir la incidencia de fístula pancreática, a través de la inhibición de la secreción del páncreas exócrino.

Varios estudios randomizados han mostrado resultados contrapuestos.

Gurusamy y cols. en una revisión Cochrane ${ }^{77}$, analizan 21 trabajos y encuentran una disminución en la incidencia de fístula con el uso de análogos de la somatostatina.

Sin embargo, la gran mayoría de los trabajos analizados no detallan el porcentaje de pacientes que presentan fístulas clínicamente significativas.

Cuando los autores analizan solo los trabajos que definen claramente las fístulas significativas, encuentran que no hubo diferencias en la incidencia de fístula entre ambos grupos.

Tampoco encuentran diferencias en la mortalidad, tasa de reintervenciones ni duración de la estadía hospitalaria.

Hackert ${ }^{71}$ en su revisión, no encuentra evidencia que avale el uso de octeocride y no recomienda su uso rutinario. Sin embargo, plantea que pueden existir situaciones de riesgo (ejemplo páncreas blando), en las que podría ser recomendado de manera empírica su uso.

La colocación de stent en el Wirsung en el perioperatorio, buscando disminuir la presión del muñón, ha sido propuesta como método preventivo de la fístula pancreática postpancreatectomía distal.

La colocación puede hacerse previa a la cirugía por colangiopancreatografía endoscópica retrógrada (CPER) o en el intraoperatorio a través del Wirsung seccionado, previo a su cierre. ${ }^{78}$

La casuística es escasa y se han reportado complicaciones vinculadas a esta maniobra como pancreatitis y colestasis. ${ }^{79}$ Un estudio randomizado sueco que incluye 58 pacientes, no encuentra beneficios con la colocación del stent. ${ }^{80}$

Existen varios factores de riesgo que han sido vinculados con la aparición de fístula pancreática.

El índice de masa corporal $>25 \mathrm{~kg} / \mathrm{m} 2$, ha sido reconocido como factor de riesgo de aparición de fístula pancreática en varios trabajos. ${ }^{46,81,82}$

Otros factores de riesgo que han sido invocados, son: el volumen de pérdida sanguínea ${ }^{82}$, la resección multivisceral y la duración de la cirugía. ${ }^{43}$ 
Por tanto, el problema del cierre del muñón pancreático y la prevención de la fístula pancreática, continúa sin tener solución. No existe un método de cierre que haya demostrado superioridad, deberemos esperar el desarrollo de nuevas técnicas y tecnología que permitan mejorar los resultados en este punto.

\section{Resultados de la pancreatectomía distal por adenocarcinoma.}

Dos estudios multicéntricos recientes, presentan los resultados de la pancreatectomía distal por adenocarcinoma en Francia ${ }^{83}$ y Holanda. ${ }^{84}$

En estos estudios la tasa de complicaciones mayores fue del 33 y 34\% y la mortalidad a 90 días del 5-6\% respectivamente.

Tabla 4: Resultados oncológicos de estudios multicéntricos en la pancreatectomía distal

\begin{tabular}{|c|c|c|c|c|c|c|c|}
\hline & $\begin{array}{c}\text { Nocentros / } \\
\text { No pacientes }\end{array}$ & R0 (\%) & No ganglios & $\begin{array}{c}\text { Reseccion } \\
\text { multivisceral } \\
(\%)\end{array}$ & $\begin{array}{c}\text { Sobrevida } \\
\text { media } \\
\text { (meses) }\end{array}$ & $\begin{array}{c}\text { Sobrevida } \\
\text { a 3 años } \\
(\%)\end{array}$ & $\begin{array}{c}\text { Sobrevida } \\
\text { a 5 años } \\
(\%)\end{array}$ \\
\hline $\begin{array}{c}\text { Kooby } \\
\mathbf{2 0 1 0}\end{array}$ & $9 / 212$ & 74 & 12 & - & 16 & - & - \\
\hline $\begin{array}{c}\text { P8) } \\
\mathbf{2 0 1 5} \\
(83)\end{array}$ & $28 / 278$ & 74 & 17 & 20 & 35 & 44 & 29 \\
\hline $\begin{array}{c}\text { De Rooij } \\
\mathbf{2 0 1 6} \\
(84)\end{array}$ & $17 / 141$ & 50 & 8 & 30 & 17 & 29 & 22 \\
\hline
\end{tabular}

En la tabla 4 se presentan los resultados oncológicos de los estudios antes descritos y los presentados por un trabajo multicéntrico norteamericano. ${ }^{58}$

Como queda ejemplificado en la tabla 4, el número de pancreatectomías distales es bajo, ya que estos trabajos abarcan períodos de tiempo que varían entre 5 y 8 años.

En las tres series el porcentaje de pacientes que recibió adyuvancia varió entre el 63 y el 71\%. ${ }^{58,83,84}$

Los resultados a largo plazo son pobres con sobrevidas medias apenas superior al año, excepto en la serie francesa que llega a 35 meses.

La sobrevida a 5 años reportada en la serie francesa y holandesa varió entre el 22 y 29\%. ${ }^{83,84}$ 


\section{BIBLIOGRAFIA}

1. Pave, F. Pancreatectomie gauche pour adenocarcinome pancreatique . Monographies de L'Association Francaise de Chirurgie, 2010.

2. Callery MP, Chang KJ, Fishman EK,et al.Pretreatment assessment of resectable and borderline resectable pancreatic cancer: expert consensus statement. Ann Surg Oncol. 2009;16(7):1727-1733.

3. Bockhorn M, Uzunoglu FG, Adham M,et al. Borderline resectable pancreatic cancer: a consensus statement by the International Study Group of Pancreatic Surgery (ISGPS). Surgery. 2014;155(6):977-988.

4. Tempero MA, Malafa MP, Behrman SW, et al. Pancreatic adenocarcinoma, version 2.2014: NCCN guidelines.J Natl Compr Cancer Netw. 2014;12(8):1083-1093.

5. Varadhachary GR, Tamm EP, Abbruzzese JL, et al. Borderline resectable pancreatic cancer: definitions, management, and role of preoperative therapy. Ann Surg Oncol. 2006 ;13(8):1035-1046.

6. Mayumi T, Nimura Y, Kamiya J, et al: Distal pancreatectomy with en bloc resection of the celiac artery for carcinoma of the body and tail of the pancreas.Int J Pancreatol, 1997; 22: 15-21 (abstract).

7. Yamaguchi K, Nakano K, Kobayashi K, et al. Appleby operation for pancreatic body-tail carcinoma: report of three cases. Surg Today.2003;33(11):873-878.

8. Appleby LH.The coeliac axis in the expansion of the operation for gastric carcinoma. Cancer.1953;6(4):704-707. (abstract).

9. Hartwig W, Vollmer CM, Fingerhut A,el al; International Study Group on Pancreatic Surgery. Extended pancreatectomy in pancreatic ductal adenocarcinoma: definition and consensus of the International Study Group for Pancreatic Surgery (ISGPS). Surgery. 2014;156(1):1-14.

10. Nakao A, Harada A, Nonami T, et al. Lymph node metastasis in carcinoma of the body and tail of the pancreas. Br J Surg 1997;84:1090-1092.

11. Kanda M, Fujii T, Nagai S, et al. Pattern of lymph node metastasis spread in pancreatic cancer. Pancreas 2011;40:951-955.

12. Japan Pancreas Society. Classification of pancreatic carcinoma. 2nd English ed. Tokyo: Kanehara \& Co. Ltd; 2003.

13. Tol JA, Gouma DJ, Bassi C, Dervenis C,et al; International Study Group on Pancreatic Surgery.Definition of a standard lymphadenectomy in surgery for pancreatic ductal adenocarcinoma: a consensus statement by the International Study Group on Pancreatic Surgery (ISGPS). Surgery. 2014;156(3):591-600.

14. Tomlinson JS, Jain S, Bentrem DJ, et al. Accuracy of staging node-negative pancreas cancer: a potential quality measure. Arch Surg. 2007;142(8):767-773.

15. Slidell MB, Chang DC, Cameron JL, et al. Impact of total lymph node count and lymph node ratio on staging and survival after pancreatectomy for pancreatic adenocarcinoma: a large,population-based analysis. Ann Surg Oncol 2008;15(1):165-174.

16. Roland CL, Yang AD, Katz MH, et al. Neoadjuvant therapy is associated with a reduced lymph node ratio in patients with potentially resectable pancreatic cancer. Ann Surg Oncol 2015;22(4):1168 -1175.

17. Riediger H, Keck T, Wellner U, et al. The lymph node ratio is the strongest prognostic factor after resection of pancreatic cancer. J Gastrointest Surg 2009;13(7):1337-1344.

18. Valsangkar NP, Bush DM, Michaelson JS, et al. N0/N1, PNL, or LNR? The effect of lymph node number on accurate survival prediction in pancreatic ductal adenocarcinoma. J Gastrointest Surg 2013;17(2):257-266.

19. Malleo G, Maggino L, Capelli P, et al. Reappraisal of Nodal Staging and Study of Lymph Node Station Involvement in Pancreaticoduodenectomy with the Standard International Study Group of Pancreatic Surgery Definition of Lymphadenectomy for Cancer.J Am Coll Surg. 2015;221(2):367-79.

20. Murakami Y, Uemura K, Sudo T, et al. Number of metastatic lymph nodes, but not lymph node ratio, is an independent prognostic factor after resection of pancreatic carcinoma. J Am Coll Surg 2010;211(2):196-204.

21. Kim SH, Hwang HK, Lee WJ, et al. Identification of an N staging system that predicts oncologic outcome in resected left-sidedpancreatic cancer. Medicine. 2016;95(26). doi: 10.1097/MD.0000000000004035.

22. Sahin TT, Fujii T, Kanda M, et al. Prognostic implications of lymph node metastases in carcinoma of the body and tail of the pancreas.Pancreas. 2011;40(7):1029-1033.

23. Ishikawa $\mathrm{O}$, Ohhigashi $\mathrm{H}$, Sasaki $\mathrm{Y}$, et al. Practical usefulness of lymphatic and connective tissue clearance for the carcinoma of the pancreas head.Ann Surg. 1988; 208(2):215-220.

24. Manabe T, Ohshio G, Baba N, et al. Radical pancreatectomy for ductal cell carcinoma of the head of the pancreas.Cancer. 1989; 64(5):1132-1137.

25. Pedrazzoli S, DiCarlo V, Dionigi R, et al. Standard versus extended lymphadenectomy associated with pancreatoduodenectomy in the surgical treatment of adenocarcinoma of the head of the pancreas: a multicenter, prospective, randomized study. Lymphadenectomy Study Group.Ann Surg. 1998; 228(4):508-517. 
26. Yeo CJ, Cameron JL, Lillemoe KD,et al. Pancreaticoduodenectomy with or without distal gastrectomy and extended retroperitoneal lymphadenectomy for periampullary adenocarcinoma, part 2: randomized controlled trial evaluating survival, morbidity, and mortality. Ann Surg. 2002;236(3):355-366.

27. Riall TS, Cameron JL, Lillemoe KD, et al. Pancreaticoduodenectomy with or without distal gastrectomy and extended retroperitoneal lymphadenectomy for periampullary adenocarcinoma--part 3: update on 5-year survival. J Gastrointest Surg. 2005(9):1191-1204.

28. Farnell MB, Pearson RK, Sarr MG, et al ; Pancreas Cancer Working Group. A prospective randomized trial comparing standard pancreatoduodenectomy with pancreatoduodenectomy with extended lymphadenectomy in resectable pancreatic head adenocarcinoma. Surgery. 2005;138(4):618-628.

29. Nimura Y, Nagino M, Takao S, et al. Standard versus extended lymphadenectomy in radical pancreatoduodenectomy for ductal adenocarcinoma of the head of the pancreas: long-term results of a Japanese multicenter randomized controlled trial.J Hepatobiliary Pancreat Sci. 2012;19(3):230-241.

30. Jang JY, Kang MJ, Heo JS, et al. A prospective randomized controlled study comparing outcomes of standard resection and extended resection, including dissection of the nerve plexus and various lymph nodes, in patients with pancreatic head cancer. Ann Surg. 2014;259(4):656-664.

31. Michalski CW, Kleeff J, Wente MN,et al. Systematic review and meta-analysis of standard and extended lymphadenectomy in pancreaticoduodenectomy for pancreatic cancer.Br J Surg. 2007;94(3):265-273.

32. Orci LA, Meyer J, Combescure C,et al. A meta-analysis of extended versus standard lymphadenectomy in patients undergoing pancreatoduodenectomy for pancreatic adenocarcinoma. HPB (Oxford). 2015;17(7):565572.

33. Dasari BV, Pasquali S, Vohra RS, et al. Extended Versus Standard Lymphadenectomy for Pancreatic Head Cancer: Meta-Analysis of Randomized Controlled Trials. J Gastrointest Surg. 2015;19(9):1725-1732.

34. Strasberg SM, Drebin JA, Linehan D. Radical antegrade modular pancreatosplenectomy. Surgery. 2003; 133(5):521-527.

35. Mitchem JB, Hamilton N, Gao F,et al. Long-term results of resection of adenocarcinoma of the body and tail of the pancreas using radical antegrade modular pancreatosplenectomy procedure.J Am Coll Surg. 2012;214(1):46-52.

36. Strasberg SM, Fields R.Left-sided pancreatic cancer: distal pancreatectomy and its variants: radical antegrade modular pancreatosplenectomy and distal pancreatectomy with celiac axis resection. Cancer J. 2012 ;18(6):562570 .

37. Trottman $\mathrm{P}$, Swett K, Shen $\mathrm{P}$, et al. Comparison of standard distal pancreatectomy and splenectomy with radical antegrade modular pancreatosplenectomy.Am Surg. 2014;80(3):295-300.

38. Park HJ, You DD, Choi DW,et al. Role of radical antegrade modular pancreatosplenectomy for adenocarcinoma of the body and tail of the pancreas.World J Surg. 2014;38(1):186-193.

39. Abe T, Ohuchida K, Miyasaka Y, et al. Comparison of Surgical Outcomes Between Radical Antegrade Modular Pancreatosplenectomy (RAMPS) and Standard Retrograde Pancreatosplenectomy (SPRS) for Left-Sided Pancreatic Cancer. World J Surg. 2016;40(9):2267-2275.

40. Zhou Y, Shi B, Wu L, et al. A systematic review of radical antegrade modular pancreatosplenectomy for adenocarcinoma of the body and tail of the pancreas.HPB (Oxford). 2016. doi: 10.1016/j.hpb.2016.07.014.

41. Sasson AR, Hoffman JP, Ross EA, et al. En bloc resection for locally advanced cancer of the pancreas: is it worthwhile? J Gastrointest Surg. 2002;6(2):147-157.

42. Shoup M, Conlon KC, Klimstra D,et al. Is extended resection for adenocarcinoma of the body or tail of the pancreas justified?J Gastrointest Surg. 2003;7(8):946-952.

43. Kleeff J, Diener MK, Z'graggen K, et al.Distal pancreatectomy: risk factors for surgical failure in 302 consecutive cases. Ann Surg. 2007;245(4):573-582.

44. Hartwig W, Hackert T, Hinz U, et al. Multivisceral resection for pancreatic malignancies: risk-analysis and long-term outcome. Ann Surg . 2009;250:81-87.

45. Burdelski CM, Reeh M, Bogoevski D, et al. Multivisceral resections in pancreatic cancer: identification of risk factors.World J Surg. 2011;35(12):2756-2763.

46. Seeliger H, Christians S, Angele MK,et al. Risk factors for surgical complications in distal pancreatectomy. Am J Surg 2010;200:311-317.

47. Beane JD, House MG, Pitt S, et al. Distal pancreatectomy with celiac axis resection: what are the added risks? HPB (Oxford). 2015;17(9):777-784.

48. Tanaka E, Hirano S, Tsuchikawa T, et al. Important technical remarks on distal pancreatectomy with en-bloc celiac axis resection for locally advanced pancreatic body cancer. J Hepatobiliary Pancreat Sci.2012;19(2):141147.

49. Gong H, Ma R, Gong J, et al. Distal Pancreatectomy With En Bloc Celiac Axis Resection for Locally Advanced Pancreatic Cancer: A Systematic Review and Meta-Analysis. Medicine (Baltimore). 2016;95(10). doi: 10.1097/MD.0000000000003061. 
50. Klompmaker S, de Rooij T, Korteweg JJ,et al. Systematic review of outcomes after distal pancreatectomy with coeliac axis resection for locally advanced pancreatic cancer. Br J Surg. 2016;103(8):941-949.

51. Zhou YM, Zhang XF, Li XD, et al. Distal pancreatectomy with en bloc celiac axis resection for pancreatic body-tail cancer: Is it justified? Med Sci Monit. 2014;20:1-5.

52. Jusoh AC, Ammori BJ. Laparoscopic versus open distal pancreatectomy: a systematic review of comparative studies. Surg Endosc.2012;26(4):904-913.

53. Sui CJ, Li B, Yang JM, et al. Laparoscopic versus open distal pancreatectomy: a meta-analysis. Asian J Surg. 2012;35(1):1-8.

54. Venkat R, Edil BH, Schulick RD, et al. Laparoscopic distal pancreatectomy is associated with signifi-cantly less overall morbidity compared to the open technique: a systematic review and meta-analysis. Ann Surg. 2012;255(6):1048-1059.

55. Pericleous S, Middleton N, McKay SC,et al.Systematic review and meta-analysis of case-matched studies com-paring open and laparoscopic distal pancreatectomy: is it a safe procedure? Pancreas. 2012;41(7):9931000.

56. Jin T, Altaf K, Xiong JJ, Huang,et al. A systematic review and meta-analysis of studies comparing laparoscopic and open distal pancreatectomy. HPB (Oxford). 2012;14(11):711-724.

57. Xie K, Zhu YP, Xu XW,et al. Laparoscopic distal pancreatectomy is as safe and feasible as open procedure: a meta-analysis. World J Gastroenterol. 2012 8;18(16):1959-1967.

58. Kooby DA, Hawkins WG, Schmidt CM, et al.A multicenter analysis of distal pancreatectomy for adenocarcinoma: is laparoscopic resection appropriate? J Am Coll Surg. 2010 May;210(5):779-785, 786-787.

59. Magge D, Gooding W, Choudry H,et al. Comparative effectiveness of minimally invasive and open distal pancreatectomy for ductal adenocarcinoma.JAMA Surg. 2013;148(6):525-531.

60. Rehman S, John SK, Lochan R, et al. Oncological feasibility of laparoscopic distal pancreatectomy for adenocarcinoma: a single-institution comparative study.World J Surg. 2014;38(2):476-483.

61. Zhang M, Fang R, Mou Y, et al. LDP vs ODP for pancreatic adenocarcinoma: a case matched study from a single-institution. BMC Gastroenterol. 2015 22;15:182. doi: 10.1186/s12876-015-0411-2.

62. Adam MA, Choudhury K, Goffredo P, et al. Minimally Invasive Distal Pancreatectomy for Cancer: ShortTerm Oncologic Outcomes in 1,733 Patients. World J Surg. 2015 ;39(10):2564-2572.

63. Ricci C, Casadei R, Taffurelli G,et al. Laparoscopic versus open distal pancreatectomy for ductal adenocarcinoma: a systematic review and meta-analysis. J Gastrointest Surg. 2015;19(4):770-781.

64. Riviere D, Gurusamy KS, Kooby DA, et al. Laparoscopic versus open distal pancreatectomy for pancreatic cancer. Cochrane Database Syst Rev. 2016; 4. doi: 10.1002/14651858.CD011391.pub2.

65. Kang CM, Lee SH, Lee WJ. Minimally invasive radical pancreatectomy for left-sided pancreatic cancer: current status and future perspectives. World J Gastroenterol. 2014 7;20(9):2343-2351.

66. Magge D, Zureikat A, Hogg M,et al. Minimally Invasive Approaches to Pancreatic Surgery.Surg Oncol Clin N Am. 2016;25(2):273-286.

67. Butturini G, Damoli I, Crepaz L, et al.A prospective non-randomised single-center study comparing laparoscopic and robotic distal pancreatectomy. Surg Endosc. 2015;29(11):3163-3170.

68. Gavriilidis P, Lim C, Menahem B, et al. Robotic versus laparoscopic distal pancreatectomy - The first meta-analysis. HPB (Oxford). 2016 Jul;18(7):567-574.

69. Zhou JY,Xin C, Mou YP, et al.Robotic versus Laparoscopic Distal Pancreatectomy: A Meta-Analysis of ShortTerm Outcomes. PLoS One. 2016 14;11(3):e0151189. doi: 10.1371/journal.pone.0151189.

70. Bassi C, Dervenis C, Butturini G,et al; International Study Group on Pancreatic Fistula Definition. Postoperative pancreatic fistula: an international study group (ISGPF) definition.Surgery. 2005 ;138(1):8-13.

71. Hackert T, Büchler MW. Remnant closure after distal pancreatectomy: current state and future perspectives. Surgeon. $2012 ; 10(2): 95-101$.

72. Knaebel HP, Diener MK, Wente MN,et al. Systematic review and meta-analysis of technique for closure of the pancreatic remnant after distal pancreatectomy. Br J Surg. 2005 ;92(5):539-546.

73. Diener MK, Seiler CM, Rossion I,et al.Efficacy of stapler versus hand-sewn closure after distal pancreatectomy (DISPACT): a randomised, controlled multicentre trial. Lancet. 2011;377(9776):1514-1522.

74. Zhou W, Lv R, Wang X, et al. Stapler vs suture closure of pancreatic remnant after distal pancreatectomy: a meta-analysis. Am J Surg. 2010 ;200(4):529-536.

75. Probst P, Hüttner FJ, Klaiber U, et al.Stapler versus scalpel resection followed by hand-sewn closure of the pancreatic remnant for distal pancreatectomy. Cochrane Database Syst Rev. 2015 ;(11):CD008688. doi: 10.1002/14651858.CD008688.pub2.

76. Zhang H, Zhu F, Shen M,et al. Systematic review and meta-analysis comparing three techniques for pancreatic remnant closure following distal pancreatectomy. Br J Surg. 2015;102(1):4-15.

77. Gurusamy KS, Koti R, Fusai G,et al. Somatostatin analogues for pancreatic surgery.Cochrane Database Syst Rev. 2013;(4):CD008370. doi: 10.1002/14651858.CD008370.pub3. 
78. Fischer CP, Bass B, Fahy B,et al.Transampullary pancreatic duct stenting decreases pancreatic fistula rate following left pancreatectomy. Hepatogastroenterology. 2008;55(81):244-248.

79. Okamoto T, Gocho T, Futagawa Y, et al. Does preoperative pancreatic duct stenting prevent pancreatic fistula after surgery? A cohort study. Int J Surg. 2008;6(3):210-213.

80. Frozanpor F, Lundell L, Segersvärd R,et al. The effect of prophylactic transpapillary pancreatic stent insertion on clinically significant leak rate following distal pancreatectomy: results of a prospective controlled clinical trial. Ann Surg 2012; 255(6): 1032-1036.

81. Sledzianowski JF, Duffas JP, Muscari F, et al. Risk factors for mortality and intra-abdominal morbidity after distal pancreatectomy. Surgery. 2005;137(2):180-185.

82. Weber SM, Cho CS, Merchant N, et al. Laparoscopic left pancreatectomy: complication risk score correlates with morbidity and risk for pancreatic fistula. Ann Surg Oncol. 2009;16(10):2825-2833.

83. Paye F, Micelli Lupinacci R, Bachellier P, et al; French Surgical Association (AFC) . Distal pancreatectomy for pancreatic carcinoma in the era of multimodal treatment. Br J Surg. 2015;102(3):229-236.

84. de Rooij T, Tol JA, van Eijck CHet al Dutch Pancreatic Cancer Group. Outcomes of Distal Pancreatectomy for Pancreatic Ductal Adenocarcinoma in the Netherlands: A Nationwide Retrospective Analysis. Ann Surg Oncol. 2016;23(2):585-591 


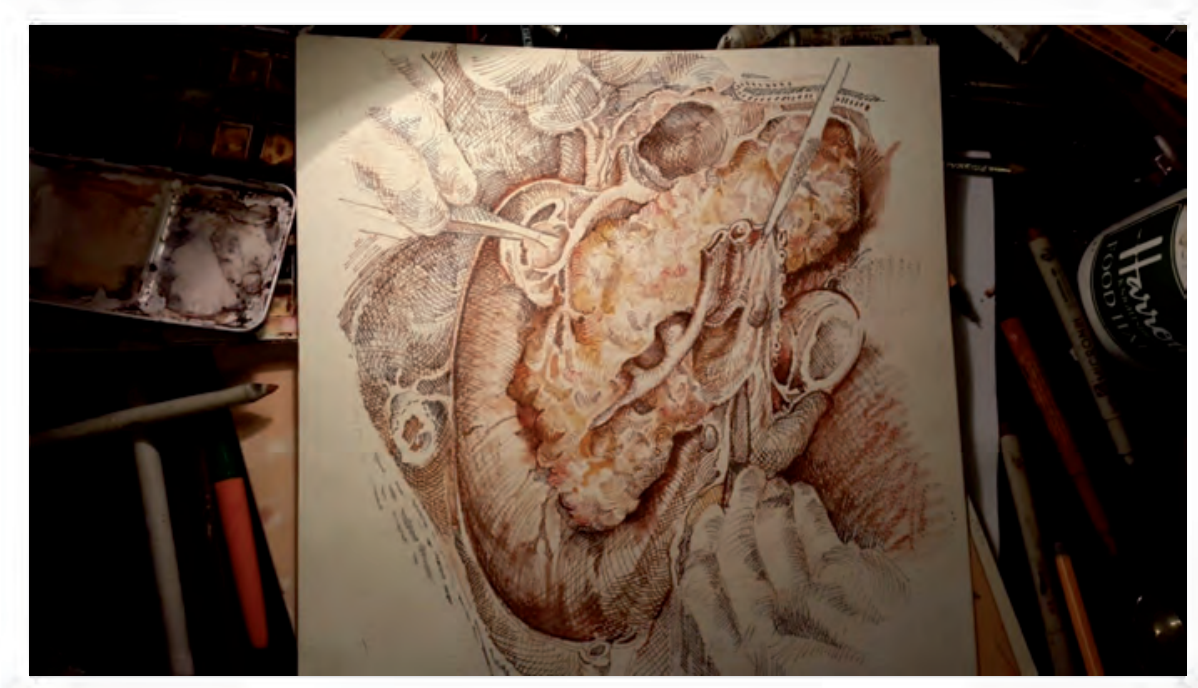

\section{SECCION IV TRATAMIENTO PALIATIVO}

- PANCREATECTOMIA PALIATIVA

- PALIACION DE LA ICTERICIA

-TRATAMIENTO DE LA ESTENOSIS GASTRODUODENAL

-TRATAMIENTO DEL DOLOR

- QUIMIOTERAPIAY RADIO-QUIMIOTERAPIA PALIATIVA 


\section{TRATAMIENTO PALIATIVO DEL CANCER DE PANCREAS INTRODUCCIÓN}

Al momento del diagnóstico, solo un 10 a 20\% de los pacientes con cáncer de páncreas son pasibles de una resección con intención curativa.

El 50 a $60 \%$ presenta una enfermedad con metástasis s a distancia y el restante 30-40\% una enfermedad locamente avanzada o irresecable de inicio. ${ }^{1}$

Este último grupo de pacientes pueden convertirse en un tratamiento neoadyuvante, consiguiendo un $30 \%$ o más de resecabilidad. ${ }^{1,2}$

Por lo tanto, casi el 80\% de los pacientes a los que se les diagnostica un cáncer de páncreas, recibirá algún tipo de tratamiento paliativo.

El pronóstico de este grupo de pacientes, es hoy en día muy pobre. La sobrevida del paciente con enfermedad metastásica es de 3 a 5 meses, mientras que el paciente que debuta con una enfermedad irresecable no metastásica, tiene una sobrevida de entre 6 y 12 meses. ${ }^{1,3}$

En este capítulo discutiremos el rol de la pancreatectomía paliativa, las diferentes modalidades de paliación de la obstrucción biliar y digestiva, así como el manejo del dolor.

\section{PANCREATECTOMIA PALIATIVA}

Existe un amplio abanico de situaciones clínicas que pueden hacer que una pancreatectomía sea paliativa.

En un extremo, tenemos al paciente que se le realizó una pancreatectomía con intención curativa y el estudio anatomopatológico postoperatorio nos informa que la resección fue R1.

En el otro extremo, el paciente operado con intención curativa que durante la exploración quirúrgica presenta una enfermedad irresecable (por el compromiso regional o a distancia) y el cirujano debe decidir si realiza una resección R2 o una derivación paliativa.

Esta decisión se ve aún más comprometida, por el hecho que el tumor pancreático está rodeado de un importante componente desmoplásico, que impide definir correctamente sus límites. Por otra parte, al momento de realizar el diagnóstico de irresecabilidad, muchas veces, se han sorteando los puntos de "no retorno" (por ejemplo la sección pancreática) y estamos obligados a realizar una resección R2 de necesidad.

La gran mayoría de los trabajos comparativos incluyen dentro del grupo de pancreatectomías paliativas a las resecciones R1 y R2. Sin embargo, como veremos, estas tienen un pronóstico muy diferente y por lo tanto deben ser analizadas por separado.

\section{Definición de resección R1 y $\mathrm{R} 2$}

Existe claro consenso en definir a las resecciones R2 como aquellas que dejan residuo tumoral macroscópico. Sin embargo, la definición de resección R1 es controversial ya que existen una multiplicidad de criterios para definirla.

La International Union Against Cancer (UICC) define como R1, la presencia de tumor microscópico en el margen de sección. ${ }^{4}$

Por otro lado, las guías del Royal College of Pathologists, definen actualmente como R1 la presencia de tumor microscópico a menos de $1 \mathrm{~mm}$ del margen circunferencial. ${ }^{5}$

Esta diferencias entre las definiciones, provoca que las tasas de resecciones R1 reportadas sean muy variables dependiendo del criterio utilizado.

Cuando se aplica la definición de la UICC, las tasas de resecciones R1 van del 16 al 30\%. ${ }^{6-10}$

Pero cuando la definición aplicada es la presencia de tumor microscópico a menos de $1 \mathrm{~mm}$ del margen, la tasas de resecciones R1 reportadas son más elevadas, en el entorno del 74 al 85\%. ${ }^{11-14}$

Las mayores tasas de R1, no están determinadas solamente por el cambio en la definición del margen microscópico, sino también por el intento de estandarizar el estudio de la pieza de resección, teniendo en cuenta el borde circunferencial, anterior, posterior, venoso y arterial. Estos representan por lo tanto, un marcador de calidad del estudio anatomopatológico. 


\section{$\underline{\text { Rol del R1 como factor pronóstico . Es un indicador de recaída? }}$}

Las tasas reportadas de recidiva local o sistémica, luego de resecciones pretendidamente curativas, varían del 68 al $75 \%{ }^{8,15,16}$ y en estudios necrópsicos llegan al $91 \% .^{17}$

Cuando se analizan por separado, la recaída exclusivamente local es de 13 a 23\%, las recaídas combinadas (local y a distancia) representan aproximadamente el 22\% y las sistémicas puras 55 a $66 \%$ (fundamentalmente hepáticas). ${ }^{15,16}$

Los estudios necrópsicos muestran un patrón de recaída distinto. La recurrencia luego de una pancreatectomía pretendidamente curativa hay mayores tasas de recaída local 75\%, mientras que recaída hepática es de 50\% y la recaída combinada local y sistémica de $46 \% .^{17,18}$

Por lo tanto, el patrón de recurrencia presenta un alto indice de la recaída sistémica, a pesar de un tratamiento pretendidamente curativo y parece indicar que el adenocarcinoma pancreático es una enfermedad diseminada de inicio.

En este contexto, el rol de la resección R1 como predictor de recidiva local no muestra resultados concluyentes. Mientras existen trabajos que lo encuentran un factor pronóstico de recaída, ${ }^{15,19,20}$ otros estudios no lo identifican como indicador de recurrencia local. ${ }^{21,22}$

\section{¿E1 R1 afecta la sobrevida global?}

En este punto los resultados tampoco son concluyentes.

Existen trabajos que demuestran que las resecciones R1 son un factor pronóstico independiente, que afecta la sobrevida. ${ }^{15,22,23}$ Otros, encuentran un peor pronóstico del R1 en el análisis univariable, pero no reproducen los hallazgos en el análisis multivariable. ${ }^{11,14}$

Mientras tanto, otros estudios directamente no encuentran significación pronóstica del R1 sobre la sobrevida global. $8,13,20,22$

En este contexto de controversia, el metaanálisis de Butturini que revisa el valor del margen de resección en estudios controlados randomizados de pacientes que recibieron adyuvancia, tampoco evidenció que la resección R1 se asociará con un peor pronóstico. ${ }^{24}$

Por lo tanto, para el adenocarcinoma pancreático, los términos R0-R1 no deberían ser utilizados como sinónimos de curativo-paliativo, ya que no se ha podido demostrar su significación pronóstica. ${ }^{25}$

\section{Pancreatectomía R2}

A una resección R2 se puede llegar por diferentes causas:

- Hallazgo intra-operatorio inesperado de enfermedad avanzada, luego de pasar los "puntos de no retorno", por lo que se realiza una pancreatectomía de necesidad,

- De intención, por la presencia de una complicación (sangrado, perforación).

¿Existe lugar para la pancreatectomía R2 con criterio de cito-reducción?

La respuesta a esta pregunta parece estar en la comparación entre los pacientes con resecciones R2 y aquellos en los que se practicó una derivación quirúrgica.

\section{Pancreatectomía paliativa vs derivación quirúrgica.}

En este punto, discutiremos el lugar de la pancreatectomía paliativa vs la derivación paliativa.

Intentaremos responder algunos interrogantes:

- ¿existen diferencias en la morbimortalidad de ambos procedimientos?

- ¿hay diferencias en la sobrevida?

- ¿cuál ofrece mejor calidad de vida?

Cuando se analiza este punto, nos encontramos con algunas dificultades.

Es muy difícil, en este caso, realizar estudios prospectivos randomizados.

Muchos trabajos al comparar los procedimientos, no distinguen entre R1 y R2, y como veremos la significación pronóstica es muy diferente.

Existe también una falta de criterio uniforme en la definición de R1, como ya hemos analizado. 
Entonces cabe preguntarnos ¿se puede comparar un paciente al que se le realizó una pancreatectomía con criterio pretendidamente curativo y en el estudio histológico definitivo surge la presencia un margen microscópico positivo, frente a un paciente al que se le realizó una derivación por el hallazgo intraoperatorio de enfermedad irresecable?

¿Cuál es la verdadera pancreatectomía paliativa, la R1 o la R2?, ¿no deberá ser la resección R2 la que se compare con la derivación?

Por este motivo, trabajos recientes han puesto énfasis en la necesidad de distinguir entre R1 y R2, cuando se compara pancreatectomía paliativa vs by pass (derivación). ${ }^{26,27}$

(TABLAS 1 Y 2)

TABLA 1: Estudio comparativo entre Resecciones R1 vs Derivación Quirurgica. Bp (By Pass).

\begin{tabular}{|c|c|c|c|c|c|c|c|c|c|c|}
\hline \multirow{2}{*}{ Autor } & \multirow{2}{*}{$N^{*}$} & \multirow{2}{*}{ Estudio } & \multicolumn{2}{|c|}{$\begin{array}{c}\text { Estadía } \\
\text { (días) }\end{array}$} & \multicolumn{2}{c|}{$\begin{array}{c}\text { Morbilidad } \\
(\%)\end{array}$} & \multicolumn{2}{c|}{$\begin{array}{c}\text { Mortalidad } \\
(\%)\end{array}$} & \multicolumn{2}{c|}{$\begin{array}{c}\text { Sobrevida } \\
\text { (meses) }\end{array}$} \\
\cline { 5 - 11 } & & & R1 & BP & R1 & BP. & R1 & BP & R1 & BP \\
\hline Reinders 1995 (28) & 60 & Retrospectivo & 25 & $18^{*}$ & 44 & 33 & 1 & 1 & 10.2 & 7,8 \\
\hline Kuhlmann 2006 (29) & 170 & Retrospectivo & 16 & $10^{*}$ & 41 & 31 & 0 & 2 & 15,8 & $9,5^{*}$ \\
\hline Fusai 2008 (30) & 72 & Retrospectivo & 13 & 11 & 30 & 31 & 3 & 3 & 18 & $9^{*}$ \\
\hline Lavu 2009 (31) & 71 & Prospectivo & 7 & 5,5 & 48 & 33 & 0 & 0 & 15.6 & $6,5^{*}$ \\
\hline Tol 2015 (27) & 170 & Prospectivo & 13 & $9^{*}$ & 52 & 34 & 2 & 5 & 17 & $9^{*}$ \\
\hline
\end{tabular}

* Estadísticamente significativo.

Tabla 2: Compración entre R2 vs Derivación Quirurgica. Bp (By Pass).

\begin{tabular}{|c|c|c|c|c|c|c|c|c|c|c|}
\hline \multirow[t]{2}{*}{ Autor } & \multirow[t]{2}{*}{$\mathrm{Na}^{\mathrm{a}}$} & \multirow[t]{2}{*}{ Estudio } & \multicolumn{2}{|c|}{$\begin{array}{c}\text { Estadía } \\
\text { (días) }\end{array}$} & \multicolumn{2}{|c|}{$\begin{array}{c}\text { Morbilidad } \\
(\%) \\
\end{array}$} & \multicolumn{2}{|c|}{$\begin{array}{c}\text { Mortalidad } \\
(\%) \\
\end{array}$} & \multicolumn{2}{|c|}{$\begin{array}{c}\text { Sobrevida } \\
\text { (meses) }\end{array}$} \\
\hline & & & $\mathrm{R} 2$ & $\mathrm{BP}$ & $\mathrm{R} 2$ & $\mathrm{BP}$ & $\mathrm{R} 2$ & $\mathrm{BP}$ & $\mathrm{R} 2$ & $\mathrm{BP}$ \\
\hline Köninger 2008 (32) & 84 & Prospectivo & 12 & $10^{*}$ & 47 & $22^{*}$ & 8 & 2 & 10,7 & 10,7 \\
\hline Bockhorn 2009 (33) & 80 & Prospectico & 21 & $17^{*}$ & 43 & $18^{*}$ & 5 & 5 & 11,5 & 7,5 \\
\hline Tachezy 2011 (34) & 68 & Retrsopectivo & 16 & $11^{*}$ & 59 & $33^{*}$ & 27 & $6,2^{*}$ & 5,1 & 5,8 \\
\hline Tol 2015 (27) & 214 & Prospectivo & 16 & $9^{*}$ & 73 & $34^{*}$ & 0 & 2 & 8,5 & 9 \\
\hline
\end{tabular}

Cuando se compara la resección R1 vs la derivación paliativa, (tabla 1) se encuentra que la derivación tiene en promedio menos días de internación, pero la sobrevida es significativamente mayor en el grupo de pacientes resecados. No presentando diferencias en la morbimortalidad de los procedimientos.

Por el contrario, cuando se compara R2 vs derivación (tabla 2), todos los trabajos encuentran mayor estadía hospitalaria y mayor tasa de complicaciones en la resección R2. Un solo estudio encuentra mayor mortalidad en la resección R2 y ninguno demuestra beneficios significativos en la sobrevida.

¿Qué ocurre cuando analizamos la calidad de vida de los pacientes sometidos a pancreatectomía paliativa vs doble derivación? Son pocos los trabajos que analizan este punto, pero todos ellos encuentran mejor calidad de vida inicial y más rápida recuperación funcional en el grupo de pacientes derivados. ${ }^{34-37}$

\section{En suma:}

Las resecciones $\mathrm{R} 1$ tienen un claro beneficio comparados con la derivación en términos de sobrevida. Debe hacerse hincapié, en que en general la resección R1 es un hallazgo histológico luego de una resección con criterio curativo, y que no es clara su significación pronóstica.

Las resecciones R2 están asociadas a una mayor morbimortalidad, peor calidad de vida y ausencia de beneficio en la sobrevida, cuando se las compara con la derivación quirúrgica.

Por lo tanto, hoy en día, la resección R2 no se recomienda, ni siquiera con un criterio de cito-reducción. Solo debe realizarse de necesidad. 


\section{PALIACIÓN DE LA ICTERICIA.}

La ictericia es uno de los síntomas más precoces del adenocarcinoma cefalopancreático. Provoca una serie de alteraciones secundarias a la estasis biliar, genera morbilidad y deterioro de la calidad de vida del paciente dado por la presencia de anorexia, malabsorción, prurito invalidante, alteraciones de la coagulación, disfunción renal, entre otras.

Por lo tanto, en el contexto de un paciente irresecable, la paliación de la ictericia cobra fundamental importancia.

La paliación puede ser endoscópica, mediante la colocación de stents (plásticos o metálicos), o a través de procedimientos quirúrgicos de derivación biliodigestiva.

En la decisión del método más apropiado de derivación, se debe tener en cuenta la efectividad del procedimiento, su morbimortalidad, la calidad de vida que genera y la relación costo-beneficio. Debe considerarse también, la expectativa de vida y el deseo del paciente.

En esta sección analizaremos la paliación quirúrgica versus la endoscópica, el tipo de stent a utilizar, y la vía de colocación.

\section{Derivación bilio-digestiva quirúrgica versus stent}

La evaluación de la eficacia entre la cirugía y los métodos endoscópicos en la paliación de la obstrucción biliar, es difícil debido a la escasez de datos disponibles y al bajo número de pacientes incluidos en los trabajos.

Existen 6 estudios prospectivos randomizados que comparan la derivación quirúrgica paliativa vs la colocación de stent. (Tabla 3)

Los estudios iniciales comparaban stent plástico vs derivación quirúrgica ${ }^{38-41}$ y solo dos trabajos recientes comparan stent metálico vs derivación quirúrgica. ${ }^{42,43}$

En el primer estudio prospectivo randomizado, realizado por Bornman ${ }^{39}$ en 1986, la prótesis se colocaba por vía transparietohepática, mientras que en los trabajos posteriores la colocación fue por colangiopancreatografía endoscópica retrograda (CPER). ${ }^{39-43}$

Todos estos trabajos, salvo uno, incluyen menos de 50 pacientes $^{41}$.

Cuando analizamos los estudios randomizados que comparan stent plástico vs derivación quirúrgica, encontramos que todos ellos tienen similares tasas de éxito en lo que respecta a paliación inicial de la ictericia ${ }^{39,40,41}$, pero la internación fue más prolongada en el grupo de pacientes operados.

La morbilidad inicial del procedimiento es mayor en los pacientes sometidos a cirugía, aunque la diferencia estadísticamente significativa se documentó solamente en un trabajo ${ }^{42}$.

No hubo diferencia significativa en a la mortalidad de los procedimientos.

Por el contrario, la tasa de recurrencia de la ictericia es significativamente mayor en el grupo de pacientes con stent plástico en 2 de los estudios analizados. ${ }^{40,42}$

En 2007 Moss $^{44}$ publica un metaanálisis que incluye la revisión de 24 trabajos (2436 pacientes) que comparan cirugía y stent, en la paliación de la ictericia por obstrucción neoplásica maligna de la vía biliar distal.

El estudio analiza tres de los ensayos randomizados incluidos en la tabla 3, que comparan stent plástico y derivación quirúrgica. Encontrando que el riesgo de complicaciones ligadas al procedimiento es significativamente menor en el grupo de stent plástico, (RR 0.60, 95\% CI 0.45-0.81, p < 0.0007) pero el riesgo de recurrencia de la ictericia fue 18 veces mayor comparado que con la cirugía (RR 18.59, 95\% CI $5.33-64.86, \mathrm{p}<0.00001)$.

Prácticamente no hay trabajos comparativos entre stent metálico y derivación quirúrgica.

Solo hay dos estudios prospectivos randomizados con escaso número de pacientes.

El primero no encuentra diferencias en morbimortalidad ni en la tasa de readmisiones. ${ }^{42}$

Mientras que en el segundo estudio se randomizaron pacientes con metástasis a distancia, por lo tanto la sobrevida global de este grupo fue corta debido al sesgo de la selección. En él, no se encontraron diferencias en la tasa de complicaciones, número de readmisiones ni en la sobrevida. El grupo tratado con stent presentó una menor estadía hospitalaria, pero una tasa mayor de recurrencia de la ictericia. El uso de Stent endoscópico se asoció a una mejor calidad de vida y menores costos hospitalarios. ${ }^{43}$

Finalmente un estudio retrospectivo comparó by pass quirúrgico y stent metálico con tasas de éxito similares en la paliación (95-100\%), pero con mayor número de complicaciones precoces en el grupo de cirugía.

La internación fue significativamente más prolongada en el grupo de pacientes operados y la tasa de recurrencia de la ictericia fue significativamente mayor en el grupo de pacientes con stent. ${ }^{45}$ 
Un reciente metaanálisis, de estudios randomizados comparativos (stent vs cirugía), que incluye 379 pacientes, no encuentra diferencias significativas en la eficacia de la paliación inicial de la ictericia. Pero en este análisis se incluyeron pacientes tanto con stent plástico como metálicos, sin diferenciarlos.

Tampoco se encuentra que la morbimortalidad vinculada a la cirugía sea significativamente mayor, pero la recurrencia de la ictericia fue significativamente menor tras realizar una derivación quirúrgica, que luego de colocar un stent. (RR, 0.14; 95\% CI, 0.03-0.63; $\mathrm{P}<0.01)$.

Tabla 3: Estudios randomizados Stent vs Cirugía en la palpación de la ictericia.

\begin{tabular}{|c|c|c|c|c|c|c|c|c|}
\hline Autor & $\begin{array}{c}\text { Tipo } \\
\text { procedimiento }\end{array}$ & No & $\begin{array}{c}\text { Mortalidad } \\
\qquad \%)\end{array}$ & $\begin{array}{c}\text { Morbilidad } \\
\text { (\%) }\end{array}$ & $\begin{array}{l}\text { Estadia } \\
\text { hospitalaria } \\
\text { (dias) }\end{array}$ & $\begin{array}{l}\text { Exito } \\
(\%)\end{array}$ & $\begin{array}{l}\text { Recurrencia } \\
\text { ictericia (\%) }\end{array}$ & $\begin{array}{l}\text { Sobrevida } \\
\text { (semanas) }\end{array}$ \\
\hline \multirow{2}{*}{$\begin{array}{c}\text { Bornman } \\
1986 \\
(39)\end{array}$} & $\begin{array}{c}\text { Stent plastico } \\
\text { TPH }\end{array}$ & 25 & 8 & 28 & 18 & 76 & 38 & 19 \\
\hline & By Pass & 25 & 20 & 32 & 24 & 84 & 16 & 15 \\
\hline \multirow{2}{*}{$\begin{array}{c}\text { Schepherd } \\
\begin{array}{c}1988 \\
(40)\end{array}\end{array}$} & $\begin{array}{l}\text { Stent plastico } \\
\text { CPER }\end{array}$ & 23 & 9 & 22 & 8 & 91 & $43^{*}$ & 21 \\
\hline & By pass & 25 & 20 & 40 & 13 & 92 & 0 & 17 \\
\hline \multirow{2}{*}{$\begin{array}{c}\text { Andersen } \\
\begin{array}{c}1989 \\
(41)\end{array} \\
\end{array}$} & $\begin{array}{l}\text { Stent plastico } \\
\text { CPER }\end{array}$ & 25 & 30 & 36 & 26 & 96 & 28 & 12 \\
\hline & By pass & 25 & 21 & 26 & 27 & 76 & 16 & 14 \\
\hline \multirow{2}{*}{$\begin{array}{c}\text { Smith } \\
1994 \\
(42) \\
\end{array}$} & $\begin{array}{l}\text { Stent plastico } \\
\text { CPER }\end{array}$ & 100 & 8 & 11 & 19 & 95 & $36^{*}$ & 21 \\
\hline & By pass & 101 & 15 & $29^{*}$ & 26 & 94 & 2 & 26 \\
\hline \multirow{2}{*}{$\begin{array}{c}\text { Nieveen } \\
2003 \\
(43)\end{array}$} & Metálico CPER & 14 & 7 & 43 & 3 & - & - & 16 \\
\hline & By pass & 13 & 8 & 32 & 12 & - & - & 27 \\
\hline \multirow{2}{*}{$\begin{array}{c}\text { Artifon } \\
2006 \\
(44)\end{array}$} & MetálicoCPER & 15 & 0 & 20 & 5 & 100 & 26 & 18 \\
\hline & By pass & 15 & 0 & 33 & 19 & 100 & 0 & 12 \\
\hline
\end{tabular}

* Estadísticamente significativo.

Ambos grupos tuvieron similar supervivencia, pero los pacientes a los que se colocó stent tuvieron mayor estadía hospitalaria a lo largo de toda la sobrevida.

El estudio recomienda para pacientes con expectativa de vida mayor a 6 meses, la realización de una derivación quirúrgica y si la sobrevida estimada es menor, recomienda el uso de stent ${ }^{46}$

Una revisión monográfica francesa del $2010^{47}$ analiza este punto y plantea que ambos métodos son complementarios y en general se adaptan a situaciones clínicas diferentes. Propone además, que la paliación por stent endoscópico debe ser utilizada en pacientes inoperables por sus co-morbilidades, o cuando se define que la enfermedad es irresecable con una expectativa de vida menor a 6 meses. Mientras que la derivación quirúrgica encuentra su lugar, cuando la irresecabilidad se determina en el intra-opertorio o en pacientes con tumores irresecables cuya expectativa de vida es mayor a 6 meses.

\section{¿Stent por por vía endoscópica o percutánea?}

Analizaremos dos estudios prospectivos randomizados que comparan ambos abordajes.

Speer, ${ }^{48}$ basa su comparación en pacientes con tumores de páncreas irresecables, encontrando que el abordaje endoscópico era significativamente mejor en resolver la ictericia, con una menor morbimortalidad.

Por su parte Piñol, ${ }^{49}$ encuentra que el abordaje percutáneo fue más efectivo en la paliación de la ictericia, sin diferencias significativas en la morbimortalidad.

Sin embargo, la comparación realizada fue entre diferentes tipos de stents. Mientras que en el drenaje percutáneo se utilizaron prótesis metálicas autoexpandibles, en el abordaje endoscópico se colocaron stents plásticos. 
Hoy en día es claro que la vía endoscópica es de elección, y el abordaje percutáneo debe reservarse ante el fracaso del primero.

La tasa de éxitos en la colocación de stent por vía endoscópica es superior al 90\%, y no varía según el tipo de stent utilizado. ${ }^{50}$

\section{¿Stent plástico o metálico?}

La decisión del tipo de stent a colocar debe basarse en la durabilidad del dispositivo, la relación costo-beneficio, y la expectativa de vida del paciente.

El stent plástico que ha demostrado mejores resultados es el de polietileno ${ }^{39,50}$ y el calibre más utilizado es de $10 \mathrm{Fr}$. Calibres superiores no han mostrado beneficios. ${ }^{50,51}$

La causa de la obstrucción de la prótesis plástica es debida al desarrollo de un biofilm por colonización bacteriana y precipitación de sales biliares, secundarias a la deconjugación de la bilirrubina sobre la superficie interna del dispositivo. ${ }^{47,51}$ Otra complicación es la migración de la prótesis, que se produce en hasta el 5\% de los casos. ${ }^{50}$

No se ha demostrado que el uso de antibióticos o el ácido ursodeoxicólico aumente la permeabilidad del stent plástico. ${ }^{50}$

Los stent metálicos autoexpandibles logran un mayor tiempo de permeabilidad, al obtener un mayor calibre (expandidos pueden tener de 6 a $10 \mathrm{~mm}$ de diámetro).

Están fabricados de diferentes materiales (nitinol, platinol, acero inoxidable) pero el nitinol es el más utilizado.51 Pueden ser forrados, no forrados o parcialmente forrados.

El stent metálico no forrado no migra y se ocluye habitualmente por crecimiento del tumor a través de la pared del dispositivo o por hiperplasia de la mucosa.

Por este motivo, se crearon dispositivos forrados que si bien no se ocluyen, tienen una mayor tendencia a la migración $(17-35 \%) .^{50,51}$

La permeabilidad promedio de la prótesis plástica es de 4 a 5 meses $^{52-54}$, mientras que la de una prótesis metálica es de $9-12$ meses. $^{54}$

Moss, $^{52}$ en un meta-análisis Cochrane del 2006, en base a 21 estudios randomizados controlados, compara resultados de cirugía, stents plásticos y metálicos en la paliación de la ictericia por cáncer de páncreas.

Cuando compara la prótesis plástica con él stent autoexpandible, no encuentra diferencias en el resultado inicial medido por la remisión de la ictericia y el prurito, así como tampoco en la velocidad de descenso de la bilirrubina. No hubieron diferencias en la morbimortalidad de los procedimientos a 30 días.

En 2007 el mismo autor realiza un segundo metaanálisis ${ }^{53}$ en el que compara específicamente el stent plástico con el metálico en la paliación de la obstrucción maligna de la vía biliar. En él, se incluyen 7 estudios randomizados controlados, con 724 pacientes.

Los hallazgos en cuanto a los resultados iniciales son similares (remisión inicial de la ictericia y morbimortalidad a 30 días). Pero encuentra que a 4 meses la tasa de recurrencia de la ictericia es el doble en los pacientes a los que se colocó un stent plástico.

Está demostrado que la presencia de carcinomatosis peritoneal o metástasis hepáticas, en el contexto de un cáncer de páncreas, determinan una corta expectativa de vida (menor a 4 meses), similar a la permeabilidad del stent plástico. Por lo cual parecería lógico su uso en este tipo de pacientes. ${ }^{54,55}$

Existen múltiples estudios que analizan el costo-beneficio entre los diferentes tipos de stent, fundamentalmente en pacientes a los que se les realiza tratamiento paliativo de la ictericia.

El costo promedio de un stent metálico es aproximadamente 20 veces superior al del stent plástico. ${ }^{56,57}$

Pero si se analiza el costo global, valorando los gastos que se generan en días de internación, reingresos, repetición de endoscopías por obstrucción y colangitis, los costos del stent plástico pueden ser mayores.

Tanto el trabajo de Yeoh, ${ }^{58}$ como el meta-análisis de Moss, ${ }^{53}$ encuentran que si la sobrevida es mayor a 4 meses, los costos globales del stent metálico son menores o similares al stent plástico.

Otro estudio randomizado y recientemente publicado de origen canadiense, ha reproducido estos hallazgos. ${ }^{57}$

En base a lo antes analizado, la Sociedad Europea de Endoscopía plantea, en sus guías del año $2012^{50}$, que si la expectativa de vida del paciente es menor a 4 meses se recomienda colocar una prótesis plástica, mientras que si es mayor, debe colocarse un stent metálico.

Otros autores han llegado a las mismas conclusiones. ${ }^{46,47}$ 


\section{¿Prótesis metálica forrada o no forrada?}

Existen múltiples trabajos enfocados en comparar ambos tipos de dispositivos.

Como ya hemos analizado, la causa de obstrucción de la prótesis no cubierta es el crecimiento tumoral a través de la pared del stent. Mientras que el dispositivo forrado tiene una tasa más alta de migración y puede ocluirse por la formación de una lámina de barro en su pared (similar a lo ocurre en los stent plásticos) o por crecimiento tumoral en los extremos del dispositivo.

Se han desarrollado prótesis parcialmente cubiertas con resultados intermedios. ${ }^{50}$

La revisión de la bibliografía muestra resultados contradictorios en este sentido.

$\mathrm{El}$ análisis de ensayos randomizados controlados, que comparan stent cubierto y no cubierto, no arrojan conclusiones claras.

$\mathrm{Kullman}^{59}$ en un estudio randomizado multicéntrico sueco del 2010, que incluye 400 pacientes, no encuentra diferencias en la duración de la permeabilidad ni en las complicaciones del procedimiento, pero si una mayor tasa de migración en el stent cubierto y de obstrucción por invasión tumoral en el no cubierto, ambas estadísticamente significativas.

Similares hallazgos tiene Telford ${ }^{60}$ en otro estudio multicéntrico americano con 129 pacientes.

Sin embrago, Isayama ${ }^{61}$ en un estudio randomizado controlado con 112 pacientes, encuentra que la permeabilidad fue significativamente mayor cuando se utilizo stent forrado.

Kitano $^{62}$ en otro estudio multicéntrico randomizado, en el que se utilizó una prótesis forrada con un sistema antimigración, reclutó 122 pacientes, encontrando que la permeabilidad fue significativamente mayor con el stent forrado.

Por el contrario, $\mathrm{Lee}^{63}$ recientemente randomiza 40 pacientes, y encuentra que la permeabilidad fue significativamente mayor con el stent no forrado.

Como sucede en los trabajos randomizados, los metaanálisis también muestran resultados controversiales.

Almadi $^{64}$, en un meta-análisis sobre 9 estudios controlados randomizados (RCT), con un total de 1061 pacientes, no encuentra diferencias entre el stent cubierto y no cubierto en términos de permeabilidad a 6 y 12 meses, ni en cuanto al índice de complicaciones derivadas del procedimiento, pero el stent forrado se asoció a una mayor tasa de migración. Por su parte Saleem, ${ }^{65}$ en un metaanálisis de 5 RCT (781 pacientes), demuestra que si bien la tasa de oclusión es similar con ambos dispositivos, en el stent cubierto ocurre más tardíamente (60 días promedio).

Finalmente $\mathrm{Li}^{66}{ }^{66}$ en otro metaanálisis muy reciente, no encuentra diferencias entre ambos tipos de stent, en cuanto a permeabilidad y tasa de disfunción.

Por lo tanto, al momento actual, no se ha podido definir qué tipo de stent autoexpandible es el más recomendable en la paliación de la ictericia por cáncer de páncreas.

Las Guías Europeas de Endoscopía, ${ }^{50}$ no recomiendan ninguno de los 2 tipos específicamente y plantean que la elección debe basarse en la experiencia individual del endoscopista y en el costo.

\section{En suma:}

- la derivación biliodigestiva y el stent biliar son efectivos en la paliación inicial de la ictericia.

- la paliación quirúrgica tiene mayor morbilidad inicial, pero asegura una paliación más prolongada, por lo tanto tiene su lugar en pacientes con expectativa de vida mayor a 6 meses, o en aquellos en los que se determina la irresecabilidad en el intraoperatorio.

- la vía de elección para la colocación de stent biliar es la endoscópica.

- en pacientes con expectativa de vida menor a 4 meses (enfermedad diseminada), la paliación debe realizarse con stent plástico.

- si la expectativa de vida es mayor y se decide colocar stent, este debe ser metálico autoexpandible.

- no esta definido aún que tipo de prótesis metálica (forrada o no cubierta) es la más efectiva. 


\section{¿Qué derivación bilio-digestiva quirúrgica realizar?}

En la paliación de la ictericia por cáncer cefalopancreático existen básicamente cuatro formas de derivación bilio-digestivas quirúrgicas:

- hepaticoyeyunostomía

- coledocoduodenostomía

- colecistoduodenostomía

- colecistoyeyunostomía

Solo existe un antiguo estudio prospectivo randomizado que comparaba los procedimientos de derivación colecisto-entérica y bilio-entérica. ${ }^{67}$ En él, se incluían 31 pacientes de los cuales 20 eran derivaciones por cáncer periampular. En este estudio la derivación bilio-entérica fue significativamente mejor, en términos de permeabilidad a largo plazo, que la colecisto-entérica.

Estudios posteriores, todos retrospectivos, han tenido similares hallazgos, evidenciando una mayor permeabilidad a largo plazo de la derivación cuando se realiza a la vía biliar principal.

En todos, la morbimortalidad quirúrgica de los procedimientos fue similar. ${ }^{68-70}$

En 2003 Urbach, ${ }^{71}$ un estudio de cohorte canadiense revisa 1919 pacientes sometidos a derivación biliar paliativa por cáncer de páncreas, a 945 pacientes se le realizó colecisto-enteroanastomosis y en 974 se realizó derivación a la vía biliar principal.

El estudio encuentra que la morbimortalidad de ambos procedimientos fue similar, pero la permeabilidad fue significativamente menor cuando se utilizó la vesícula biliar. Asociado este, a una tasa tres veces mayor de procedimientos complementarios sobre la vía biliar y cuatro veces más reintervenciones.

La menor duración de la permeabilidad al utilizar la vesícula es debida a la infiltración del confluente cístico-coledociano. ${ }^{71,72}$ Tarnasky, ${ }^{72}$ plantea que debe demostrarse por imagenología la existencia de por lo menos $1 \mathrm{~cm}$ de distancia entre el borde macroscópico del tumor y la unión cístico-coledociana, para plantear una derivación utilizando la vesícula biliar.

Por lo tanto en la derivación biliar se debe utilizar como primera opción el conducto biliar principal, ya sea por medio de una coledocoduodenostomía o mediante una hepaticoyeyunostomía sobre un asa desfuncionalizada.

La coledocoduodenostomía es más fácil técnicamente, pero debe realizarse sobre un duodeno móvil y sin evidencias de invasión.

En caso contrario, debe optarse por la hepaticoyeyunostomía sobre asa desfuncionalizada. ${ }^{48}$

La vesícula biliar puede ser utilizada, como derivación biliodigestiva, en algunas situaciones como el hallazgo intraoperatorio de hipertensión portal, secundaria a infiltración del eje venoso que dificulte el acceso a la vía biliar principal. ${ }^{71}$

\section{Rol de la cirugía laparoscópica}

No existen estudios randomizados que comparen la derivación biliar por laparotómica y laparoscópica.

Múltiples trabajos muestran la factibilidad de la derivación biliar laparoscópica, pero el número de pacientes es escaso. La gran mayoría de ellos están incluidos en una revisión de Toumi, ${ }^{73}$ que incluye 19 trabajos, con un total de 89 pacientes, a los que se les realizó derivación biliar laparoscópica, en 72 de los casos por patología maligna.

En 64 pacientes se realizó colecistoyeyunostomía, en 14 hepaticoyeyunostomía y en 11 coledocoduodenostomía. En 37 se realizo derivación gástrica asociada.

La tasa de éxito en resolver la ictericia fue del 99\%, la morbilidad operatoria fue del 11\% y la mortalidad a 30 días del $5 \%$.

Estas cifras son similares a las reportadas en una revisión reciente ${ }^{74}$ de derivación biliar paliativa por cirugía lapartómica en cáncer pancreático, con una tasa de morbilidad de $20 \%$ y mortalidad de $6.5 \%$.

La colecistoyeyunostomía es la derivación más utilizada en cirugía laparoscópica por su facilidad técnica (se realiza con máquina de sutura)..$^{73}$

Hamade ${ }^{75}$ argumenta en su defensa, que la sobrevida del paciente es corta y en ese lapso la tasa de oclusión es similar a la de la derivación al conducto biliar principal $(2,9 \% \text { vs } 7,2 \% \text { al año })^{71}$. A su vez, plantea que debe realizarse hepaticoyeyunostomía solo en caso de que la imagen preoperatoria muestre una distancia menor a $1 \mathrm{~cm}$ entre el borde del tumor y la unión cístico-coledociana. ${ }^{75}$

Otras derivaciones como la coledocoduodenostmía laparoscópica, son factibles de realizar con buenos resultados, pero requieren mayor entrenamiento del cirujano. ${ }^{76}$ 
Están claros los beneficios de la cirugía laparoscópica y las derivaciones biliodigestivas no escapan a ello, sobre todo en pacientes con baja sobrevida, mejorando su calidad de vida. Su efectividad ha sido demostrada, pero requiere de habilidad técnica y entrenamiento para su realización. ${ }^{47}$

\section{Otras técnicas de paliación de la ictericia}

\section{Drenaje biliar guiado por ecoendoscopía}

Ante la imposibilidad por razones anatómicas o falla en el procedimiento al intentar colocar un stent por colangiopancreatografía endoscópica retrógrada (CPER), en los últimos años ha surgido como una novedad el drenaje biliar guiado por ecoendoscopía, como alternativa al drenaje transparietohepático y a la derivación quirúrgica.

Básicamente existen 3 técnicas de drenaje biliar guiado por ecoendoscopía:

- La técnica transpapilar o de "rendez vous", consistente en el acceso a la vía biliar a través de una punción transgástrica o duodenal guiada por ecoendoscopía, el posterior pasaje de una guía transpapilar a través del tumor, para la posterior colocación de stent por vía anterógrada.

- el drenaje transgástrico-transhepático, (hepático-gastrostomía), consiste en el abordaje por punción guiada por ecoendoscopía de la vía biliar intrahepática izquierda a través de la pared gástrica, el posterior pasaje de una guía, dilatación del trayecto y colocación de stent.

- el drenaje transduodenal transcoledociano, (colédoco-duodenostomía), consistente en el abordaje de la vía biliar extrahepática, por punción transduodenal guiada por ecocoendocopía, con el posterior pasaje de guía, dilatación del trayecto y colocación de stent

Estas dos últimas técnicas son denominadas transmurales, en contraposición a la vía transpapilar.

Están indicados: ante la falla de la CPER, anatomía alterada (por cirugías previas, como asas desfuncionalizadas o cirugía bariátrica), imposibilidad de acceder a la papila por infiltración del tumor al duodeno 2, o la presencia de ascitis que impida abordajes percutáneos. ${ }^{77}$

A su vez, cada técnica puede tener indicaciones específicas vinculadas a la situación local y anatómica de cada paciente. Si bien inicialmente se utilizaban stent plásticos, hoy en día se han desarrollado prótesis autoexpandibles para esta técnica. ${ }^{77}$

Una revisión reciente, sobre 27 artículos publicados de drenaje biliar guiado por ecoendoscopía ${ }^{78}$ sobre un total de 1127 pacientes, reporta una tasa de éxito en completar el procedimiento de 91\%, en paliar la ictericia de 88\%, pero reporta una alta morbilidad de $26 \%$ y un mortalidad de $0.4 \%$.

El drenaje biliar guiado por ecoendoscopía tiene complicaciones que pueden ser comunes a todos los procedimientos, peritonitis biliar, perforación visceral, sangrado, neumperitoneo, migración del stent, y otras que son específicas de cada técnica. En el abordaje transhepático: absceso hepático, colangitis, pseudoaneurisma, obstrucción biliar intrahepática por hiperplasia. En el abordaje por vía transduodenal, retroperitonitis y en el transpapilar pancreatitis. ${ }^{77-79}$

Como mencionamos, el drenaje biliar guiado por ecoendoscopía surge hoy en día como alternativa al drenaje transparietohepático, en pacientes con obstrucción neoplásica de la vía biliar irresecable, en los que falló la CPER.

Los trabajos comparativos son escasos.

Artifon, ${ }^{80}$ en un estudio randomizado con 25 pacientes, compara coledocoduodenostomía guiada por ecoendoscopía vs drenaje transparietohepático, no encontrando diferencias en la tasa de éxito del procedimiento, complicaciones, ni costos.

Un estudio retrospectivo que compara 50 pacientes, encuentra mayor tasa de éxitos y menos complicaciones en el grupo de drenaje biliar guiado por ecoendoscopía. ${ }^{81}$

Finalmente Khashab, ${ }^{82}$ en un estudio comparativo con 73 pacientes, encuentra similares tasa de éxito en ambos procedimientos, pero mayor tasa de complicaciones, reintervenciones y costos vinculados al drenaje transparietohepático. En base a estos resultados y apoyados en el argumento de la mejor calidad de vida del paciente sin un drenaje biliar externo, es que algunos autores plantean como primera opción el drenaje biliar guiado por ecoendoscopía. ${ }^{79}$

Tres estudios multicéntricos, ${ }^{83-85}$ y un estudio randomizado, ${ }^{86}$ comparan la coledocoduodenostomía y la hepaticogastrsotomía guiadas por ecoendoscopía y demuestran similar tasa de éxito, pero una mayor tasa de complicaciones con el abordaje transgástrico-transhepático. 
Por lo tanto, la coledocoduodenostomía guiada por ecoendoscopía parece ser el método de elección cuando hay obstrucción distal de la vía biliar, como la provocada por el cáncer de páncreas.

El abordaje transgástrico-transhepático, tiene su lugar cuando no es posible realizar procedimientos a través del duodeno por infiltración tumoral, entre otras. ${ }^{79}$

De todas formas, esta es una técnica que requiere un alto nivel de equipamiento y entrenamiento y se deben esperar más evidencias que avalen su efectividad.

\section{Nuevas técnicas.}

Como es sabido, la mayoría de los pacientes con cáncer de páncreas recibirán algún tipo de tratamiento paliativo, es por ello que las estrategias para conseguir la mejor paliación continúan avanzado.

Además de las derivaciones biliodigestivas ecoguiadas antes mencionadas, se le suman la ablación endobiliar por radiofrecuencia y la terapia fotodinámica.

La primera (ablación endobiliar por radiofrecuencia), es una nueva técnica consistente en la realización de radiofrecuencia sobre la lesión, a través de un catéter

endobiliar colocado por endoscopía, con posterior colocación de stent. Los reportes aún son iniciales. ${ }^{87-89}$

Por su parte, la terapia fotodinámica se basa en los resultados conseguidos para el colangiocarcinoma ${ }^{90}$ y su uso ha sido propuesto para la obstrucción biliar por cáncer de páncreas. ${ }^{91}$ 


\section{TRATAMIENTO DE LA ESTENOSIS GASTRO-DUODENAL}

Al momento del diagnóstico, 20\% de los pacientes con cáncer cefalopancreático tienen una estenosis gastro-duodenal, secundaria a la infiltración duodenal por el tumor. Por otra parte, un 30 a 50\% van a desarrollarla en la evolución de la enfermedad..$^{92}$

Si bien la infiltración tumoral es la causa más frecuente del síndrome de estenosis gastroduodenal, en algunos casos puede ser provocada por una dismotilidad gástrica secundaria a la infiltración del plexo solar. ${ }^{93}$

En este capítulo discutiremos dos puntos que están vinculados a diferentes situaciones clínicas:

- Paciente sin elementos clínicos de estenosis gastroduodenal que se interviene con intención curativa y se evidencia una enfermedad irresecable o paciente sometido a cirugía para paliación de la ictericia. ¿Está indicada la gastroyeyunostomía profiláctica?

- Paciente que debuta con estenosis gastroduodenal, y tiene una enfermedad irresecable. ¿Cual es la mejor forma de paliación? ¿Cirugía o stent?

\section{¿Está indicada la derivación gastroyeyunal profiláctica?}

En 1999 Lillemoe ${ }^{94}$ realiza un estudio prospectivo randomizado analizando el rol de la derivación digestiva profiláctica. El estudio incluyó 87 pacientes con tumores periampulares irresecables, sin evidencia de compromiso duodenal durante la exploración quirúrgica. A 44 se les realizó doble derivación y a 43 solo derivación biliodigestiva. La morbilidad fue similar (32 y $33 \%$ respectivamente), igual que la estadía hospitalaria (8 días promedio) y la sobrevida global fue de 8,3 meses para ambos grupos.

Sin embargo, casi $20 \%$ de los pacientes que no recibieron una derivación gastroyeyunal desarrollaron una estenosis gastroduodenal en la evolución.

Mientras que ningún paciente del grupo con doble derivación presentó esta complicación.

En 2003 Van Heek, ${ }^{95}$ publica un estudio prospectivo randomizado multicéntrico.

En el se incluyeron 65 pacientes con cáncer periampular irresecable sin elementos de estenosis gastroduodenal. A 36 pacientes se le realizó doble derivación y en 29 solamente una hepaticoyeyunostomía.

En la evolución desarrollaron una estenosis gastroduodenal el 5,5\% de los pacientes con doble derivación, y 41,4\% de los que recibieron solo derivación biliar $(\mathrm{P}=0.001)$.

No hubo diferencias significativas en morbilidad, estadía hospitalaria ni sobrevida global.

Ambos trabajos recomiendan la realización de una gastroyeyunostomía profiláctica.

En 2009 Huser, ${ }^{96}$ publica un metaanálisis que incluye estudios retrospectivos y prospectivos, que comparan resultados de la gastroyeyunostomía profiláctica en cáncer de páncreas irresecable.

Encuentra que la gastroyeyunostomía profiláctica disminuye de manera significativa el riesgo de desarrollo de estenosis gastroduodenal, sin aumentar la morbimortalidad operatoria, ni las tasa de gastroparesia. También recomienda su realización.

Gurusamy ${ }^{97}$ realiza en 2013 otro metaanálisis que revisa estudios prospectivos randomizados con un total de 152 pacientes ( 80 con doble derivación y 72 con derivación simple). No encuentra diferencias en morbimortalidad, estadía hospitalaria o calidad de vida. Solo $2 \%$ de los pacientes sometidos a doble derivación desarrollaron estenosis gastroduodenal, mientras que $27 \%$ de los pacientes con derivación biliodigestiva la instalaron en la evolución. Recomienda por tanto su realización sistemática.

En conclusion, la evidencia avala que la gastroyeyunostomía profiláctica puede ser realizada al mismo tiempo que la derivación biliodigestiva, en pacientes sometidos a una cirugía con criterio paliativo.

Con ello se logra un significativo descenso de la incidencia de estenosis gastroduodenal, sin que aumente la morbilidad operatoria, la estadía hospitalaria o haya cambios en la sobrevida global, evitando de esta manera una segunda cirugía. 


\section{¿Derivación quirúrgica o stent duodenal?}

Cuando el paciente se presenta clínicamente con una estenosis gastroduodenal y tiene una enfermedad irresecable, contamos con dos opciones terapéuticas, la derivación quirúrgica o la colocación de un stent duodenal por vía endoscópica.

Hoy en día tenemos tres estudios prospectivos randomizados que comparan ambos métodos de paliación. (tabla 4) Las conclusiones están limitadas por el escaso número de pacientes incluidos en los estudios.

Los dos primeros, 98,99 encuentran que el grupo tratado con stent presentó menor estadía hospitalaria y una reinstalación más temprana de la vía oral, con tasas similares de complicaciones derivadas del procedimiento.

Por tanto, estos estudios basados sus en sus resultados inmediatos recomiendan la colocación de stents.

Tabla 4: Estudios comparativos entre derivación mediante gastroyeyunostomía vs stent, en la paliación de la estenosis gastroduodenal.

\begin{tabular}{|c|c|c|c|c|c|c|}
\hline Autor & Procedimiento & No & $\begin{array}{c}\text { Exito } \\
\text { Procedimiento } \\
\text { (\%) }\end{array}$ & $\begin{array}{c}\text { Eficacia } \\
\text { clínica } \\
(\%)\end{array}$ & $\begin{array}{c}\text { Hospitalización } \\
\text { (días) }\end{array}$ & $\begin{array}{c}\text { Tasa } \\
\text { complicaciones } \\
(\%)\end{array}$ \\
\hline \multirow{2}{*}{$\begin{array}{c}\text { Fiori } \\
2004(98)\end{array}$} & GY convencional & 9 & 100 & 89 & 10 & 22 \\
\hline & Stent & 9 & 100 & 100 & $3 *$ & 22 \\
\hline \multirow{2}{*}{$\begin{array}{c}\text { Mehta } \\
2006(99)\end{array}$} & GY laparo & 14 & 93 & - & 11 & 62 \\
\hline & Stent & 13 & 77 & - & $5^{*}$ & 0 \\
\hline \multirow{2}{*}{$\begin{array}{l}\text { Jeurnink } \\
2010(100)\end{array}$} & GY (conv/lap) & 18 & - & 77 & 8 & 28 \\
\hline & Stent & 21 & - & 62 & 5 & 38 \\
\hline
\end{tabular}

* Estadísticamente significativo.

Un estudio multicéntrico holandés ${ }^{100}$ también encuentra mejores resultados inmediatos con la colocación de stent (menor estadía hospitalaria y reinstalación precoz de la vía oral), pero a largo plazo mayor número de re-estenosis (stent: 8 en 5 pacientes vs GY: 1 en 1 paciente; $\mathrm{P}=.02$ ), y por tanto mayores reintervenciones ( stent: 10 en 7 pacientes vs GY: 2 en 2 pacientes; $\mathrm{P}<01$ )

Los autores concluyen que el stent, dado sus mejores resultados a corto plazo, es recomendable en pacientes con una expectativa de vida menor a 2 meses, en caso contrario es recomendable la derivación quirúrgica por sus mejores resultados a largo plazo.

Estos hallazgos son comparables con la revisión sistemática previa realizada por mismo grupo, ${ }^{101}$ en base a 44 publicaciones, con 1046 pacientes que recibieron stent y 297 una gastroyeyunostomía (GY).

El estudio mostró que la prótesis duodenal permitió una resolución más rápida de los síntomas, con una menor estadía hospitalaria (7 vs 13días). En cambio, la persistencia de los síntomas fue similar (8 y 9\%), lo mismo que las complicaciones mayores, tanto precoces ( $7 \%$ para Stent y $4 \%$ GY), como tardías ( $18 \%$ stent y $17 \%$ GY).

En cuanto a la tasa de re-estenosis, la misma fue significativamente mayor en el grupo de pacientes con stent, lo que significó una mayor tasa de reintervenciones (18\% vs 1\%)

Los autores concluyen que el stent es recomendable en pacientes con expectativa de vida corta y la derivación quirúrgica debe ser propuesta a pacientes con expectativa de vida más prolongada.

Khashab, ${ }^{102}$ en un estudio retrospectivo del Johns Hopkins, que incluye 227 pacientes derivados por gastroyeyunostomía y 120 tratados con stent, encuentra menos complicaciones precoces $(22.10$ vs. $11.66 \%, \mathrm{p}=0.02)$ y menor estadía hospitalaria en el grupo con stent. Sin embrago, la tasa de reintervenciones vinculadas a obstrucción tardía fue significativamente mayor en este grupo de pacientes.

Por otro lado, el costo de ambos procedimientos fue similar cuando se incluyen las reintervenciones.

$\mathrm{Ho}^{103}$ publica un estudio retrospectivo que analiza las complicaciones tardías de ambos procedimientos (113 pacientes, 72 stent y $41 \mathrm{GY})$.

Los dos grupos no difieren en resultados técnicos ni funcionales, tampoco en las complicaciones precoces, sin embargo, la tasa de complicaciones tardías fue significativamente mayor en el grupo con stent $(44.4 \%$ vs $12.2 \%$; < .001).

En tanto que la permeabilidad fue más corta con el stent que con la gastroyeyunostomía (125 días vs 282 días; $\mathrm{P}=.001$ ). 
Recientemente Nagaraja, ${ }^{104}$ publica un meta-análisis de 20 estudios que incluye los 3 estudios randomizados ya analizados, encontrando una tasa similar de complicaciones, costos y sobrevida global.

El grupo de pacientes que recibió stent tuvo una estadía hospitalaria menor y retomó la vía oral más precozmente.

En conclusión, la evidencia parece indicar que ambos procedimientos tienen similares resultados en paliar la estenosis gastroduodenal.

El stent duodenal tiene la ventaja de una menor morbilidad vinculada al procedimiento y una menor estadía hospitalaria comparada con la cirugía de derivación, pero la desventaja de una mayor tasa de re-obstrucciones a largo plazo y por ende de reintervenciones.

Por lo tanto, la elección del método, dependerá del estado general del paciente, lo avanzado su enfermedad y fundamentalmente de la sobrevida estimada.

Finalmente deberá pesar la opinión individual de cada paciente.

\section{Tipos de Stent}

Los stents utilizados en la paliación de la estenosis gastroduodenal son autoexpandibles, generalmente de nitilol (aleación de niquel y titanio), y pueden ser forrados o no forrados.

Adolecen las mismas complicaciones a largo plazo que el stent biliar, mientras que el forrado puede migrar, el no cubierto se ocluye por crecimiento tumoral a través de la pared del stent.

Dos estudios recientes, una revisión sistemática y un metaanálisis han comparando ambos tipos de stent. El primero, ${ }^{105}$ incluye 19 estudios con un total de 1281 pacientes tratados con stent por estenosis gastroduodenal, portadores de un cáncer gástrico o pancreático.

La tasa de éxito del procedimiento fue $97 \%$ y el éxito clínico de $86 \%$.

La tasa de disfunción global a largo plazo fue 19,6\%, a causa de una obstrucción en 12,6\% y migración en 4,3\%.

La tasa de disfunción fue comparable entre el stent cubierto y el no cubierto ( $21 \%$ vs $19,1 \%$ ), pero la obstrucción fue más frecuente en la prótesis no forrada $(14.9 \%$ vs 5.1\%,P $<0.001)$. La migración, mientras tanto, se presentó asociada al stent cubierto $(10.9 \%$ vs $2.2 \%, \mathrm{P}<0.001)$.

El segundo, un metaanálisis106 que incluye 9 estudios con 849 pacientes. No encuentra diferencias en el éxito de la colocación, en la mejoría clínica, ni en la tasa de complicaciones entre ambos stents. Sin embargo, encuentra una mayor tasa de migración con el stent cubierto y una mayor obstrucción con el stent no forrado, pero la permeabilidad global fue similar.

Ninguno de los trabajos demuestra ventajas significativas entre los dos tipos de stent, salvo las diferencias entre migración y obstrucción. Deberán pesar en la decisión la experiencia clínica y los costos.

\section{Paliación quirúrgica de la estenosis gastroduodenal.}

La derivación mediante una gastroyeyunostomía, es la forma de paliar la estenosis gastroduodenal más utilizada. Sin embargo, los pacientes pueden persistir con retardo en el vaciamiento gástrico pese a la derivación, manifestada por imposibilidad de retomar la vía oral, persistencia de vómitos y retención por sonda nasogástrica.

La incidencia de esta complicación es variable de 4 a 20\% 3,92,107-109 y su etiología es multifactorial, se invocan como causas la infiltración tumoral del plexo celíaco, la presencia previa de estenosis gastroduodenal (asociada a una gastroparesia) y variaciones en la técnica quirúrgica. ${ }^{109}$

Clásicamente se planteó que el ascenso del asa yeyunal debía ser precólica, para alejarla del lecho tumoral, sin embargo una revisión retrospectiva del Johns Hopkins encuentra que la tasa de gastroperaesia post gastroyeyunostomía fue del $6 \%$ cuando el ascenso fue transmesocolónico y 17\% cuando fue precólico.

Revisiones posteriores proponen también el ascenso transmesocolónico o retrocólico del asa yeyunal. ${ }^{47,110}$

La realización de exclusión pilórica o el uso de asas defuncionalizadas tipo Y de Roux, también han sido propuestos como formas de evitar la gastroparesia.

Pero prácticamente no existen trabajos comparativos, el número de pacientes es muy limitado y los resultados son discordantes como para sacar conclusiones. ${ }^{111,112}$ 
En tumores de páncreas distal irresecables, con estenosis gastroduodenal secundaria a infiltración de duodeno 3-4 o del ángulo duodeno-yeyunal, puede plantearse como una buena opción la paliación mediante una duodeno-yeyunostomía latero-lateral en el sector inframesocolónico de D2, técnica descrita para la estenosis producida por la pinza aorto-mesentérica.

La factibilidad de la cirugía laparoscópica en la confección de gastroyeyunostomía paliativa ha sido demostrada por diferentes trabajos, ${ }^{113,114,115}$ sin embrago está limitada a centros y cirujanos con alta experiencia en cirugía videoasistida.

En suma, la gastoyeyunostomía con pasaje retrocólico parece ser una buena opción para la paliación de una estenosis gastroduodenal por cáncer de páncreas, asociada a una menor gatroparesia.

Para obstrucciones duodenales dislates (D III- D IV), la derivación duodenoyeyunal inframesocólica, es una forma de paliación recomendable para este tipo de obstrucciones.

Por ultimo el abordaje laparoscópico sería de elección en centros con entrenamiento en esta técnica. 


\section{TRATAMIENTO DEL DOLOR}

Al momento del diagnóstico el dolor puede estar presente hasta en el 30 a 40 \% de los pacientes, y en las etapas terminales de la enfermedad alcanza al $90 \% .{ }^{47}$

Este síntoma puede llegar a ser invalidante, de muy difícil control y afectar de forma muy significativa la calidad de vida del paciente.

Su etiopatogenia es multifactorial, su principal mecanismo es la infiltración neoplásica del plexo celíaco. Otras causas invocadas son la distensión del conducto Wirsung, la inflamación pancreática asociada (pancreatitis) y la distensión de la cápsula de Glisson por metástasis. ${ }^{47,116}$

Dentro del arsenal terapéutico para combatir el dolor vinculado al cáncer de páncreas, encontramos básicamente tres opciones:

- El manejo farmacológico basado en la recomendación de la OMS de tres etapas progresivas, muchas veces insuficiente por la refractariedad del dolor a los fármacos, a lo que se agregan sus efectos secundarios.

- La destrucción del plexo celíaco propuesta para el tratamiento del dolor en base a su etiopatogenia, puede realizarse por dos vías, la neurolisis química y la neurectomía quirúrgica

- Como tercera opción la radio-quimiterapia paliativa

\section{Neurolisis química}

Consiste en la destrucción del plexo celíaco mediante la instilación de alcohol u otra sustancia neurolítica.

Esta puede realizarse por vía laparotómica (al mismo tiempo que se realiza una cirugía por indicación resectiva o paliativa), mediante laparoscopía, por vía percutánea (bajo tomografía computada (TC) o radioscopía) y más recientemente por ecoendoscopía.

La efectividad de la neurolisis química, en el transcurso de una laparotomía, fue demostrada por Lillemoe 117 en 1993, en un estudio prospectivo randomizado comparaba los resultados de neurolisis celíaca con alcohol vs placebo, en pacientes con tumores pancreáticos irresecables.

Los pacientes del grupo que recibieron neurolisis con alcohol, tuvieron una disminución significativa del dolor $(\mathrm{p}<0.05)$ comparada con el grupo placebo y esta se mantuvo de manera significativa a los 2,4 y 6 meses ( $<<0.05)$.

En los pacientes que no presentaban dolor en el preoperatorio, la alcoholización retrasó su aparición y redujo su intensidad.

La factibilidad del bloqueo celíaco por vía laparoscópica ha permitido su utilización en el transcurso de una laparoscopía estadificadora o diagnóstica, frente al hallazgo de tumores pancreáticos irresecables. ${ }^{118}$

En el paciente no quirúrgico con dolor, la neurolisis del plexo celíaco puede realizarse por vía percutánea (bajo radioscopía o TC, en la denominada vía posterior), o a través de una ecoendoscopía.

Arcidiacono, en un reciente metaanálisis ${ }^{119}$ que incluye 6 estudios randomizados (358 pacientes), compara bloqueo del plexo celíaco percutáneo o guiado por ecoendoscopía vs el tratamiento farmacológico.

Encuentra que los niveles de dolor fueron significativamente menores en los pacientes que recibieron bloqueo del plexo celíaco a las 4 y 8 semanas, y que el consumo de opioides en este grupo fue significativamente menor, con la consiguiente disminución de sus efectos secundarios.

Estos hallazgos, están en sintonía con un metaanálisis previo de Eisenberg, ${ }^{120}$ que analizó los resultados de 24 estudios (1145 pacientes) tratados con neurolisis celíaca percutánea. Este trabajo encuentra que la eficacia en el control del dolor fue del $89 \%$ en las primeras dos semanas y el efecto se mantuvo en el $90 \%$ de los casos en los primeros tres meses y en el 70-90\% en los meses posteriores.

Finalmente, un metaanálisis de Puli ${ }^{121}$ analiza los resultados de la neurolisis celíaca guiada por ecoendoscopía, logrando control del dolor en $80 \%$ de los casos, con una duración del efecto antálgico a los tres meses en el 79-88\% de los pacientes. La efectividad del procedimiento fue mayor cuando la inyección fue bilateral (84\%) comparado con la inyección central (48\%).

Los efectos adversos más comunes son el dolor en el sitio de punción, diarrea, hipotensión, náuseas, vómitos y letargo, todos ellos transitorios. ${ }^{120,121}$

Están descritas complicaciones mayores como paraplejia, (por isquemia medular secundaria a lesión o vasoespasmo, por la inyección de alcohol en la arteria de Adamkiewicz), isquemia visceral por trombosis o vasoespasmo del tronco celíaco, neumotórax y sangrado retroperitoneal. ${ }^{122,123}$ 
No existen trabajos que comparen neurolisis del plexo celíaco por ecoendoscopía vs abordaje posterior en cáncer de páncreas. Hay un estudio comparativo de pacientes con pancreatitis crónica que muestra superioridad del abordaje por ecoendoscopía ${ }^{124}$, esto se vincularía a la posibilidad de identificar las distintas estructuras anatómicas e incluso los propios ganglios celíacos. ${ }^{125}$

\section{Neurectomía quirúrgica}

La esplacnicectomía quirúrgica ha sido propuesta para el tratamiento del dolor pancreático, fundamentalmente originado en las pancreatitis crónicas y también en el cáncer de páncreas irresecable.

Básicamente incluye dos técnicas, la esplacnicectomía transhiatal bilateral y la esplacnicectomía por toracoscopía bilateral. ${ }^{126}$

Si bien ambas son efectivas, no muestran superioridad a la neurolisis química. En el caso del abordaje toracoscópico tiene la desventaja de ser bilateral empeorando la calidad de vida post-procedimiento. ${ }^{127}$ 


\section{QUIMOTERAPIAY RADIO-QUIMIOTERAPIA PALIATIVA}

La quimioterapia paliativa busca aumentar la sobrevida y mejorar los síntomas vinculados al tumor en pacientes en etapa de paliación. Generando, a su vez, un efecto positivo sobre la calidad de vida de estos pacientes. ${ }^{128}$

Se debe tener en cuenta que el beneficio que consiguen estos tratamientos, en términos de sobrevida, es muy pobre, de unos pocos meses y tiene el costo de la toxicidad farmacológica, internaciones y estudios paraclínicos. Por lo cual, la decisión debe ser tomada en conjunto con el paciente y familiares, una vez que toda la información haya sido transmitida.

El beneficio de la quimioterapia y quimiorradioterapia como tratamiento paliativo en el cáncer de páncreas, tiene limitantes en la interpretación de los datos publicados.

Por un lado los estudios comparan poblaciones heterogéneas, donde se incluyen pacientes con tumores localmente avanzados, hasta aquellos con enfermedad diseminada de diferentes grados.

Por otro lado, las definiciones de borderline, localmente avanzados e irresecables son diferentes según las guías utilizadas.

Finalmente, existe la posibilidad de que un tumor inicialmente irresecable, tenga respuesta a la quimiorradioterapia y se haga resecable, lo que convierte un tratamiento paliativo en neoadyuvante.

Estas situaciones impiden una correcta comparación de los datos y los beneficios de la quimioterapia o quimiorradioterapia como tratamiento paliativo.

Asumidas estas dificultades en la interpretación de los datos, los pacientes que reciben este tipo de tratamiento paliativo pueden dividirse en 4 grupos: pacientes con lesiones borderline que no tuvieron respuesta a la neoadyuvancia, pacientes con tumores localmente avanzados, pacientes con metástasis y por último pacientes inoperables por su terreno.

Los resultados, en términos de sobrevida, son diferentes en cada una de las poblaciones mencionadas.

La quimioterapia ha mostrado beneficios en los pacientes cuando se compara con el tratamiento sintomático de soporte.

Es así que el metaanálisis de Sultana (2007), ya muestra una mejora en la sobrevida con el uso de 5FU y gemcitabina. ${ }^{128}$ Cuando se compararon ambos tratamientos se evidenció que la gemcitabina prolonga la sobrevida frente al $5 \mathrm{FU}(5,65$ vs 4,41 meses) en los pacientes con metástasis, con una toxicidad aceptable. ${ }^{129}$

Chaffert en el 2008, sin incluir pacientes con metástasis, logra sobrevidas medias de 13 meses con el uso de gemcitabina como tratamiento paliativo. ${ }^{130}$

Luego de demostrado el beneficio de la gemcitabina como tratamiento standard para los pacientes con adenocarcinomas de páncreas localmente avanzados y metastásico, surgió el interés por su combinación con otros fármacos.

La asociación de la gemcitabina a platinos y a capecitabina, muestra resultados favorables en cuanto a sobrevida y el tiempo libre de progresión, frente a la gemcitabina sola.

Este beneficio es para pacientes con buen performance status (PS), con un Eastern Cooperative Oncology Group (ECOG) 0-1, mientras que el 60-80\%, que presentan un mal PS (mayor igual a 2), no muestran resultados satisfactorios con estos tratamientos. ${ }^{131,132}$

Las asociaciones de la gemcitabina con las terapias blanco moleculares, en los tumores avanzados y metastásico de páncreas, no han mostrado mayor impacto. ${ }^{133}$ Dentro de los fármacos estudiados se encuentra el cetuximab y el bevacizumab, sin buenos resultados.

Morris en el 2007 encuentra que la asociación de gemcitabina y erlotinib mejora la sobrevida media a 6.24 vs 5.91 meses frente a la gemcitabina sola. ${ }^{134}$ Pero cuando se comparan los beneficios y la seguridad de esta asociación $(\mathrm{Ge}-$ neralised pairwise comparisons), no se justificó el uso como terapia paliativa. ${ }^{135}$

Actualmente hay 2 asociaciones de quimoterápicos que han suscitado el interés por los resultados demostrados, si bien están acompañados de aumento de la toxicidad farmacológica, ellos son el FOLFIRINOX (ácido folínico, 5-fluorouracilo, irinotecán, oxaliplatino) y la asociación gemcitabina/ nab-paclitaxel.

El estudio PRODIGE que incluyó pacientes con metástasis, comparó los tratamientos con FOLFIRINOX vs gemcitabina.

La respuesta al tratamiento con FOLFIRINOX fue de $31.6 \%$ sobre $9.4 \%$ con gemcitabina exclusiva y la sobrevida media de 11.1 vs 6.8 meses, en favor del FOLFIRINOX. En cuanto a el tiempo libre de progresión, también fue mayor en el grupo tratado con FOLFIRINOX 6.4 vs 3.3 meses.

Estos resultados están asociados a grados 3-4 de toxicidad hematológica ( neutropenia, neutropenia feribril, trombocitopenia), no hematológica (diarrea y neuropatía) y grado toxicidad 2 de alopecia. Esto determina una disminución en la calidad de vida, por lo que PRODIGE concluye que el FOLFIRINOX sería una opción de primera línea para 
pacientes menores de 76 años con buen performance status, sin isquemia cardiaca y bilirrubinas normales ${ }^{136}$. Estudios dirigidos a valorar la calidad de vida con el uso de FOLFIRINOX, han demostrado que la misma se deteriora en pacientes con metástasis de origen pancreático bajo este tratamiento. ${ }^{137}$

El primer estudio reportado, no randomizado, que evidenció los resultados del FOLFIRINOX en el tratamiento paliativo del cáncer de páncreas, fue el de Conroy del 2005. En él, se destaca que la sobrevida media de los pacientes con tumores localmente avanzados (sin metástasis) fue de 15.7 meses. ${ }^{138}$

Las cifras actuales parecen alentadoras y muestran sobrevidas medias de hasta 24.2 meses, similar a la de los pacientes resecados en estadios I y II con adyuvancia. Estos resultados se basan en estudios con paciente no randomizados, con lo cual sus resultados podrían no ser representativos. ${ }^{139}$

La asociación de Nab-Paclitaxel/ gemcitabina, permite que una mayor concentración del fármaco (gemcitabina) atraviese el estroma y actúe sobre las células tumorales. Estudios en pacientes con metástasis de origen pancreático, muestran una mejora en la sobrevida media de 8.5 vs 6.7 meses de los pacientes tratados con gemcitabina exclusiva, así como también mejora el tiempo libre de progresión y la respuesta sobre el tumor y las metástasis.

Incluso, aquellos pacientes que toleran dosis completas del tratamiento, muestran un aumento de la sobrevida media a 12 meses. ${ }^{140}$

Esta combinación no esta exenta de toxicidad, pero tiende a ser menor y mejor tolerada que con el uso de FOLFIRINOX. En términos generales, se trata de bajos grados de toxicidad como ser neuropatía, neutropenia, leucopenia y trombocitopenia, muchas veces reversible frente al cese del tratamiento.

Si bien los resultados son mejores en los pacientes con un buen performance status, su uso puede ser de elección en los pacientes con ECOG mayor igual a 2. ${ }^{141}$

Por lo cual, frente a un paciente con una enfermedad localmente avanzada que presenta un buen PS se podría optar de inicio por el FOLFIRINOX, en caso contrario se podría comenzar con la combinación de gemcitabina- nab-paclitaxel.

El rol de la quimiorradioterapia ha sido siempre controversial en sus formas de adyuvancia y tratamiento paliativo. Los resultados de los estudios siguen siendo contradictorios.

La radioterapia tiene mejor efecto en los pacientes no operados, lo cual es un argumento en favor de su uso paliativo. El problemas más importante es su toxicidad y el cuestionamiento en su uso radica en que una parte importante de los pacientes tienen o desarrollaran metástasis en corto plazo. Esto no justificaría asumir los riesgos de la toxicidad por una posible respuesta, frente a una baja sobrevida.

Hay varios trabajos que han mostrado los beneficios de la quimiorradioterapia sobre la quimioterapia sola en lo que respecta a sobrevida, tiempo libre de progresión y calidad de vida. Pero asociado a una mayor toxicidad, grado 3/4 hematológica y no hematológica. ${ }^{142}$

Mientras se espera por una evidencia definitiva que aclare estas controversias, se ha propuesto realizar una tratamiento inicial con quimioterapia (2-6 ciclos o 3/4 meses), seguido de quimiorradioterapia si no se evidencia progresión de la enfermedad, para luego continuar con quimioterapia de mantenimiento. Esto tiene 2 ventajas, por un lado disminuye un 30\% de radioterapia innecesaria y en segundo lugar es un test de tolerancia a la toxicidad, antes de agregar radioterapia a la quimioterapia. El estudio GERLOC mostró una mejoría en la sobrevida y en el tiempo libre de progresión con esta combinación de terapias ${ }^{143}$. Así como un reciente metaanálisis, también mostró una mejora en la sobrevida de 15.4 meses vs 9.3 con esta modalidad de quimiorradioterapia frente a la quimioterapia exclusiva. ${ }^{144}$

Las líneas actuales de investigación para el control de la enfermedad local, se basan en las terapias ablativas. Estas buscan lograr un efecto mayor sobre la lesión, con un buen control de la enfermedad local, y una baja toxicidad. ${ }^{145}$

Una revisión de la British Journal Of Surgery, estudió el beneficio de las terapias ablativas en el cáncer avanzado de páncreas. Las más estudiadas y con mejores resultados son la radiofrecuencia y la radioterapia esterotáxica, con sobrevidas que pueden llegar a los 24 meses. Ambas mostraron ser seguras, con baja toxicidad y mejoran la calidad de vida. ${ }^{146}$ La radiofrecuencia se utilizó incluso en tratamiento de metástasis hepáticas en pacientes con enfermedad pancreática controlada, con buenos resultados. ${ }^{147}$

Estas terapias, así como otras terapias ablativas (crioablación y quimiembolización), están bajo análisis, pero se basan en trabajos con muy pocos casos. Faltan estudios de mayor calidad estadística y científica que convaliden sus resultados.

Las medidas de soporte eran el standard de tratamiento para los pacientes en los cuales progresaba la enfermedad bajo la primera línea de quimioterapia. Los buenos resultados de estas primeras líneas ha impulsado la utilización de una segunda línea en los pacientes con buen performance status.

Se destaca, que la mayoría de los pacientes reciben como primera línea gemcitabina sola, seguida de FOLFIRINOX y en último lugar combinaciones con gemcitabina. Un estudio Francés mostró que el 40\% recibe segunda línea y hasta un $20 \%$ una tercera línea de quimioterapia. ${ }^{148}$ 
Los tratamientos en base a oxaliplatino mostraron una mejora en la sobrevida media de 4.82 meses vs 2.30 meses de los pacientes con tratamientos de soporte. Sin presentar toxicidad grado $4 .{ }^{149}$

Si la calidad de vida del paciente está determinada por su enfermedad metastásica y no por la toxicidad de la primera línea, una buena opción es la realización de una segunda línea. Esta debe basarse en fármacos distintos a los utilizados en la primera oportunidad, por su toxicidad y quimiorresitencia. De haber recibido FOLFIRINOX, se debe realizar una segunda línea con terapias basadas en gemcitabina. De haber recibido gemcitabina, la opción son las combinaciones de oxaliplatino.

No todos los pacientes son candidatos a tratamientos de quimioterapia de primera, segunda línea, o quimiorradioterapia. Sea cual sea la terapéutica utilizada, su eficacia dura entre 4 y 5 meses para la enfermedad metastásica.

La base para el tratamiento de una enfermedad incurable y agresiva debe sustentarse en una buena relación medico-paciente. Este debe ser informado de su enfermedad, posibles tratamientos, evolución y complicaciones.

Como concluye en su artículo Korkelia "la esperanza es al menos tan importante como la honestidad". Los pacientes en los cuales los síntomas vinculados a su enfermedad sean mayores que los efectos adversos de los tratamientos, serán los que obtendrán el mayor beneficio de este tipo de terapia. 


\section{BIBILOGRAFIA}

1. Gillen S, Schuster T, Meyer Zum Bfschernfelde C et al. Preoperative/neoadjuvant therapy in pancreatic cancer: a systematic review and meta-analysis of response and resection percentages. PLoS Med. 2010;7(4):e1000267. doi: 10.1371/journal.pmed.1000267.

2. Heinemann V, Has M, Boeck S, et al. Neoadjuvant treatment of borderline resectable and non-resectable pancreatic cancer. Ann Oncol. 2013;24(10):2484-2492.

3. Sohn TA, Lillemoe KD, Cameron JL, et al. Surgical palliation of unresectable periampullary adenocarcinoma in the 1990s. J Am Coll Surg. 1999;188(6):658-666

4. Sobin LH, Gospodarowicz MK, Witterkind C. TNM Classification of malignant tumors. 7th ed. New York: Wiley-Blackwell; 2009.

5. The Royal College of Pathologists. Standards and Minimum Datasets for Reporting Cancers. Minimum Dataset for the Histopathological Reporting of Pancreatic, Ampulla of Vater and Bile Duct Carcinoma. London: The Royal College of Pathologists. 2002.

6. Bassi C, Stocken DD, Olah A, et al. Influence of surgical resection and post-operative complications on survival following adjuvant treatment for pancreatic cancer in the ESPAC-1 randomized controlled trial. Dig Surg 2005;22(5):353-363.

7. Howard TJ, Krug JE, Yu J, et al. A margin-negative R0 resection accomplished with minimal postoperative complications is the surgeon's contribution to long-term survival in pancreatic cancer. J Gastrointest Surg. 2006;10(10):1338-1345.

8. Raut CP, Tseng JF, Sun CC, et al. Impact of resection status on pattern of failure and survival after pancreaticoduodenectomy for pancreatic adenocarcinoma.Ann Surg. 2007;246(1):52-60.

9. Hernandez J, Mullinax J, Clark W et al. Survival after pancreaticoduodenectomy is not improved by extending resections to achieve negative margins. Ann Surg. 2009;250(1):76-78

10. Fatima J, Schnelldorfer T, Barton J et al. Pancreatoduodenectomy for ductal adenocarcinoma: implications of positive margin on survival.Arch Surg. 2010.;145(2):167-172.

11. Verbeke CS, Letich D, Menon KV et al. Redefining the R1 resection in pancreatic cancer. Br J Surg. 2006;93(10):1232-1237.

12. Esposito I, Kleeff J, Bergmann F el al. Most pancreatic cancer resections are R1 resections. Ann Surg Oncol. 2008;15(6):1651-1660.

13. Jamieson NB, Foulls AK, Olen KA, et al. Positive mobilization margins alone do not influence survival following pancreatico-duodenectomy for pancreatic ductal adenocarcinoma. Ann Surg. 2010;251(6):1003-1010

14. Campbell F, Smith RA, Whelan P, et al. Classification of R1 resections for pancreatic cancer: the prognostic relevance of tumour involvement within $1 \mathrm{~mm}$ of a resection margin. Histopatholgy 2009 55(3):277-283.

15. Gnerlich JL, Luks SR, Dwahpande AD, et al. Microscopic margins and patterns of treatment failure in resected pancreatic adenocarcinoma. Arch Surg 2012 147(8):753-760.

16. van den Broeck A, Sergeant G, Ectors N, et al.Patterns of recurrence after curative resection of pancreatic ductal adenocarcinoma. Eur J Surg Oncol 2009 35(6):600-604.

17. Hishinuma S, Ogata Y, Tomikawa M, et al Patterns of recurrence after curative resection of pancreatic cancer, based on autopsy findings. J Gastrointest Surg. 2006 ;10(4):511-518.

18. Kayahara M, Nagakawa T, Reno K, et al. An evaluation of radical resection for pancreatic cancer based on the mode of recurrence as determined by autopsy and diagnostic imaging. Cancer. 1993 72(7):2118-2123.

19. Rau BM, Moritz K, Schuschan S, et al. R1resection in pancreatic cancer has significant impact on longterm outcome in standardized pathology modified for routine use. Surgery 2012;152:103-111.

20. Sugiura T, Uesaka K, Mihara K, et al. Margin status, recurrence pattern, and prognosis after resection of pancreatic cancer. Surgery 2013;154(5):1078-1086.

21. Asiyanbola B, Gleisner A, Herman JM, et al. Determining pattern of recurrence following pancreaticoduodenectomy and adjuvant 5-flurouracil-based chemoradiation therapy: effect of number of metastatic lymph nodes and lymph node ratio. J Gastrointest Surg 2008;13(4):752-759.

22. Parikh AA, Maiga A, Bentrem D et al. Adjuvant Therapy in Pancreas Cancer: Does It Influence Patterns of Recurrence? J Am Coll Surg. 2016 Apr;222(4):448-456.

23. Konstantinidis IT, Warshaw AL, Allen JN, et al. Pancreatic ductal adenocarcinoma: is there a survival difference for R1 resections versus locally advanced unresectable tumors? What is a "true" R0 resection? Ann Surg. 2013;257(4):731-736.

24. Butturini G, Stockenn DD, Weente MN, et al. Pancreatic Cancer Meta-Analysis Group. Influence of resection margins and treatment on survival in patients with pancreatic cancer:meta-analysis of randomized controlled trials. Arch Surg 2008 143(1):75-83.

25. Verbeke CS, Resection margins in pancreatic cancer. Surg Clin North Am. 2013;93(3):647-662. 
26. Gillen $\mathrm{S}, \mathrm{Schuster} \mathrm{T}$, Friess $\mathrm{H}$, et al. Palliative resections versus palliative bypass procedures in pancreatic cancer--a systematic review. Am J Surg. 2012;203(4):496-502.

27. Tol JA, Eshuis WJ, Besselink MG, et al.Non-radical resection versus bypass procedure for pancreatic cancer - a consecutive series and systematic review. Eur J Surg Oncol. 2015;41(2):220-227.

28. Reinders ME, Allema JH, van Gulik TM, et al. Outcome of microscopically nonradical, subtotal pancreaticoduodenectomy (Whipple's resection) for treatment of pancreatic head tumors.World J Surg. 1995 ;19(3):410414.

29. Kuhlmann K, de Castro S, van Heek T, et al. Microscopially incomplete resection offers acceptable palliation on pancreatic cancer .Surgery. 2006;139(2):188-196.

30. Fusai G, Warnaar N, Sabin CA, et al. Outcome of R1 resection in patients undergoing pancreatico-duodenectomy for pancreatic cancer. Eur J Surg Oncol. 2008 ;34(12):1309-1315.

31. Lavu H, Mascaro AA, Grenda DR, et al. Margin positive pancreaticoduodenectomy is superior to palliative bypass in locally advanced pancreatic ductal adenocarcinoma. J Gastrointest Surg. 2009;13(11):1937-1946.

32. Köninger J, Went Mn, Maller-Stich BP, et al. R2 resection in pancreatic canceredoes it make sense? Langenbeck's Arch Surg 2008;393(6):929-934.

33. Bockhorn M, Cataldegirmen, Kutup A, et al. Crossing the Rubicon: when pancreatic resection with curative intent ends in an R2 status. Impact of "desmoplastic pseudo-pancreatitis" and anatomical site of irresectability. Ann Surg Oncol. 2009;16(5):1212-1221.

34. Tachezy M, Bockhorn M, Gebauer F, et al. Bypass surgery versus intentionally incomplete resection in palliation of pancreatic cancer: is resection the lesser evil? J Gastrointest Surg 2011;15(5):829-835.

35. Nieveen van Dijkum EJ, Kuhlmann KF, Terwee CB, et al. Quality of life after curative or palliative surgical treatment of pancreatic and periampullary carcinoma. Br j Surg 2005; 92(4): 471-477.

36. Schniewind B, Bestmann B, Kurdow R, et al. Bypass surgery versus palliative pancreaticoduodenectomy in patients with advanced ductal adenocarcinoma of the pancreatic head, with an emphasis on quality of life analyses. Ann Surg Oncol. 2006;13(11):1403-1411.

37. Walter J, Nier A, Rose T, et al. Palliative partial pancreaticoduodenectomy impairs quality of life compared to bypass surgery in patients with advanced adenocarcinoma of the pancreatic head. Eur J Surg Oncol. 2011;37(9):798-804.

38. Bornman PC, Harries-Jones EP, et al. Prospective controlled trial of transhepatic biliary endoprosthesis versus bypass surgery for incurable carcinoma of head of pancreas. Lancet 1986;1(8472):69-71.

39. Shepherd HA, Royle G, Rose AP, et al. Endoscopic biliary endoprosthesis in the palliation of malignant obstruction of the distal common bile duct: a randomized trial. Br J Surg 1988;75(12):1166-1168.

40. Andersen JR, Sorensen SM, Kruse A, et al. Randomised trial of endoscopic endoprosthesis versus operative bypass in malignant obstructive jaundice. Gut 1989;30(8):1132-1135.

41. Smith AC,n Dowsett JF, Russell, RC, et al. Randomised trial of endoscopic stenting versus surgical bypass in malignant low bile duct obstruction. Lancet 1994; 344(8938):1655-1660.

42. Nieveen van Dijkum EJ, Rominj MG, Terwee CB, et al. Laparoscopic staging and subsequent palliation in patients with peripancreatic carcinoma. Ann Surg 2003; 237(1):66-73.

43. Artifon EL, Sakai P, Cunha JE, et al. Surgery or endoscopy for palliation of biliary obstruction due to metastatic pancreatic cancer. Am J Gastroenterol. 2006;101(9):2031-2037.

44. Moss Ac, Morris E, Leyden J, et al. Malignant distal biliary obstruction: a systematic review and meta-analysis of endoscopic and surgical bypass results. Cancer Treat Rev. 2007;33(2):213-221.

45. Maosheng D, Ohtsuka T, Ohuchida J, et al. Surgical bypass versus metallic stent for unresectable pancreatic cancer. J Hepatobiliary Pancreat Surg. 2001;8(4):367-373

46. Glazer ES, Hornbrook MC, Krouse RS, et al. A Meta-Analysis of Randomized Trials: Immediate Stent Placement vs. Surgical Bypass in the Palliative Management of Malignant Biliary Obstruction J Pain Symptom Manage. 2014 ; 47(2): 307-314.

47. Scwarz L, Lesurtel M. Chirurgie palliative de l'adenocarcinome du pancréas. En Delpero JR, Paye F, Bachellier P. Cancer du Pancréas. Paris: Arnette; 2010. p 367-378.

48. Speer AG, Cotton PB, Russell, et al. Randomised trial of endoscopic versus percutaneous stent insertion in malignant obstructive jaundice. Lancet 1987;2(8550):57-62

49. Piñol V,Castells A,Bordas JM, et al.Percutaneous self-expanding metal stents versus endoscopic polyethylene endoprostheses for treating malignant biliary obstruction: randomized clinical trial. Radiology.2002;225(1):27-34

50. Dumonceau J, Tringali A, Blero D, et al., "Biliary stenting: indications, choice of stents and results: European Society of Gastrointestinal Endoscopy (ESGE) clinical guideline”.Endoscopy. 2012; 44( 3): 277-298.

51. Moy BT, Bird JW. An Update to Hepatobiliary Stents. J Clin Transl Hepatol. 2015;3(1): 67-77.

52. Moss AC, Morris E, Mav Mathuna P. Palliative biliary stents for obstructing pancreatic carcinoma.Cochrane Database Syst Rev. 2006 19;(2): Doi: 10.1002/14651858.CD004200.pub4. 
53. Moss AC, Morris E, Leyden J, et al. Do the benefits of metal stents justify the costs? A systematic review and meta-analysis of trials comparing endoscopic stents for malignant biliary obstruction. Eur J Gastroenterol Hepatol 2007;19(12):1119-1124.

54. Kaassis M, Boyer J, Dumas R, et al. Plastic or metal stents for malignant stricture of the common bile duct? Results of a randomized prospective study. Gastrointest Endosc. 2003;57(2):178-182.

55. Soderlund C, Linder S, et al. Covered metal versus plastic stents for malignant common bile duct stenosis: a prospective, randomized, controlled trial. Gastrointest Endosc. 2006 ;63(7):986-995.

56. Yoon WJ, Ryu JK, Yang Ky, et al. A comparison of metal and plastic stents for the relief of jaundice in unresectable malignant biliary obstruction in Korea: an emphasis on cost-effectiveness in a country with a low ERCP cost.Gastrointest Endosc. 2009;70(2):284-289.

57. Barkun AN, Adam V, Martel M, et al. Partially covered self-expandable metal stents versus polyethylene stents for malignant biliary obstruction: A cost-effectiveness analysis. Can J Gastroenterol Hepatol 2015;29(7):377383.

58. Yeoh KG, Zimmerman MJ, Cunningham JT, et al. Comparative costs of metal versus plastic biliary stent strategies for malignant obstructive jaundice by decision analysis. Gastrointest Endosc 1999;49:466-471.

59. Kullman E, Frozannpor F, Söderlund C, et al. Covered versus uncovered self-expandable nitinol stents in the palliative treatment of malignant distal biliary obstruction: results from a randomized, multicenter study. Gastrointest Endosc. $2010 ; 72(5): 915-923$.

60. Telford JJ, Carr-Locke DL, Baron TH, et al. A randomized trial comparing uncovered and partially covered self-expandable metal stents in the palliation of distal malignant biliary obstruction. Gastrointestinal endoscopy. 2010; 72(5):907-914.

61. Isayama H, Komatsu Y, Tsujino T, et al. A prospective randomised study of "covered" versus "uncovered" diamond stents for the management of distal malignant biliary obstruction. Gut 2004;53(5):729-734.

62. Kitano M, Yamashita Y, Tanaka K, et al. Covered self-expandable metal stents with an anti-migration system improve patency duration without increased complications compared with uncovered stents for distal biliary obstructioncaused by pancreatic carcinoma: a randomized multicenter trial. Am J Gastroenterol. 2013;108(11):1713-1722.

63. Lee SJ, Kim MD, Lee MS, et al. Comparison of the efficacy of covered versus uncovered metallic stents in treating inoperable malignant common bile duct obstruction: a randomized trial. J Vasc Interv Radiol. 2014;25(12):1912-1920.

64. Almadi MA, Barkun AN, Martel M. No benefit of covered vs uncovered self-expandable metal stents in patients with malignant distal biliary obstruction: a meta-analysis. Clin Gastroenterol Hepatol. 2013;11(1):2737.

65. Saleem A, Laggett, Murad MH, et al. Meta-analysis of randomized trials comparing the patency of covered and uncovered self-expandable metal stents for palliation of distal malignant bile duct obstruction. Gastrointest Endosc. 2011;74(2):321-327.

66. $\mathrm{Li}$ J, Li T, Sun P, et al. Covered versus Uncovered Self- exandable Metal stents for Managing Malignant Distal BiliaryObstruction: A Meta-Analysis. PLoS One. 2016;11(2): doi: 10.1371/journal.pone.0149066.

67. Sarfeh IJ, Rypins EB, Jakowatz JG, et al. A prospective, randomized clinical investigation of cholecystoenterostomy and choledochoenterostomy. Am J Surg. 1988;155(3):411-414. (Abstract).

68. Rosemurgy AS, Burnett CM, Wasselle. A comparison of choledochoenteric bypass and cholecystoenteric bypass in patients with biliary obstruction due to pancreatic cancer. Am Surg. 1989;55(1):55-60. (Abstract).

69. Rappaport MD, Villalba M. A comparison of cholecysto- and choledochoenterostomy for obstructing pancreatic cancer.Am Surg. 1990;56(7):433-435. (Abstract).

70. Di Fronzo LA, Egrari S, O Connell TX. Choledochoduodenostomy for palliation in unresectable pancreatic cancer.Arch Surg. 1998;133(8):820-825.

71. Urbach DR, Bell CM, Swanstrom LL, et al. Cohort study of surgical bypass to the gallbladder or bile duct for the palliation of jaundice due to pancreatic cancer. Ann Surg. 2003;237(1):86-93.

72. Tarnasky PR, England RE, Laid LM, et al. Cystic duct patency in malignant obstructive jaundice. An ERCP-based study relevant to the role of laparoscopic cholecystojejunostomy. Ann Surg. 1995;221(3):265-267.

73. Toumi Z, Aljarabah M, Amor BJ. Role of the laparoscopic approach to biliary bypass for benign and malignant biliary diseases: a systematic review. Surg Endosc. 20111;25(7):2105-2116.

74. Bartlett EK, Wactek H, Fracker DL, et al. Surgical palliation for pancreatic malignancy: practice patterns and predictors of morbidity and mortality.J Gastrointest Surg. 2014;18(7):1292-1298.

75. Hamade AM,Al- Bahrani AZ, Opera AM, et al. Therapeutic, prophylactic, and preresection applications of laparoscopic gastric and biliary bypass for patients with periampullary malignancy. Surg Endosc. 2005;19(10):13331340 .

76. Khalid K, Shafi M, Dar HM, et al. Choledochoduodenostomy: reappraisal in the laparoscopic era.ANZ J Surg. 2008;78(6):495-500. 
77. Salgado SM, Gaidhane M, Kahaleh M. Endoscopic palliation of malignant biliary strictures.World J Gastrointest Oncol. 2016 15;8(3):240-247.

78. Fabbri C, Luigiano C, Lisotti A, et al. Endoscopic ultrasound-guided treatments: are we getting evidence based--a systematic review. World J Gastroenterol. 2014;20(26):8424-8448.

79. Hara K, Yamao K, Mizuno N, et al. Endoscopic ultrasonography-guided biliary drainage: Who, when, which, and how? World J Gastroenterol. 2016;22(3):1297-1303.

80. Artifon EL, Aparicio D, Paione JB, et al. Biliary drainage in patients with unresectable, malignant obstruction where ERCP fails: endoscopic ultrasonography-guided choledochoduodenostomy versus percutaneous drainage.J Clin Gastroenterol. 2012 ;46(9):768-774.

81. Bapaye A, Dubale N, Aher A. Comparison of endosonography-guided vs. percutaneous biliary stenting when papilla is inaccessible for ERCP. United European Gastroenterol J. 2013;1(4):285-293.

82. Khashab MA, Valeshabad AK, Afghani E, et al. A comparative evaluation of EUS-guided biliary drainage and percutaneous drainage in patients with distal malignant biliary obstruction and failed ERCP.Dig Dis Sci. 2015;60(2):557-565.

83. Kawakubo K, Isayama $\mathrm{H}$, Dato $\mathrm{H}$, et al. Multicenter retrospective study of endoscopic ultrasound-guided biliary drainage for malignant biliary obstruction in Japan. J Hepatobiliary Pancreat Sci 2014; 21(5):328-334.

84. Gupta K, Perez-Miranda M, Kahaleh, et al. Endoscopic ultrasound-assisted bile duct access and drainage: multicenter, long-term analysis of approach, outcomes, and complications of a technique in evolution. J Clin Gastroenterol 2014; 48(1): 80-87.

85. Dhir V, Artifon EL, Gupta K,et al. Multicenter study on endoscopic ultrasound-guided expandable biliary metal stent placement: choice of access route,direction of stent insertion, and drainage route. Dig Endosc 2014; 26(3): 430-435.

86. Artifon EL, Marion FP, Gaidhane M, et al. Hepaticogastrostomy or choledochoduodenostomy for distal malignant biliary obstruction after failed ERCP: is there any difference? Gastrointest Endosc 2015; 81(4): 950959.

87. Steel AW, Postgate AJ, Khorsandi, et al. Endoscopically applied radiofrequency ablation appears to be safe in the treatment of malignant biliary obstruction.Gastrointest Endosc. 2011;73(1):149-153.

88. Wu TT, Li HC, LI WM, et al. Percutaneous Intraluminal Radiofrequency Ablation for Malignant Extrahepatic Biliary Obstruction: A Safe and Feasible Method. Dig Dis Sci. 2015;60(7):2158-2163.

89. Kallis Y, Phillips N, Steel A, et al. Analysis of Endoscopic Radiofrequency Ablation of Biliary Malignant Strictures in Pancreatic Cancer Suggests Potential Survival Benefit. Dig Dis Sci. 2015;60(11):3449-3455.

90. Richter JA, Kahaleh M. Photodynamic therapy: Palliation and endoscopic technique in cholangiocarcinoma. World J GastrointestEndosc 2010; 2(11): 357-361.

91. Salgado SM, Gaidhane M, Kahaleh M. Endoscopic palliation of malignant biliary strictures. World J Gastrointest Oncol. 2016;8(3):240-247.

92. Lillemoe KD. Palliative therapy for pancreatic cancer. Surg Oncol Clin N Am. 1998 ;7(1):199-216

93. Thor PJ, Popiela T, Sobocki J, et al. Pancreatic carcinoma-induced changes in gastric myoelectric activity and emptying. Hepatogastroenterology. $2002 ; 49(43): 268-270$.

94. Lillemoe KD, Cameron JL, Hardware JM, et al. Is prophylactic gastrojejunostomy indicated for unresectable periampullary cancer? A prospective randomized trial. Ann Surg.1999;230(3):322-328.

95. Van Heek NT, De Castro SM, van Eljck CH, et al. The need for a prophylactic gastrojejunostomy for unresectable periampullary cancer: a prospective randomized multicenter trial with special focus on assessment of quality of life. Ann Surg. 2003;238(6):894-902.

96. Hüser N, Mischlski CW, Schuster T, et al. Systematic review and meta-analysis of prophylactic gastroenterostomy for unresectable advanced pancreatic cancer.Br J Surg. $2009 ; 96(7): 711-719$.

97. Gurusamy KS, Kumar S, Davidson BR. Prophylactic gastrojejunostomy for unresectable periampullary carcinoma. Cochrane Database Syst Rev. 2013;(2):doi: 10.1002/14651858.CD008533.pub3.

98. Fiori E, Lamazza A, Volpino P, et al. Palliative management of malignant antro-pyloric strictures. Gastroenterostomy vs. endoscopic stenting. A randomized prospective trial. Anticancer Res. 2004 ;24(1):269-271.

99. Mehta S, Hindmarsh A, Cheomg E, et al. Prospective randomized trial of laparoscopic gastrojejunostomy versus duodenal stenting for malignant gastric outflow obstruction.Surg Endosc. 2006 ;20(2):239-242.

100. Jeurnink SM, Steyerberg EW, van Hooft JE, et al. Surgical gastrojejunostomy or endoscopic stent placement for the palliation of malignant gastric outlet obstruction (SUSTENT study): a multicenter randomized trial. Gastrointest Endosc. 2010;71(3):490-499.

101. Jeurnink SM, van Eljck, Steyerberg EW, et al. Stent versus gastrojejunostomy for the palliation of gastric outlet obstruction: a systematic review. BMC Gastroenterol. 2007;7:18.DOI: 10.1186/1471-230X-7-18.

102. Khashab M, Alawad AS, Shin EJ, et al. Enteral stenting versus gastrojejunostomy for palliation of malignant gastric outlet obstruction. Surg Endosc. 2013;27(6):2068-2075. 
103. Ho JH, Kim SW, Lim CH, et al. Long-term outcome of palliative therapy for gastric outlet obstruction caused by unresectable gastric cancer in patients with good performance status: endoscopic stenting versus surgery. Gastrointest Endosc. 2013 ;78(1):55-62.

104. Nagaraja V, Slick GD, Cox MR. Endoscopic stenting versus operative gastrojejunostomy for malignant gastric outlet obstruction-a systematic review and meta-analysis of randomized and non-randomized trials.J Gastrointest Oncol. 2014;5(2):92-98.

105. van Halsema EE, Rauws EA, Fockens $P$, et al. Self-expandable metal stents for malignant gastric outlet obstruction: A pooled analysis of prospective literature. World J Gastroenterol. 201521;21(43):12468-12481.

106. Pan Ym, Pan J, Goo LK, et al. Covered versus uncovered self-expandable metallic stents for palliation of malignant gastric outlet obstruction: a systematic review and meta-analysis. MC Gastroenterol. 2014;14 :170-178.

107. Singh SM, Longmire WP, Weber HA. Surgical palliation for pancreatic cancer. The UCLA experience. Ann Surg 1990;212(2):132-139.

108. Shyr YM, Su CH, Wu CW, et al. Prospective study of gastric outlet obstruction in unresectable periampullary adenocarcinoma. World J Surg 2000;24(1):60-65.

109. Horstmann O, Klwy CW, Post S, et al. 'Cross-section gastroenterostomy' in patients with irresectable periampullary carcinoma. HPB (Oxford). 2001;3(2):157-163.

110. House MG, Choti MA. Palliative therapy for pancreatic/biliary cancer. Surg Clin North Am. 2005;85(2):359371.

111. Shyr YM, et al. Randomized trial of three types of gastrojejunostomy in unresectable periampullary cancer. Surgery. 1997;121(5):506-512.

112. Szymanski D, Durczynski A, Nowicki M, et al . Gastrojejunostomy in patients with unresectable pancreatic head cancer - the use of Roux loop significantly shortens the hospital length of stay. World J Gastroenterol. 2013;19(45):8321-8325.

113. Bergamaschi R, Marvin R, Thoresen JE, et al. Open versus laparoscopic gastrojejunostmy for palliation in advanced pancreatic cancer. Surg Laparosc Endosc 1998;8(2):92-96.

114. Navarra G, Mussolini C, Venneri A, et al. Palliative antecolic isoperistaltic gastrojejunostomy: a randomized controlled trial comparing open and laparoscopic approaches. Surg Endosc. 2006 ;20(12):1831-1834.

115. Kohan G, Ocampo CG, Zandalazini HI, et al. Laparoscopic hepaticojejunostomy and gastrojejunostomy for palliative treatment of pancreatic head cancer in 48 patients. Surg Endosc. 2015;29(7):1970-1975.

116. Pancreatric Section, British Society of Gastroenterology; Pancreatic Society of Great Britain and Ireland; Association of Upper Gastrointestinal Surgeons of Great Britain and Ireland; Royal College of Pathologists; Special Interest Group for Gastro-Intestinal Radiology. Guidelines for the management of patients with pancreatic cancer periampullary andampullary carcinomas. Gut. 2005;54 (Suppl 5):1-16.

117. Lillemoe KD, Cameron JL, Kaufman HS, et al. Chemical splanchnicectomy in patients with unresectable pancreatic cancer. A prospective randomized trial. Ann Surg. 1993;217(5):447-455.

118. Allen PJ, Chou J, Janakos M, et al. Prospective evaluation of laparoscopic celiac plexus block in patients with unresectable pancreatic adenocarcinoma.Ann Surg Oncol. 2011 ;18(3):636-641.

119. Arcidiacono PG, Carol G, Carrara S et al. Celiac plexus block for pancreatic cancer pain in adults. Cochrane Database Syst Rev. 2011;(3). Doi: 10.1002/14651858.CD007519.pub2.

120. Eisenberg E, Carr DB, Chalmers TC, et al. Neurolytic celiac plexus block for treatment of cancer pain: a meta-analysis.Anesth Analg. $1995 ; 80(2): 290-295$. (Abstract).

121. Puli SR, Ready JB, Bechtold ML, et al. EUS-guided celiac plexus neurolysis for pain due to chronic pancreatitis or pancreatic cancer pain: a meta-analysis and systematic review Dig Dis Sci. 2009 ;54(11):2330-2337.

122. Fujii L, Slain JE, Morris JM, et al . Anterior spinal cord infarction with permanent paralysis following endoscopic ultrasound celiac plexus neurolysis. Endoscopy 2012; 44 Suppl 2 UCTN: E265-E266.

123. Gimeno-García AZ,et al. Fatal complication after endoscopic ultrasound-guided celiac plexus neurolysis. Endoscopy 2012; 44 (Suppl 2): 265- 266.

124. Gress F, Schmitt C, Sherman S, et al. A prospective randomized comparison of endoscopic ultrasound-and computed tomography-guided celiac plexus block for managing chronic pancreatitis pain. Am J Gastroenterol 1999; 94(4): 900-905.

125. Wyse JM, Chen YI, Sahai AV. Celiac plexus neurolysis in the management of unresectable pancreatic cancer: when and how? World J Gastroenterol. 2014 ;20(9):2186-2192.

126. Borie F, et al. Splanchnicectomies chirurgicales. EMC, Techniques chirugicales-Appareil digestif, 2008; 40-850

127. Stefaniak T, Basinski A, Vingerhoets A, et al.A comparison of two invasive techniques in the management of intractable pain due to inoperable pancreatic cancer: neurolytic celiac plexus block and videothoracoscopic splanchnicectomy.Eur J Surg Oncol. 2005 ;31(7):768-773.

128. Sultana A, Smith CT, Cunningham D, et al. Meta-analyses of chemotherapy for locally advanced and metastatic pancreatic cancer. J Clin Oncol. 2007;25(18):2607-2615. 
129. Burris HA, Moore MJ, Andersen J, et al. Improvements in survival and clinical benefit with gemcitabine as first-line therapy for patients with advanced pancreas cancer: a randomized trial.J Clin Oncol. 1997;15(6):24032413.

130. Chauffert B, Mornex F, Bonnetain F, et al. Phase III trial comparing intensive induction chemoradiotherapy (60 Gy, infusional 5-FU and intermittent cisplatin) followed by maintenance gemcitabine with gemcitabine alone for locally advanced unresectable pancreatic cancer. Definitive results of the 2000-01 FFCD/SFRO study. Ann Oncol 2008; 19(9): 1592-1599.

131. Heinemann V, Boeck S, Hinke A, et al. Meta-analysis of randomized trials: evaluation of benefit from gemcitabine-based combination chemotherapy applied in advanced pancreatic cancer. BMC Cancer 2008;8:82. doi: 10.1186/1471-2407-8-82.

132. Xie D, Yang Q, Chen D, et al. Gemcitabine-based Cytotoxic Doublets Chemotherapy for Advanced Pancreatic Cancer: Updated Subgroup Meta-analyses of Overall Survival. Jpn J Clin Oncol. 2010;40(5)432-441.

133. Korkeila EA. Advanced pancreatic cancer - how to choose an adequate treatment option. World J Gastroenterol 2015; 21(38): 10709-10713.

134. Moore MJ, Goldstein D, Hamm J, et al. Erlotinib plus gemcitabine compared with gemcitabine alone in patients with advanced pancreatic cancer: a phase III trial of the National Cancer Institute of Canada Clinical Trials Group. J Clin Oncol 2007; 25(15): 1960-1966.

135. Péron J, Roy P, Ding K, et al. Assessing the benefit-risk of new treatments using generalised pairwise comparisons: the case of erlotinib in pancreatic cancer. British Journal of Cancer 2015;112(6): 971-976.

136. Conroy T, Desseigne F, Ychou M, et al. FOLFIRINOX versus gemcitabine for metastatic pancreatic cancer. N Engl J Med 2011; 364(19): 1817-1825.

137. Gourgou-Bourgade S, Bascoul-Mollevi C, Desseigne F, et al. Impact of FOLFIRINOX Compared With Gemcitabine on Quality of Life in Patients With Metastatic Pancreatic Cancer: Results From the PRODIGE 4/ACCORD 11 Randomized Trial. J Clin Oncol 2013;31(1):23-29.

138. Conroy T, Paillot B, François E, et al. Irinotecan plus oxaliplatin and leucovorin-modulated fluorouracil in advanced pancreatic cancer-a Groupe Tumeurs Digestives of the Federation Nationale des Centres de Lutte Contre le Cancer study. J Clin Oncol 2005; 23(6): 1228-1236.

139. Suker M, Beumer BR, Sadot E, et al. FOLFIRINOX for locally advanced pancreatic cancer: a systematic review and patient-level meta-analysis . Lancet Oncol. 2016; 17(6):801-810.

140. Von Hoff DD, Ramanathan RK, Borad MJ, et al. Gemcitabine plus nab-paclitaxel is an active regimen in patients with advanced pancreatic cancer: a phase I/II trial. J Clin Oncol 2011; 29(4): 4548-4554.

141. Von Hoff DD, Ervin T, Arena FP, et al. Increased survival in pancreatic cancer with nab-paclitaxel plus gemcitabine. N Engl J Med. 2013;369(18):1691-1703.

142. Chen Y, Sun XJ, Jiang TH, et al. Combined radiochemotherapy in patients with locally advanced pancreatic cancer: A meta-analysis.World J Gastroenterol 2013; 19(42): 7461-7471.

143. Huguet F, André T, Hammel P, et al. Impact of Chemoradiotherapy After Disease Control With Chemotherapy in Locally Advanced Pancreatic Adenocarcinoma in GERCOR Phase II and III Studies. J Clin Oncol 25(3):326-331.

144. Choi Y, Oh DY, Kim K, et al. Concurrent Chemoradiotherapy Versus Chemotherapy Alone for Unresectable Locally Advanced Pancreatic Cancer: A Retrospective Cohort Study. Cancer Res Treat. 2016; 48(3): 10451055.

145. Trakul N, Koong AC, Chang DT. Stereotactic body radiotherapy in the treatment of pancreatic cancer. Semin Radiat Oncol 2014; 24(2): 140-147.

146. Rombouts SJ, Vogel JA, van Santvoort HC, et al. Systematic review of innovative ablative therapies for the treatment of locally advanced pancreatic cancer. Br J Surg. 2015;102(3):182.193.

147. Park JB, Kim YH, Kim J, et al. Radiofrequency ablation of liver metastasis in patients with locally controlled pancreatic ductal adenocarcinoma. J Vasc Interv Radiol 2012; 23(5): 635-641.

148. Rombouts SJ, Vogel JA, van Santvoort HC, van Lienden KP, van Hillegersberg R, Busch OR, Besselink MG, Molenaar IQ. Systematic review of innovative ablative therapies for the treatment of locally advanced pancreatic cancer. Br J Surg 2015; 102: 182-193 [PMID: 25524417 DOI: 10.1002/bjs.9716]

149. Pelzer U, Schwaner I, Stieler J, et al. Best supportive care (BSC) versus oxaliplatin, folinic acid and 5-fluorouracil (OFF) plus BSC in patients for second-line advanced pancreatic cancer: a phase III-study from the German CONKO-study group. Eur J Cancer 2011; 47(11): 1676-1681. 



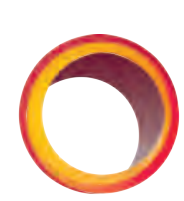

\section{GRUPOELIS}

MEETINGS MANAGEMENT

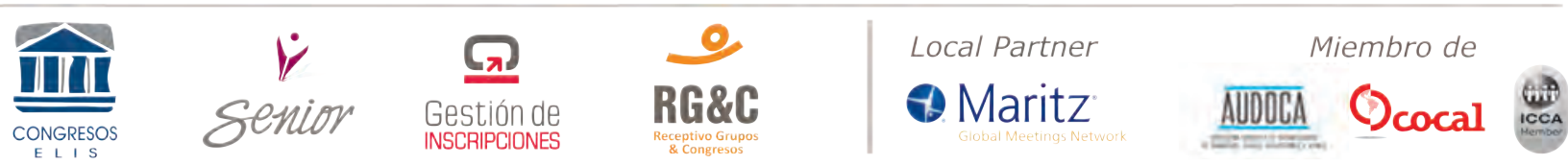

www.grupoelis.com.uy | info@grupoelis.com.uy | Palmar 2240, Montevideo - Uruguay | $\mathbf{0}+598$ 24010534/35/36 